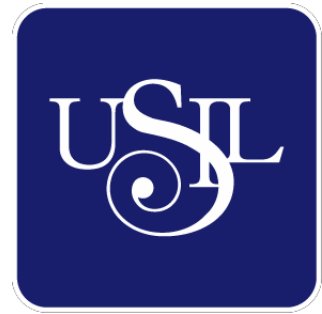

UNIVERSIDAD

SAN IGNACIO

DE LOYOLA

ESCUELA DE POSTGRADO

Maestría en Dirección de Marketing y Gestión Comercial

\title{
PLAN DE MARKETING PARA LA BODEGA SANTA MARIA: JOLLY ROGER
}

Tesis para optar el grado de Maestro en Dirección de Marketing y Gestión Comercial

\author{
CARRANZA LAGOS, JOAN MANUEL \\ GARCIA SERRA, MAURICIO \\ PORTUGUEZ LUYO, JULIO \\ SANTIAGO CHAVEZ, CARLOS ALBERTO
}

\author{
Asesor: \\ José Miguel Solano Morales \\ Lima - Perú \\ 2018
}




\section{ÍNDICE GENERAL}

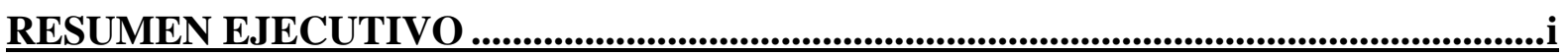

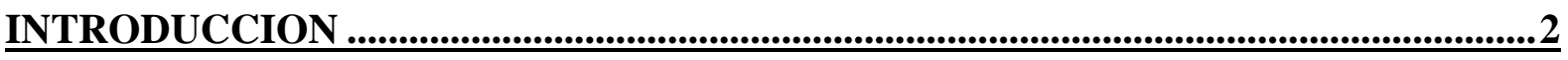

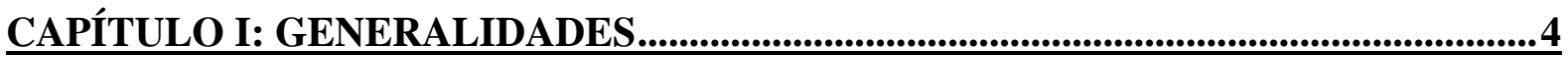

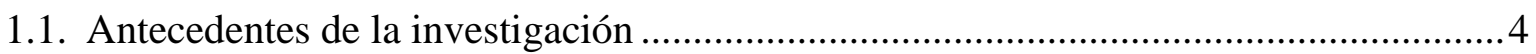

1.2. Determinación del Problema u Oportunidad .............................................................

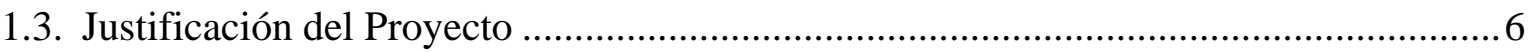

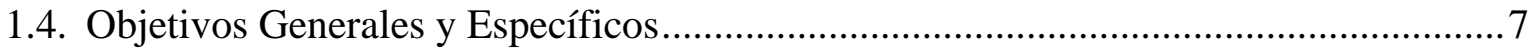

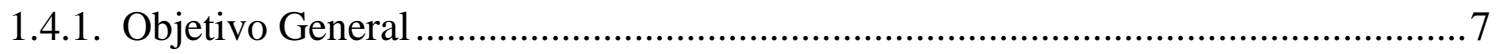

1.4.2. Objetivos Específicos..............................................................................

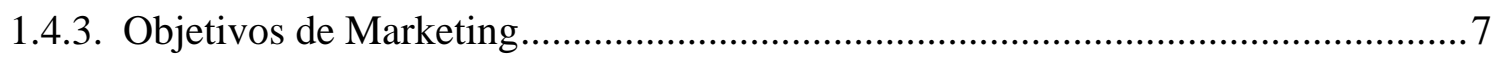

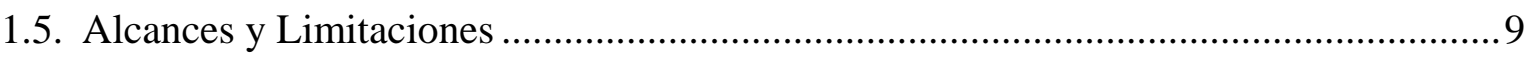

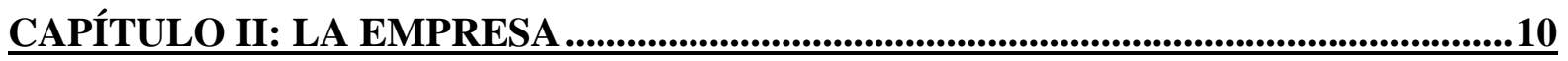

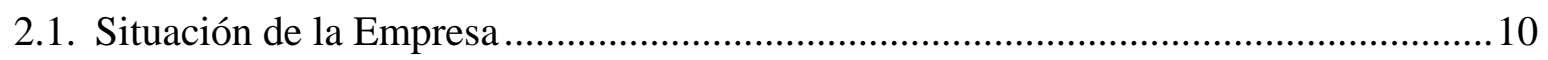

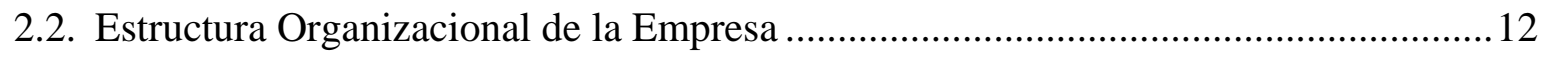

2.3. Situación de mercado y financiera de la empresa ................................................... 13

2.4. Visión, Misión y Valores de la Empresa................................................................... 18

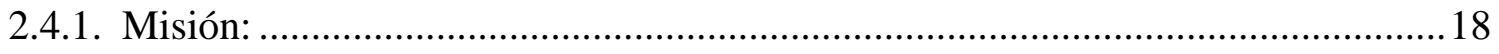

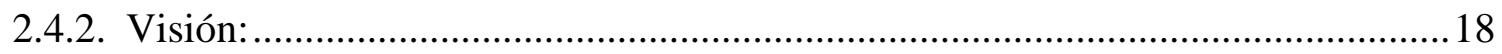

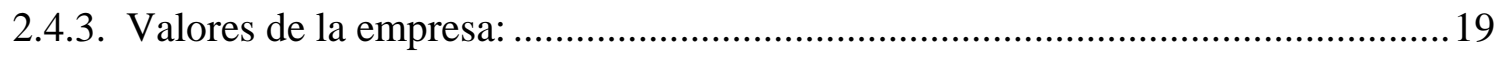

CAPÍTULO III: ANÁLISIS DE LA SITUACIÓN DE LA EMPRESA ..........................20

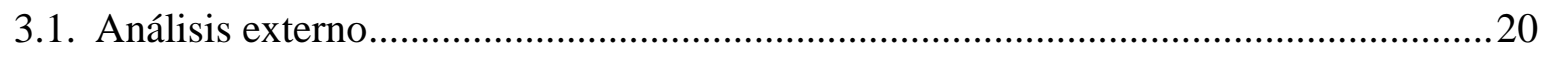

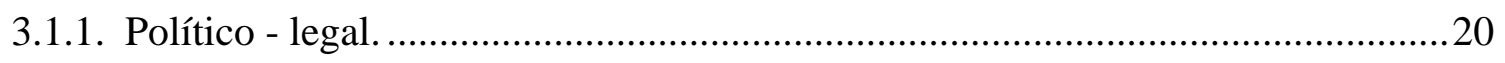

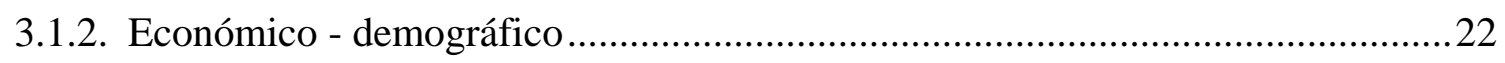

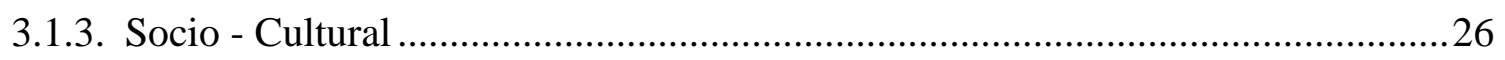

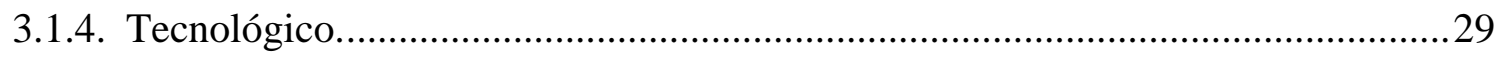




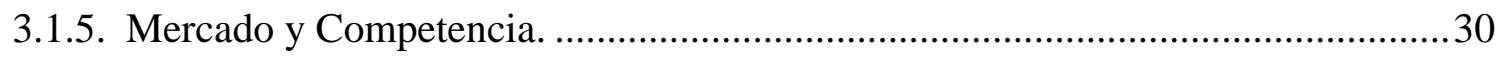

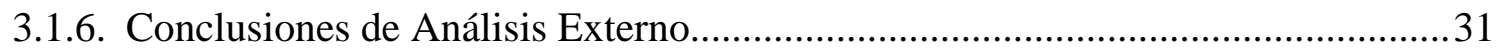

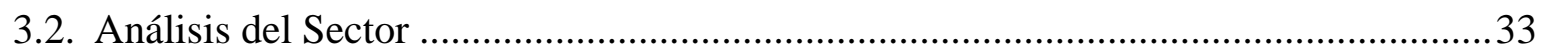

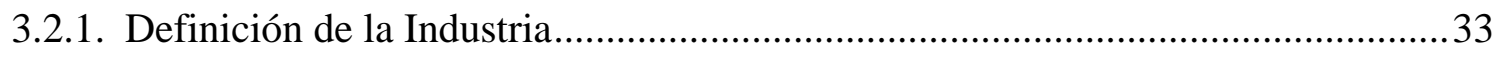

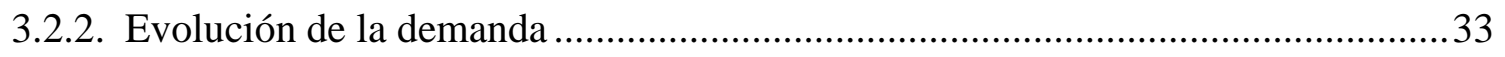

3.2.3. Matriz de competencia de Porter .................................................................... 33

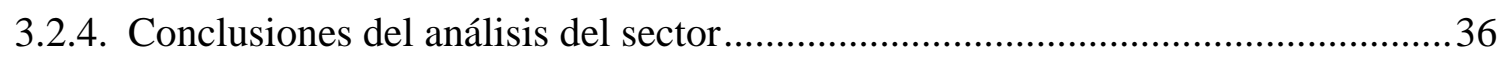

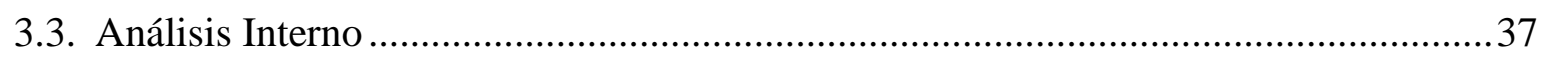

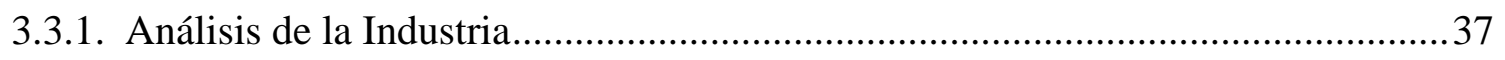

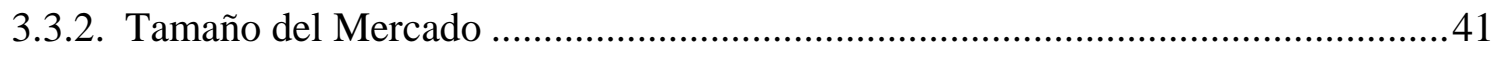

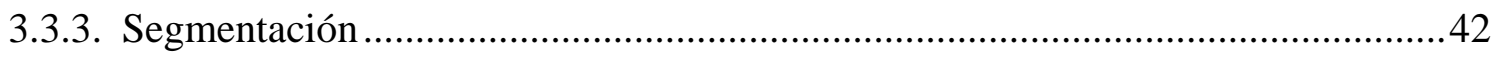

3.3.4. Productos, Ciclo de Vida, Precios, Distribución, Comunicación y Fuerza de

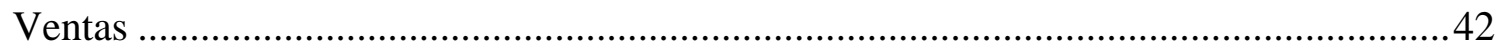

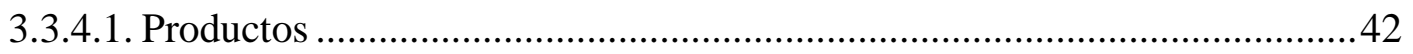

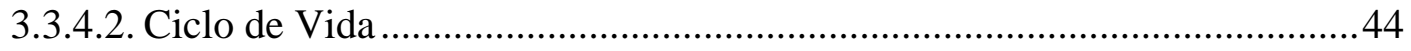

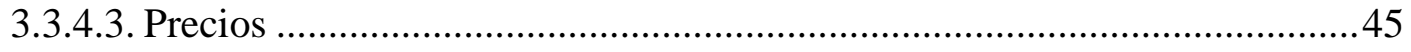

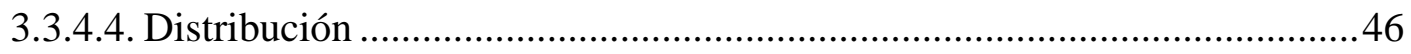

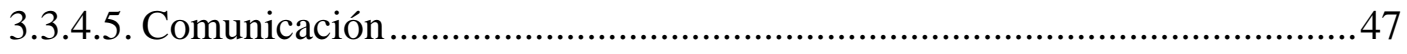

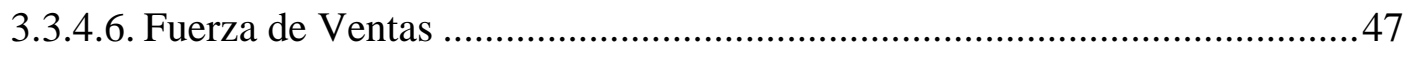

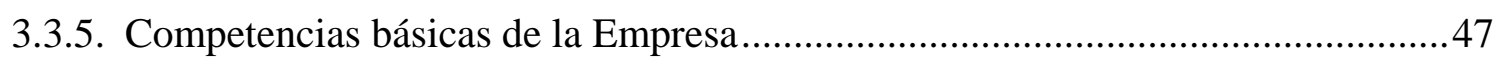

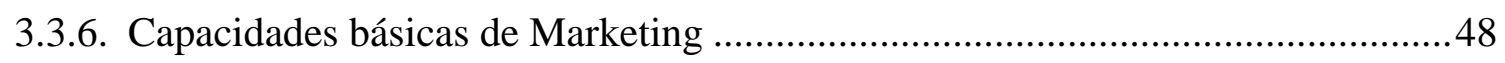

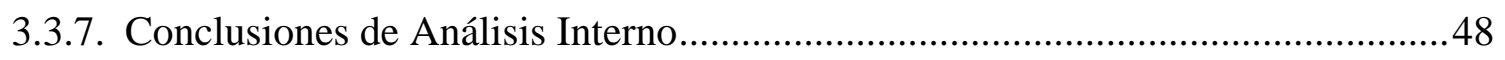

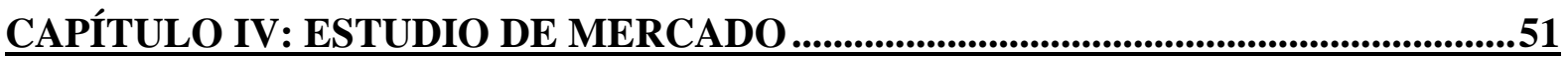

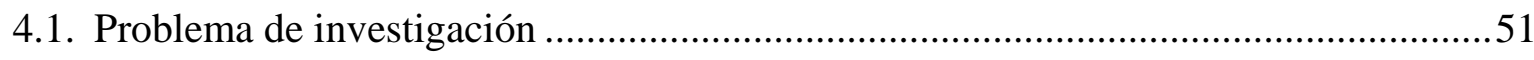

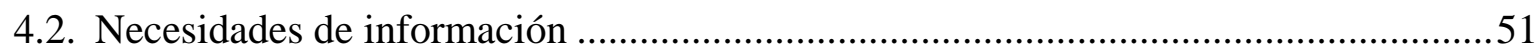

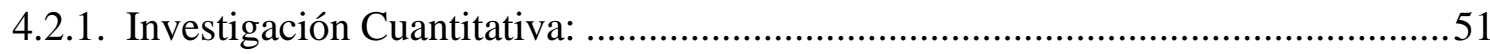

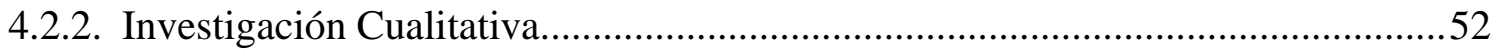




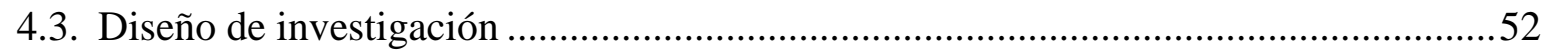

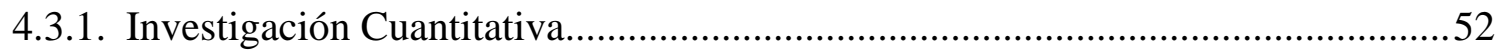

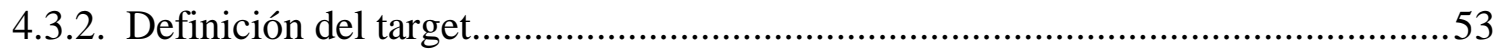

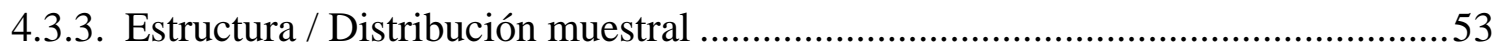

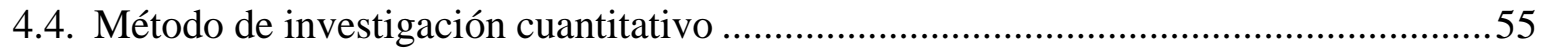

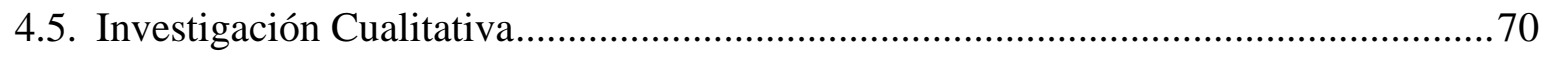

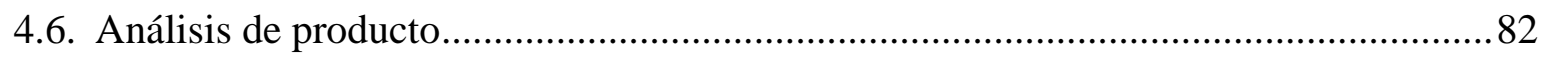

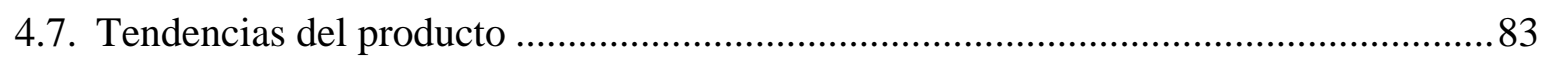

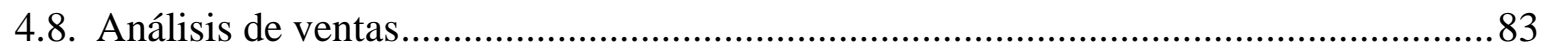

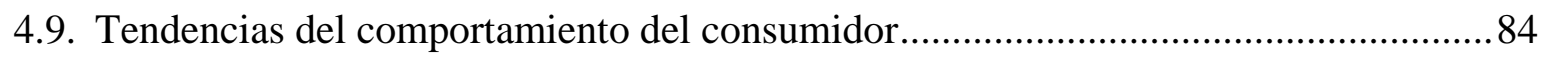

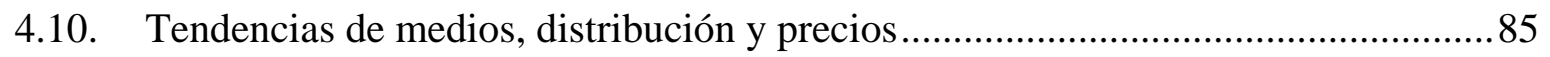

4.11. Segmentos del mercado que compran el producto (empresa e industria) ..............87

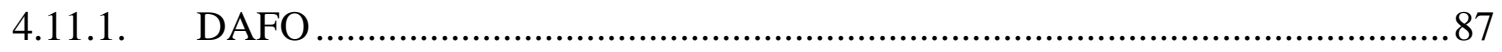

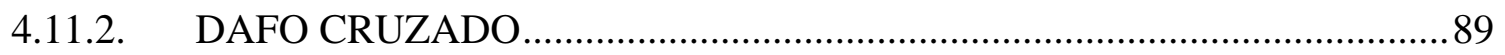

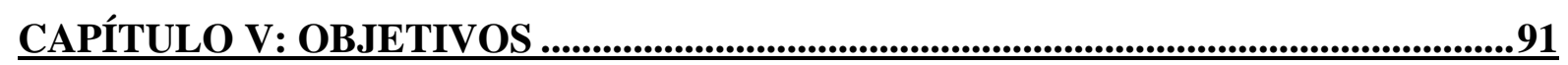

5.1. Relación entre Plan Estratégico y el Plan de Marketing (Objetivos estratégicos y

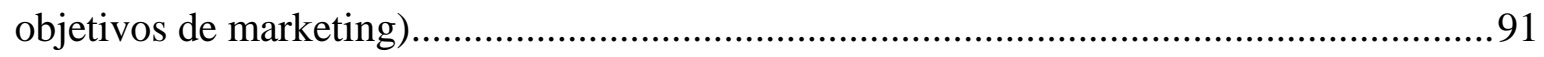

5.2. Formulación de Objetivos: Ventas, Margen, Comerciales, Producto y Comunicación. 91

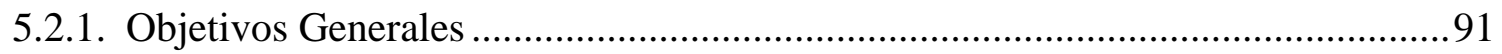

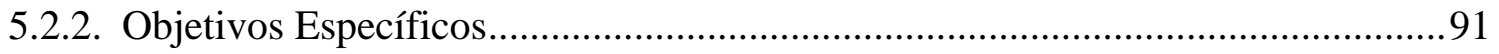

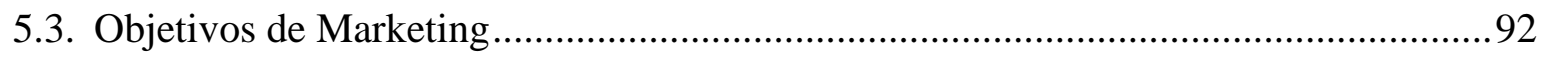

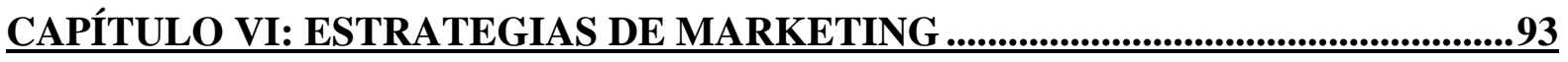

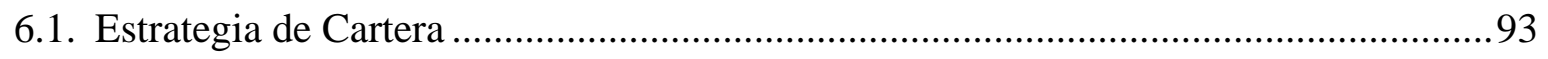

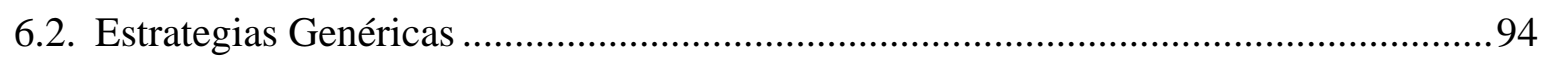

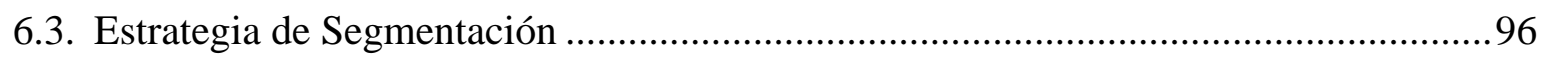

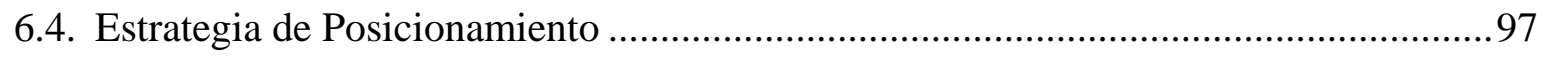




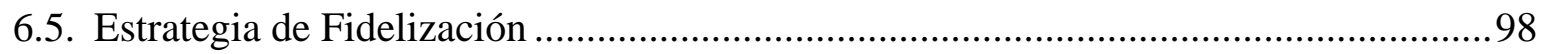

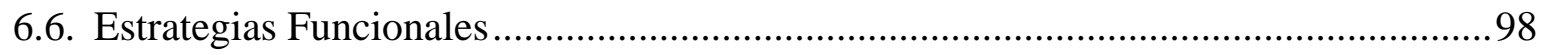

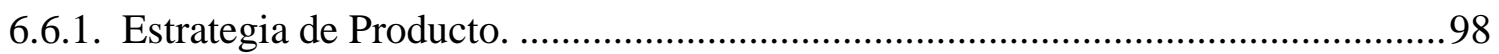

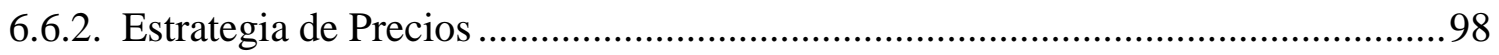

6.6.3. Estrategia de Distribución y Ventas.......................................................................99

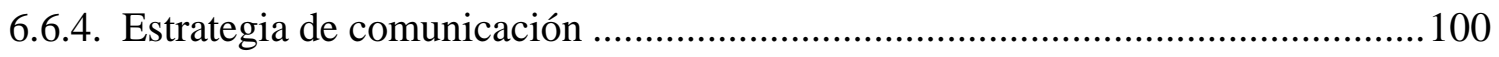

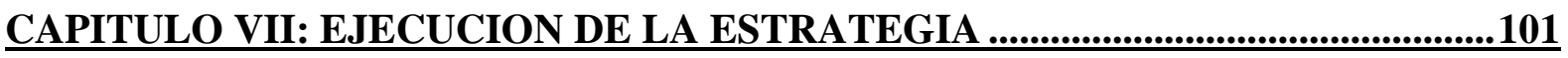

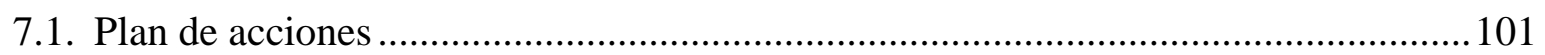

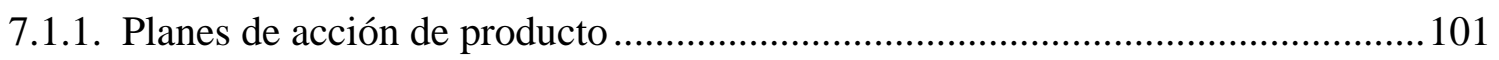

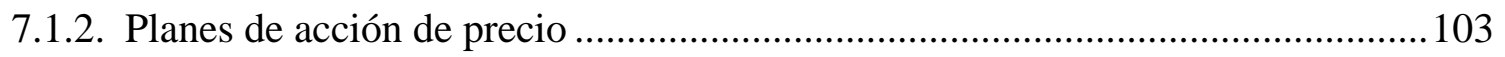

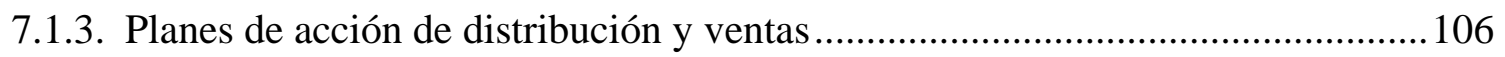

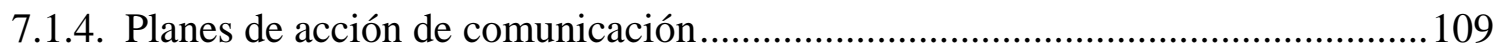

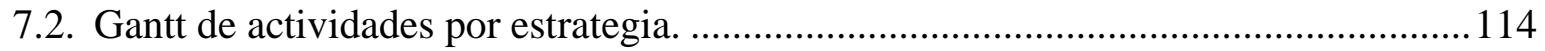

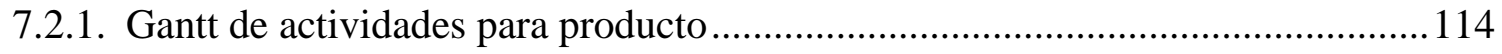

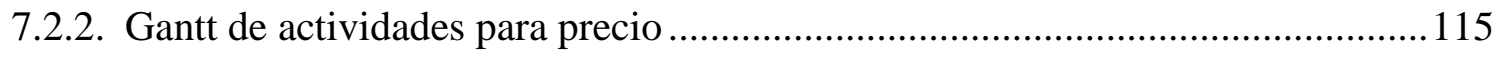

7.2.3. Gantt de actividades para distribución y ventas ................................................... 116

7.2.4. Gantt de actividades para comunicación.............................................................. 117

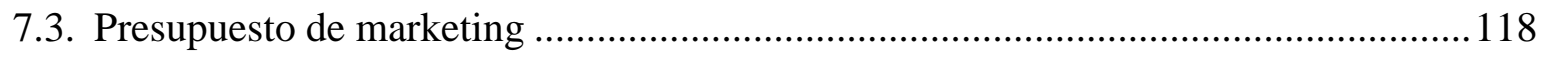

7.4. Proyección de estados de resultados ................................................................... 119

CAPITULO VIII: EVALUACIÓN DE LA ESTRATEGIA ......................................121

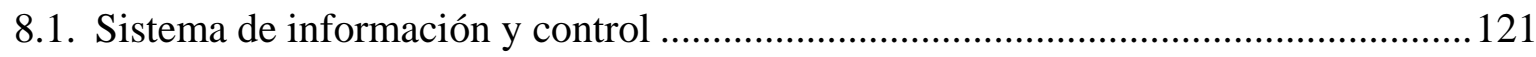

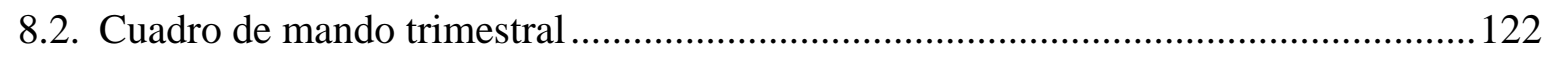

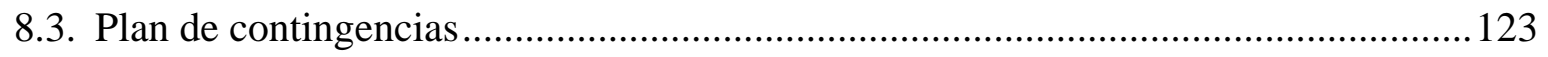

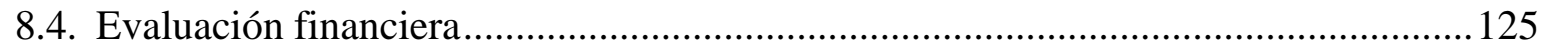

CAPITULO IX: CONCLUSIONES Y RECOMENDACIONES ................................126

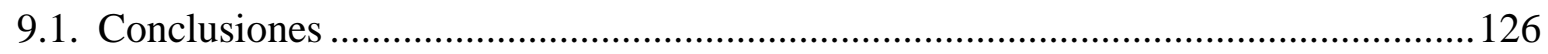


9.2. Recomendaciones.

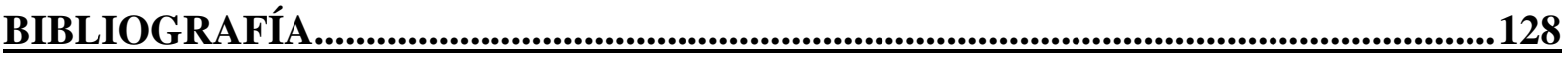

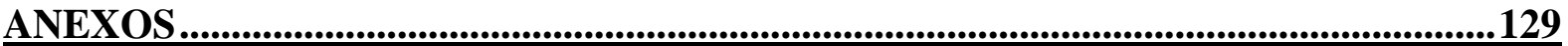




\section{ÍNDICE DE CUADROS}

Tabla1: Exportación Mensual de Pisco Don Benedicto 2016. .14

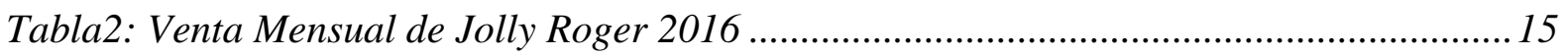

Tabla 3: Ventas Anuales de Pisco Don Benedicto..................................................................... 16

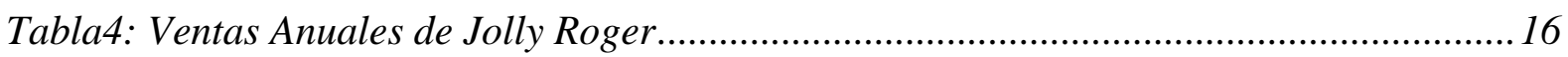

Tabla 5: Costo de Ventas Anuales de Don Benedicto ........................................................... 17

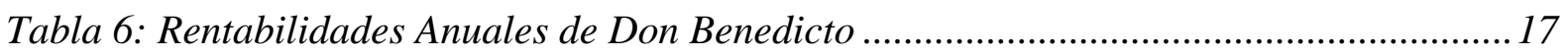

Tabla 7:Rentabilidades Anuales de Jolly Roger.................................................................. 17

Tabla 8: Principales proyecciones para el 2017 y 2018 .......................................................24

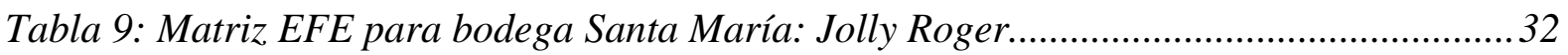

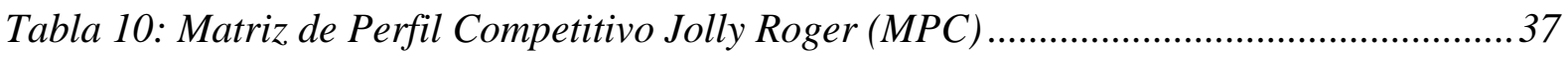

Tabla 11: Proyección de Mercado Objetivo para Jolly Roger................................................ 41

Tabla 12: Estructura de precios Bodega Santa María ..........................................................45

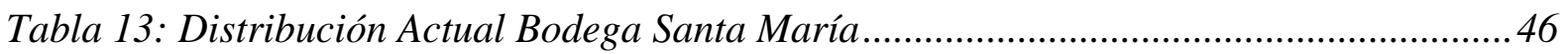

Tabla 14: Matriz de Evaluación de Factores Internos para la bodega Santa María: Jolly

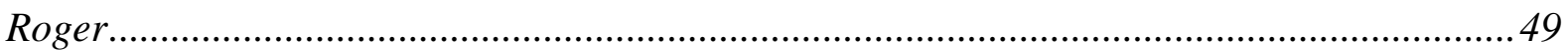

Tabla 15: Distribución de la población por distritos y edad de Lima Metropolitana y Callao

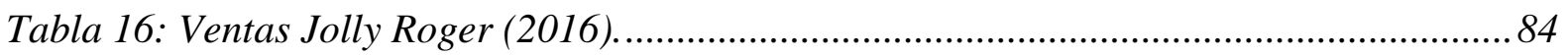

Tabla 17: Estrategia Segmentación para Bodega Santa María, producto Jolly Roger..........96

Tabla 18: Estrategia de Posicionamiento Jolly Roger ..........................................................97

Tabla 19: Propuesta de valor Jolly Roger.....................................................................97

Tabla 18: Road to Market por canal de venta ..................................................................... 99

Tabla 19: Presupuesto Plan de Marketing Jolly Roger (Dólares Americanos).................... 118

Tabla 20: Estado de Resultados Jolly Roger (Dólares Americanos) .................................... 119 
Tabla 21: Proyección de ventas Jolly Roger 2018 ............................................................. 120

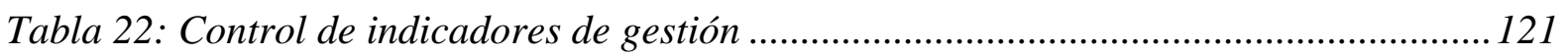

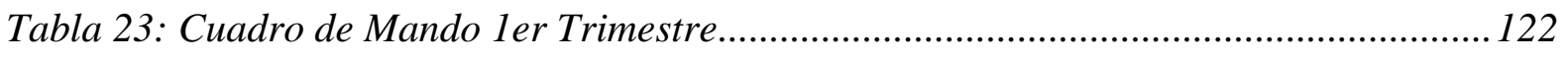

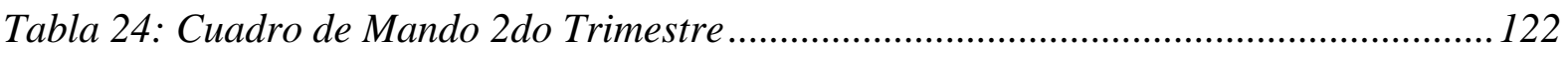

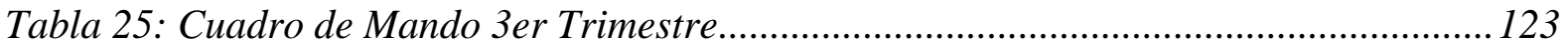

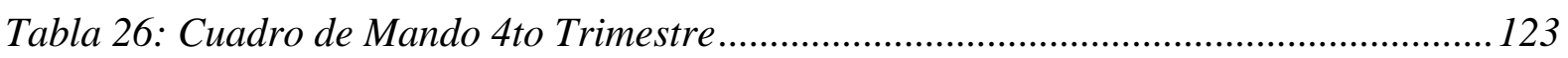

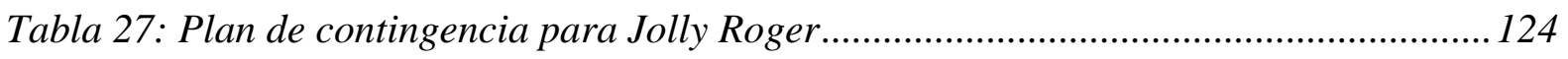

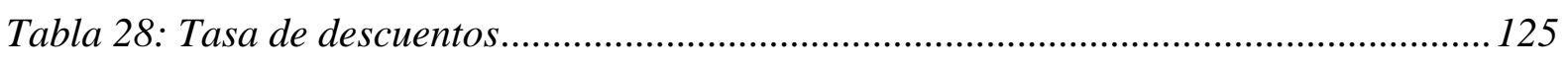

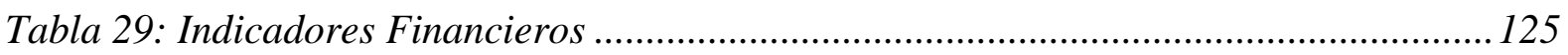




\section{ÍNDICE DE FIGURAS}

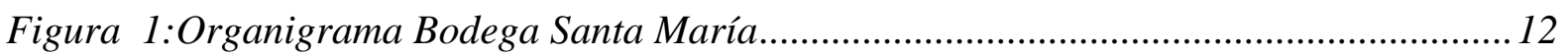

Figura 2: Proyecciones de crecimiento para América Latina y el Caribe..............................23

Figura 3: Índice de Precios al Consumidor Jun.2016 - Jun.2017 .......................................24

Figura 4: Variación de consumo en Perú............................................................................25

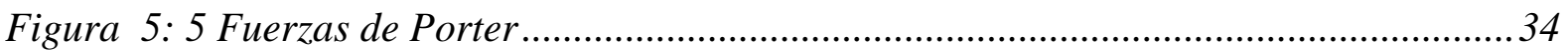

Figura 6: Producción de Pisco Anual en el Perú....................................................................38

Figura 7: Consumo per cápita de Pisco 2014 - 2017...............................................................39

Figura 8: Número de empresas por tipo de producción de Pisco, según...............................39

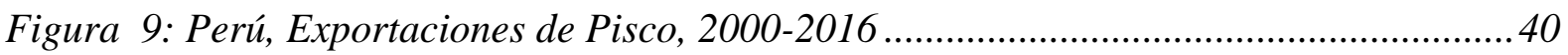

Figura 10: Ciclo de vida de los productos de la Bodega Santa María ..................................45

Figura 11: ¿Usted conoce el macerado de hierbas en base a Pisco Jolly ...............................55

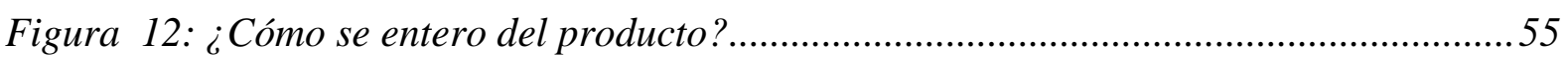

Figura 13: Figura: ¿Ha consumido Jolly Roger? ...........................................................56

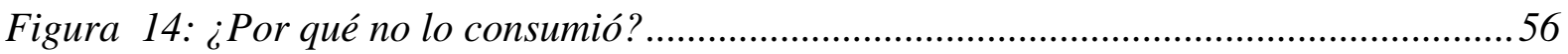

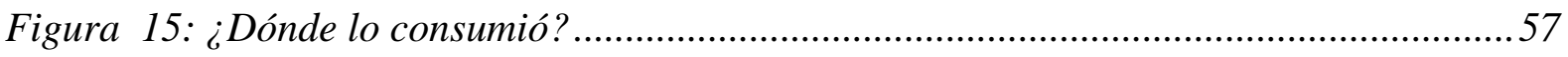

Figura 16: ¿Qué tan agradable es el Jolly Roger? ..........................................................57

Figura 17: ¿Qué tan agradable es el Jolly Roger? ............................................................58

Figura 18: ¿Qué tan agradable es el Jolly Roger? ...........................................................5

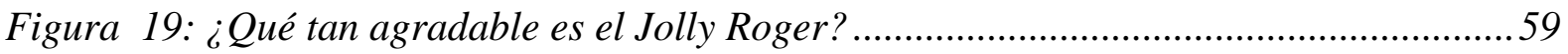

Figura 20: ¿Qué tan agradable es el Jolly Roger? ..............................................................59

Figura 21: ¿Cuál consideras que es la cantidad ideal en una botella de Jolly Roger?.........60

Figura 22: ¿Cuál es el precio ideal que pagaría por una botella de Jolly Roger de 750ml? 60

Figura 23: ¿Cuál considera es el producto competencia de Jolly Roger? ............................61

Figura 24: En general, ¿Cómo calificaria a Jolly Roger?................................................61 
Figura 25: Del 1 al 5 ¿Qué caracteristica de Jolly Roger considera mas importante? Siendo 1 el mas importante y 5 el menos importante con respecto a la botella. .62

Figura 26: Del 1 al 5 ¿Qué característica de Jolly Roger considera más importante? Siendo 1 el más importante y 5 el menos importante con respecto a la cantidad de mililitros 62

Figura 27: Del 1 al 5 ¿Qué característica de Jolly Roger considera más importante? Siendo 1 el más importante y 5 el menos importante con respecto a la tapa.

Figura 28: Del 1 al 5 ¿Qué característica de Jolly Roger considera más importante? Siendo 1 el más importante y 5 el menos importante con respecto al color .63

Figura 29: ¿Con que frecuencia lo consume?.... 64

Figura 30: ¿Cómo lo tomaría? .64

Figura 31: ¿Con que suele combinar el Jolly Roger? .65

Figura 32: ¿Lo ha comprado? .65

Figura 33: ¿Dónde lo compro? .66

Figura 34: Del 1 al 5 marque que tan importante considera los siguientes factores al momento de realizar la compra de Jolly Roger, donde 1 es lo más importante y 5 lo menos importante con respecto a la Calidad Percibida.....

Figura 35: Del 1 al 5 marque que tan importante considera los siguientes factores al momento de realizar la compra de Jolly Roger, donde 1 es lo más importante y 5 lo menos importante con respecto al precio.

Figura 36: Del 1 al 5 marque que tan importante considera los siguientes factores al momento de realizar la compra de Jolly Roger, donde 1 es lo más importante y 5 lo menos importante con respecto a la cantidad de mililitros

Figura 37: Del 1 al 5 marque que tan importante considera los siguientes factores al momento de realizar la compra de Jolly Roger, donde 1 es lo más importante y 5 lo menos importante con respecto a la Marca 68 
Figura 38: Del 1 al 5 marque que tan importante considera los siguientes factores al momento de realizar la compra de Jolly Roger, donde 1 es lo más importante y 5 lo menos importante con respecto a la Disponibilidad.........................................................................6 68

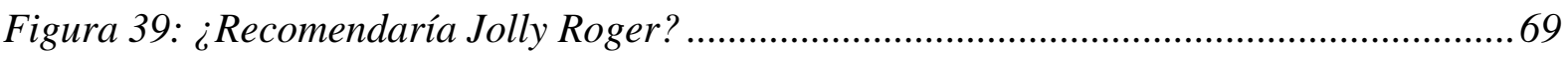

Figura 40: ¿Compraría o volvería a comprar Jolly Roger? ..............................................69

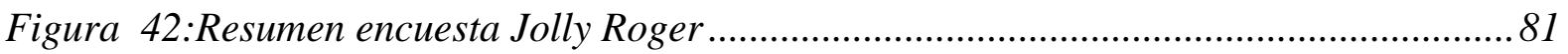

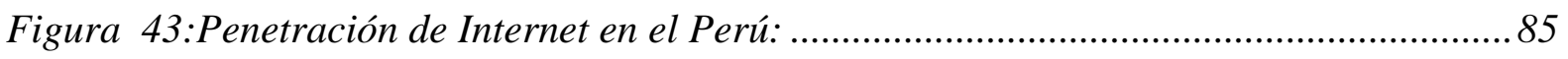

Figura 44: Top 15 de aplicaciones más usadas en Latinoamérica ......................................86

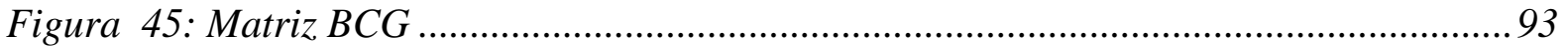

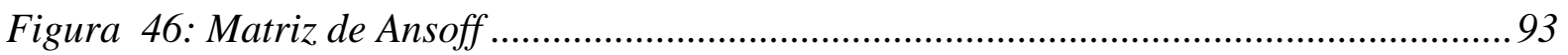

Figura 47: Estrategia Genérica de Michael Porter a utilizar: DIFERENCIACION.............95 


\section{RESUMEN EJECUTIVO}

El mercado de bebidas alcohólicas en el Perú y sobre todo en Lima está en constante crecimiento, pero si lo comparamos con la región el consumo sigue siendo bajo. Si sólo medimos el consumo de bebidas espirituosas tenemos al Pisco como la bebida de mayor crecimiento y participación dentro de esta categoría.

El pisco como bebida nacional tiene todo el apoyo de del Estado, teniendo como base la denominación de Origen del Pisco peruano, además de leyes que protegen e incentivan el consumo del verdadero pisco peruano. En el mercado existen diversas marcas de pisco en todas sus variedades de uva, unas enfocadas al precio y otras a características que solo un buen pisco suele tener. Por otro lado, el consumidor peruano muy lentamente está aprendiendo a consumir esta bebida espirituosa y tiene poco conocimiento de la misma.

La evaluación interna y externa del mercado del pisco presenta una gran oportunidad para el crecimiento del consumo de esta bebida, además de tener el segmento de mayores de 18 años y menos de 40 un segmento en crecimiento y con estilos de vida que podrían ayudar a incrementar el conocimiento y el consumo de nuestro pisco peruano.

La propuesta es dar una alternativa diferente para consumir pisco peruano, este producto será diferente a los ya existentes en el mercado peruano, dirigido al segmento con mayor proporción y que tienen todas las ganas de hacer y consumir de manera diferente a los demás. Esta alternativa diferente llamada Jolly Roger, bajo el respaldo de La Bodega Santa María, nos brinda la mejor opción de juventud, diferencia, calidad que este gran sector está buscando. 


\section{INTRODUCCION}

En el año 2017 fue un año difícil para la economía peruana, ya que diversos factores externos como el fenómeno del Niño Costero, la corrupción por cuenta de empresas del sector construcción, la caída del precio de cobre y otros afectaron el crecimiento sostenido del PBI, teniendo bajos crecimientos y caídas en varios sectores como agroindustrial, pesca, construcción, minería y manufactura. Esto incidió mucho en la producción de uvas pisqueras y por ende tuvo efecto en la producción de pisco peruano con Denominación Origen.

El año 2017 se empezó con más de 500 productores de pisco peruano, intentando superar los 10.2 millones de litros de la producción del año 2016. Es por eso que Bodegas Santa María toma la oportunidad de lanzar al mercado un producto elaborado con pisco peruano, macerado de hierbas peruanas en base a pisco, llamado Jolly Roger.

Este mercado es nuevo en el Perú y no existe registro de un producto similar, Jolly Roger es el único macerado. Existe un mercado de macerados, pero todos son elaborados de manera artesanal por los productores del pisco y diferentes personas que encuentran en esta bebida espirituosa la alternativa de ofrecer al consumidor algo diferente.

Condiciones que hacen que Jolly Roger ingrese al mercado de Lima y Callao:

- Producto nuevo en el mercado, diferente a cualquier producto existente en el mercado.

- Las pocas opciones de consumo que ofrecen las bodegas ya establecidas en el mercado de Lima y Callao. 
Estas condiciones en la que se encuentra el mercado de piscos, hacen que el consumo per cápita supere los 0.22 litros al año, comparado con el aguardiente de uva chileno cuyo consumo per cápita es de 1.9 litros al año.

En el año 2017 se promulgó una ley que sirve como base la protección del pisco bajo la denominación de origen y que convierte al pisco patrimonio cultural del Perú, esto con el afán de incrementar la producción y el consumo interno de nuestra bebida espirituosa. Bajo este escenario la Bodega Santa María busca ingresar al mercado peruano con este macerado de hierbas en base a Pisco Peruano y así poder competir con una nueva alternativa. 


\section{CAPÍTULO I: GENERALIDADES}

La presente tesis abordará el Plan de Marketing para el año 2018 de la bodega Santa María para el producto Jolly Roger (macerado de hierbas en base a pisco), nuevo producto en su portafolio de marcas. La Bodega está ubicada en el departamento de Lima, provincia de Cañete, distrito de Lunahuaná (Anexo 1). Fue creada en el año 1929 por el Sr. Benedicto Peña como una bodega productora de bebidas destiladas de uva. Dentro de sus marcas tiene a "Don Benedicto" (Piscos) y "Santa María” (Vinos), además del Jolly Roger (Macerado). La bodega se destaca por la producción y exportación de Pisco, siendo reconocida con premios por la calidad de estos productos en los años 2006 y 2011.

El Plan de Marketing para Jolly Roger ayudará a la bodega Santa María a ingresar al mercado de Lima y Callao de manera planificada y ordenada, con objetivos claros y estrategias definidas, además de incrementar la línea de productos de la empresa para alcanzar nuevos segmentos dentro del mercado actual.

\subsection{Antecedentes de la investigación}

En los últimos 5 años la producción de pisco en el Perú ha tenido un crecimiento de $10.8 \%{ }^{1}$ en promedio, lo cual muestra un interés por parte de los consumidores en este producto y sus derivados, incrementando así el número de empresas productoras y comercializadores con diferentes tipos de productos, calidad, precios y posicionamiento. En la actualidad hay 523 bodegas productoras de pisco en todo el Perú (48.8\% en Lima, $34.6 \%$ en Ica y $16.6 \%$ en el resto del país) ${ }^{1}$.

1"Juan Carlos Mathews Salazar | Perfil profesional - LinkedIn." https://pe.linkedin.com/in/juan-carlos-mathews-salazar-49712a37. Fecha de acceso 11 ago.. 2017. 
Este incremento en la producción viene de la mano con el esfuerzo del Estado Peruano en apoyar y promover la comercialización y consumo de Pisco acompañado de un aumento en el número de empresas dedicadas a la comercialización del producto lo que obliga a la bodega Santa María a ser competitiva y rediseñar estrategias, planes de comercialización y marketing más efectivos y eficaces generando un valor diferencial y agregado con respecto a la competencia y así alcanzar los objetivos planteados.

En el Perú algunas empresas del sector han realizado investigaciones en cuanto a producción y comercialización de Pisco, la gran mayoría abarcan puntos de mejora en el proceso tecnológico de elaboración, estudios de evaluaciones de materia prima y análisis de las exportaciones. En lo referente a macerado de hierbas en base a Pisco, no hay información del mercado que pueda ser tomada como antecedente para la presente investigación, ni en el área tecnológica ni comercial.

Existen macerados de hierbas artesanales de Pisco similares al Jolly Roger; sin embargo, estos no se comercializan de manera masiva. La comercialización del nuevo producto de la bodega generaría un interés por parte de los consumidores de Pisco y macerados, teniendo un producto de calidad y cumpliendo con todas las normas necesarias para su consumo.

\subsection{Determinación del Problema u Oportunidad}

El crecimiento en la producción y consumo de Pisco en el Perú en la última década, genera una oportunidad comercial para Bodega Santa María para incrementar su nivel de ventas. El mercado de Pisco en el Perú es muy competitivo, resultaría costoso ingresar y posicionar el Pisco Don Benedicto en el mercado peruano, es por esta razón que José 
Espinoza, Gerente General de la Bodega Santa María, después de un año de tener en el mercado el producto Jolly Roger, nota que las ventas no son las esperadas y surge el interés de realizar un Plan de Marketing profesional que ayude al incremento de las ventas y el conocimiento del producto en el mercado. Además de reforzar su posicionamiento o determinar uno nuevo que sea el ideal para el mercado peruano.

De manera académica utilizaremos el Libro de Plan de Marketing en la Práctica de José María Sainz de Vicuña Ancín, que nos ayudará a estructurar de la mejor manera el Plan de Marketing para Jolly Roger.

Las decisiones tomadas en el último año y el apuro por lanzar el producto, junto con la falta de presupuesto afectaron los resultados, no teniendo un objetivo claro, ni estrategias definidas.

\subsection{Justificación del Proyecto}

Con el Plan de Marketing a implementar, Bodega Santa María espera incrementar su nivel de producción y ventas. La investigación de mercado que se realice dentro del plan, brindará información de las preferencias, gustos, necesidades, ocasiones de consumo del target y ayudará a Jolly Roger a cumplir sus objetivos. Los accionistas de la bodega quieren tomar decisiones de descarte, de mejora y/o permanencia del producto en el mercado.

Existe un incremento en el consumo de bebidas alcohólicas no tradicionales en el mercado peruano, como el licor de hierbas Jägermeister (elaborado en Alemania) ${ }^{2}$ así como los macerados artesanales ${ }^{3}$ en base a pisco que se venden en bares y discotecas.

2 Data Trade 2017| Adex datatrade 
En base a los estudios cualitativos y cuantitativos y análisis interno y externo de la empresa se determinaron los siguientes objetivos:

- Incrementar el conocimiento de Jolly Roger

- Incrementa las ventas de Jolly Roger

- Ingresar a nuevos autoservicios

- Aumentar la participación de mercado

- Incrementar la utilidad operativa

\subsection{Objetivos Generales y Específicos}

Previamente al planteamiento del objetivo general, se realizó un estudio de mercado para determinar el nivel de conocimiento de Jolly Roger (Ver figura 12).

\subsubsection{Objetivo General}

- Incrementar el Nivel de Conocimiento de Jolly Roger de $10.9 \%$ a $20 \%$ en Lima Metropolitana y Callao para el 2018.

- Incrementar las ventas de 88,452 a 173,189 dólares en el 2018.

\subsubsection{Objetivos Específicos.}

- Ingresar a 3 autoservicios en Lima Metropolitana y Callao para el 2018.

- Aumentar la participación de mercado de $7.75 \%$ a $12.90 \%$ en el 2018.

- Incrementar la utilidad operativa de 36,762 a 40,463 dólares en el 2018.

\subsubsection{Objetivos de Marketing}

\section{- Producto:}


- Incrementar de 1 a 2 las presentaciones de la botella de Jolly Roger en cuanto a cantidad para el 2018.

\section{- $\quad$ Plaza:}

○ Ingresar a 2 nuevos canales de venta para el 2018.

- Precio:

- Mantener el $25 \%$ de diferencia de precio con el referente en el mercado, Jagermeister, en todos los canales de venta para el 2018.

\section{- Comunicación:}

○ Obtener un nivel de recordación del $21.82 \%$ del mercado potencial en 1 año.

○ Obtener un alcance de 1millones de usuarios utilizando redes sociales para el 2018.

○ Obtener un ratio de participación del 1\%(7,500 usuarios) en promedio mensual para el año 2018.

○ Incrementar el tráfico web a 5,000 visitas en promedio mensualmente.

- Tener un tiempo de respuesta al usuario de como máximo 1 hora en promedio en redes sociales para el 2018. 


\subsection{Alcances y Limitaciones}

\section{Alcances}

- El Plan de Marketing tiene como finalidad brindar información fidedigna a la Bodega Santa María de su producto macerado de hierbas en base a Pisco, Jolly Roger, para mejorar la comercialización y estimar el nivel de aceptación del producto en base a una investigación de mercado.

- El presente Plan tendrá como alcance la ciudad de Lima Metropolitana y Callao por temas de accesibilidad y recursos.

\section{Limitaciones}

- Poca información acerca del sector de macerados de pisco y escasa información de planes comerciales de macerados a nivel industrial.

- Difícil acceso a información del referente (Jagermeister) 


\section{CAPÍTULO II: LA EMPRESA}

En el presente capítulo se desarrollará la información de la Bodega Santa María de los últimos 2 años, 2016 y 2017, se podrá conocer también las marcas de productos que comercializa en el mercado nacional e internacional.

Posteriormente se especificará la situación actual de la Bodega señalando la estructura organizacional lineal. También presentaremos la situación actual del mercado y situación financiera de la empresa, además de la misión y visión, así como los valores de la organización, con la finalidad de conocer los objetivos en el futuro de la empresa en este estudio.

Los datos obtenidos para el presente Plan de Marketing fueron extraídos mediante una entrevista al Gerente General de la Bodega Santa María, José Espinoza.

\subsection{Situación de la Empresa}

Este Plan de Marketing tiene como fuente de información datos de producción y comercialización de la Bodega Santa María, empresa peruana fundada en 1929, por Don Benedicto Peña, abuelo de José Espinoza, Gerente General.

Bodega Santa María produce y comercializa productos derivados de la uva como Vinos y Piscos, además de maquila para terceros, que ayudan a aumentar su producción y venta. Los Piscos Don Benedicto son exportados a diferentes partes del mundo, siendo su 
principal destino Estados Unidos e Israel. En el caso del vino se comercializa a nivel local, sobre todo en las periferias de Lima.

La línea de vinos Santa María cuenta con 4 variedades:

- Vino Rose, elaborado en base a uva Quebranta, liviano y frutado, de color rosado, obtenido gracias a la fermentación parcial de los orujos y acompaña a cualquier tipo de comida.

- Vino Borgoña Blanco, vino ligero y frutado, obtenido de la selección cuidadosa de uvas Borgoña blanca, vino joven y bien balanceado, ideal para aperitivos y excelente para acompañar carnes blancas y mariscos.

- Vino Borgoña Tinto, exótico, único en su género, semi seco, elaborado con la variedad de uva Borgoña negra, acompaña bien a todo tipo de comida peruana.

- Vino Burdeos, elaborado con uvas tintas, armonioso cuerpo y color, aroma distinto y especial bouquet. Acompaña perfecto a carnes rojas y comidas condimentadas.

La línea de piscos cuenta con 5 variedades:

- Pisco Quebranta, obtenido de la destilación del mosto de la uva Quebranta, limpio, con estructura y equilibrio.

- Pisco Italia, muy aromático, en proceso igual a la uva quebranta, elaborado con la uva italia, intenso y con extraordinario aroma.

- Pisco Acholado, elaborado con 2 o más uvas pisqueras, pudiendo ser aromáticas y no aromáticas, perfecto para la elaboración de cócteles. 
- Pisco Uvina, elaborado de la uva pisquera uvina con gran cuerpo y aroma original.

- Pisco Mosto Verde, excepcional pisco de un brillo extraordinario, cautivante aroma, buen cuerpo y largo final. Pueden ser elaborados de uva quebranta, Italia y moscatel.

Tenemos un producto nuevo dentro la cartera de la bodega, macerado de hierbas en base a pisco llamado Jolly Roger. Este producto está elaborado en base a pisco quebranta; macerado con hierbas, frutas y especias como anís, canela, naranja, maíz morado, etc.

\subsection{Estructura Organizacional de la Empresa}

Bodega Santa María es una organización familiar ubicada en el departamento de Lima, provincia de Cañete, distrito de Lunahuaná. A continuación, el organigrama actual de la empresa en la Figura 1:

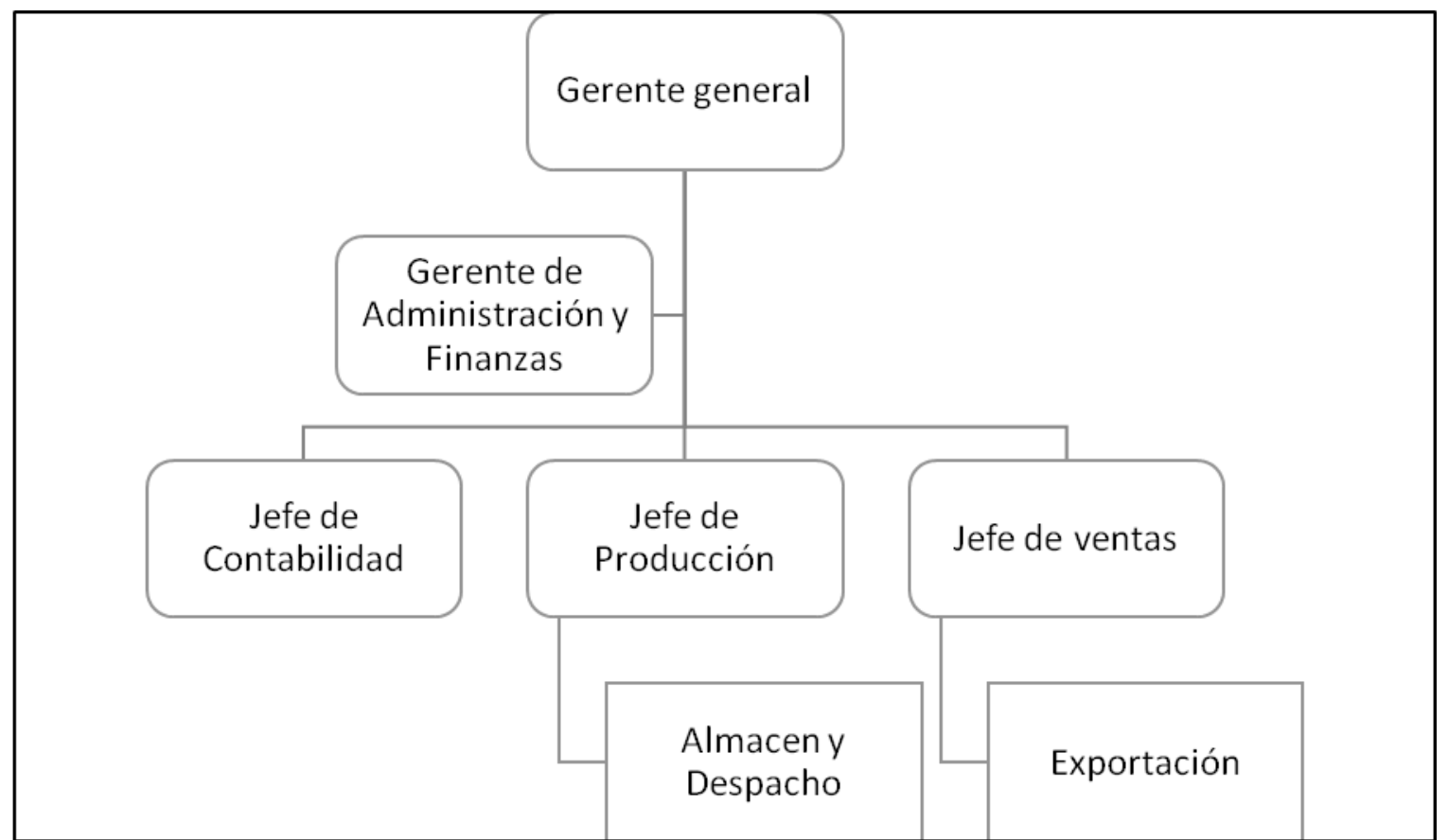

Figura 1:Organigrama Bodega Santa María 
La estructura organizacional de Bodega Santa María está conformada por un Gerente General y una Gerencia de Administración y Finanzas. El Nivel Operativo y Técnico está conformado por el área Contable, Producción y Ventas. Dentro del área de Producción se encuentra el área de despacho. El área de Ventas está conformada por la oficina de exportación y venta de mostrador (venta en la misma bodega).

\subsection{Situación de mercado y financiera de la empresa}

Hace 20 años y ante la necesidad del mercado, José Espinoza, nieto del fundador Benedicto Peña, registra las marcas Santa María para Vinos y Don Benedicto para los Piscos y empieza a comercializar estas marcas en el mercado de Cañete.

Las ventas de los Piscos Don Benedicto desde un principio fueron solo en la misma bodega hasta el año 2015, posteriormente gracias a una inversión considerable, se realizaron varios contratos de exportación a clientes externos interesados en el producto. Es así que las ventas del Pisco Don Benedicto en el año 2016 se muestran en la siguiente Tabla 1: 
Tabla1: Exportación Mensual de Pisco Don Benedicto 2016

\begin{tabular}{|c|c|c|c|c|}
\hline \multirow[t]{2}{*}{ Mes } & \multicolumn{4}{|c|}{ Venta en unidades } \\
\hline & Pisco Mosto verde & Pisco Quebranta & Pisco Acholado & Pisco Italia \\
\hline Enero & 3000 & 0 & 0 & 0 \\
\hline Febrero & 4000 & 0 & 0 & 0 \\
\hline Marzo & 4000 & 3000 & 1500 & 1500 \\
\hline Abril & 3000 & 1000 & 0 & 1000 \\
\hline Mayo & 3500 & 500 & 3000 & 3000 \\
\hline Junio & 2500 & 2000 & 1000 & 500 \\
\hline Julio & 1000 & 0 & 0 & 0 \\
\hline Agosto & 3000 & 2000 & 3000 & 1000 \\
\hline Septiembre & 2500 & 3000 & 1500 & 1000 \\
\hline Octubre & 4000 & 0 & 1800 & 3200 \\
\hline Noviembre & 5000 & 1000 & 3000 & 1000 \\
\hline Diciembre & 6000 & 2000 & 1500 & 500 \\
\hline Total & 41500 & 14500 & 16300 & 12700 \\
\hline
\end{tabular}

Fuente: Elaboración propia 
El macerado de hierbas en base a Pisco Jolly Roger ingresó al mercado en mayo de 2016 por medio de algunas tiendas de conveniencia y logrando un nivel de ventas de \$25200.00, lo cual se muestra en la Tabla 2:

Tabla2: Venta Mensual de Jolly Roger 2016

\begin{tabular}{ll}
\hline \multicolumn{1}{c}{ Mes } & $\begin{array}{l}\text { Venta en dólares } \\
\text { Jolly Roger }\end{array}$ \\
\hline Enero & 0 \\
Febrero & 0 \\
Marzo & 0 \\
Abril & 0 \\
Mayo & 1,400 \\
Junio & 1,350 \\
Julio & 1,650 \\
Agosto & 3,600 \\
Septiembre & 4,125 \\
Octubre & 4,260 \\
Noviembre & 4,105 \\
Diciembre & 4,710 \\
\multicolumn{1}{c}{ Total } & 25,200 \\
\hline
\end{tabular}

Fuente: Elaboración propia

Las ventas para el año 2016 ascendieron a 1,121,590 dólares para todas las variedades de los piscos; para Jolly Roger 25,200 dólares y para los vinos ascendió a 302,726 dólares, teniendo la Bodega una venta total de 1, 449,517 dólares. Ver Tabla 3 y 4 : 
Tabla 3: Ventas Anuales de Pisco Don Benedicto

\begin{tabular}{llclc}
\hline Año & \multicolumn{2}{c}{ Venta en dólares } & Total & Var \% \\
& Mosto Verde & Quebranta/Acholado/Italia & & \\
& & & & \\
\hline 2016 & $660,227.27$ & $461,363.64$ & $1,121,590.91$ & \\
2017 & $772,465.91$ & $539,795.45$ & $1,312,261.36$ & $17 \%$ \\
\hline
\end{tabular}

Fuente: Elaboración propia

Tabla4: Ventas Anuales de Jolly Roger

\begin{tabular}{llll}
\hline Año & \multicolumn{2}{l}{ Venta } & Var \% \\
\hline 2016 & $\$$ & 25,200 & \\
2017 & $\$$ & 88,452 & $251 \%$ \\
$2018^{*}$ & $\$$ & 173,189 & $95,8 \%$ \\
& & & \\
\hline *: Estimada \\
Fuente: Elaboración Propia
\end{tabular}

Los costos no han variado en el tiempo, el fenómeno del niño del año 2017 no afectó la producción de uva en la zona de Lunahuaná. Al incrementar la producción el costo unitario se mantiene o disminuye en alguno de los casos. Ver en Tabla 5: 
Tabla 5: Costo de Ventas Anuales de Don Benedicto

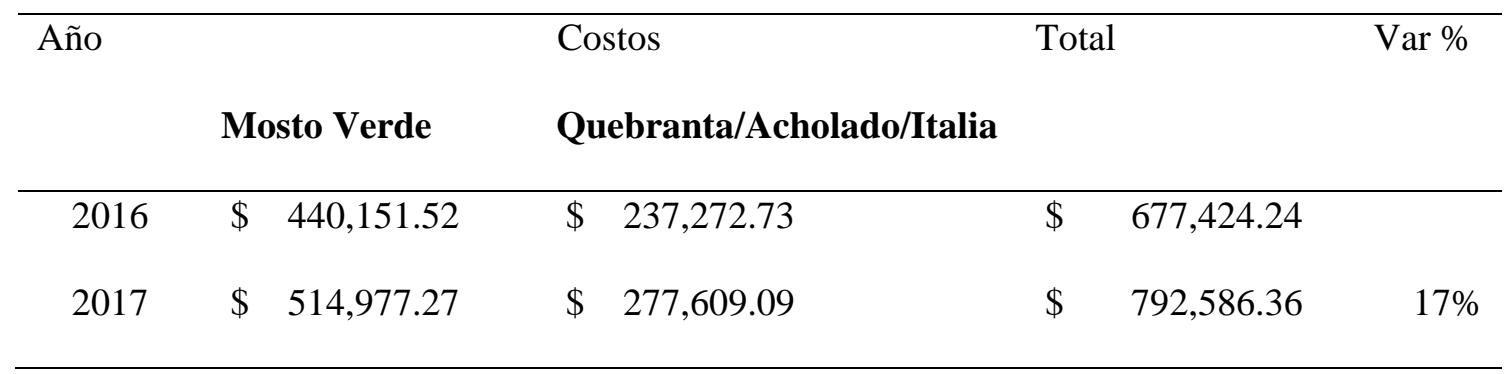

Fuente: Elaboración propia

La Rentabilidad se mantiene, teniendo un $49 \%$ de margen para los piscos quebranta, italia y acholado, el margen del pisco mosto verde es de 33\%. Ver Tabla 6 y 7:

Tabla 6: Rentabilidades Anuales de Don Benedicto

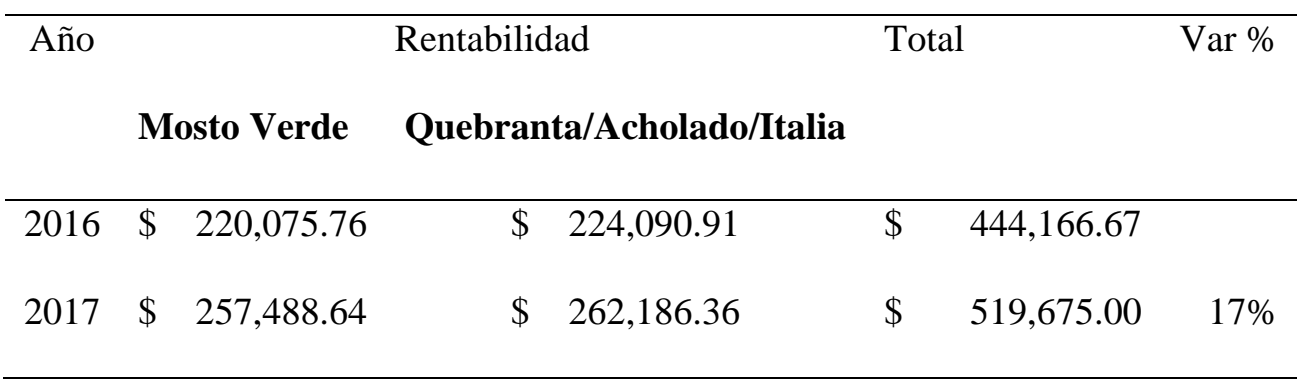

Fuente: Elaboración propia

Tabla 7:Rentabilidades Anuales de Jolly Roger

\begin{tabular}{clc}
\hline Año & Rentabilidad & Var \% \\
\hline 2016 & $\$ 10,840$ & \\
2017 & $\$ 36,762$ & $239 \%$ \\
2018 & $\$ 40,463$ & $10 \%$ \\
\hline
\end{tabular}

Fuente: Elaboración propia 


\subsection{Visión, Misión y Valores de la Empresa}

\subsubsection{Misión:}

Elaborar licores derivados de la uva, la misma que son cosechados en la tierra pisquera de Lunahuaná, en equilibrio con el medio ambiente, mejorando la calidad de vida de nuestros colaboradores e incrementando la rentabilidad para la organización.

\subsubsection{Visión:}

Consolidarnos como líderes en la industria vitivinícola en Lima, desarrollando productos de calidad reconocidos a nivel nacional e internacional.

Para la definición de la misión y visión de la empresa se tomó como referencia el libro de Fred Davis (“Conceptos de Administración Estratégica”, capítulo 2, páginas 45 - 52) y se tomaron como base los siguientes criterios teóricos:

\section{Misión:}

- ¿Cuál es nuestro negocio?

Producir vinos, piscos y productos derivados de uva de la mejor calidad, respetando la tradición en la elaboración.

\section{Visión:}

- ¿En qué queremos convertirnos?

Ser la Bodega líder en la fabricación y comercialización de productos innovadores en base a la uva.

Adicionalmente y en base al análisis DAFO realizado para la bodega Santa elaboramos la siguiente Misión y Visión. 


\section{Misión:}

Producir vinos, piscos y productos derivados de uva de la mejor calidad, respetando la tradición en la elaboración y ofreciendo una experiencia única con productos innovadores respetando el medio ambiente y mejorando la calidad de vida de los trabajadores, productores y accionistas de la bodega.

\section{Visión:}

Ser la Bodega líder en la fabricación y comercialización de productos innovadores en base a la uva, siendo reconocidos a nivel Nacional e Internacional.

\subsubsection{Valores de la empresa:}

- Honestidad: En los procesos de producción y demás acciones de la empresa.

- Responsabilidad Social: Respetamos el medio ambiente.

- Respeto: Escuchamos, entendemos y valoramos.

- Confianza: Cumplimos con lo prometido.

- Trabajo en equipo: Aporte de todos los que intervienen en la organización. 


\section{CAPÍTULO III: ANÁLISIS DE LA SITUACIÓN DE LA EMPRESA}

\subsection{Análisis externo}

\subsubsection{Político - legal.}

Actualmente el Perú cuenta con una estabilidad política y legal durante más de una década, lo que genera confianza para los inversionistas. El 2017 el Gobierno del Perú afronta una serie de conflictos sociales, además de fricciones con el congreso de mayoría opositora, que han desacelerado el proceso de inversión económica, pero que no han afectado la estabilidad política y jurídica del país.

Luego del primer año del gobierno del presidente del Perú Pedro Pablo Kuczynscki, muchas promesas ofrecidas no fueron cumplidas, influenciado principalmente por los casos de corrupción Lava Jato y por el fenómeno del Niño Costero. En la memoria de Gobierno 2016-2017 presentada por el presidente Kuczynski durante su discurso por su primer año de gobierno, se hace un balance de la estabilidad político-jurídico que tiene el Perú ${ }^{4}$. En su discurso luego del primer año de gestión, el presidente del Perú pidió disculpas por la desaceleración económica, ya que para el 2017 se estimó un PBI de 4,8\%, para el segundo semestre del mismo año se espera pueda llegar a un PBI de $3.8 \% \%^{5}$. Queda pendiente muchas leyes esperadas por todos que el congreso tiene que evaluar y promulgar, como la reforma electoral, sobre todo porque se acerca en el 2018 las elecciones para los gobiernos locales y municipales.

\footnotetext{
${ }^{4}$ Memoria de Gobierno 2016-2017. http://www.gob.pe/450-memoria-de-gobierno-2016-2017. Fecha de acceso: 19 de Agosto 2017 ${ }^{5}$ Carlos García, CCL. http://gestion.pe/economia/whisky-y-ron-son-licores-que-mas-importo-peru-primer-trimestre-2130975 . Fecha de acceso 20 de Agosto del 2017
} 
En cuanto al aspecto legal, la estabilidad y la independencia del poder judicial, hacen que la confianza por parte de los inversionistas sea alta, debido a la confianza que tienen en el cumplimiento de las leyes en el Perú. En el Perú no existen leyes proteccionistas que restringen la importación de muchos productos, entre ellos los licores. Según la Cámara de Comercio de Lima (CCL) ${ }^{7}$, en el primer trimestre del 2014 comparado al primer trimestre del 2015, hubo un incremento de la importación de licores del 52\%. El 2016, el crecimiento de la importación de licores fue de 6\%. Para el primer trimestre del 2017, el crecimiento en importación de licores fue de $6 \%$ con respecto al mismo periodo del $2016^{8}$.

En el Perú tenemos una Ley publicada en el año 2009 que regula la comercialización, consumo y publicidad de bebidas alcohólicas: Reglamento de Ley N.- 28681, Decreto Supremo N.- 012 - 2009 SA. Anexo. Tenemos también la Ley N.30460, que declara de interés Nacional la promoción y difusión del Vino Peruano y del Pisco como Bebidas Nacionales. En Agosto del año 2017 el congreso de la República del Perú promulga la ley 30639 que permitirá generar acciones y políticas públicas de cumplimiento obligatorio en favor de la industria del Pisco, las cuales serán promovidas por el Ministerio de la Producción ${ }^{7}$.Esta ley ayudará a promover la bebida pisco y declara Patrimonio Cultural de la Nación la Denominación de Origen Pisco; una medida que solo protege al Pisco en el territorio Peruano, como un licor nacional.

\footnotetext{
7 Pedro Olaechea,http://gestion.pe/tendencias/congreso-eleva-rango-ley-declaracion-al-pisco-como-patrimonio-cultural-nacion-2197972 Fecha de acceso 20 de Agosto del 2017

${ }^{8} \mathrm{CCL}$, https://camaralima.org.pe/principal/noticias/noticia/whisky-continua-siendo-el-licor-importado-mas-consumido-de-peru/795. Fecha de acceso 20 de Agosto del 2017
} 
Como Oportunidad podemos apreciar que el Perú tanto en el segundo semestre del 2017 y en el año 2018 tendrá una estabilidad política y jurídica que ayude al crecimiento del consumo. La ley de protección de Denominación de Origen del pisco y tener al pisco como patrimonio cultural del Perú, hacen que la industria se formalice, se le agregue valor al pisco

Como Amenazas tenemos a los diferentes conflictos sociales que se desatan en el país, sobre todo en Lima, haciendo que muchos negocios no tengan atención al público.

\subsubsection{Económico - demográfico}

En el aspecto económico, el Perú es visto como una de las economías con más expectativas de crecimiento en la región. Un informe de proyecciones del Fondo Monetario Internacional (FMI), coloca al Perú como líder en crecimiento económico en la región para el 2017, influenciado por la producción de cobre y del gasto interno. Ver Fig. 2

Las estimaciones del FMI para el Perú no se han ido cumpliendo según lo estimado, influenciado por los efectos de la corriente del Niño Costero y la poca inversión de las empresas peruanas y del estado peruano. 


\begin{tabular}{|c|c|c|c|c|}
\hline \multicolumn{5}{|c|}{$\begin{array}{l}\text { Ültimas proyecciones de crecimiento } \\
\text { para Améria Latina y el Caribe } \\
\text { avariación porcentual del PBI real }\end{array}$} \\
\hline & 2015 & 2016 & 2017 & 2018 \\
\hline América Latina y el Caribe & 0.2 & -0.7 & 1.2 & 2.1 \\
\hline América del Sur & -1.3 & -2.3 & 0.8 & 1.8 \\
\hline $\begin{array}{l}\text { América del Sur sin } \\
\text { economias en } \\
\text { contracción" }\end{array}$ & 2.9 & 2.4 & 2.9 & 3.3 \\
\hline \multicolumn{5}{|l|}{ América Latina } \\
\hline II Perú & 3.3 & 4.0 & 4.3 & 3.5 \\
\hline = Colombia & 3.1 & 1.9 & 2.6 & 3.5 \\
\hline - Argentina & 2.5 & -2.4 & 2.2 & 2.8 \\
\hline D. Chile & 2.3 & 1.6 & 2.1 & 2.7 \\
\hline H México & 2.6 & 2.2 & 1.7 & 3.0 \\
\hline 으 Brasil & -3.8 & -3.5 & 0.2 & 1.5 \\
\hline a Venezuela & -6.2 & -12.0 & -6.0 & -3.0 \\
\hline \multicolumn{5}{|c|}{ 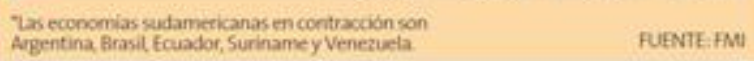 } \\
\hline
\end{tabular}

Figura 2: Proyecciones de crecimiento para América Latina y el Caribe Fuente: FMI

El segundo semestre del 2017, no fueron los mejores para la economía en el Perú, los conflictos sociales, las obras paralizadas y los actos de corrupción no ayudaron en el crecimiento del PBI, pero se tiene estimado un incremento del PBI para el 2018 de $3.8 \%$. El consumo sólo tuvo un crecimiento de $2.6 \%$ y se espera llegar a 2.9\% para el 2018, en el caso de la inversión privada cayó en 2.2\% y para el 2018 solo crecerá en un $2.1 \%$. La inflación se mantiene en un $2.3 \%$ y $2.0 \%$ para el 2018. Según se indica en la Tabla 8. 
Tabla 8: Principales proyecciones para el 2017 y 2018

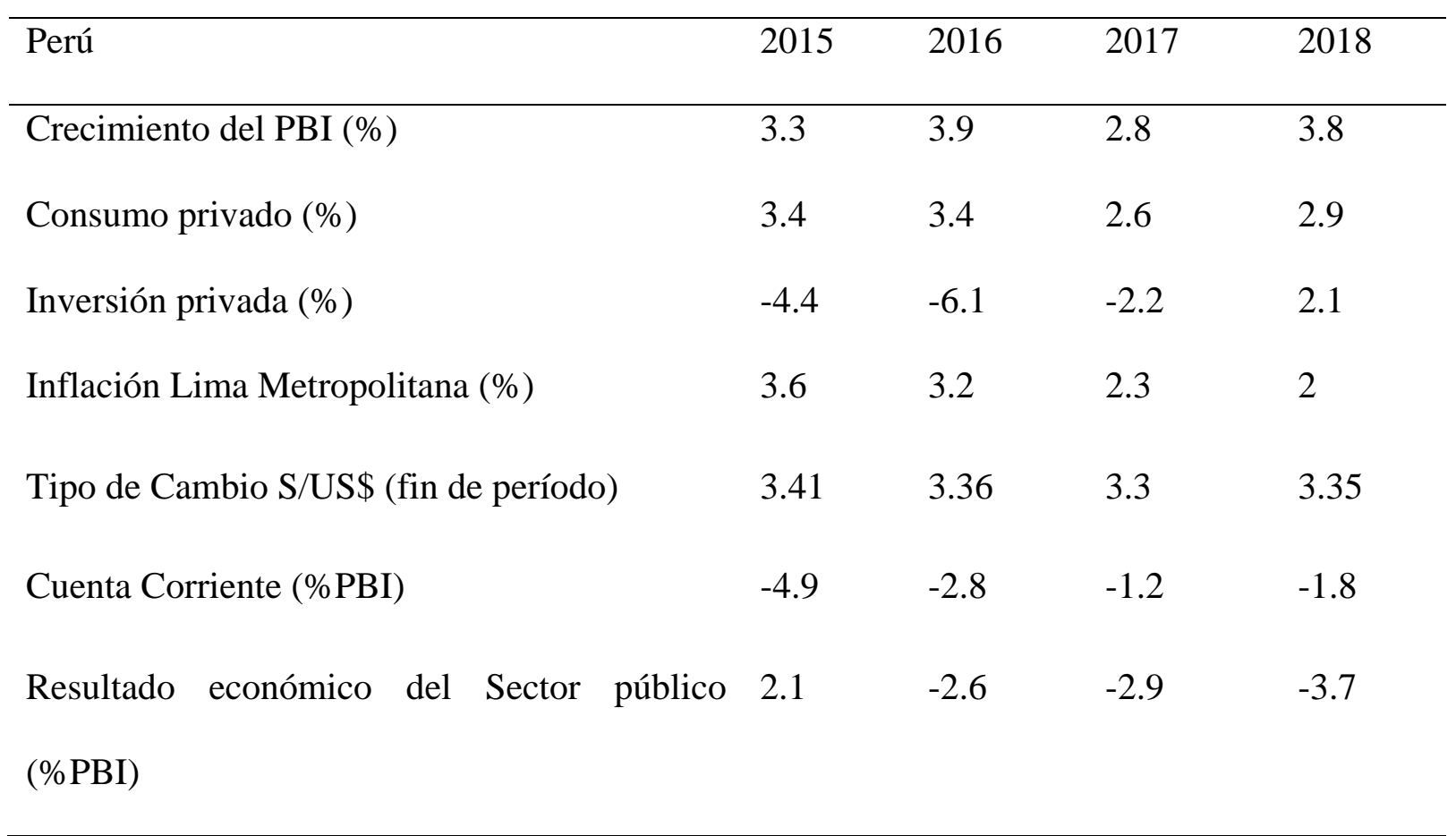

Fuente BCR, INEI

El índice de precios del consumidor se mantiene dentro de las expectativas ya que mide el comportamiento de los precios de bienes y servicios, en julio esta variación fue de $0.2 \%$, este incremento se dio sobre todo por el aumento de precios en alimentos y bebidas de $0.28 \%$, esparcimiento, servicios culturales y enseñanza con 0.2\%. Ver Fig. 3.

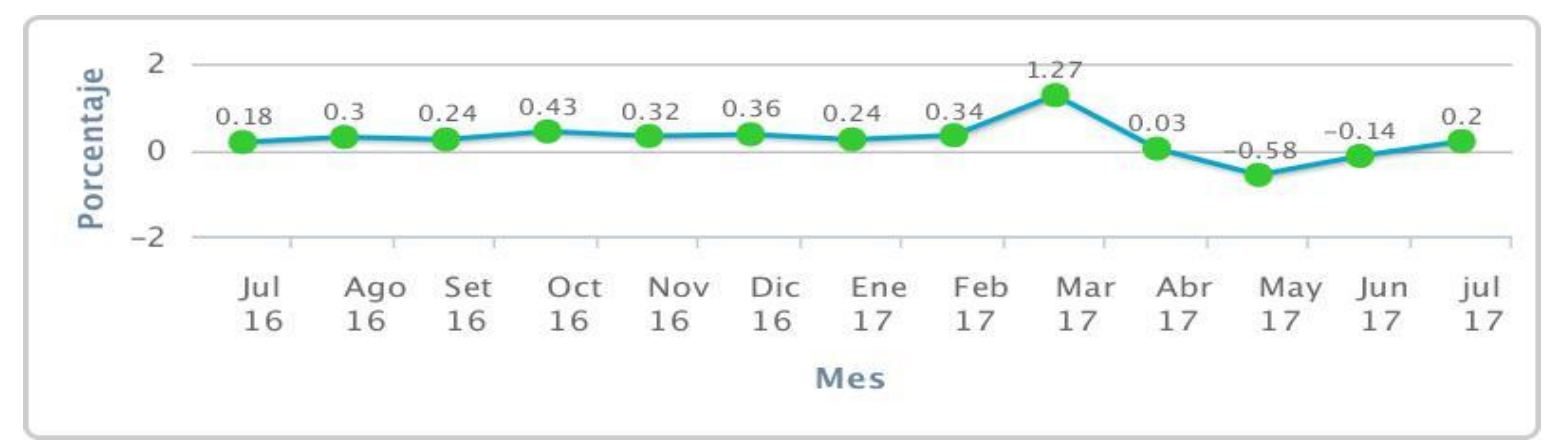

Figura 3: Índice de Precios al Consumidor Jun.2016 - Jun.2017 
Para el primer bimestre del 2017, se observa una caída en el consumo del $4 \%$ influenciado por los problemas de paralización de inversiones (Caso Odebrecht) y por el fenómeno del Niño Costero. Pero a pesar de ello, se ha visto un incremento en el rubro de bebidas $(\mathrm{htt})^{9}$ del $0,8 \%$ a diferencia de los productos alimenticios, oportunidad para Bodega Santa María con su producto Jolly Roger. Ver Figura 4

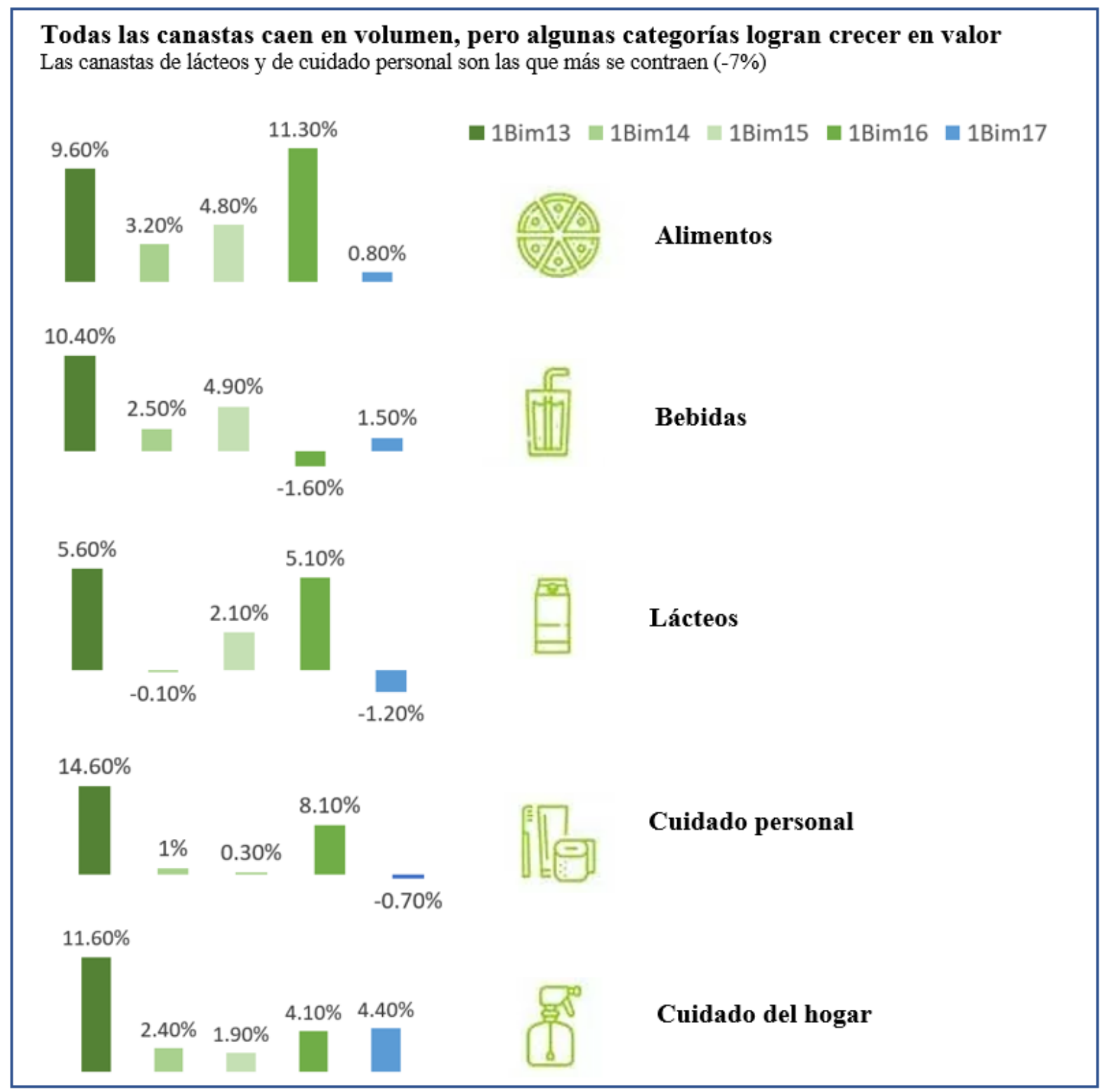

Figura 4: Variación de consumo en Perú

Elaborado: Consultora Kantar World Panel

${ }^{9}$ Perú Retail.http://www.peru-retail.com/consumo-peru-caida-2017/Fecha de acceso 21 de Agosto del 2017 
Para el 2017, el Instituto Nacional de Estadística e Informática (INEI) indica que la población en el Perú bordea los 32 millones de personas, de las cuales Lima alberga 9 millones 243 mil habitantes. De esta cantidad la PEA en Lima supera los 5 millones de personas, siendo el 93,2\% la PEA ocupada. El 54,2\% de la PEA ocupada de Lima Metropolitana tiene de 25 a 44 años de edad siendo este grupo una parte importante del segmento objetivo del producto Jolly Roger.

En este punto solo podemos observar una oportunidad, que las expectativas de mejora después de los desastres naturales, el consumo tendrá una mejora al igual que la inversión. Una oportunidad importante es que la PEA supera los 5 millones de personas se concentran en Lima, 1/6 de la población total del país.

- Expectativas de mejora en indicadores como consumo e inversión.

- Un nuevo desastre natural que afectaría la estabilidad productiva y económica del país.

\subsubsection{Socio - Cultural}

Hoy en día, la industria de bebidas alcohólicas busca nuevos productos para acercarse al público joven. El gobierno peruano incentiva el consumo de productos peruanos y esto ayuda a cada vez más personas empiecen a consumir el licor de bandera peruano, Pisco.

El boom gastronómico, ha generado una nueva búsqueda por parte del consumidor peruano en productos innovadores, esto ha sido el punto de partida para 
que Bodega Santa María elabore un producto en base al licor de bandera nacional, macerado de hierbas en base a Pisco, Jolly Roger.

La mejora en la economía en el país, ha traído como consecuencia un cambio en las costumbres socio-culturales de la población; el aumento del poder adquisitivo en la población ha generado un mejor nivel de educación, cambio en sus costumbres de alimentación y esto también ha influenciado en el consumo de bebidas alcohólicas. El nivel de consumo de cerveza en el Perú es alto en comparación con otros licores, pero en los últimos años se ha producido un aumento en el consumo de bebidas alcohólicas destiladas, lo cual ha favorecido al consumo del Pisco. El crecimiento de la economía en el Perú, hacen que los consumidores busquen bebidas que reflejan su nuevo status, bebidas más selectas que los diferencien del consumidor habitual de licores. Años atrás, el consumo de Pisco en el Perú era despreciable, para el 2017 hablamos de 0,22 ${ }^{10}$ litros de consumo per cápita, un valor que ha ido aumentando en los últimos años.

La búsqueda de bebidas alcohólicas innovadoras, la elaboración de cócteles con licores Premium y ser parte de un grupo diferente es la oportunidad que Jolly Roger tiene de ingresar al mercado de Lima y Callao. El incremento de la clase media en el Perú, sobretodo en Lima, la independencia de las mujeres con mayor educación y liderazgo, hacen que el consumo fuera del hogar aumente, sobre todo en gastos en vida social y/o nocturna, la mayor parte de la población en Lima son jóvenes, es decir habrá más ingresos para cubrir gastos de menos persona, ellos son los millennials con espíritu de la generación Z, (Rolando Arellano) y cuentan con una estabilidad económica.

10http://revistasinvestigacion.unmsm.edu.pe/index.php/administrativas/article/view/11699 
Varios estudios ${ }^{10}$ de este target (millennials) nos dan los siguientes insights:

- Tecnología: La computadora de escritorio fue su primer interés, luego la notebook y actualmente los Smartphone, siempre usando la última tecnología existente, la comunicación y la distracción se encuentran en estos medios.

- Vivir el momento: Quieren vivir el momento actual intensamente y buscan la felicidad y la pasión en todo lo que hacen. Esto genera un cambio importante los millennials ponderan el trabajar de lo que les gusta por sobre el ejercicio del poder o incluso lo material.

- Trabajo: Suelen ser multifacéticos (hacen varias cosas al mismo tiempo), es probable que tengan varios trabajos, como free-lance.

- Crítica: Los millennials son participativos y les gusta compartir sus $\operatorname{conocimientos}^{11}$. No creen demasiado en los derechos de autor y están a favor de democratizar la información compartiéndola. Revisan siempre lo que las empresas les dicen.

- Disfrute: Los Smartphone y los viajes son sus disfrutes y en lo que suelen gastar.

Los millennials siempre piensan en el envase de los productos y el aporte al ambiente, $73 \%$ compran envases reciclables y 59\% con envase renovable. Exigen etiquetas limpias y envases transparentes, el $86 \%$ cree que los alimentos y bebidas contienen ingredientes químicos, creen que los envases de vidrio preservan la inocuidad y mantienen la frescura.

Los consumidores demandan bebidas que brinden energía (maca), fortalezcan el sistema inmunológico y ayuden a controlar el sueño. El $60 \%$ buscan los antioxidantes en las bebidas que consumen ${ }^{\text {EError! Marcador no definido. }}$ 
El peruano por ser un consumidor muy tradicional prefiere disfrutar las bebidas en cocteles como el cuba libre, chilcano, pisco sour o el vodka tonic, la coctelería en el Perú viven en su mejor momento.

Giovanna Lopez, docente de técnicas de bar y coctelería de Dgallia, destaca el uso de bebidas espirituosas para dar paso a las nuevas presentaciones y sabores ${ }^{11}$.

\subsubsection{Tecnológico.}

La globalización y el avance tecnológico en el mundo han permitido que se establezcan nuevos medios de comunicación y herramientas que facilitan y mejoran la calidad de vida de las personas. Esto se ve reflejado en el Perú por medio del incremento del consumo de internet, las adquisiciones de Smartphone y el uso de redes sociales.

El proceso de producción de Jolly Roger, parte de la producción de Pisco. Hablar de macerados en el Perú, es hablar de un licor artesanal elaborado generalmente en hogares y pequeñas licorerías. Algunos restaurantes peruanos elaboran su propio macerado en base a Pisco de forma artesanal, utilizando como parte de la materia prima algunos frutos locales. La industrialización de macerados en el Perú no ha sido desarrollada, el proceso de maceración pasa por etapas de control para poder obtener el producto óptimo, estas etapas pueden durar días, semanas o meses, dependiendo de cada productor. La industrialización del proceso de maceración, agilizaría los tiempos de maceración y generaría una mejor rentabilidad para las empresas dedicadas a la elaboración de estos productos. Con la implementación de nuevas tecnologías para el proceso de maceración se podría estandarizar el proceso y tener un macerado con

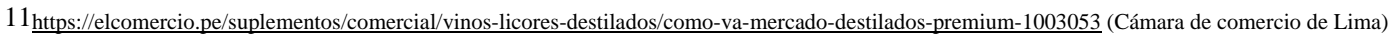


características organolépticas homogéneas durante el proceso de producción de lo largo del tiempo, ya que se implementaría adecuados procesos de control de calidad que garanticen la calidad del producto final. Existen varios instrumentos de alta tecnología que pueden intervenir en el proceso de producción del pisco, pero no está determinado en las políticas de la Denominación de Origen del pisco.

Ser la primera bodega en producir y comercializar el primer y único macerado es una oportunidad que se debe aprovechar para ingresar al mercado de Lima y Callao.

\subsubsection{Mercado y Competencia.}

En el Perú no existe un mercado medible en lo referente a macerados, ya que es un producto elaborado artesanalmente. En los últimos años, el incremento de la aceptación de la gastronomía peruana, ha originado un aumento en el desarrollo de nuevos productos y esto ha hecho que se vea por parte del empresariado peruano en industrializar el producto artesanal "macerado". Para los macerados en base a Pisco, al tener como ingrediente un licor selecto, el mercado de estos productos son consumidores de los niveles altos, cuyo poder adquisitivo puede permitirles consumir este tipo de licores.

Un licor macerado que se comercializa en el Perú (importado) que ha tenido aceptación por el consumidor es el licor de hierbas Jagermeister, de procedencia alemana. Este licor es un macerado de hierbas elaborado industrialmente que en los años 2015 y 2016 ha ingresado sus productos por un valor promedio de USD 400 000.00 anuales (Consulta Veritrade), con lo que se observa que el mercado de 
macerados lo tiene este licor de hierbas y es un mercado en la que solo habría un competidor para Jolly Roger.

\subsubsection{Conclusiones de Análisis Externo}

\section{Oportunidades}

- Creación de la ley que declara patrimonio nacional a la denominación de origen Pisco.

- Estabilidad Política y Jurídica para el año 2018

- Expectativas de mejora en indicadores como consumo e inversión

- Nuevos consumidores buscan alternativas nuevas en el mercado.

- Incremento del poder adquisitivo de los consumidores.

- Aumento del mercado potencial para consumo de bebidas alcohólicas

- Mercado nuevo con solo un producto como competencia indirecta.

- Producto nuevo y categoría nueva para los clientes

- Proveedores leales a la bodega

- El incremento del uso de internet permitirá establecer nuevos canales de ventas nuevas para la categoría.

\section{Amenazas}

- Conflictos sociales en Lima.

- Bajas barreras de ingreso al mercado para macerados importados

- Un nuevo desastre natural que afectaría la estabilidad productiva y económica del país.

- Tendencia en una baja de lealtad hacia la marca por parte de los consumidores.

- Ingreso de nuevos competidores a un mercado aún sin explotar. 
- Alto poder de Negociación por parte de los clientes retail.

- Falta de información sobre el mercado de macerados en base a pisco.

- Sustitutos con alto presupuesto de comunicación y marketing.

En la Tabla 9 se elaboró la Matriz EFE donde indicamos los factores Externos Claves para Jolly Roger:

Tabla 9: Matriz EFE para bodega Santa María: Jolly Roger

\begin{tabular}{|c|c|c|c|}
\hline \multicolumn{4}{|l|}{ Factores Externos Claves } \\
\hline Oportunidades & Ponderación & Calificación & $\begin{array}{l}\text { Puntuación } \\
\text { Ponderada }\end{array}$ \\
\hline $\begin{array}{l}\text { Creación de la ley que declara patrimonio nacional a } \\
\text { la denominación de origen Pisco. }\end{array}$ & 0.05 & 3 & 0.15 \\
\hline Estabilidad Política y Jurídica para el año 2018 & $\mathbf{0 . 0 3}$ & 3 & 0.09 \\
\hline $\begin{array}{l}\text { Expectativas de mejora en indicadores como consumo } \\
\text { e inversión }\end{array}$ & 0.09 & 2 & 0.18 \\
\hline $\begin{array}{l}\text { Nuevos consumidores buscan alternativas nuevas en } \\
\text { el mercado. }\end{array}$ & 0.1 & 3 & 0.30 \\
\hline $\begin{array}{l}\text { Incremento del poder adquisitivo de los } \\
\text { consumidores. }\end{array}$ & 0.06 & 3 & 0.18 \\
\hline $\begin{array}{l}\text { Aumento del mercado potencial para consumo de } \\
\text { bebidas alcohólicas }\end{array}$ & 0.05 & 2 & 0.1 \\
\hline $\begin{array}{l}\text { Mercado nuevo con solo un producto como } \\
\text { competencia indirecta. }\end{array}$ & 0.08 & 4 & 0.32 \\
\hline Producto nuevo y categoría nueva para los clientes & 0.1 & 4 & 0.4 \\
\hline Proveedores leales a la bodega & 0.05 & 2 & 0.1 \\
\hline $\begin{array}{l}\text { El incremento del uso de internet permitirá establecer } \\
\text { nuevos canales de ventas nuevas para la categoría. } \\
\text { Amenazas }\end{array}$ & 0.08 & 3 & 0.24 \\
\hline Conflictos sociales en Lima. & 0.01 & 1 & 0.01 \\
\hline $\begin{array}{l}\text { Bajas barreras de ingreso al mercado para macerados } \\
\text { importados }\end{array}$ & 0.02 & 2 & 0.04 \\
\hline $\begin{array}{l}\text { Un nuevo desastre natural que afectaría la estabilidad } \\
\text { productiva y económica del país. }\end{array}$ & 0.04 & 3 & 0.12 \\
\hline $\begin{array}{l}\text { Tendencia en una baja de lealtad hacia la marca por } \\
\text { parte de los consumidores. }\end{array}$ & 0.02 & 3 & 0.06 \\
\hline $\begin{array}{l}\text { Ingreso de nuevos competidores a un mercado aún sin } \\
\text { explotar. }\end{array}$ & 0.04 & 3 & 0.12 \\
\hline
\end{tabular}




\begin{tabular}{llcc}
\hline $\begin{array}{l}\text { Alto poder de Negociación por parte de los clientes } \\
\text { retail. }\end{array}$ & $\mathbf{0 . 0 3}$ & 2 & $\mathbf{0 . 0 6}$ \\
$\begin{array}{l}\text { Falta de información sobre el mercado de macerados } \\
\text { en base a pisco. }\end{array}$ & $\mathbf{0 . 0 5}$ & 2 & $\mathbf{0 . 1}$ \\
$\begin{array}{l}\text { Sustitutos con alto presupuesto de comunicación y } \\
\text { marketing. }\end{array}$ & $\mathbf{0 . 1}$ & 2 & $\mathbf{0 . 2}$ \\
& $\mathbf{1 . 0}$ & & $\mathbf{2 . 7 7}$ \\
\hline
\end{tabular}

\section{Fuente: Elaboración Propia}

\subsection{Análisis del Sector}

\subsubsection{Definición de la Industria}

La Bodega Santa María se encuentra en la industria destilados - macerados

\subsubsection{Evolución de la demanda}

El consumo de Pisco en el Perú ha aumentado en los últimos años como consecuencia de diferentes estrategias de promoción realizadas por organismos públicos y privados. Según los datos de la Cámara de Comercio de Lima, dentro del top 3 de las bebidas alcohólicas más consumidas en Lima del 2016, la cerveza lidera la lista con un consumo de 47 litros por persona seguida del vino con 1.5 litros por persona y en tercer lugar se encuentra el Pisco con un consumo en promedio de 0.22 litros por persona al año.

\subsubsection{Matriz de competencia de Porter}

Para emprender un Análisis del Modelo de las Cinco Fuerzas de Porter es preciso primero tener en cuenta que "existen dos dimensiones del entorno empresarial: el macro ambiente, el cual comprende las fuerzas que a nivel macro tienen y/o pueden tener implicaciones en el comportamiento del sector y de la empresa en particular 
(fuerzas de carácter económico, político, cultural, social, jurídico, ecológico, demográfico y tecnológico); y el sector (conjunto de empresas que producen los mismos tipos de bienes o servicios), cuyo análisis se relaciona con el comportamiento estructural, estudiando las fuerzas que determinan la competitividad en el sector", (Baena et al., 2003). Ver Figura 5:

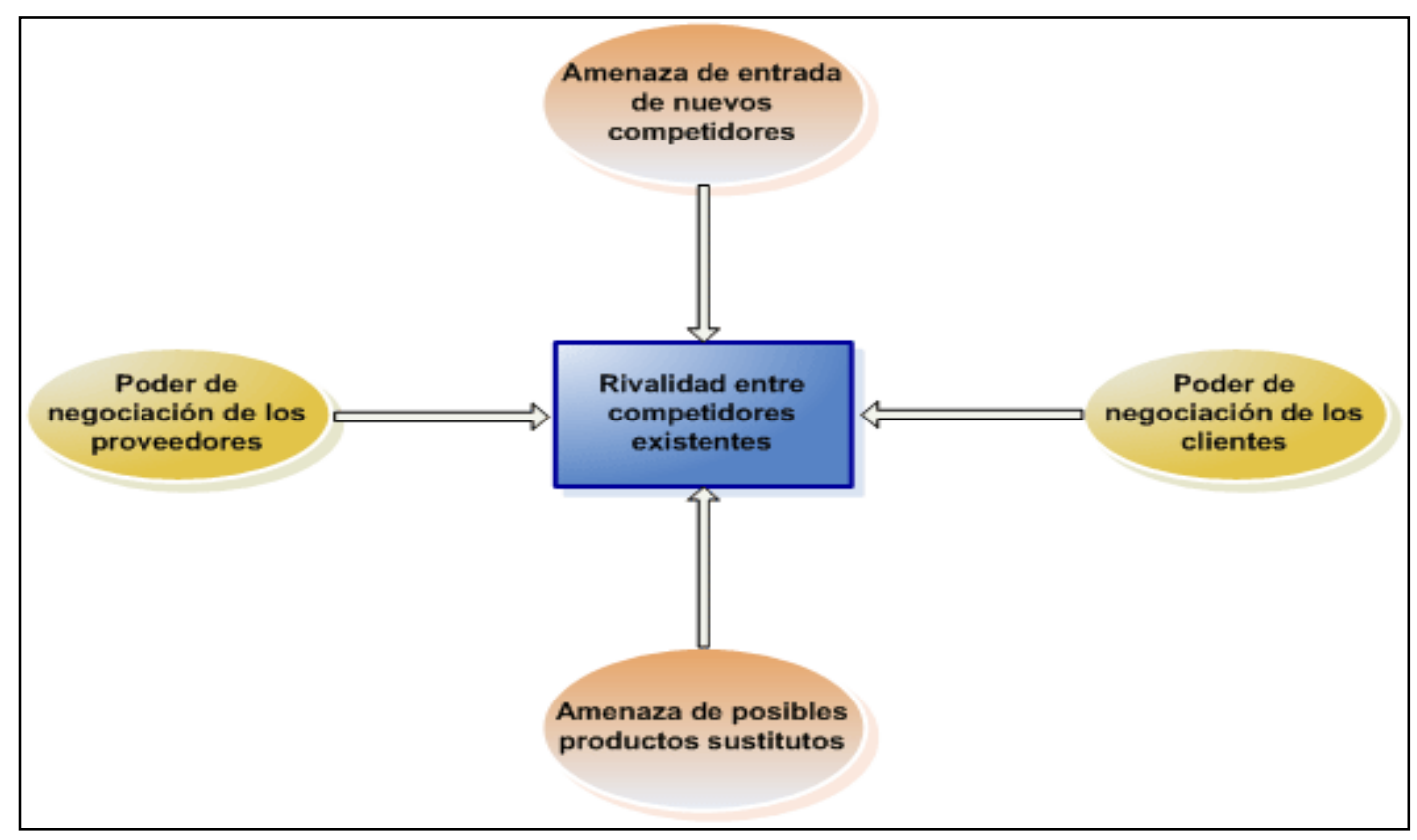

Figura 5: 5 Fuerzas de Porter

Fuente: Baena et al., 2003

\section{- Poder de negociación de los clientes}

Los principales clientes de la Bodega Santa María son mayoristas y minoristas. La empresa al tener un producto nuevo e innovador como es Jolly Roger, puede tener un mayor poder de negociación con los clientes y ofrecer acciones pull. 


\section{- Poder de negociación de los proveedores}

Los principales abastecedores de la materia prima son los productores de uva con los cuales la bodega tiene una buena relación y contratos ya establecidos lo cual permitirá tener insumos de alta calidad.

\section{- Competencia en el mercado}

Técnicamente, Jolly Roger no cuenta con competidor directo actualmente. Sin embargo, consideremos como competencia referencial a la marca Jägermeister, licor de hierbas y menta.

\section{- Amenaza de productos sustitutos}

En el mercado existen varias marcas que pueden ser un reemplazo de Jolly Roger como la cerveza, whisky, ron, vodka, tequila, etc. También se debe tomar en cuenta la categoría ready to drink, la cual está penetrando al mercado en los últimos meses.

\section{- Nuevos competidores entrantes}

Hasta el momento, no existe en el mercado un producto igual al Jolly Roger. Además, la venta de macerados en el Perú no está comercializado masivamente. 


\subsubsection{Conclusiones del análisis del sector}

\section{Oportunidades}

- Creación de la ley que declara patrimonio nacional a la denominación de origen Pisco.

- Estabilidad Política y Jurídica para el año 2018

- Expectativas de mejora en indicadores como consumo e inversión

- Nuevos consumidores buscan alternativas nuevas en el mercado.

- Incremento del poder adquisitivo de los consumidores.

- Aumento del mercado potencial para consumo de bebidas alcohólicas

- Mercado nuevo con solo un producto como competencia indirecta.

- Producto nuevo y categoría nueva para los clientes

- Proveedores leales a la bodega

- El incremento del uso de internet permitirá establecer nuevos canales de ventas nuevas para la categoría.

\section{Amenazas}

- Conflictos sociales en Lima.

- Bajas barreras de ingreso al mercado para macerados importados

- Un nuevo desastre natural que afectaría la estabilidad productiva y económica del país.

- Tendencia en una baja de lealtad hacia la marca por parte de los consumidores.

- Ingreso de nuevos competidores a un mercado aún sin explotar.

- Alto poder de Negociación por parte de los clientes retail.

- Falta de información sobre el mercado de macerados en base a pisco.

- Sustitutos con alto presupuesto de comunicación y marketing. 
Para el perfil competitivo podremos apreciar la Matriz MPC, ver tabla 10:

Tabla 10: Matriz de Perfil Competitivo Jolly Roger (MPC)

\begin{tabular}{|c|c|c|c|c|c|c|}
\hline & \multicolumn{3}{|c|}{ Jolly Roger } & \multicolumn{3}{|c|}{ Jagermeister } \\
\hline Factores Críticos de éxito & Ponderación & Calificación & Puntuación & Ponderación & Calificación & Puntuación \\
\hline Publicidad & 0.15 & 2 & 0.30 & 0.15 & 3 & 0.45 \\
\hline Calidad del producto & 0.13 & 3 & 039 & 0.13 & 3 & 0.39 \\
\hline Precios Competitivos & 0.12 & 3 & 0.36 & 0.12 & 2 & 0.24 \\
\hline Administración & 0.13 & 2 & 0.26 & 0.13 & 3 & 0.39 \\
\hline Fortaleza Financiera & 0.15 & 2 & 0.30 & 0.15 & 3 & 0.45 \\
\hline Conocimiento & 0.14 & 1 & 0.14 & 0.14 & 3 & 0.42 \\
\hline \multicolumn{7}{|l|}{ cliente } \\
\hline \multirow[t]{2}{*}{ Venta Global } & 0.18 & 1 & 0.18 & 0.18 & 3 & 0.54 \\
\hline & 1 & & 1.93 & 1 & & 2.88 \\
\hline
\end{tabular}

\section{Fuente: Elaboración Propia}

\subsection{Análisis Interno}

\subsubsection{Análisis de la Industria}

En los últimos años la producción de Pisco ha ido creciendo significativamente, $10.8 \%$ de promedio anual, manifestando una tendencia a la mayor producción desde el 2012. La producción fue positiva gracias al impulso del gobierno por medio del CONAPISCO, a las campañas y a los ingresos a nuevos mercados internacionales. El año 2016 tuvo una cifra récord de producción con 10.5 millones de litros, con un crecimiento de $10.2 \%$ 
Estos incrementos en la producción se deben también a la apertura a nuevos mercados como Bélgica, Emiratos Árabes y Australia y junto con el aumento del consumo del pisco en todas sus presentaciones, puro, pisco sour, chilcano y macerados, la tercera bebida más consumida en el Perú después de la cerveza y el vino. Según Juan Carlos Mathews ${ }^{12}$ Viceministro de la producción y presidente de CONAPISCO, que para el año 2017 solo se tendrá un crecimiento de 3\%, debido a los cambios climatológicos por parte del fenómeno del niño, sobre todo en la Región de Ica. Para el 2017 solo se llegará a producir 10.8 millones de litros. Ver figura 6.

\begin{tabular}{|ccc|}
\hline Año & Millones de Litros & Var.\% Anual \\
\hline 2000 & 1.6 & \\
2001 & 1.8 & 11.4 \\
2002 & 1.5 & -16.9 \\
2003 & 2.4 & 54.7 \\
2004 & 2.9 & 22.8 \\
2005 & 3.9 & 35.6 \\
2006 & 4.9 & 26.1 \\
2007 & 6.1 & 22.6 \\
2008 & 6.5 & 7.5 \\
2009 & 6.6 & 1.3 \\
2010 & 6.3 & -4.4 \\
2011 & 6.3 & -0.4 \\
2012 & 7.1 & 12.8 \\
2013 & 7.1 & -0.1 \\
2014 & 8.6 & 21.5 \\
2015 & 9.5 & 10.8 \\
2016 & 10.5 & 10.2 \\
\hline
\end{tabular}

Figura 6: Producción de Pisco Anual en el Perú Fuente: CIV SIN, PRODUCE/DIGECOMTE-DEMI Nota: Cifras estimadas

\footnotetext{
${ }^{12}$ http://plataforma.ipnoticias.com/Landing?cac=6hz57PpnKDQpIbF75soaaA\%3D\%3D\&i=8rjVc38Q1fmQN9n3eazhjw\%3D\%3D\&c=\%2F M1xzSFzITgUcz7V5SPKtDBfw4RK3sdqeccv5edw8. Revisado, 17 de Octubre 2017.
} 
En los últimos 5 años la producción de la bebida bandera se incrementó a un ritmo anual de $10.8 \%$ en promedio y el $10 \%$ de la producción se exportó (1.5 millones de litros aproximadamente), el resto es de consumo interno.

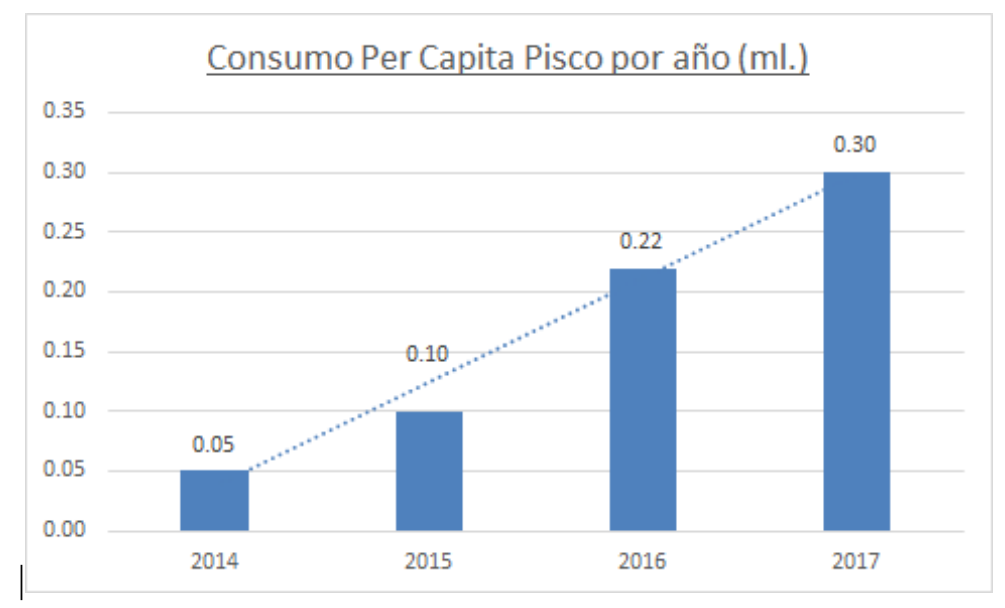

Figura 7: Consumo per cápita de Pisco 2014 - 2017

Como podemos observar en la figura 7 , el consumo per cápita del pisco en el Perú se viene incrementando de 0.05 litros en el 2014 a 0.3 litros para el 2017, proyectando un incremento para los siguientes años. Si comparamos el consumo per cápita de pisco en el Perú es mucho menor al de Chile, teniendo a Perú con un 0.3 litros por año y en Chile con un 2.3 litros al año.

En el Perú existen cerca de 523 productores de Pisco con Denominación de Origen, teniendo a Lima como la región con mayor cantidad de empresas con un $48.8 \%$, seguida de Ica con $34.6 \%$.

\begin{tabular}{|c|c|c|c|}
\hline Departamento & $\mathbf{N}^{\mathbf{*}}$ Empresa 2015 & $\mathbf{N}^{\mathbf{*}}$ Empresa 2016 & Variación \\
\hline Lima & 201 & 255 & 26.9 \\
Ica & 174 & 181 & 4.0 \\
Arequipa & 46 & 51 & 10.9 \\
Moquegua & 18 & 20 & 11.1 \\
Tacna & 14 & 16 & 14.3 \\
Total & $\mathbf{4 5 3}$ & $\mathbf{5 2 3}$ & $\mathbf{1 5 . 5}$ \\
\hline
\end{tabular}

Figura 8: Número de empresas por tipo de producción de Pisco, según regiones, 2016 
Las exportaciones de pisco registran altos porcentajes debido a la campaña de promoción del Estado Peruano en el mercado externo.

\begin{tabular}{|c|c|c|c|c|c|}
\hline \multirow{2}{*}{ Año } & \multirow{2}{*}{$\begin{array}{l}\text { Miles de } \\
\text { FOB-USS }\end{array}$} & \multirow{2}{*}{$\begin{array}{l}\text { Miles de } \\
\text { Litros }\end{array}$} & \multirow{2}{*}{$\begin{array}{c}\text { Precio } \\
\text { Promedio } \\
\text { (FOB-USS / } \\
\text { Lt) }\end{array}$} & \multicolumn{2}{|c|}{ Var.\% } \\
\hline & & & & FOB-USS & Litros \\
\hline 2000 & 141 & 32 & 4.4 & - & - \\
\hline 2001 & 224 & 54 & 4.1 & 59.1 & 67.4 \\
\hline 2002 & 84 & 21 & 4.1 & -62.5 & -62.0 \\
\hline 2003 & 305 & 58 & 5.2 & 263.6 & 184.4 \\
\hline 2004 & 424 & 74 & 5.7 & 38.9 & 27.1 \\
\hline 2005 & 483 & 88 & 5.5 & 14.0 & 18.7 \\
\hline 2006 & 682 & 108 & 6.3 & 41.1 & 22.5 \\
\hline 2007 & 1,046 & 176 & 6.0 & 53.5 & 62.5 \\
\hline 2008 & 1,528 & 249 & 6.1 & 46.1 & 41.8 \\
\hline 2009 & 1,372 & 206 & 6.7 & -10.2 & -17.3 \\
\hline 2010 & 1,982 & 285 & 6.9 & 44.5 & 38.7 \\
\hline 2011 & 3,862 & 457 & 8.6 & 94.9 & 60.4 \\
\hline 2012 & 5,049 & 560 & 9.0 & 30.7 & 22.5 \\
\hline 2013 & 5,408 & 635 & 8.5 & 7.1 & 13.3 \\
\hline 2014 & 5,480 & 794 & 6.7 & 1.3 & 24.9 \\
\hline 2015 & 8,217 & 1,058 & 7.8 & 49.9 & 33.4 \\
\hline 2016 & 8,635 & 1,192 & 7.2 & 5.1 & 12.6 \\
\hline
\end{tabular}

Figura 9: Perú, Exportaciones de Pisco, 2000-2016

Fuente: Sunat

Elaboración: PRODUCE/DIGECOMTE-DEMI

El mercado de macerados es totalmente artesanal, en donde no podemos encontrar información de producción ni de consumo, pero tenemos un producto importado, macerado de hierbas llamado Jagermeister, macerado de 56 hierbas que ingresó al mercado peruano teniendo un crecimiento continuo en los últimos años. Es la octava bebida espirituosa más consumida en el mundo. 


\subsubsection{Tamaño del Mercado}

Se estima que la población de Lima Metropolitana y Callao asciende a 9,273,237 personas de NSE A,B y C, teniendo como mercado potencial un 21.3\% de personas que están aptas para consumir bebidas alcohólicas, dentro de las cuales el $41.1 \%$ han consumido o consumen todo tipo de bebidas alcohólicas y dentro de este grupo el $53.10 \%$ consumen o han consumido pisco o alguna bebida con base en el pisco peruano.

Después de la Evaluación Cuantitativa, se obtuvo el Mercado Objetivo que es el 3.63\% del Mercado Efectivo (Personas que toman bebidas alcohólicas en base a Pisco). Es decir que 15,648 personas son nuestro Mercado Objetivo para Lima y Callao. Ver tabla 11

Tabla 11: Proyección de Mercado Objetivo para Jolly Roger

\begin{tabular}{ccccc}
\hline $\begin{array}{c}\text { Población Total 2018 } \\
\text { Lima y Callao }\end{array}$ & Mercado Potencial & Mercado & Mercado & Mercado \\
& NSE A,B y C & Disponible & Efectivo & Objetivo \\
\hline & C Edades 18 a 30 & Consumen & Consumen & Investigación \\
& $\mathbf{2 1 . 3 0 \%}$ & $41.10 \%$ & $53.10 \%$ & $3.63 \%$ \\
$\mathbf{9 , 2 7 3 , 2 3 7}$ & $\mathbf{1 , 9 7 5 , 2 0 0}$ & $\mathbf{8 1 1 , 8 0 7}$ & $\mathbf{4 3 1 , 0 7 0}$ & $\mathbf{1 5 , 6 4 8}$ \\
\hline
\end{tabular}

Fuente: Boletín 18, INEI

*: Manuel Cadenas Mujica

+: Investigación de mercado 


\subsubsection{Segmentación}

Hombres y Mujeres de 18 a 30 años de los NSE A, B y C que les guste tomar bebidas en base a Pisco. Estás personas se encuentran en el grupo llamado "Sofisticados" las cuales buscan disfrutar del dinero que han ganado, están dispuesto a pagar más por tener una mejor experiencia. Se aventuran a probar novedades y siempre están a la moda. Estas personas invierten mucho en su cuidado personal, aspiran a ser reconocidos y admirados por sus amigos y los grupos sociales a los que pertenece. Evalúan a profundidad el producto o el servicio que las empresas lesbrindan, son más analíticos a la hora de elegir una marca ya que buscan las de mejor calidad.

Tienen TV y cable pero no le dedican mucho tiempo ni atención ya que invierten más su tiempo en internet leyendo noticias y temas de su interés.

\subsubsection{Productos, Ciclo de Vida, Precios, Distribución, Comunicación y Fuerza de Ventas}

\subsubsection{Productos}

La Bodega tiene 3 líneas de productos: Vinos, Piscos y Macerados. Dentro de los vinos tenemos:

- Vino Rose, elaborado en base a uva Quebranta, liviano y frutado, de color rosado, obtenido gracias a la fermentación parcial de los orujos y acompaña a cualquier tipo de comida.

- Vino Borgoña Blanco, vino ligero y frutado, obtenido de la selección cuidadosa de uvas Borgoña blanca, vino joven y bien balanceado, ideal para aperitivos y excelente para acompañar carnes blancas y mariscos. 
- Vino Borgoña Tinto, exótico, único en su género, semi seco, elaborado con la variedad de uva Borgoña negra, acompaña bien a todo tipo de comida peruana.

- Vino Burdeos, elaborado con uvas tintas, armonioso cuerpo y color, aroma distinto y especial bouquet. Acompaña perfecto a carnes rojas y comidas condimentadas.

En la línea de piscos tenemos los siguientes:

- Pisco Quebranta, obtenido de la destilación del mosto de la uva Quebranta, limpio, con estructura y equilibrio.

- Pisco Italia, muy aromático, en proceso igual a la uva quebranta, elaborado con la uva italia, intenso y con extraordinario aroma.

- Pisco Acholado, elaborado con 2 o más uvas pisqueras, pudiendo ser aromáticas y no aromáticas, perfecto para la elaboración de cócteles.

- Pisco Uvina, elaborado de la uva pisquera uvina con gran cuerpo y aroma original.

- Pisco Mosto Verde, excepcional pisco de un brillo extraordinario, cautivante aroma, buen cuerpo y largo final. Pueden ser elaborados de uva quebranta, italia y moscatel.

En cuanto a la línea de macerados tenemos a Jolly Roger como único producto, macerado de hierbas en base a pisco acholado con $35 \%$ de alcohol y más de 25 ingredientes, varias frutas, especias y raíces milenarias como el anís, jengibre, maíz morado, maca, huanarpo, naranja, limón, etc. 
La Bodega Santa María tiene como principal debilidad no tener experiencia en el mercado peruano, no ser conocido ni reconocido en el sector de pisco, solo se tiene conocimiento de la bodega en el mercado internacional.

Los productos que comercializa la bodega Santa María se producen bajo los cumplimientos de calidad de Denominación de Origen.

\subsubsection{Ciclo de Vida}

El Ciclo de Vida de la Bodega Santa María se encuentra en etapa de crecimiento, si bien es cierto que opera desde 1929, recién está en el 2do año de exportación de los piscos, las ventas constantes año a año de los vinos y la introducción de Jolly Roger.

El Ciclo de Vida de Vinos Santa María es de madurez, las ventas son constante año tras año. En el caso de Pisco Don Benedicto está en etapa de Introducción al mercado extranjero.

En el caso de Jolly Roger está en el Ciclo de Vida INTRODUCCION, teniendo 1 año en el mercado sin ningún plan ni acción, haciendo que no tenga el impulso de un producto en esta etapa. Ver figura 10 


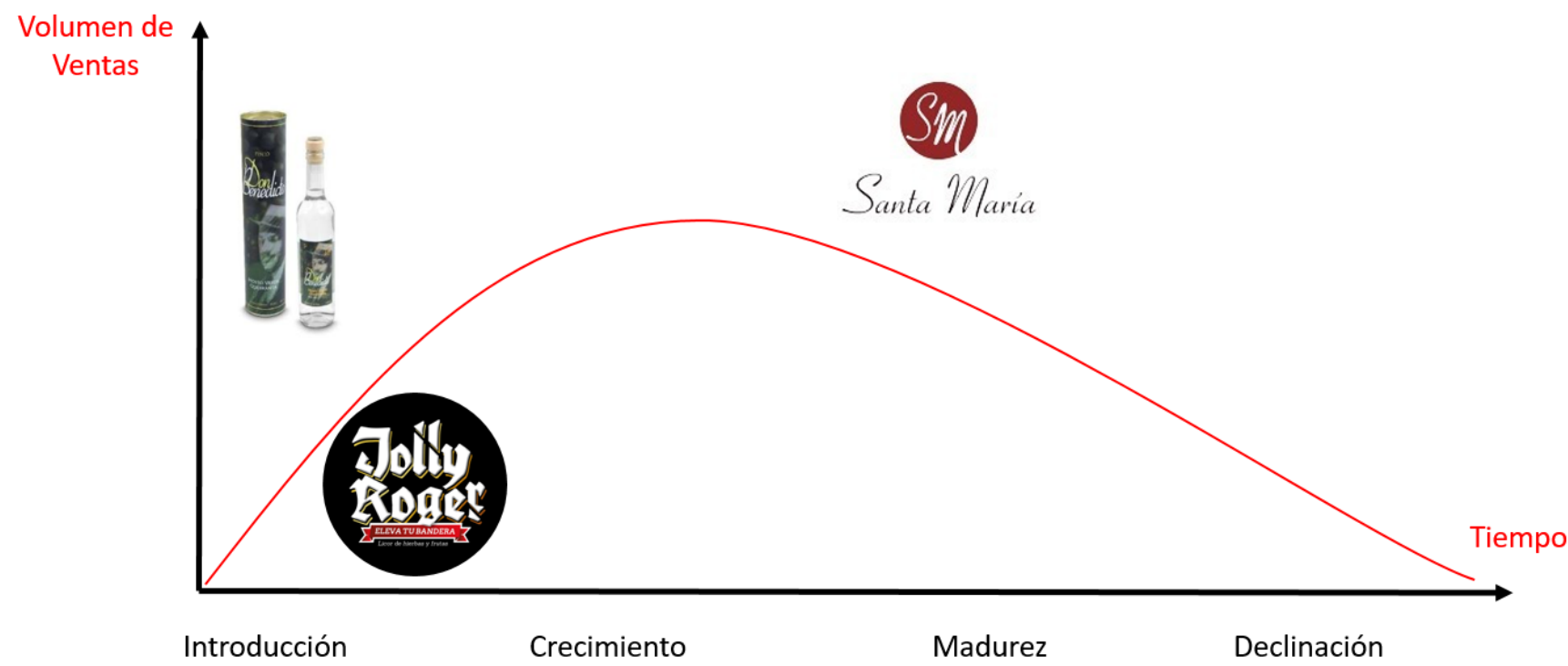

Figura 10: Ciclo de vida de los productos de la Bodega Santa María Elaboración Propia

\subsubsection{Precios}

La estructura de Precios al canal y al consumidor final se detallan en la siguiente tabla: Ver tabla 12

Tabla 12: Estructura de precios Bodega Santa María

\begin{tabular}{cccccc}
\hline & $\begin{array}{c}\text { Vinos Santa } \\
\text { María }\end{array}$ & $\begin{array}{c}\text { Pisco } \\
\text { Quebranta }\end{array}$ & $\begin{array}{c}\text { Pisco } \\
\text { Acholado }\end{array}$ & $\begin{array}{c}\text { Pisco Mosto } \\
\text { Verde }\end{array}$ & Jolly Roger \\
\hline $\begin{array}{c}\text { Costo } \\
\text { Unitario sin } \\
\text { IGV }\end{array}$ & $\$ 1.49$ & $\$ 4.62$ & $\$ 4.62$ & $\$ 8.99$ & $\$ 3.85$ \\
Precio Canal & $\$ 2.58$ & $\$ 10.61$ & $\$ 10.61$ & $\$ 15.91$ & $\$ 12.12$ \\
$\begin{array}{c}\text { Margen } \\
\text { Bodega }\end{array}$ & $31.76 \%$ & $48.57 \%$ & $48.57 \%$ & $33.33 \%$ & $62.50 \%$ \\
$\begin{array}{c}\text { Precio Canal } \\
\text { s/IGV }\end{array}$ & $\$ 2.18$ & $\$ 8.99$ & $\$ 8.99$ & $\$ 13.48$ & $\$ 10.27$ \\
Precio & $\$ 3.21$ & $\$ 11.56$ & $\$ 11.56$ & $\$ 20.55$ & $\$ 11.79$ \\
$\begin{array}{c}\text { Público sin } \\
\text { IGV }\end{array}$ & & & & & \\
\hline
\end{tabular}

Fuente: Elaboración propia 
La bodega no tiene estructurada la estrategia de precios de ninguno de sus productos, pero cuenta con un amplio margen de ganancia en el producto Jolly Roger, que le permitirá desarrollar estrategias de precios en diversos canales.

\subsubsection{Distribución}

La estrategia de Distribución actual es directa, tanto en el vino, pisco y el Jolly Roger, sin intermediarios, directo al Canal en el caso de vinos y Jolly Roger y directo a la agencia de aduanas en el caso de los piscos Don Benedicto. Ver tabla 13

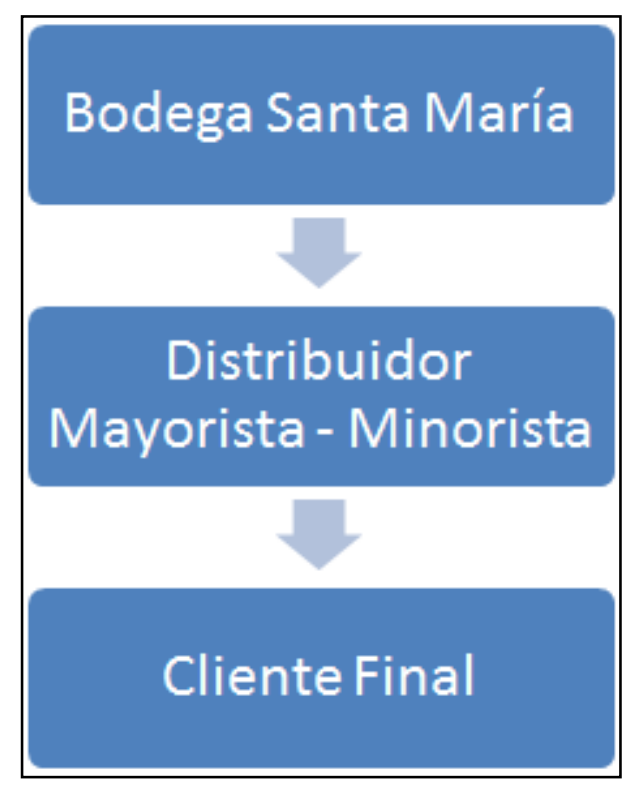

Tabla 13: Distribución Actual Bodega Santa María

La bodega Santa María no cuenta con una estrategia de distribución para Jolly Roger. 


\subsubsection{Comunicación}

En cuanto a la estrategia actual de Comunicación es sólo para el Pisco Don Benedicto, participando en ferias Internacionales y eventos en cada país de posible destino. Las acciones de comunicación para Jolly Roger se realizan con fiestas auspiciadas por el macerado, además de contar con una página oficial en Facebook.

La marca posee una estrategia de comunicación básica, sin embargo, no cuenta con un plan estructurado que valide el mensaje, los tiempos y el presupuesto.

\subsubsection{Fuerza de Ventas}

La Fuerza de Ventas es propia y se encuentra en la misma bodega, en Cañete - Lunahuaná, tanto para la línea de vinos, piscos y Jolly Roger, que consta de un personal que además de vender, explica el proceso de producción y las características de todas las líneas. Para Pisco Don Benedicto el encargado de las ventas internacionales es el mismo José Espinoza y para Jolly Roger no hay un personal dedicado.

\subsubsection{Competencias básicas de la Empresa}

La competencia básica de la bodega Santa María es que tiene sus propios viñedos y cuenta con los mejores proveedores de la zona, con las calidades que ameritan la Denominación de Origen. Además, cuenta con capacidad de 
producción y almacenaje que duplicaría la actual. La capacidad actual de producción de la bodega es de 100 mil litros de pisco y solo estamos a un 30\% de capacidad.

\subsubsection{Capacidades básicas de Marketing}

Las acciones de marketing para las líneas que produce y comercializa la bodega son mínimas, para la línea de vino son nulas, no teniendo ni un presupuesto asignado para ayudar a su comercialización o mejora del producto. En el caso de la línea de pisco el presupuesto asignado es mínimo, solo presentándose en algunos eventos y ferias en mercados internacionales.

Las acciones de marketing para Jolly Roger también cuentan con un presupuesto mínimo y sin ningún plan a seguir, solo haciendo conocer la marca en algunos eventos, sin ninguna estrategia definida, ni en producto, precio, distribución y comunicación. Es por eso que a partir del 2018 se contará con un presupuesto para realizar un plan de marketing para mejorar el Nivel de Conocimiento y mejorar las Ventas del Jolly Roger en el mercado de Lima y Callao, teniendo como presupuesto 56,580 dólares.

\subsubsection{Conclusiones de Análisis Interno}

\section{Fortalezas}

- Los productos que comercializa la bodega santa maría se producen bajo los cumplimientos de calidad de DO

- Producto innovador y único en el mercado. 
- La capacidad de ingresar el Jolly Roger al mercado de Lima.

- Amplio Margen en Jolly Roger

- Capacidad de producir doble que producción actual.

\section{Debilidades}

- No tener experiencia en el mercado peruano

- La bodega no tiene estructurada la estrategia precios de ninguno de sus productos.

- No cuenta con una estrategia de distribución.

- No cuenta con una estrategia de comunicación.

- No cuenta con Fuerza de Ventas

- No cuenta con Plan de Marketing ni presupuesto asignado a Jolly Roger

Tabla 14: Matriz de Evaluación de Factores Internos para la bodega Santa María: Jolly Roger

\begin{tabular}{lccc}
\hline \multicolumn{1}{c}{ Factores Internos Claves } & Ponderación & Calificación & $\begin{array}{c}\text { Puntuación } \\
\text { ponderada }\end{array}$ \\
\hline Fortalezas & & 4 & \\
Los productos que comercializa & $\mathbf{0 . 0 4}$ & & $\mathbf{0 . 1 6}$ \\
la bodega santa maría se & & & \\
producen bajo los cumplimientos & & $\mathbf{4}$ & $\mathbf{0 . 4 8}$ \\
de calidad de DO & & & \\
Producto innovador y único en el & $\mathbf{0 . 1 2}$ & $\mathbf{0 . 2 4}$ \\
mercado. & & & \\
La capacidad de ingresar el Jolly & $\mathbf{0 . 0 8}$ & & \\
Roger al mercado de Lima. & & & \\
\hline
\end{tabular}




\begin{tabular}{lccc}
\hline Amplio Margen en Jolly Roger & $\mathbf{0 1 2}$ & $\mathbf{4}$ & $\mathbf{0 . 4 8}$ \\
$\begin{array}{l}\text { Capacidad de producir doble que } \\
\text { producción actual. }\end{array}$ & $\mathbf{0 . 0 8}$ & $\mathbf{3}$ & $\mathbf{0 . 2 4}$ \\
& $\mathbf{1}$ & & $\mathbf{1 . 6 0}$
\end{tabular}

\section{Debilidades}

No tener experiencia en el $\mathbf{0 . 0 5}$

1

0.05

mercado peruano

La bodega no tiene estructurada

0.08

1

0.08

la estrategia precios de ninguno

de sus productos.

No cuenta con una estrategia de

0.12

1

0.12

distribución.

No cuenta con una estrategia de

comunicación.

No cuenta con Fuerza de Ventas

0.07

2

0.14

No cuenta con Plan de

0.12

1

0.12

Marketing ni presupuesto

asignado a Jolly Roger

1

2.23

Fuente: Elaboración Propia 


\section{CAPÍTULO IV: ESTUDIO DE MERCADO}

\subsection{Problema de investigación}

- Determinar el nivel de conocimiento del producto Jolly Roger entre hombre y mujeres de 18 a 30 años de NSE A, B y C en Lima Metropolitana y Callao.

- Determinar el nivel de aceptación o rechazo de Jolly Roger en hombres y mujeres de 18 a 30 años de NSE A, B y C en Lima Metropolitana y Callao.

\subsection{Necesidades de información}

\subsubsection{Investigación Cuantitativa:}

- Personas que conocen el producto Jolly Roger

- Dónde tomo conocimiento del producto

- ¿Personas que consumieron y no consumieron Jolly Roger y Por qué?

- ¿Personas que compraron y no compraron Jolly Roger y Por qué?

- Apreciación de la botella, etiqueta, cantidad, corcho y sabor

- Tamaño y precio ideal

- ¿Cuál sería la competencia?

- Cómo calificaría a Jolly Roger

- Que considera importante para la compra de Jolly Roger

- Frecuencia de consumo

- Cómo, ¿dónde y con qué lo consume?

- Factores importantes a considerar

- Si lo recomendaría y lo compraría o volvería a comprar 


\subsubsection{Investigación Cualitativa}

- Hábitos de compra y consumo de bebidas alcohólicas

- Hábitos de compras y consumo de bebidas alcohólicas en base a pisco

- Aceptación y Rechazo de Jolly Roger puro y combinado

- Hábitos de compra y consumo de Jolly Roger

- Distribución y lugares de ventas apropiados para Jolly Roger

- Precios mínimo, máximo e ideal para Jolly Roger

- Medios de comunicación y promocionales que les gustaría para Jolly Roger

- Con qué relaciona el Jolly Roger

- Evaluación de botella, etiqueta, corcho, cantidad, nombre, mensaje, etc.

\subsection{Diseño de investigación}

\subsubsection{Investigación Cuantitativa}

Se sustenta en base a parámetros estadísticos, que nos ayudan a encontrar información específica para los objetivos del estudio. Para el caso de la investigación se realizarán encuestas para la obtención de información.

\section{- Encuestas}

Cuestionario estructurado que se aplica a una muestra de la población y está diseñado para obtener información específica de los participantes con respecto a las variables de la investigación. 
- Método no probabilístico por conveniencia.

\subsubsection{Definición del target}

Personas que viven en Lima Metropolitana de NSE A, B y C de 18 a 30 años de edad que consuman bebidas elaboradas en base a pisco.

$$
n=\frac{Z^{2} p q}{E^{2}}
$$

\subsubsection{Estructura / Distribución muestral}

\section{Estructura:}

- Z: Nivel de confianza

- $\quad$ E: Nivel de error permitido

- $\quad$ p: Probabilidad de éxito o aceptación

- $\quad$ q: Probabilidad de rechazo o fracaso

- $\quad$ n: Número de encuestas

*Población "Infinita" (Población mayor o igual a 100,000)

Se trabajará con un valor $\mathrm{Z}$ de un nivel de confianza del $95 \%$

$\mathbf{Z}: 1,96$

E: 0,05

p: 0,5

q: 0,5

$\mathrm{n}=384.16$

$\mathrm{n}=385$ 
Se realizarán 385 encuestas, en los distritos de Lima Metropolitana y Callao.

Para la realización de las encuestas, estas se realizarán en los principales distritos de Lima Metropolitana y Callao, distribuidas en la siguiente tabla:

\begin{tabular}{|c|c|c|}
\hline Distrito & $\begin{array}{c}\text { Población de } 18 \text { a } 30 \\
\text { años de edad }\end{array}$ & Encuestas \\
\hline San Juan de Lurigancho & 261,088 & 46 \\
\hline San Martin de Porres & 157,499 & 30 \\
\hline Comas & 120,972 & 21 \\
\hline Villa el Salvador & 106,185 & 20 \\
\hline Villa María del Triunfo & 100,343 & 19 \\
\hline San Juan de Miraflores & 91,175 & 17 \\
\hline Callao & 86,645 & 17 \\
\hline Los Olivos & 85,107 & 16 \\
\hline Ventanilla & 82,132 & 15 \\
\hline Puente Piedra & 81,840 & 15 \\
\hline Santiago de Surco & 77,099 & 15 \\
\hline Chorrillos & 72,086 & 15 \\
\hline Carabayllo & 69,175 & 14 \\
\hline Lima & 55,224 & 13 \\
\hline Rimac & 51,844 & 10 \\
\hline Lurigancho & 49,710 & 9 \\
\hline Independencia & 46,758 & 9 \\
\hline La Molina & 38,974 & 9 \\
\hline La Victoria & 38,625 & 8 \\
\hline Pachacamac & 31,755 & 7 \\
\hline San Miguel & 29,078 & 7 \\
\hline San Borja & 23,955 & 6 \\
\hline Surquillo & 21,470 & 5 \\
\hline Lurin & 19,595 & 4 \\
\hline Miraflores & 17,108 & 3 \\
\hline San Isidro & 17,003 & 3 \\
\hline Pueblo Libre & 16,129 & 3 \\
\hline Breña & 15,306 & 3 \\
\hline Bella Vista & 15,297 & 3 \\
\hline Jesus María & 12,988 & 3 \\
\hline Mi Perú & 12,549 & 3 \\
\hline La Perla & 12,410 & 3 \\
\hline Magdalena del Mar & 11,699 & 3 \\
\hline Cieneguilla & 11,001 & 3 \\
\hline Lince & 10,187 & 2 \\
\hline Ancón & 9,845 & 2 \\
\hline Carmen de la Legua & 8,683 & 2 \\
\hline Barranco & 5,964 & 1 \\
\hline La Punta & 697 & 1 \\
\hline TOTAL & $1,975,200$ & 385 \\
\hline
\end{tabular}

Tabla 15: Distribución de la población por distritos y edad de Lima Metropolitana y Callao

Fuente: INEI - Elaboración propia. 


\subsection{Método de investigación cuantitativo}

Luego del procesamiento de los resultados y el análisis de los datos, se tiene identificado lo siguiente:

\section{Conocimiento del producto.}

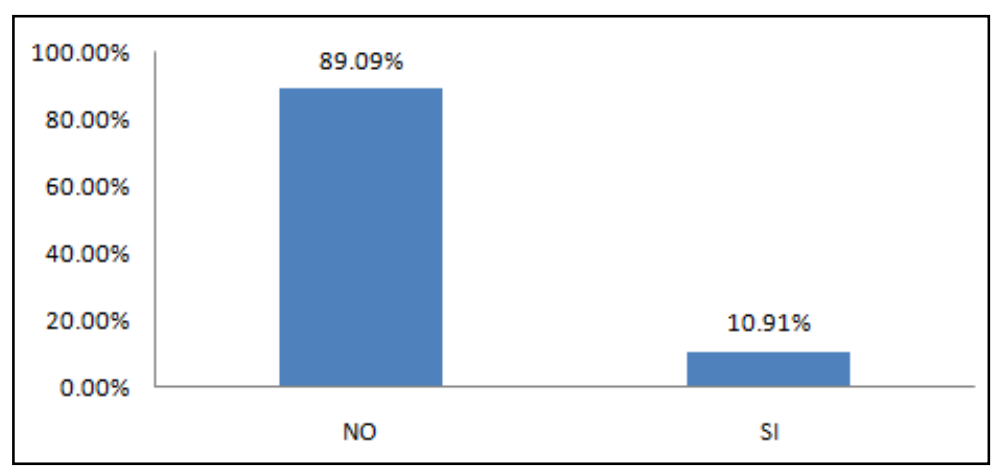

Figura 11:¿Usted conoce el macerado de hierbas en base a Pisco Jolly Roger?

De un universo de 385 encuestados, se observa que solo un $10.91 \%$ conocen el producto, frente a un $89,09 \%$ que no lo conocen.

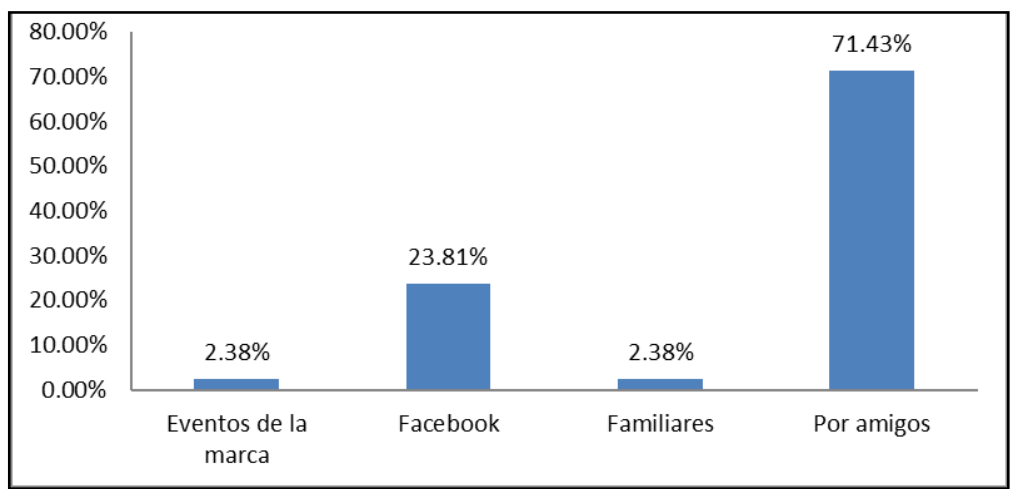

Figura 12: ¿Cómo se entero del producto?

La gran mayoría de las personas que conocen el macerado $(71,43 \%)$ lo conocen por amigos, en segundo lugar, Facebook $(23,81 \%)$ seguido por eventos de la marca y familiares con $2,38 \%$ cada uno. 


\section{Consumo del Producto.}

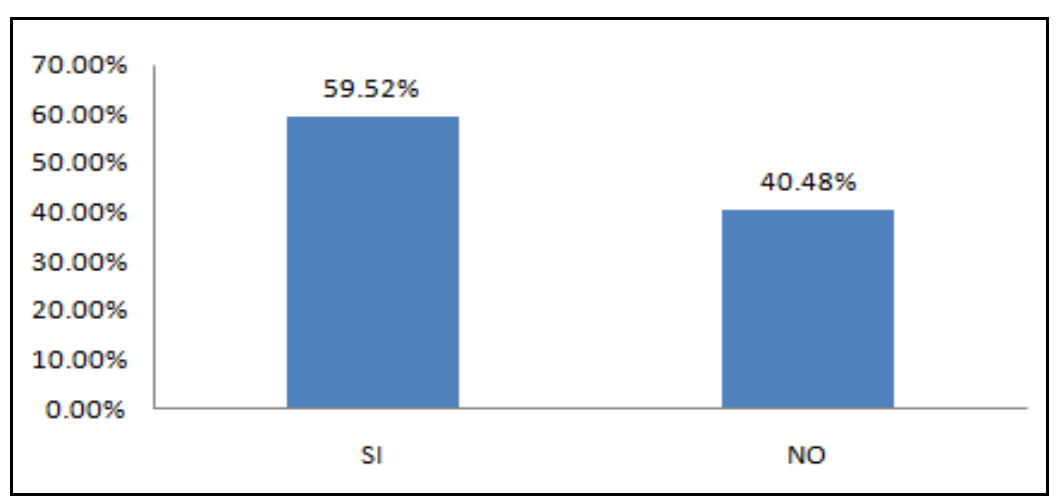

Figura 13: Figura: ¿Ha consumido Jolly Roger?

Del grupo que conoce el producto, un 59,52\% consume el macerado. Un 40,98\% no consume el producto.

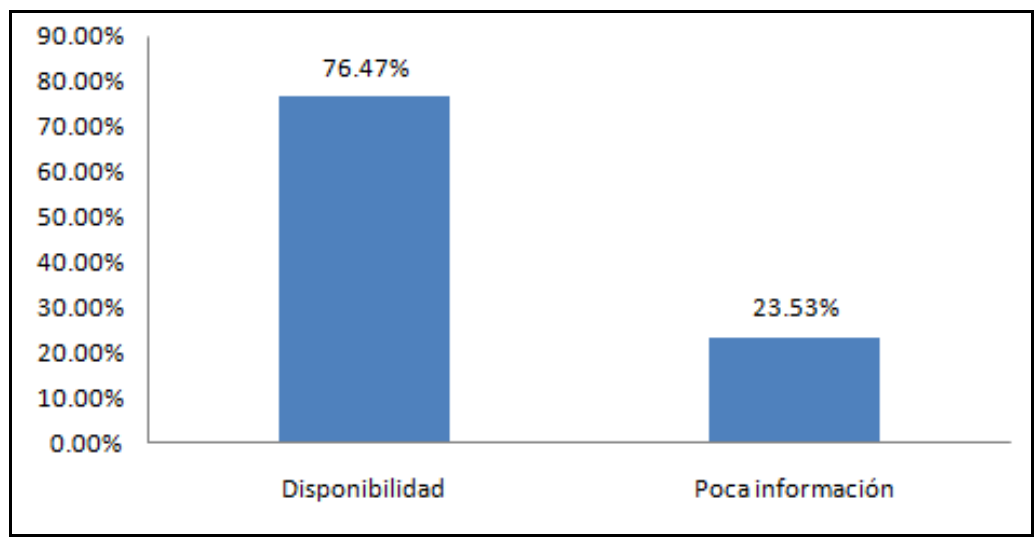

Figura 14: ¿Por qué no lo consumió?

Del $40,98 \%$ que no consume el producto, el $76,47 \%$ no lo consume por disponibilidad y el 23,53\% por falta de información. 


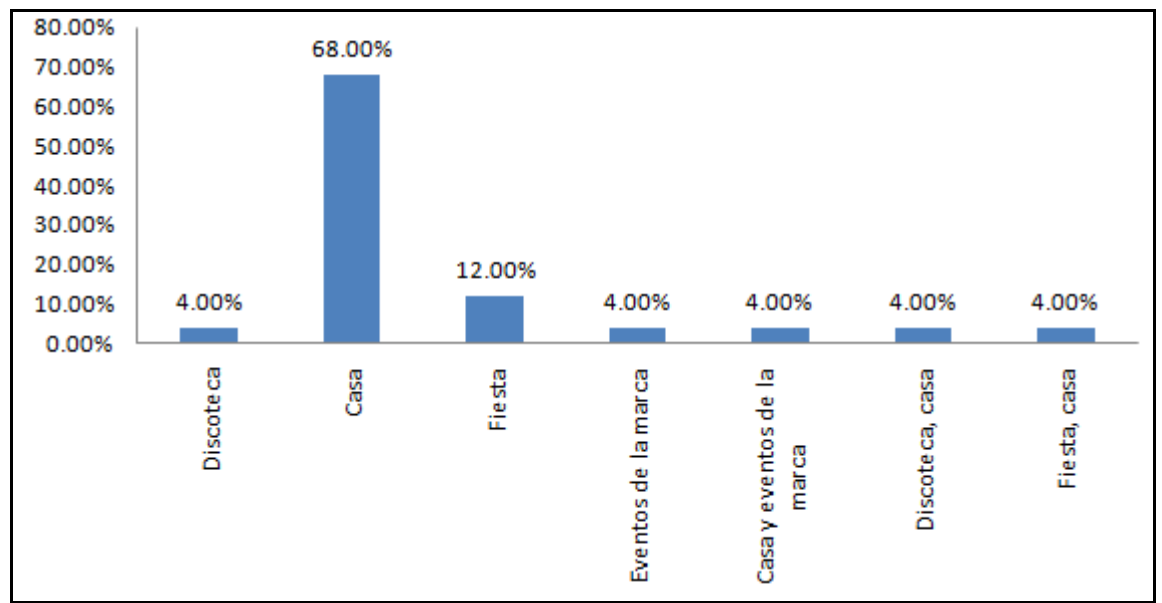

Figura 15: ¿Dónde lo consumió?

Un $68 \%$ lo consume en casa, frente a un $16 \%$ que lo consume en fiestas; un $8 \%$ lo consumen tanto discotecas como en eventos de la marca.

\section{Atributos del producto.}

Sabor

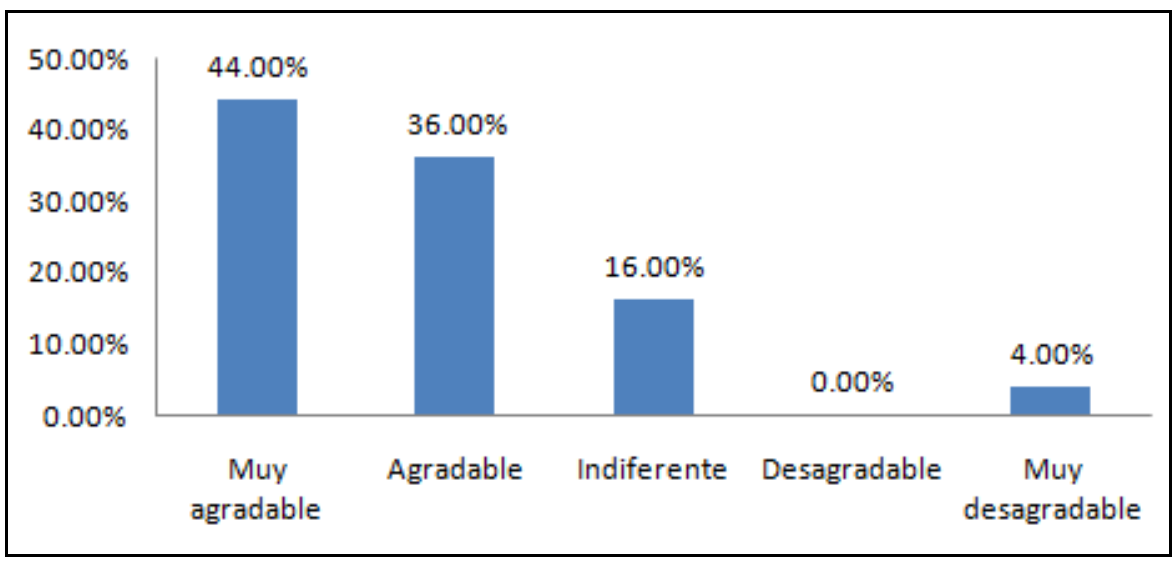

Figura 16: ¿Qué tan agradable es el Jolly Roger?

Para un $80 \%$, el sabor del macerado es agradable. Lo que nos indica que la formulación es aceptada por una parte importante de los consumidores del macerado. 


\section{Color}

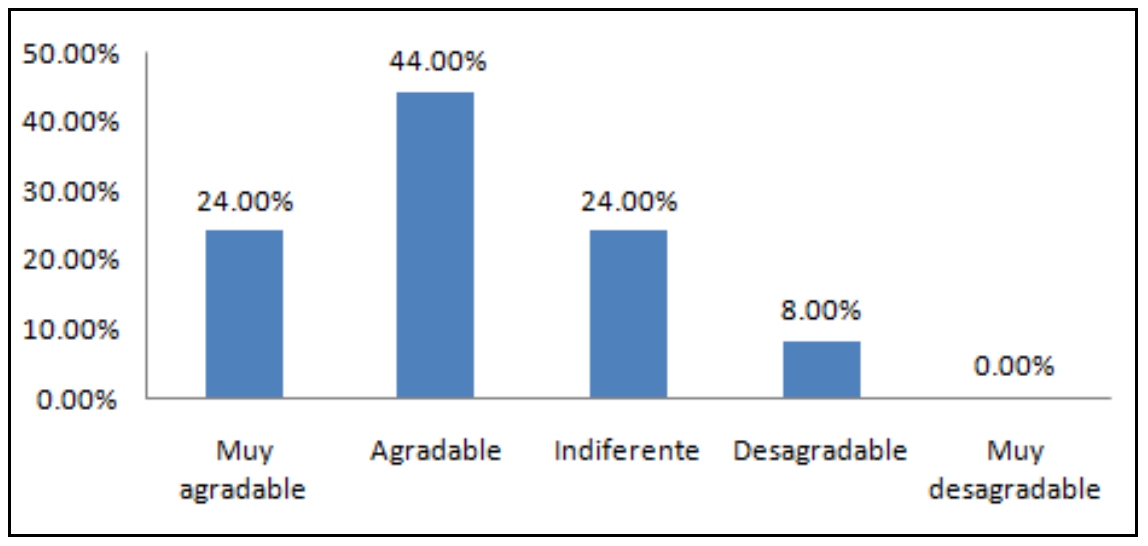

Figura 17: ¿Qué tan agradable es el Jolly Roger?

Para un 68\% de los encuestados el color del macerado es aceptable.

Presentación

\begin{tabular}{|c|c|c|c|c|c|}
\hline $40.00 \%$ & $36.00 \%$ & $36.00 \%$ & \multirow{8}{*}{$20.00 \%$} & \multirow{8}{*}{$8.00 \%$} & \\
\hline $35.00 \%$ & & & & & \\
\hline $30.00 \%$ & & & & & \\
\hline $25.00 \%$ & & & & & \\
\hline $20.00 \%$ & & & & & \\
\hline $15.00 \%$ & & & & & \\
\hline $10.00 \%$ & & & & & \\
\hline \multirow{2}{*}{$\begin{array}{l}5.00 \% \\
0.00 \%\end{array}$} & & & & & $0.00 \%$ \\
\hline & $\begin{array}{c}\text { Muy } \\
\text { agradable }\end{array}$ & Agradable & Indiferente & Desagradable & $\begin{array}{c}\text { Muy } \\
\text { desagradable }\end{array}$ \\
\hline
\end{tabular}

Figura 18: ¿Qué tan agradable es el Jolly Roger?

Un 72\% está conforme con la presentación del producto. 
Sabor Residual

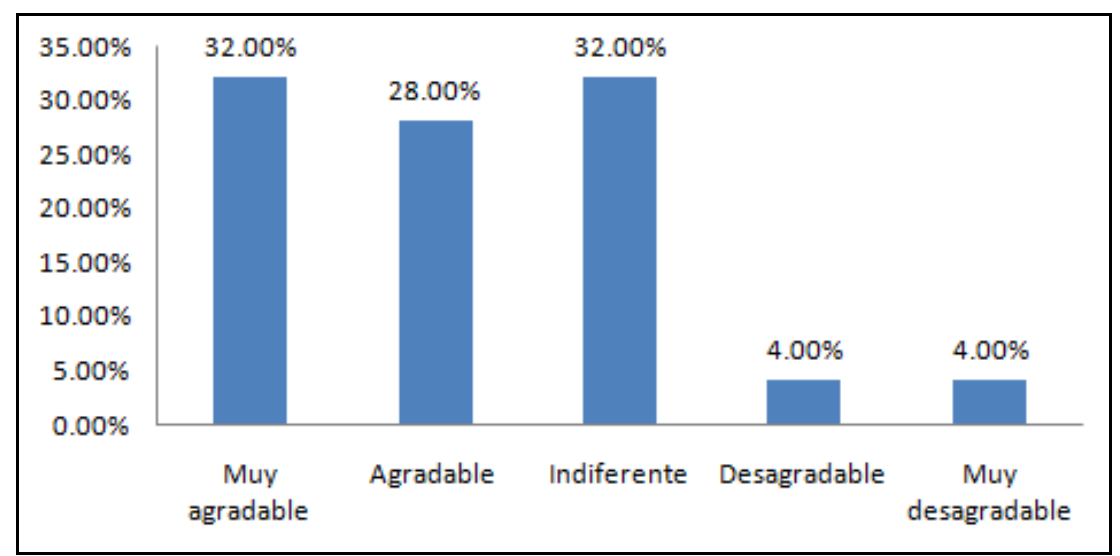

Figura 19: ¿Qué tan agradable es el Jolly Roger?

Un $60 \%$ de los encuestados, indica que el sabor residual que deja el macerado es muy agradable y agradable mientras que el $32 \%$ es indiferente con respecto al sabor residual del producto.

Grado de Alcohol

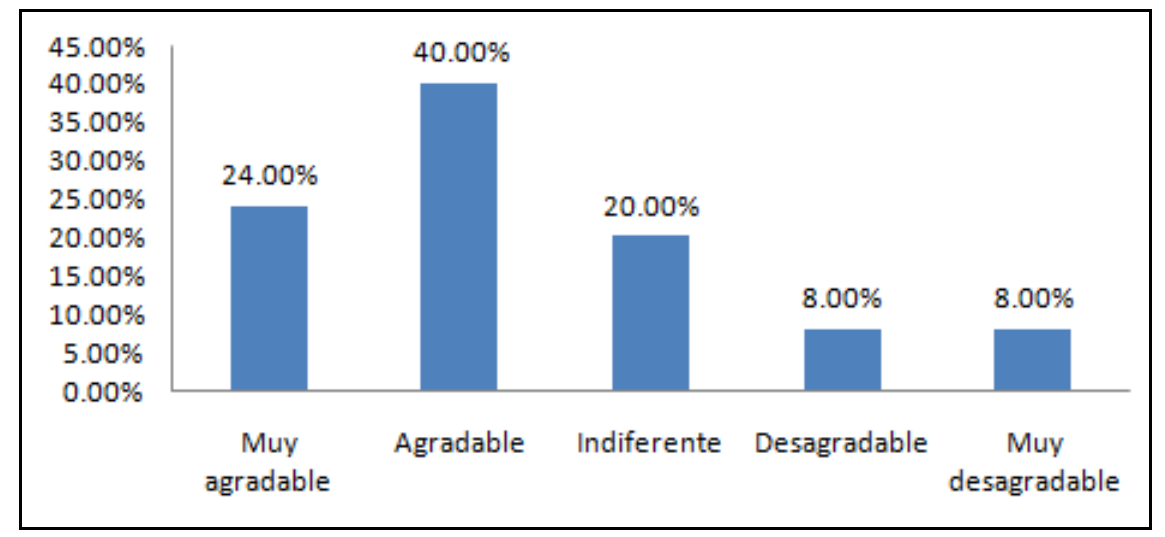

Figura 20: ¿Qué tan agradable es el Jolly Roger?

Para un $24 \%$ el grado de alcohol es muy agradable, el $40 \%$ opina que es agradable. 


\section{Cantidad de volumen.}

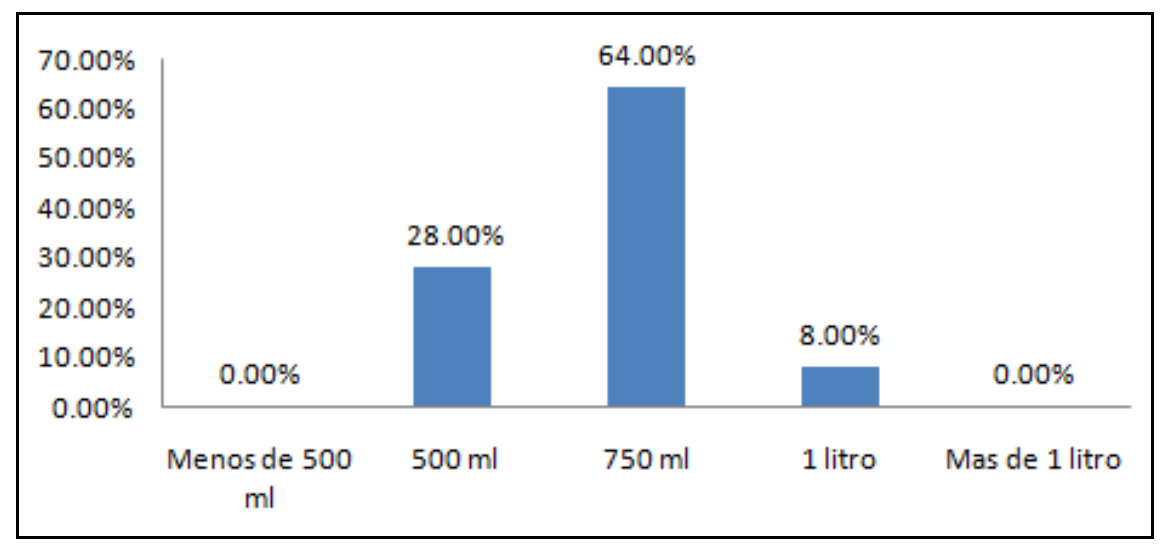

Figura 21: ¿Cuál consideras que es la cantidad ideal en una botella de Jolly Roger?

Un $64 \%$ indicaron que la presentación actual del producto es la ideal. Un $28 \%$ de encuestados indicaron que una presentación de 500 ml sería la mejor opción.

\section{Precio.}

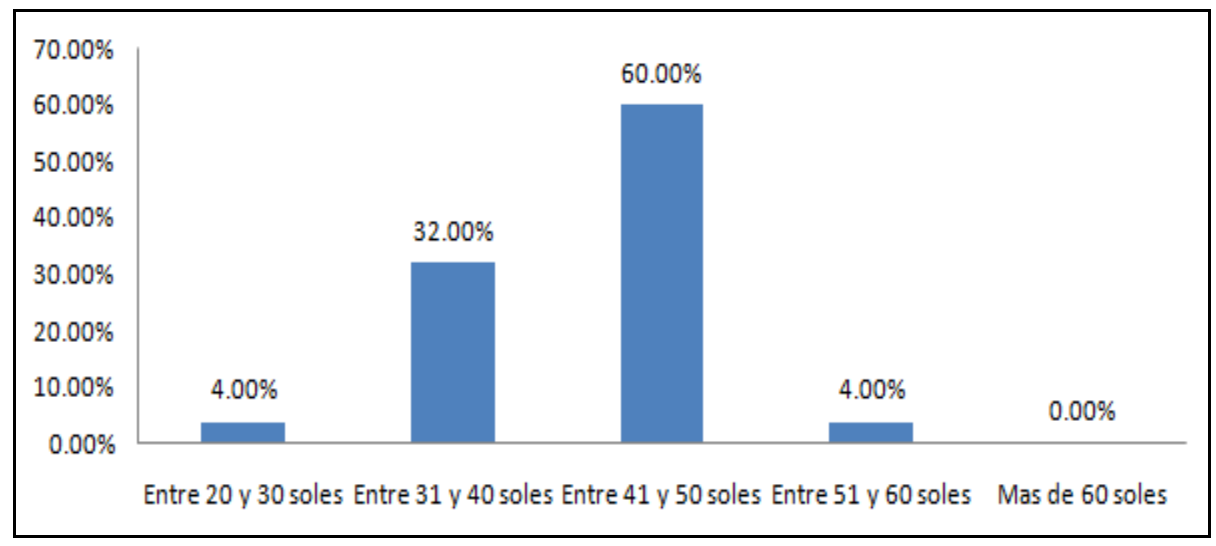

Figura 22: ¿Cuál es el precio ideal que pagaría por una botella de Jolly Roger de $750 \mathrm{ml}$ ?

Un $60 \%$ de los encuestados indica que el precio que pagarían por la botella de la presentación actual de $750 \mathrm{ml}$, debe estar entre 41 y 50 soles. El precio actual al público del producto es de S/ 44,90; el precio del producto no debería superar los 50 soles. 


\section{Competencia.}

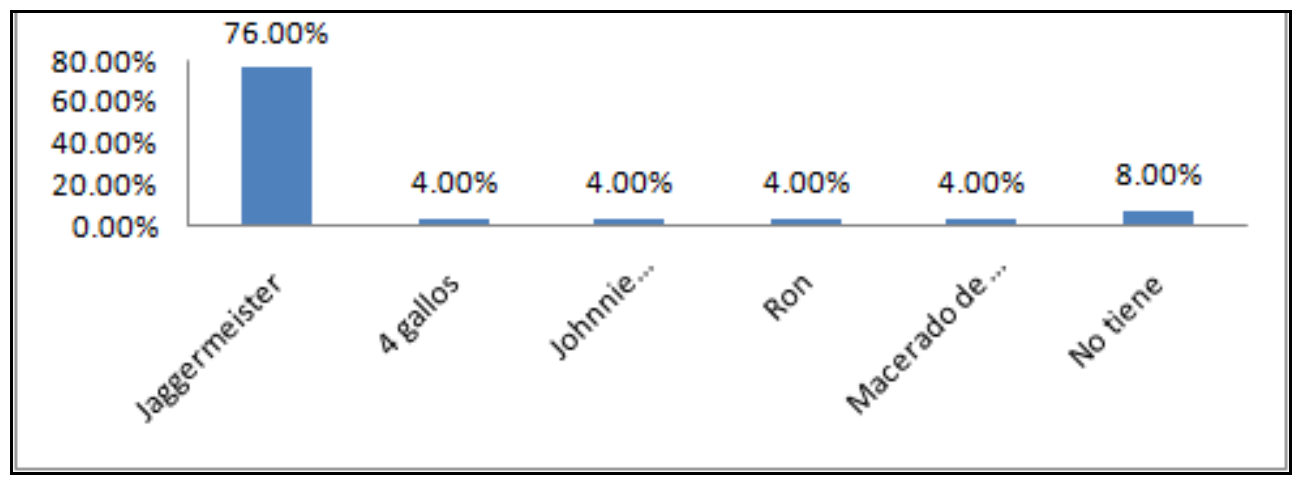

Figura 23: ¿Cuál considera es el producto competencia de Jolly Roger?

Un $76 \%$ de los encuestados indican que la marca Jagermeister (macerado de hierbas importado) es la competencia directa de Jolly Roger. Tanto el pisco, whisky, ron y otros macerados son considerados con un $4 \%$ como competencia del macerado. La similitud del producto con el Jagermeister, hace que los encuestados lo consideran como competencia directa del Jolly Roger.

\section{Calificación general.}

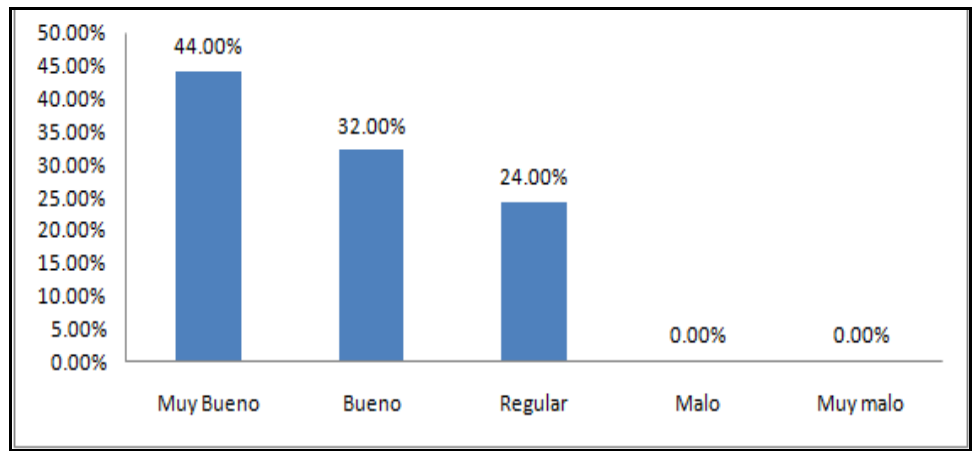

Figura 24: En general, ¿Cómo calificaria a Jolly Roger?

El 76\% consideran al Jolly Roger como un producto muy bueno y bueno; frente a un $24 \%$ que lo consideran como regular. Ninguno de los encuestados considera al producto como malo. 


\section{Características importantes.}

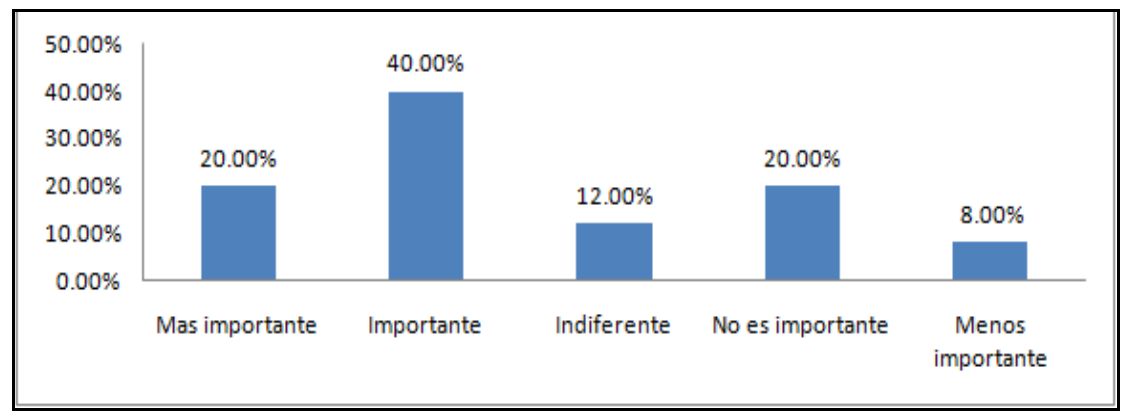

Figura 25: Del 1 al 5 ¿Qué caracteristica de Jolly Roger considera mas importante? Siendo 1 el mas importante y 5 el menos importante con respecto a la botella

Para un $60 \%$ la botella es una característica importante, un $88 \%$ considera importante la cantidad de mililitros que trae la botella.

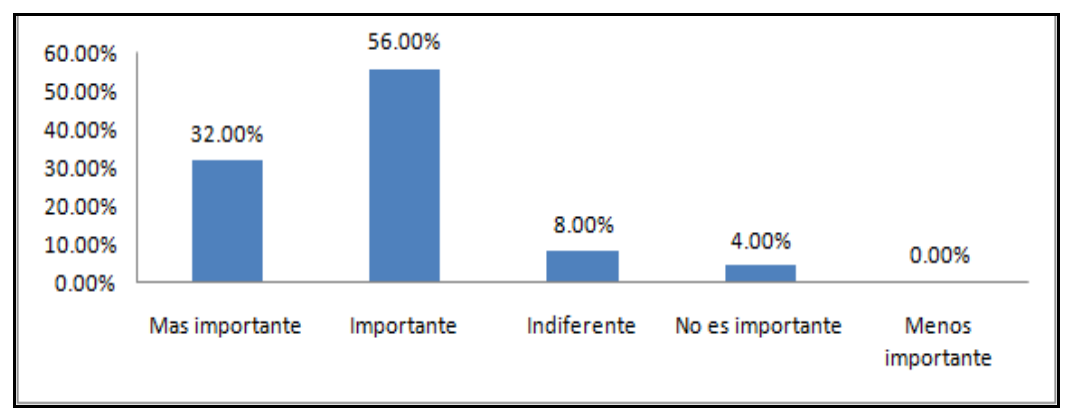

Figura 26: Del 1 al 5 ¿Qué característica de Jolly Roger considera más importante? Siendo 1 el más importante y 5 el menos importante con respecto a la cantidad de mililitros

El $88 \%$ considera que la tapa es un elemento importante a tener en cuenta en el producto mientras que el $8 \%$ es indiferente a esta variable 


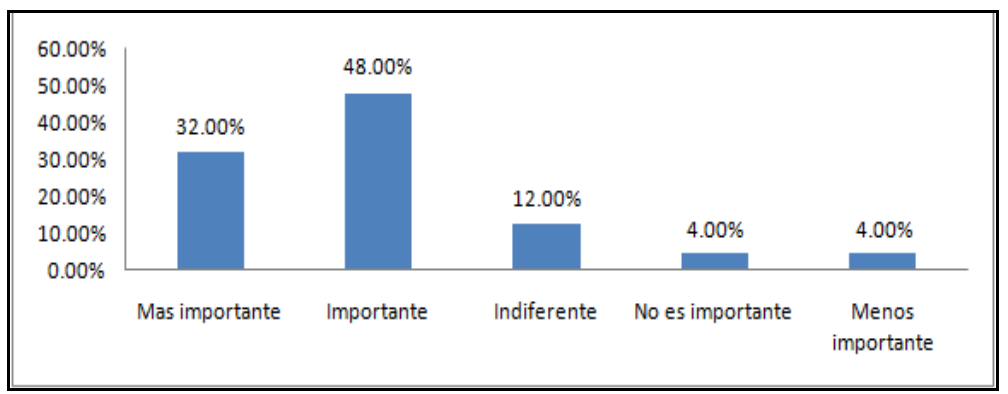

Figura 27: Del 1 al 5 ¿Qué característica de Jolly Roger considera más importante? Siendo 1 el más importante y 5 el menos importante con respecto a la tapa

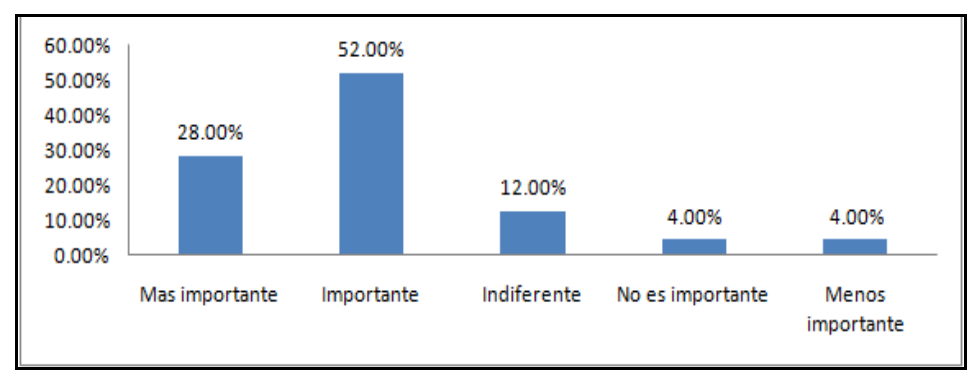

Figura 28: Del 1 al 5 ¿Qué característica de Jolly Roger considera más importante? Siendo 1 el más importante y 5 el menos importante con respecto al color

Un $80 \%$ considera la tapa y los colores del producto importante. Una variación de estas características del producto, podría generar una disminución en la aceptación del producto. 


\section{Frecuencia de consumo.}

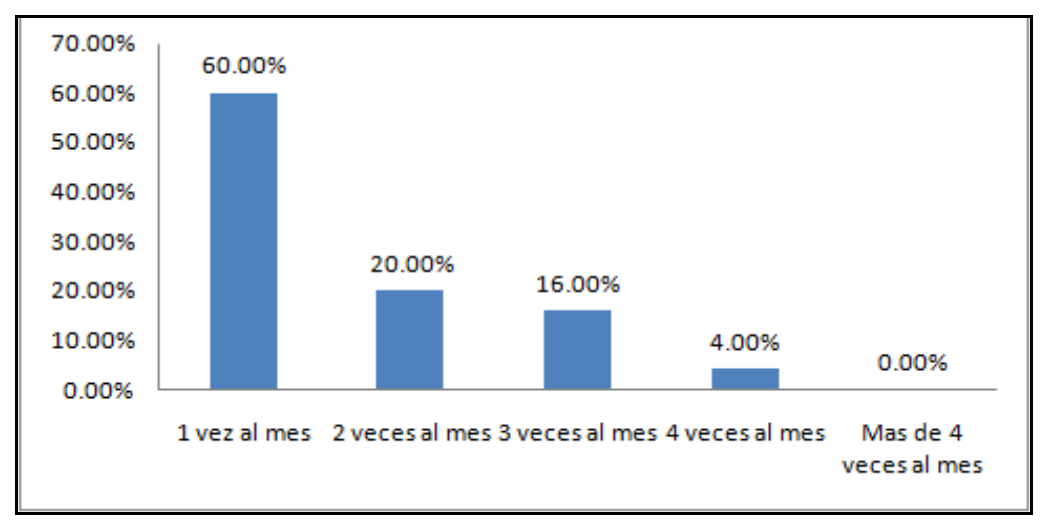

Figura 29: ¿Con que frecuencia lo consume?

Un $60 \%$ consume el producto una vez al mes, un $20 \%$ dos veces al mes, un $16 \%$ tres veces al mes, un $4 \%$ consume cuatro veces al mes. Se tiene que investigar el por qué la frecuencia de consumo de 1 vez al mes es tan alta, se puede deber a disponibilidad del producto.

\section{Forma de consumo.}

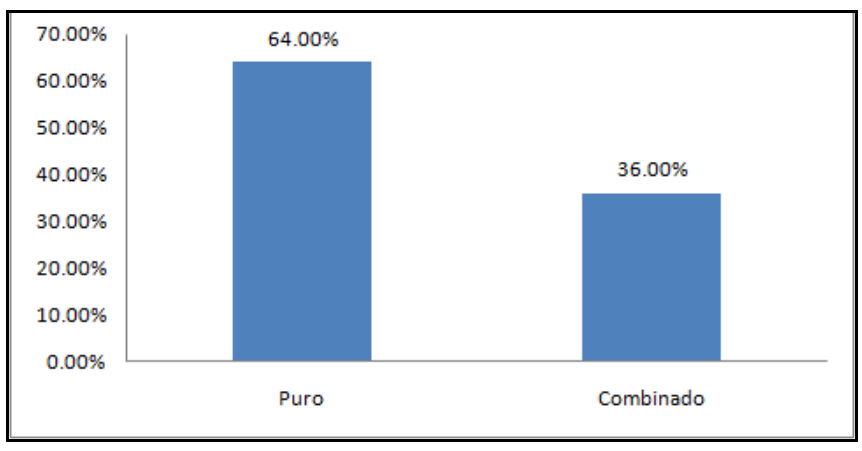

Figura 30: ¿Cómo lo tomaría?

Un $64 \%$ de los encuestados lo consumen puro, frente a un $36 \%$ que lo consumen combinado. La preferencia por mantener el sabor del producto es alta. 


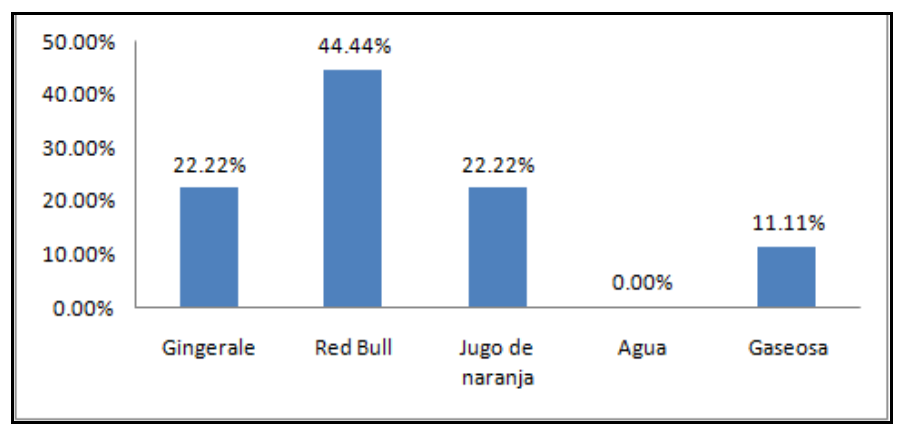

Figura 31: ¿Con que suele combinar el Jolly Roger?

Un 44,44\% combina el Jolly Roger con Red Bull, frente a un 22,22\% que lo combinan con Gingerale y Jugo de naranja. Un $11,11 \%$ lo combinan con bebidas gasificadas (gaseosa). La bebida energizante tiene más aceptación entre los encuestados al momento de realizar la combinación con Jolly Roger.

\section{Compra.}

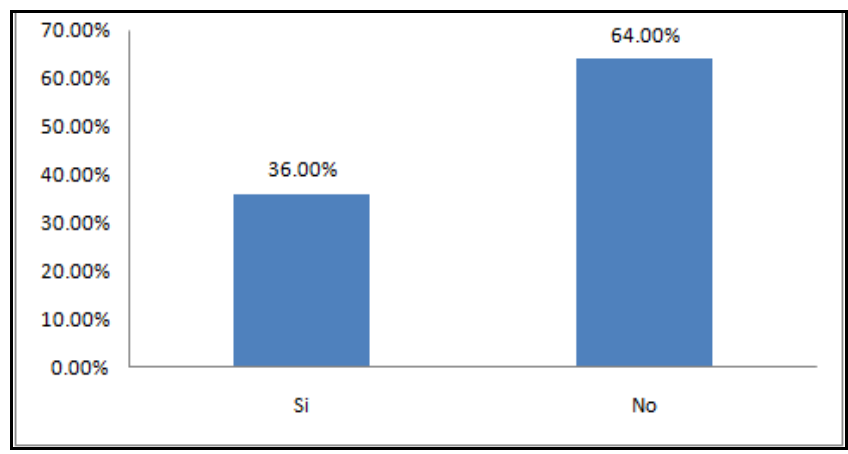

Figura 32: ¿Lo ha comprado?

Solo un $36 \%$ de los encuestados han compraron el producto, frente a un $64 \%$ que no lo han comprado. 


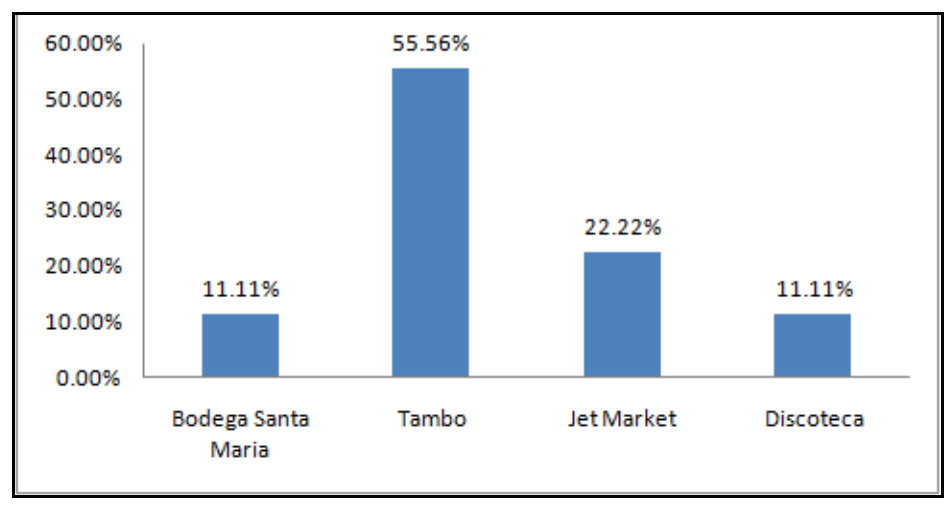

Figura 33: ¿Dónde lo compro?

Un 55,56\% de los encuestados adquirieron el macerado de hierbas en base a Pisco en las tiendas Tambo, un 22,22\% en Jet Market, y un 11,11\% en discotecas y bodegas.

\section{Factores influenciadores de compra.}

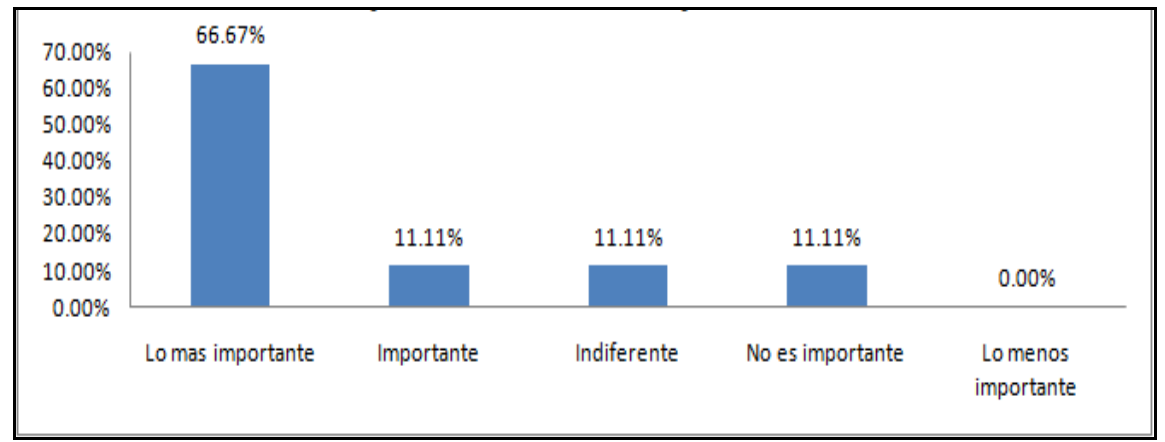

Figura 34: Del 1 al 5 marque que tan importante considera los siguientes factores al momento de realizar la compra de Jolly Roger, donde 1 es lo más importante y 5 lo menos importante con respecto a la Calidad Percibida

El $77,78 \%$ de los encuestados encuentran en la calidad percibida del producto como uno de los influenciadores importantes al momento de hacer la compra. 


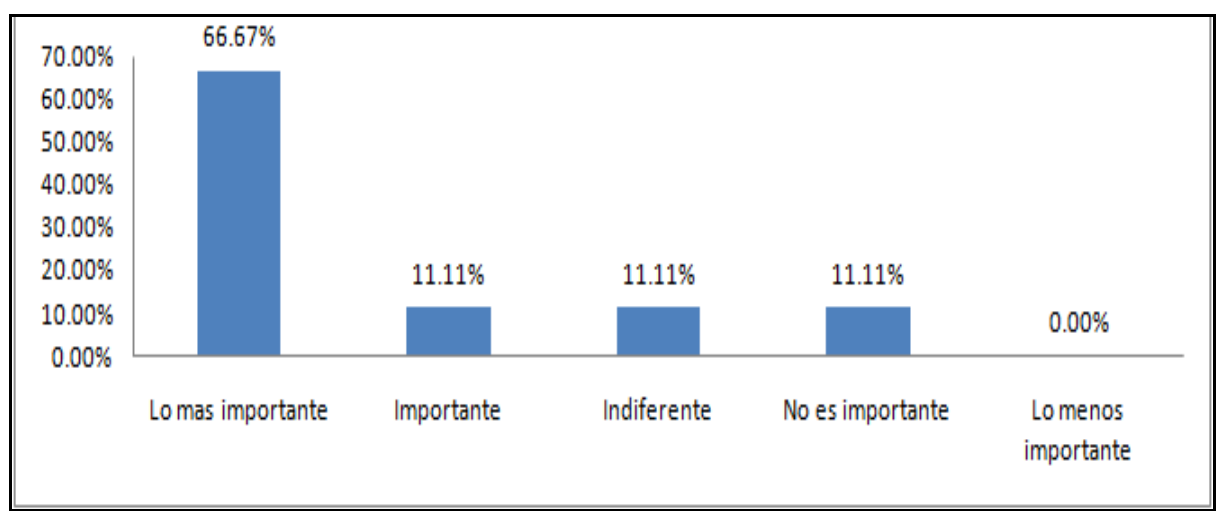

Figura 35: Del 1 al 5 marque que tan importante considera los siguientes factores al momento de realizar la compra de Jolly Roger, donde 1 es lo más importante y 5 lo menos importante con respecto al precio.

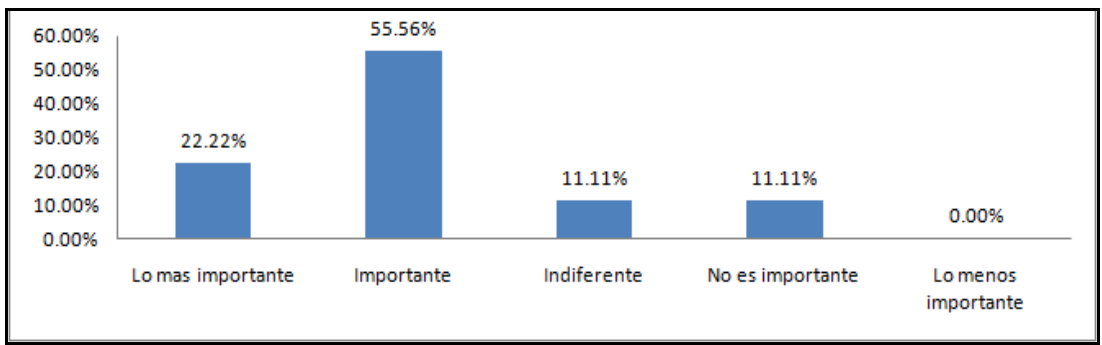

Figura 36: Del 1 al 5 marque que tan importante considera los siguientes factores al momento de realizar la compra de Jolly Roger, donde 1 es lo más importante y 5 lo menos importante con respecto a la cantidad de mililitros

Para el 77,78\% el precio es otro factor importante al momento de realizar la compra, así como la cantidad en mililitros que adquieren. 


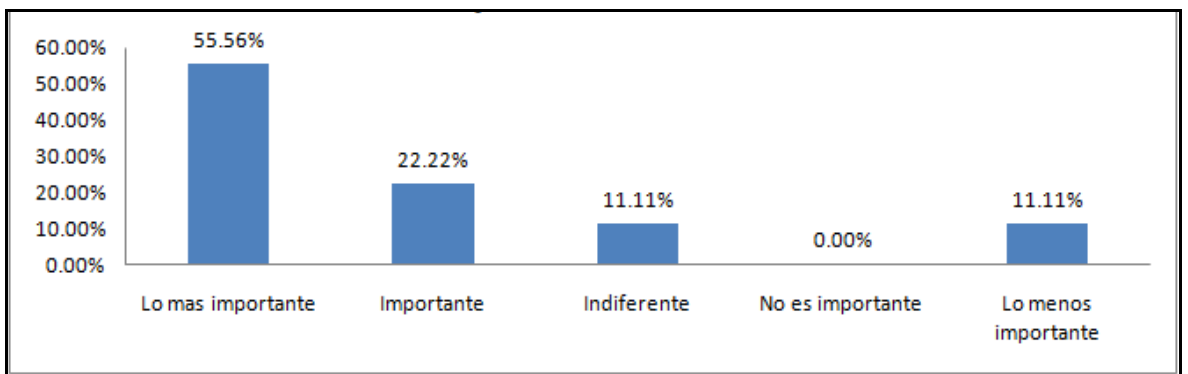

Figura 37: Del 1 al 5 marque que tan importante considera los siguientes factores al momento de realizar la compra de Jolly Roger, donde 1 es lo más importante y 5 lo menos importante con respecto a la Marca

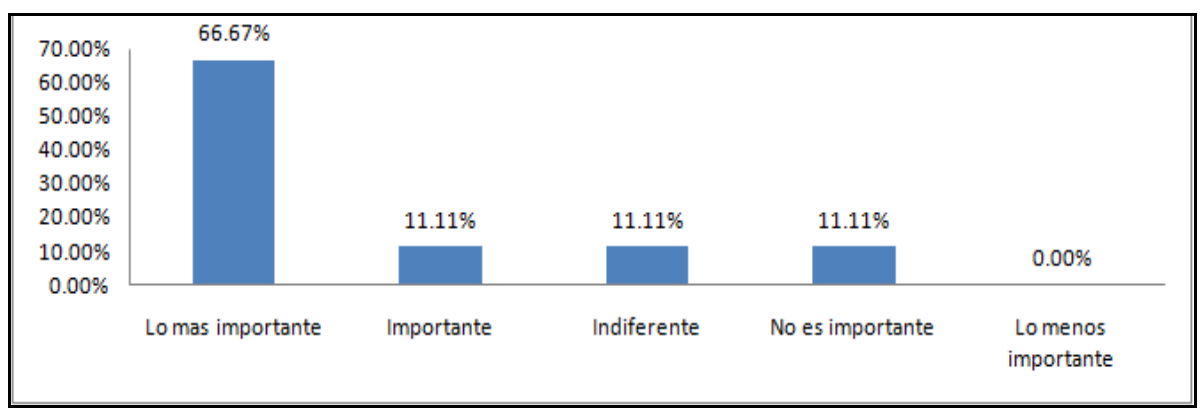

Figura 38: Del 1 al 5 marque que tan importante considera los siguientes factores al momento de realizar la compra de Jolly Roger, donde 1 es lo más importante y 5 lo menos importante con respecto a la Disponibilidad

Para el 77,78\% la marca y la disponibilidad del producto, son factores importantes al momento de realizar la compra. 


\section{Recomendación.}

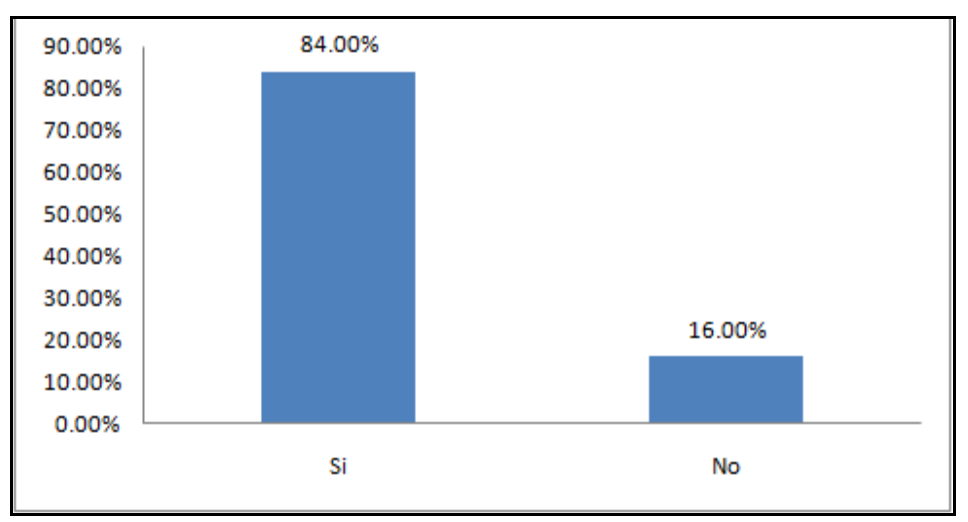

Figura 39: ¿Recomendaría Jolly Roger?

Un $84 \%$ de los encuestados recomendarían el producto, frente a un $16 \%$ que no lo recomendarían.

\section{Compra y/o Recompra.}

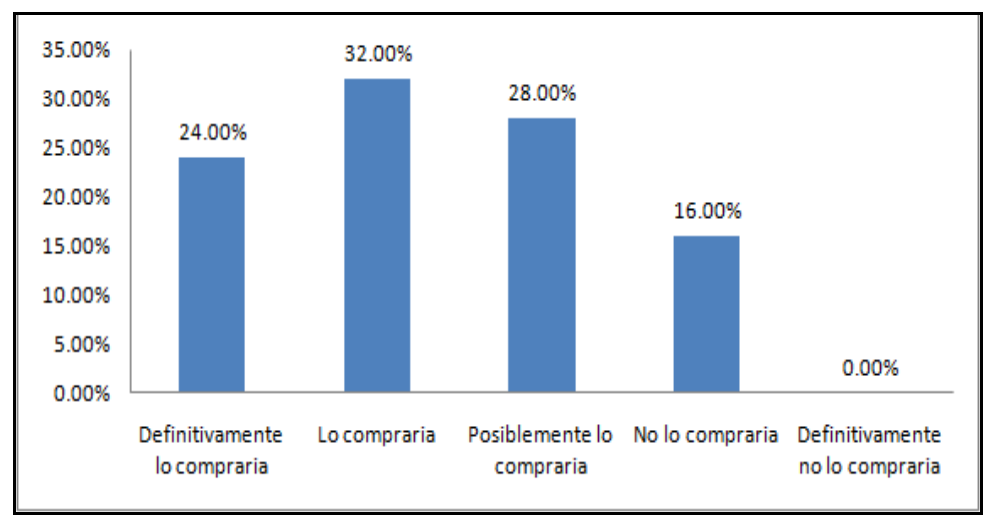

Figura 40: ¿Compraría o volvería a comprar Jolly Roger?

Un 56\% de los encuestados comprarían o volverían a comprar el Jolly Roger. Hay un $28 \%$ de indecisos en realizar la compra, frente a un $16 \%$ que no lo comprarían. Del gráfico, se observa que el público objetivo es un 3,63\% del universo. 


\subsection{Investigación Cualitativa}

La metodología a emplear en la investigación cuantitativa es de modelo "Descriptivo". Este modelo es aquel en que la información es recolectada sin cambiar el entorno (es decir, no hay manipulación del comportamiento ni actitudes del grupo en estudio). Se realizaron 3 Focus Groups.

Los dos primeros Focus Group se realizaron a este Target ya que el resultado del estudio Cuantitativo demostró que el $89.09 \%$ de encuestados no conocen el macerado de hierbas en base a Pisco Jolly Roger. El tercer Focus Group se realizó en base al porcentaje de encuestados que si conocen el producto.

\section{1er Focus Group:}

Hombre y Mujeres de 26 a 30 años de NSE A, B y C que tomen bebidas alcohólicas en base a pisco y no conocen el Jolly Roger

\section{2do Focus Group:}

Hombre y Mujeres de 18 a 25 años de NSE A, B y C que tomen bebidas alcohólicas en base a pisco y no conocen el Jolly Roger

\section{3er Focus Group:}

Hombre y Mujeres de 18 a 30 años de NSE A, B y C que tomen bebidas alcohólicas en base a Pisco que conocen y consumen Jolly Roger 


\section{Conclusiones Focus 1}

\section{Ficha Técnica}

Participantes: Hombre y mujeres de 26 a 30 años de NSE A, B y C que tomen bebidas alcohólicas en base a pisco.

Fecha: sábado 23 de Setiembre del 2017 en las instalaciones de la Escuela de Post Grado de la Universidad San Ignacio de Loyola.

Hábitos de compra y consumo de bebidas alcohólicas en base a Pisco

Dentro del grupo de personas del Focus 1, algunas preparan y consumen las bebidas en base a Pisco en sus propias casas (reuniones con amigos o familiares) mientras que otras prefieren consumir estas bebidas en un bar o restaurante ya que no tienen mucho conocimiento de recetas y/o ingredientes necesarios.

Las bebidas en base a Pisco más consumidas en este grupo son el Pisco Sour y los Chilcanos de frutas. Conocen varias marcas de Pisco pero no saben cuáles sirven para la preparación de Chilcanos y cuales para el Pisco Sour. Consideran que el Pisco Sour debe consumirse como primera bebida (aperitivo) mientras que el Chilcano puede ser tomado durante toda la noche.

En general se observa en este grupo que el consumo de Pisco Sour está relacionado con el día mientras el de Chilcano suele tomarse de noche.

El pisco Portón fue la primera opción cuando se les preguntó por alguna marca de esta bebida seguida de la marca Viñas de Oro y Cuatro Gallos. Al momento de comprar una botella de bebidas en base a Pisco suelen comparar los precios y buscar la mejor opción en la relación precio/calidad. 


\section{Evaluación Jolly Roger}

El grupo concuerda en que el producto a primera vista no parece un producto hecho en el Perú debido a que el nombre está en Ingles, no tiene ninguna simbología peruana, tipo de letra o elementos utilizados en la etiqueta (corona) y lo relacionan más con un coñac o ron por el color del producto.

La botella tuvo una alta aceptación ya que la consideran fuera de lo común (al ser cuadrada) ya que no recuerdan otra botella de similares características. Recomiendan que si el productor desea relacionar el producto con el país de origen se le coloque alguna cinta o adorno en la botella para identificarlo más fácilmente como producto hecho en el Perú.

Algunas personas sugirieron cambiar el nombre por uno en quechua y que la botella sea más estilizada para apreciar correctamente las características del producto (color). Otros participantes del focus lo relacionan más con la Costa del Perú ya que el Pisco es de esta zona y proponen un nombre más peruano.

El nombre Jolly Roger no fue bien percibido ya que se asocia a un nombre Europeo que no tiene relación con el Pisco peruano ni con un producto con ese ingrediente, lo relacionaron con el producto Bailey. Indican que la etiqueta es la adecuada ya que combina con el color del producto aunque opinan que debería tener fecha de vencimiento o fecha máxima de consumo una vez abierto. Incrementar el tamaño donde se indica que el producto es peruano.

La botella podría tener un relieve y la etiqueta debería tener motivos peruanos en color negro con elementos de la Costa peruana. El nombre debe ser mejorado. 
La cantidad de mililitros es adecuada (750 ml.), no consideran una presentación personal.

Pueden comprar la botella y consumirla de vez en cuando.

Los participantes indicaron que el precio mínimo que pagarían por el producto estaría entre los 50 y 70 soles mientras que precio ideal debería ser S/ 60 .

La frecuencia de compra de Jolly Roger estaría entre una vez al mes, una vez cada dos meses y una vez cada tres meses.

\section{Prueba de producto puro}

Todo el grupo considera que el producto tiene un sabor agradable, el color oscuro indica que el producto ha sido macerado y opinan que el aroma indica la maceración en barricas de madera, lo relacionaron con Vinos añejos. Indican que sienten un sabor a flores y frutos rojos. Una persona dentro del grupo sugirió que también podría consumirse caliente.

Reconocen como sabor residual el Pisco.

El nivel de dulzor es el adecuado, no es invasivo, no predomina en el producto, no es empalagoso, sin embargo, creen que el producto está más dirigido a mujeres que a hombres por el nivel de dulzor.

Se relaciona el producto con una situación tranquila, un momento relajado, disfrutando con amigos o con familiares. Lo tomarían en una reunión con amigos en un momento tranquilo, no lo relacionan con una discoteca o con una fiesta. Lo consumiría 
en una situación más íntima. El grado de alcohol es aceptado por todos los participantes.

\section{Prueba de producto combinado (Evervess)}

Consideran que el sabor del producto se pierde al combinarlo con Evervess y pierde consistencia.

El alcohol se siente desde el inicio y pierden sus atributos de aroma y sabor residual.

Lo relacionan con un refresco y no como una bebida alcohólica.

Coinciden al $100 \%$ que prefieren consumirlo puro y no combinado, pierde su esencia.

Sugirieron la posibilidad de cambiar el macerado con diversos tipos de Pisco.

\section{Puntos de Venta del producto}

El grupo indicó que les gustaría poder encontrar el producto en los supermercados donde suelen hacer sus compras como por ejemplo Wong y Metro o alguna licorería e inclusive en el aeropuerto ya que consideran que el producto podría ser un buen regalo para llevarlo al extranjero.

\section{Comunicación}

Una persona indicó que le gustaría que el producto utilice publicidad masiva como medio de comunicación, pero la mayoría sugirió una comunicación más selectiva como revistas especializadas. Comparan el nivel del producto con el whisky Swing. 
Debería tener una página en Facebook bastante activa para comunicar eventos, promociones, puntos de venta etc.

\section{Imagen para la marca}

Relacionan el producto con un hombre con presencia, respeto, de alrededor de 40 años.

Lo relacionan con personajes peruanos como: Salvador del Solar, Diego Bertie; o un personaje español como Antonio Banderas. 


\section{Conclusiones Focus 2}

\section{Ficha Técnica}

Participantes: Hombre y mujeres de 18 a 25 años de NSE A, B y C que tomen bebidas alcohólicas en base a pisco.

Fecha: sábado 23 de Setiembre del 2017 en las instalaciones de la Escuela de Post Grado de la Universidad San Ignacio de Loyola.

\section{Hábitos de compra y consumo de bebidas alcohólicas en general}

Los participantes nos indicaron que suelen comprar sus bebidas alcohólicas en autoservicios, en tiendas de conveniencia como Tambo y en algunas licorerías.

La mayoría de jóvenes no acuden a menudo a locales nocturnos y consumen licores los fines de semana en casas de sus amigos. Las pocas veces que salen de casa, suelen visitar discotecas y las chicas consumen bebidas alcohólicas en algún restaurante.

Los motivos de reunión son en su mayoría con compañeros del colegio y del barrio. Los participantes toman cerveza, pisco, ron y vodka. El pisco lo toman en chilcano y muy pocas veces como pisco sour o puro. No conocen de marcas de pisco, solo tienen referencia el pisco Queirolo.

\section{Evaluación de Jolly Roger}

A primera vista los participantes observaron un producto diferente a cualquiera que esté en el mercado, el nombre lo relacionaron con el Rock, un buen nombre pero que no comunica nada a simple vista. 
La botella y tapa tuvieron gran aceptación, observando que es una botella diferente y no lo relacionan con pisco. Etiqueta aceptable, pero que se pierde con el color del licor, no trae mucha información del contenido en el lado frontal. La sugerencia por parte de los participantes es de poner en la parte frontal que es Pisco macerado.

Se sugiere que el nombre podría cambiar por uno que se relacione con temas peruanos e indicar que es pisco macerado. Se considera que la cantidad ideal es 750 $\mathrm{ml}$.

\section{Precio mínimo y máximo}

El precio mínimo y máximo que pagarían los participantes fue de 40 el mínimo y 60 soles el máximo. Teniendo como precio ideal el de 50 soles para la mayoría de participantes.

\section{Frecuencia de compra}

La frecuencia de compra es de 1 a 2 veces cada 2 meses.

\section{Prueba de producto}

La prueba de producto empezó con el producto puro y fue del agrado de todos los participantes, se percataron de los sabores del anís y del maíz morado, además del sabor a pisco. Detectaron que tiene otras hierbas pero no sabían cuáles. El color por ser macerado es bueno, además de identificar el color por el maíz morado. 
Prefieren tomarlo puro para ciertas reuniones y también como bajativo después de las comidas, no es tan fuerte como el pisco pero tampoco es tan suave como otros licores. Tiene el grado de alcohol ideal para tomarlo puro.

La prueba de producto combinado con el Evervess se realizó después, pero no tuvo la misma aceptación, el sabor se pierde con la combinación, se siente muy aguado, disminuye el sabor del producto. Prefieren consumirlo puro y no combinado.

\section{Venta del producto}

Le gustaría encontrar el producto en autoservicios, licorerías, restaurantes y discotecas, además de tiendas de conveniencia y algunas estaciones de servicio.

\section{Comunicación}

A los participantes de este Focus Group les gustaría publicidad masiva, además algunas acciones en los puntos de venta. También anfitrionas en discotecas que ayuden a promocionar el producto. Facebook y las redes sociales serían para ellos el principal medio de comunicación.

Relacionaron el producto con un artista de rock y con un pirata, alguien desenfrenado y diferente. 


\section{$\underline{\text { Conclusiones Focus } 3}$}

Ficha Técnica: Participantes: Hombre y mujeres de 18 a 30 años de NSE A, B y C que tomen el producto Jolly Roger.

Fecha: sábado 30 de Setiembre del 2017 en las instalaciones de la Escuela de Post Grado de la Universidad San Ignacio de Loyola.

\section{Hábitos de compra y consumo}

La mayoría de participantes suelen consumir Jolly Roger en los eventos que la marca realiza esporádicamente.

Tres de los participantes mencionaron que solo lo han consumido en estos eventos y nunca lo han comprado. Solo 1 participante suele comprarlo y consumirlo los fines de semana y también asiste a los eventos realizados por la marca. Menciona que prefiere consumir el productor mezclándolo con jugos como naranja o maracuyá. Afirma que el sabor es mucho mejor y agradable.

Los lugares en donde disfruta del producto son generalmente en reuniones con amigos. 


\section{Percepción del producto}

Todos los participantes creen que la forma de la botella es original y que la tapa con forma de corcho le da un mejor aspecto. Mencionaron que a primera vista lo relacionan con un producto del extranjero ya que no tiene alguna característica que lo identifique como peruano.

Todos están en desacuerdo con el diseño de la etiqueta y con el nombre de la marca ya que no lo relacionan a una bebida en base a pisco.

\section{Prueba de producto}

Dos de los participantes mencionaron que el sabor a anís se sentía bastante fuerte a la hora de consumirlo. El participante que consume el producto los fines de semana, mencionó que prefiere consumirlo mezclando jugos como maracuyá y naranja ya que le parece más agradable.

Todos agregaron que el macerado es bastante empalagoso pero agradable. En cuanto al sabor residual mencionaron que el producto deja un sabor bastante fuerte a alcohol.

\section{Recomendaciones:}

La mayoría de participantes llegaron a la conclusión en bajar el dulzor del macerado ya que sienten que tiene mucha azúcar. Un participante insistió en dejar la tapa con forma de corcho ya que le da un mejor aspecto al producto. Un punto importante que concluyeron para el producto es aclarar el color del macerado ya que 
creen que esto le dará una mejor impresión. En cuanto a la etiqueta, todos recomiendan que se muestre la fecha de elaboración ya que consideran que es muy importante a la hora de comprar una bebida alcohólica. Agregaron que les gustaría encontrarlo en grifos y supermercados y en cuanto a promoción y comunicación, les parece que las redes sociales y acciones BTL son la mejor opción para enterarse del producto. Por último, sugieren que el producto tenga promociones cruzadas con jugos o gaseosas. En la presente figura podemos observar un esquema resumen de la Investigación Cualitativa y Cuantitativa, pudiendo obseravar los resultados de las encuestas cruzados con los resultados de los focus group.

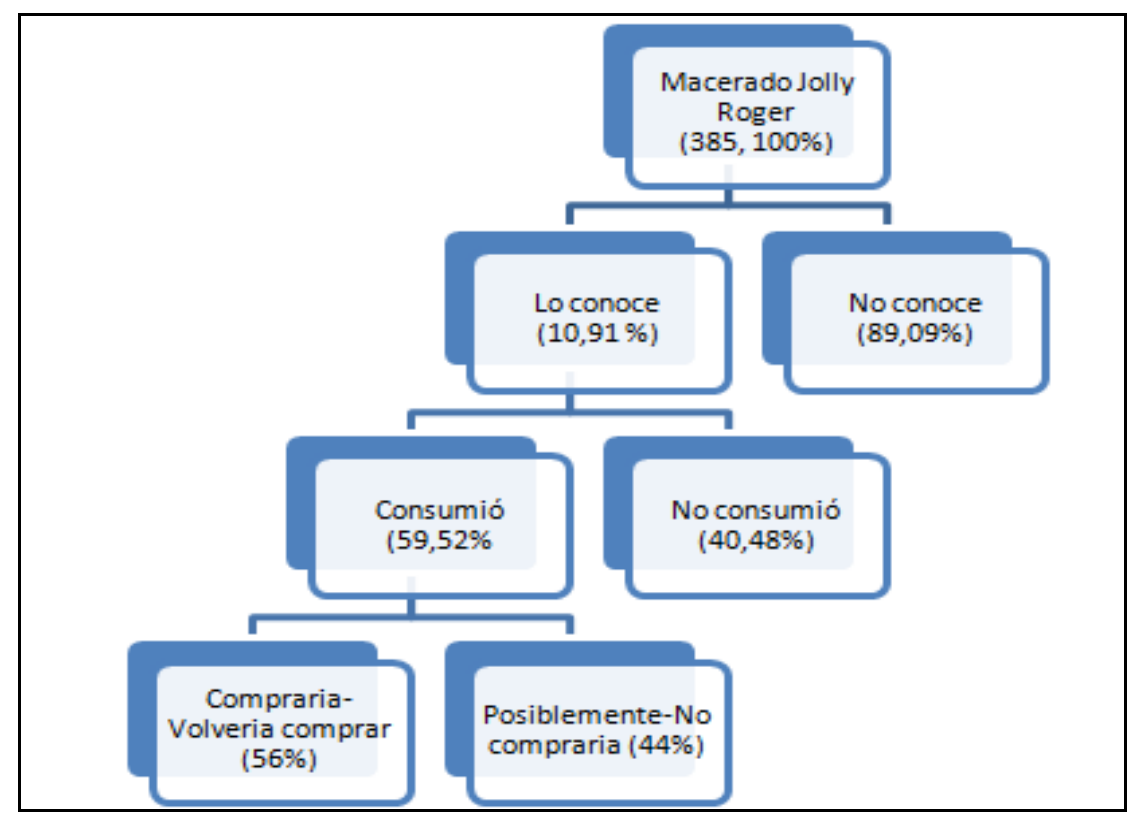

Figura 41:Resumen encuesta Jolly Roger

Elaboración propia.

\section{1.- Lo conoce}

- Eventos de la marca

- Por amigos

- Por redes sociales (Facebook) 
2.- No lo consumió

- Por disponibilidad

- Poca información

3.- Consumió

- Por amigos

- Eventos de la marca

4.- No lo compró

- Poca información

- Poca disponibilidad

5.- Compró

- Por aceptación del producto

- Calidad percibida

- Precio

- Cantidad de mililitros

6.- No lo compraría

- Sabor

\subsection{Análisis de producto}

El macerado de hierbas en base a pisco Jolly Roger es aceptado por el público en general y lo consideran bueno y muy bueno (76\%), prefieren consumirlo puro más que combinado con otras bebidas. El sabor es muy aceptado al igual que el color y el grado de alcohol. Con respecto a la botella, opinan que es diferente y única en el mercado de piscos y derivados. 
El nombre Jolly Roger no es totalmente aceptado en general, ya que no se relaciona a una bebida en base a Pisco peruano, ni a los productos de los cuales está elaborado; además no lo relacionan como una bebida alcohólica.

\subsection{Tendencias del producto}

La tendencia de Jolly Roger es poder ser identificado como un producto con más identidad nacional, producto peruano con colores más juveniles. Otro punto del producto a evaluar sería el cambio del nombre, que tenga mayor identidad nacional, ya que como resultado de los Focus Group realizados el nombre no ha sido aceptado y sugirieron el cambio del mismo. Podemos concluir que los participantes del Focus Group consideran importante relacionar el producto con temas peruanos (colores, elementos etc.).

\subsection{Análisis de ventas}

Un $56 \%$ de los consumidores indican que comprarían o volverían a comprar Jolly Roger; asimismo, un $84 \%$ indican que recomendarían el producto. Estos valores indican el nivel de aceptación del macerado en el mercado y en un escenario moderado de crecimiento en el nivel de ventas. Para el primer año de ventas del macerado en el mercado peruano (2016), se tiene un nivel de ventas según lo indicado en la Tabla 14: 
Tabla 16: Ventas Jolly Roger (2016).

\begin{tabular}{ll}
\hline \multicolumn{1}{c}{ Mes } & $\begin{array}{l}\text { Venta en dólares } \\
\text { Jolly Roger }\end{array}$ \\
\hline Enero & 0 \\
Febrero & 0 \\
Marzo & 0 \\
Abril & 0 \\
Mayo & 1,400 \\
Junio & 1,350 \\
Julio & 1,650 \\
Agosto & 3,600 \\
Septiembre & 4,125 \\
Octubre & 4,260 \\
Noviembre & 4,105 \\
Diciembre & 4,710 \\
Total & 25,200 \\
\hline
\end{tabular}

Fuente: Elaboración propia

\subsection{Tendencias del comportamiento del consumidor}

La tendencia del consumidor es de aumentar el consumo de pisco en todas sus modalidades y Jolly Roger ayudaría de una manera diferente y nueva a aumentar este consumo del Pisco peruano. Jolly Roger es visto como la alternativa juvenil para consumir Pisco peruano. 


\subsection{Tendencias de medios, distribución y precios}

La tendencia en medios de comunicación es el uso de las redes sociales, como Facebook, Twitter, YouTube, etc. Las aplicaciones en celulares se utilizan cada vez más y es importante considerar su uso para Jolly Roger.

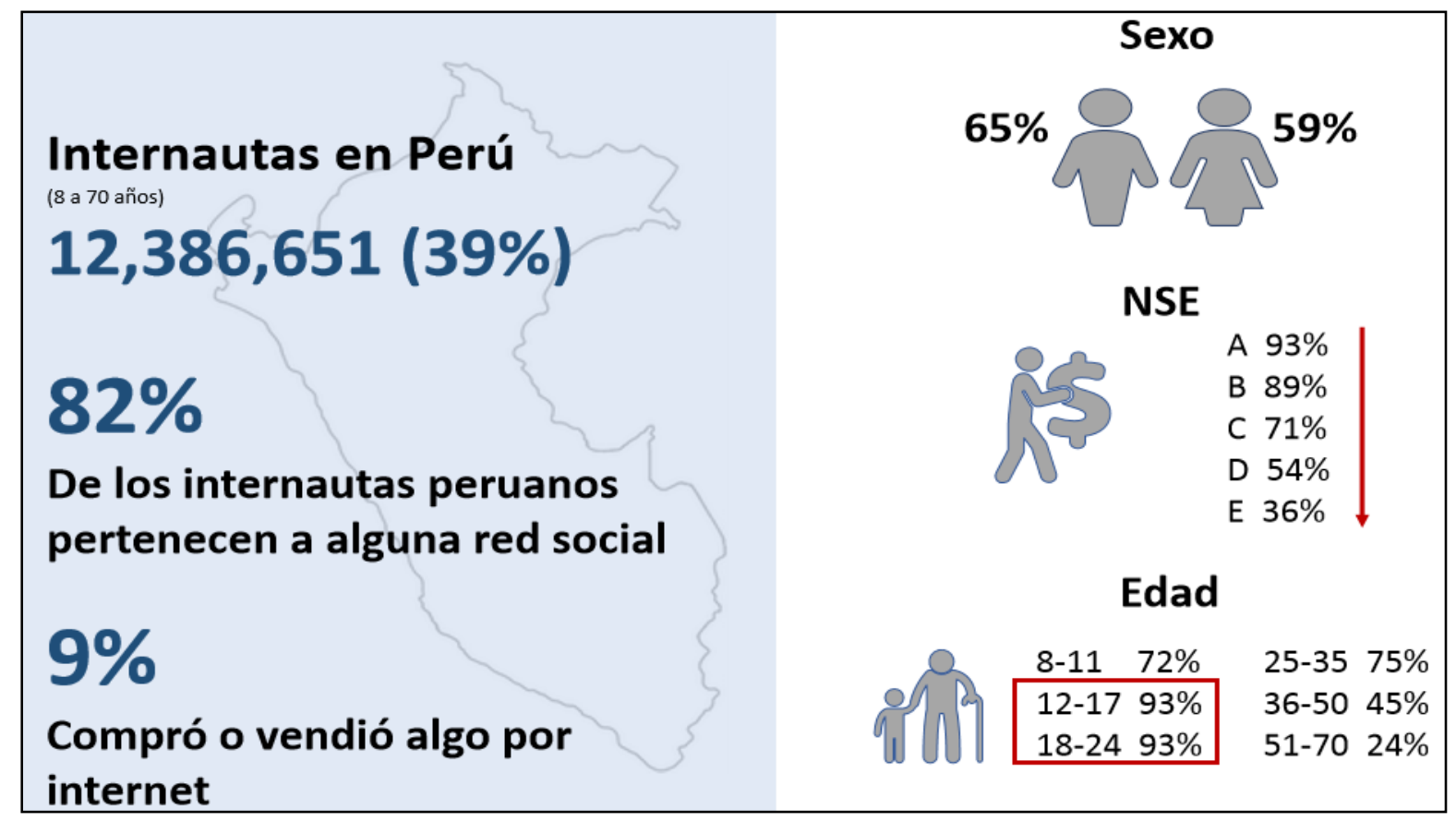

Figura 42:Penetración de Internet en el Perú:

Fuente: IPSOS / Desarrollo e importancia de la publicidad digital 2016 


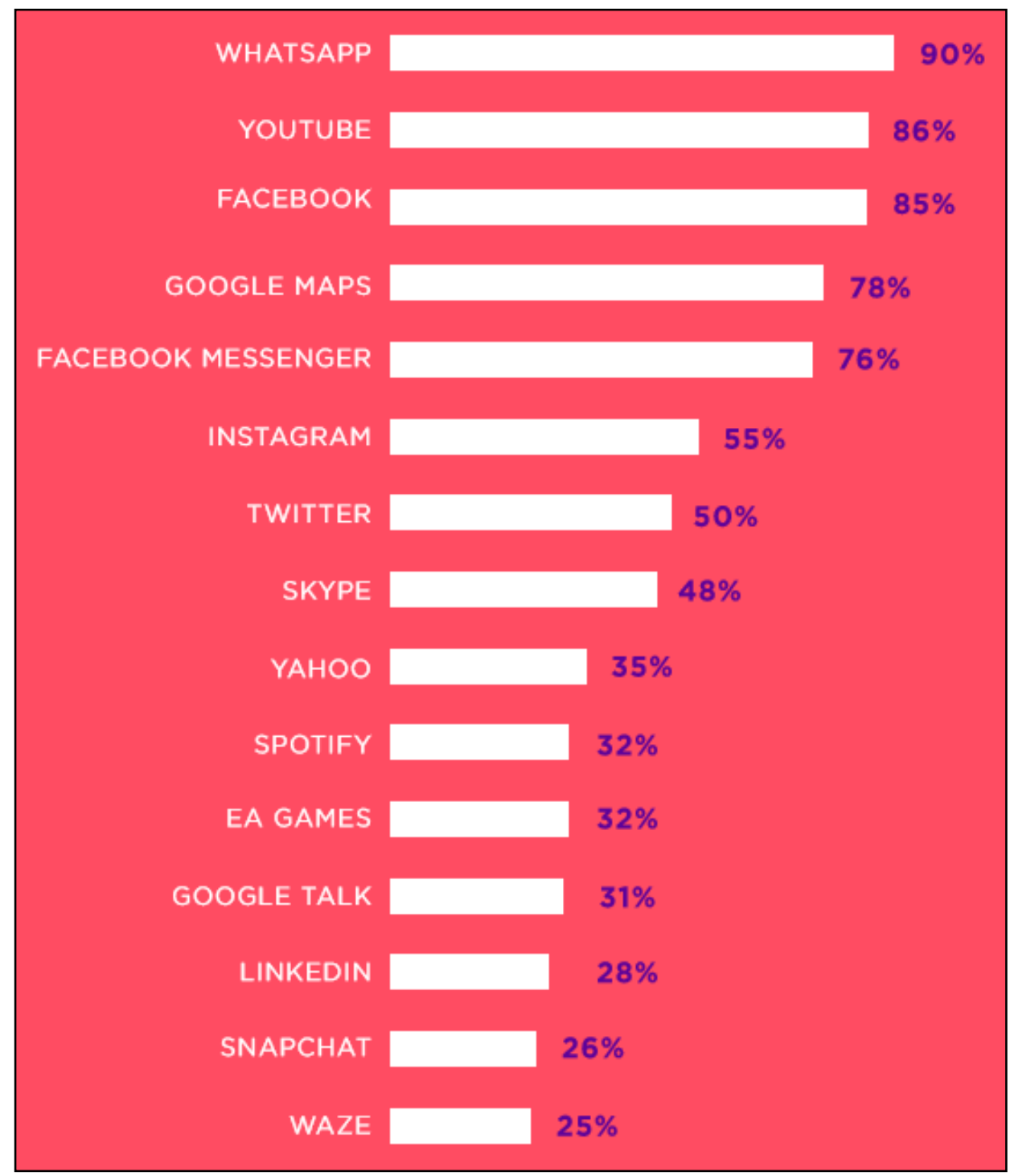

Figura 43: Top 15 de aplicaciones más usadas en Latinoamérica Fuente: IMS / Mobile In Latam Study 2nd edition Septiembre 2016

En lo referente al precio del macerado, el precio tendría que mantenerse en valores menores a los S/ 50.00, ya que un precio mayor influenciará negativamente en la decisión de compra del consumidor; en la actualidad el precio de venta del producto es de $\mathrm{S} / 44,90$. 


\subsection{Segmentos del mercado que compran el producto (empresa e industria)}

\subsubsection{DAFO}

\section{DEBILIDADES}

- D1 No tener experiencia en el mercado peruano

- D2 La bodega no tiene estructurada la estrategia precios de ninguno de sus productos.

- No cuenta con una estrategia de distribución.

- No cuenta con una estrategia de comunicación.

- D3 No cuenta con Fuerza de Ventas

- D4 No cuenta con Plan de Marketing ni presupuesto asignado a Jolly Roger

\section{AMENAZAS}

- Conflictos sociales en Lima.

- A1 Bajas barreras de ingreso al mercado para macerados importados

- A2 Un nuevo desastre natural que afectaría la estabilidad productiva y económica del país.

- Tendencia en una baja de lealtad hacia la marca por parte de los consumidores.

- A3 Ingreso de nuevos competidores a un mercado aún sin explotar.

- $\quad$ A4 Alto poder de Negociación por parte de los clientes retail.

- Falta de información sobre el mercado de macerados en base a pisco.

- Sustitutos con alto presupuesto de comunicación y marketing. 


\section{FORTALEZAS}

- F1 Los productos que comercializa la bodega santa maría se producen bajo los cumplimientos de calidad de DO

- F2 Producto innovador y único en el mercado.

- La capacidad de ingresar el Jolly Roger al mercado de Lima.

- F3 Amplio Margen en Jolly Roger

- F4 Capacidad de producir doble que producción actual.

\section{OPORTUNIDADES}

- O1 Creación de la ley que declara patrimonio nacional a la denominación de origen Pisco.

- Estabilidad Política y Jurídica para el año 2018

- O2 Expectativas de mejora en indicadores como consumo e inversión

- O3 Nuevos consumidores buscan alternativas nuevas en el mercado.

- O4 Incremento del poder adquisitivo de los consumidores.

- Aumento del mercado potencial para consumo de bebidas alcohólicas

- Mercado nuevo con solo un producto como competencia indirecta.

- O5 Producto nuevo y categoría nueva para los clientes

- O6 Proveedores leales a la bodega

- El incremento del uso de internet permitirá establecer nuevos canales de ventas nuevas para la categoría. 


\subsubsection{DAFO CRUZADO}

\section{- Fortaleza - Oportunidad}

F1 - O1 Informar en el producto acerca de la calidad y el respeto a los procesos de la DO, solicitar a las entidades promotoras del gobierno comunicar nuestro respaldo de la Ley y ser parte de la promoción y de las actividades que ellos promuevan.

F2 - O4 Jolly Roger es un producto nuevo en el mercado, en una categoría nueva y los nuevos consumidores están en la búsqueda de nuevas alternativas, eso nos pondrá como una nueva opción para ellos, es por eso que dentro del plan de marketing se realizará una Investigación de mercados cualitativa y cuantitativa.

F3 - O5 No tener una competencia directa y tener altos márgenes, nos ayudará a tener el soporte para una estrategia de precios eficaz, también nos ayudará a poder ofrecer un valor adicional al consumidor, como diferentes promociones, etc. Estructurando dentro del plan de marketing una estrategia de precios para los diferentes canales.

F2 - O5 Realizar una estrategia de posicionamiento aprovechando que no existe competidor directo en el mercado.

\section{- Debilidad - Oportunidad}

D4- O5 Al ser una categoría nueva en el mercado peruano la falta de experiencia en el no sería un impedimento para ingresar con Jolly Roger con un presupuesto de Trade Marketing en los diferentes puntos de venta. 
D4- O6 Al tener una estabilidad política-legal y una expectativa de crecimiento económico e inversión, la bodega podrá asignar un presupuesto para un plan de marketing, con la posibilidad de estructurar estrategias de precios, ventas, distribución y comunicación, sin temor a un fracaso por temas externos, este presupuesto será asignado a la nueva área de marketing.

\section{- Debilidad - Amenazas}

D1- A1 Al ser primeros en la categoría y no tener información de mercado, nos hace los pioneros con Jolly Roger y se podrían fijar las barreras de entrada, los estándares de calidad en la categoría. Se realizará el análisis al producto en base a lo que el mercado necesita.

D4- A3 Implementar o tercerizar el área de Marketing y realizar el respectivo plan para ingresar al mercado peruano con la categoría macerados.

\section{- Fortaleza - Amenaza}

F2- A3 Productos sustitutos existentes con baja lealtad de marca favorece el ingreso de una marca peruana Jolly Roger con DO con el respaldo de la ley de protección, campaña de comunicación implementada para crear lealtad.

F5- A2 Capacidad de producción y abastecimiento ante posibles desastres naturales (fenómeno del niño). Previniendo el acopio de materia prima (uva) un periodo anterior, invirtiendo en protección de sembríos, etc.

F2- A3 Producto único e innovador que dificulta el ingreso de un producto similar en características organolépticas del producto. Realizando en un mediano plazo, extensiones de línea o mejorando el producto periodo a periodo. 


\section{CAPÍTULO V: OBJETIVOS}

\subsection{Relación entre Plan Estratégico y el Plan de Marketing (Objetivos estratégicos y} objetivos de marketing)

La Bodega Santa María no cuenta con un Plan Estratégico que sea la base para el Plan de Marketing. El presente documento es el primero que realiza la bodega para Jolly Roger.

\subsection{Formulación de Objetivos: Ventas, Margen, Comerciales, Producto y}

\section{Comunicación.}

\subsubsection{Objetivos Generales}

- Incrementar las ventas de 88,452 a 173,189 dólares en un año en Lima Metropolitana y Callao.

- Incrementar el Nivel de Conocimiento de $10.9 \%$ a $20 \%$ en Lima Metropolitana y Callao en un año.

\subsubsection{Objetivos Específicos}

- Incrementar la participación de mercado de $7.75 \%$ a $12.90 \%$ en Lima Metropolitana y Callao en un año.

- Aumentar la presencia de 1 a 3 autoservicios en Lima Metropolitana y Callao en un año. 


\subsection{Objetivos de Marketing}

- Producto:

○ Incrementar de 1 a 2 las presentaciones de la botella de Jolly Roger en cuanto a cantidad, antes de terminar el año.

\section{- Plaza:}

- Incrementar a 2 nuevos canales de venta al término del año.

- Precio:

- Mantener el $25 \%$ de diferencia de precio con el referente Jagermeister.

\section{- Comunicación:}

- Obtener un nivel de recordación del $21.82 \%$ del mercado potencial en 1 año.

- Obtener un alcance de 1 millón de usuarios utilizando redes sociales en 1 año.

- Incrementar el tráfico web en 5,000 visitas en promedio mensualmente.

- Tener un tiempo de respuesta de como máximo 1 hora en redes sociales.

- Obtener un ratio de participación de 1\% (10 mil personas) en promedio al año en Facebook. 


\section{CAPÍTULO VI: ESTRATEGIAS DE MARKETING}

\subsection{Estrategia de Cartera}

Para el análisis de la estrategia de cartera se realizó un análisis con la matriz BCG y Ansoff.

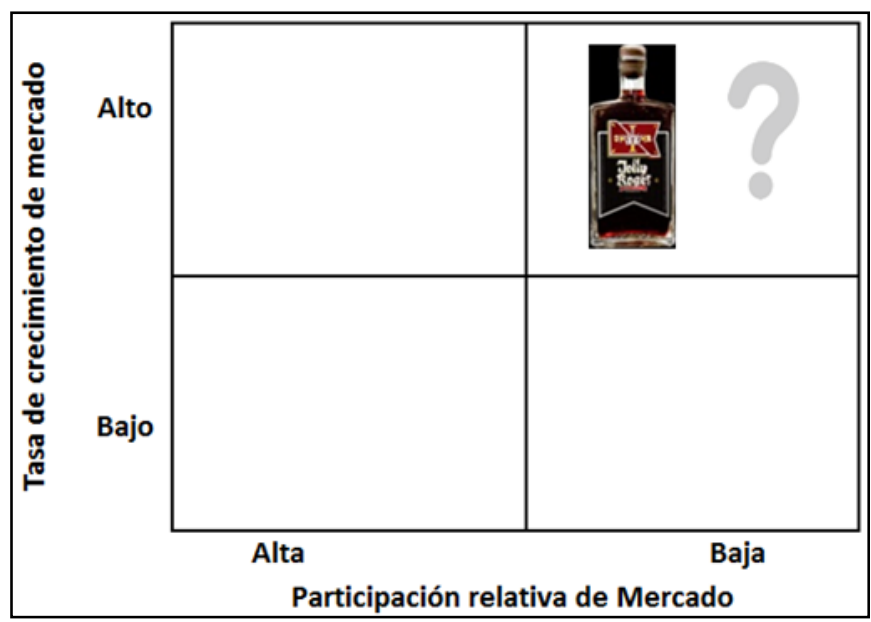

Figura 44: Matriz BCG

Elaboración propia.

\begin{tabular}{|c|c|c|}
\hline Mercados Productos & Actuales & Nuevos \\
\hline Actuales & & \\
\hline Nuevos & & \\
\hline
\end{tabular}

Figura 45: Matriz de Ansoff Elaboración propia.

El mercado para el consumo de licores en Perú está en crecimiento, por lo que el atractivo es alto. La Bodega tiene una participación de mercado baja con Jolly Roger, ya que aún es una marca nueva, poco conocida en el mercado, pero tiene una buena calidad percibida, aceptación del producto por los consumidores, capacidad de 
producción de la Bodega, precio de producto dentro de las posibilidades de pago del consumidor (información de focus group realizado).

Según el análisis de la Matriz BCG, Jolly Roger se encuentra en una posición de Interrogante, ya que su participación de mercado es baja. Es necesario realizar una inversión en el producto para convertirlo en estrella y aprovechar el crecimiento del mercado. La estrategia a seguir es la de incrementar la participación de mercados.

De la matriz de Ansoff, la estrategia a desarrollar con Jolly Roger es de Penetración de mercado (expandir el mercado). La combinación de ambas estrategias, nos indica invertir para ganar mayor participación de mercado, lo que nos permitirá mejorar nuestra posición competitiva frente a Jagermeister.

\subsection{Estrategias Genéricas}

De acuerdo a Michael Porter, las estrategias permiten que las organizaciones obtengan una ventaja competitiva a partir de tres ejes fundamentales: liderazgo en costos, diferenciación y enfoque. Porter llama a estos ejes estrategias genéricas.

La estrategia genérica tipo 3 de Porter es la diferenciación. Su finalidad es producir bienes y servicios considerados únicos en toda la industria, y dirigirlos a consumidores que son relativamente poco sensibles al precio. 


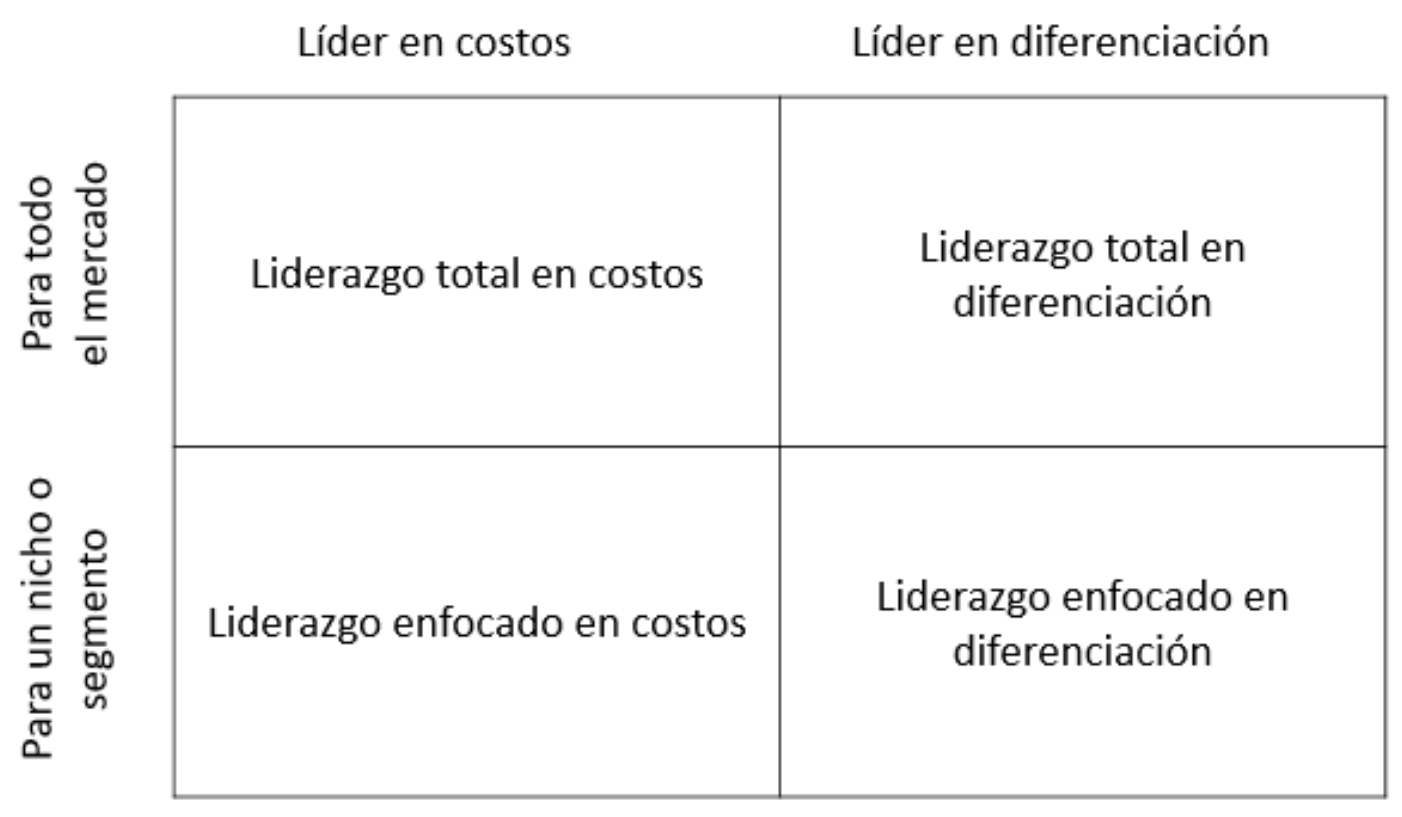

Figura 46: Estrategia Genérica de Michael Porter a utilizar: DIFERENCIACION

Hemos elegido la estrategia genérica de Diferenciación ya que consideramos que contamos con un producto único en el mercado, si bien puede existir un producto que se asemeje al Jolly Roger creemos que al tener Pisco peruano como ingrediente base del producto lo vuelve innovador en el mercado de bebidas alcohólicas.

Consideramos importante trabajar en el desarrollo de productos para continuar con la estrategia genérica adoptada, este desarrollo de nuevos productos debe venir acompañado de un cuidadoso análisis del mercado, así como de las necesidades y preferencias de sus consumidores, identificar oportunidades para introducir productos con características únicas y altas barreras de entrada que cierren la puerta de ingreso a la competencia y productos similares. 


\subsection{Estrategia de Segmentación}

En la presente tabla presentaremos la estrategia de segmentación para Jolly Roger, podemos definir el segmento estratégico prioritario y el segmento estratégico simple.

Tabla 17: Estrategia Segmentación para Bodega Santa María, producto Jolly Roger

\begin{tabular}{|c|c|c|}
\hline Segmentos & $\begin{array}{c}\text { Aspectos que valora el } \\
\text { segmento }\end{array}$ & Estrategia de Segmentación \\
\hline Segmento Principal 1 & $\begin{array}{l}\text { - Macerado de hierbas } \\
\text { - Elaborado con Pisco } \\
\text { Peruano } \\
\text { - Percepción de alta } \\
\text { calidad } \\
\text { - Sabor y color }\end{array}$ & 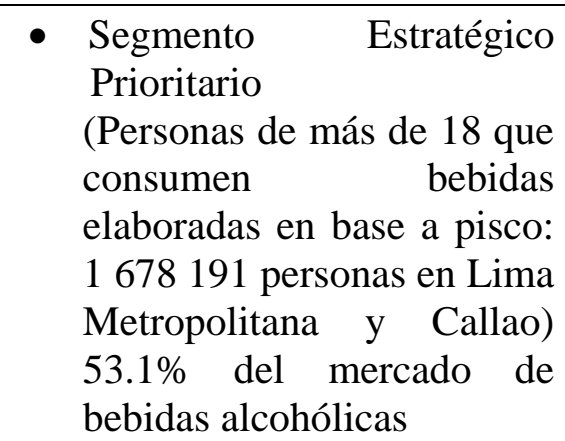 \\
\hline Segmento Principal 2 & $\begin{array}{l}\text { - Se puede combinar } \\
\text { con otras bebidas }\end{array}$ & $\begin{array}{l}\text { - Segmento Estratégico } \\
\text { prioritario (Personas que } \\
\text { toman bebidas alcohólicas } \\
\text { en base a pisco, incluido } \\
\text { macerados y que las } \\
\text { combinan con otras } \\
\text { bebidas en Lima } \\
\text { Metropolitana y Callao) }\end{array}$ \\
\hline Segmento Medio & $\begin{array}{l}\text { - Envase diferente } \\
\text { - Producto nuevo en el } \\
\text { mercado }\end{array}$ & 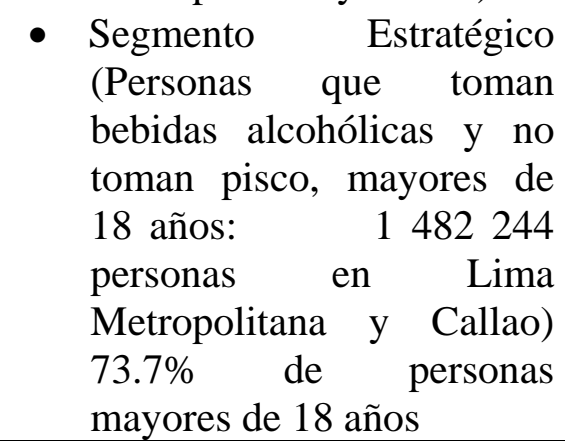 \\
\hline
\end{tabular}

Fuente: Elaboración propia 


\subsection{Estrategia de Posicionamiento}

Para cumplir con toda estrategia, no debe de faltar establecer el posicionamiento a comunicar al segmento prioritario establecido. Este posicionamiento se debe coordinar en tres puntos estratégicos de marketing: posicionamiento de la empresa, posicionamiento del producto y posicionamiento ante el cliente.

En la presente tabla determinaremos el posicionamiento en estos tres puntos clave para la bodega Santa María.

Tabla 18: Estrategia de Posicionamiento Jolly Roger

Jolly Roger Eleva tu bandera. Marca tu camino.

\section{Fuente: Elaboración propia}

\section{Propuesta de Valor}

Para cada segmento al que dirigiremos el mensaje y las acciones de marketing tendrán diferente propuesta de valor, como se indica en la siguiente tabla:

Tabla 19: Propuesta de valor Jolly Roger

\begin{tabular}{cc}
\hline Segmento & Propuesta de Valor \\
\hline Segmento Principal 1 & El nuevo camino del pisco \\
Segmento Principal 2 & Combinación perfecta. \\
Segmento Medio & Diversión diferente.
\end{tabular}

Fuente: Elaboración propia 


\subsection{Estrategia de Fidelización}

Para fidelizar a los clientes del canal de autoservicio y el cliente final, se considerará principalmente los siguientes puntos:

- Tener una comunicación activa con los clientes brindándoles toda la información sobre el producto y las novedades que se plantearán en el futuro.

- Soporte y apoyo constante para impulsar la compra en los puntos de venta.

- Tener constantes promociones como una herramienta para fidelizar a los heavy user. (programa de fidelización)

- Implementar un programa de fidelización

\subsection{Estrategias Funcionales}

Las estrategias funcionales estarán en función de alcanzar los objetivos del plan.

\subsubsection{Estrategia de Producto.}

1. Introducir una nueva presentación de botella.

2. Evaluar el diseño de botella del producto.

3. Mejorar el etiquetado.

4. Evaluar el nombre del producto.

\subsubsection{Estrategia de Precios}

- Evaluar periódicamente los precios de venta al público del referente Jagermeister, en los diferentes canales en los que tiene presencia para mantener una diferencia.

- Implementar política de pagos clara para cada canal de venta. 
- Evaluación de créditos trimestrales para clientes

-Descuento sobre precio de lista para nuevos canales.

- Evaluar la percepción de valor de la competencia y del producto.

En la siguiente tabla se observa el detalle de los precios y margen que ofrece la Bodega Santa María a cada canal para su macerado Jolly Roger. Ver tabla 18.

Tabla 20: Road to Market por canal de venta

\begin{tabular}{cccccc}
\hline Canal & $\begin{array}{c}\text { Margen } \\
(\%)\end{array}$ & $\begin{array}{c}\text { P.Vta } \\
\text { Canal }(\$)\end{array}$ & $\begin{array}{c}\text { Util. por } \\
\text { Canal }(\$)\end{array}$ & $\begin{array}{c}\text { Util. por } \\
\text { Canal }(\%)\end{array}$ & $\begin{array}{c}\text { Cantidad } \\
\text { Locales }\end{array}$ \\
\hline Autoservicios & 30 & 9.54 & 5.0 & $54 \%$ & 18 \\
Horecas & 20 & 10.9 & 6.36 & $41.6 \%$ & 100 \\
Licorerías & 20 & 10.9 & 6.36 & $41.6 \%$ & 20 \\
Mayoristas & 8 & 11.15 & 6.60 & $40.8 \%$ & 5 \\
\hline
\end{tabular}

Fuente: Elaboración propia

\subsubsection{Estrategia de Distribución y Ventas}

- Reclutar y consolidar el Área Comercial

- Ingresar a los 2 autoservicios más importantes de Lima y Callao, Wong y Vivanda

- Ingresar al Canal Horecas más importante de Lima y Callao

- Ingresar al Canal Especialistas (Licorerías)

- Ingresar al canal mayorista de Lima y Callao.

-Establecer programas de incentivos para vendedores.

- Capacitación a los distribuidores y canales. 


\subsubsection{Estrategia de comunicación}

La estrategia de comunicación se basará en 2 tipos de canales:

\section{A) Offline}

- Implementar Soporte de material POP en los puntos de ventas

- Implementar Acciones BTL para generar un mayor impacto en el punto de venta

- Implementar un plan de comunicación con los canales de venta.

- Recopilar información para mantenernos informados de todas las tendencias del target

\section{B) Online}

- Recopilar información para mantenernos informados de todas las tendencias y gustos del target

-Utilizar las redes sociales para comunicarnos directamente con nuestro público, generar prospectos y gestionar la atención al cliente.

- Generar una página web mediante la cual puedan obtener información de la empresa, promociones, novedades y del producto

- Utilizar KOL's para reforzar el concepto de la marca.

- Implementar un programa de fidelización para generar la recompra del producto.

El mensaje a comunicar en toda la campaña de publicidad será: "Eleva tu bandera, marca tu camino" 


\section{CAPITULO VII: EJECUCION DE LA ESTRATEGIA}

En este capítulo se definirán los planes de acción para cada una de las estrategias planteadas. Asimismo; se indicarán los responsables, el plazo, los costos de cada acción y los indicadores de control para las acciones planteadas.

\subsection{Plan de acciones}

Se presentan los planes de acción en el orden en que se plantearon las estrategias para el presente Plan de Marketing.

Las tareas de los diferentes planes de acción se describirán en el anexo $\mathrm{N}^{\circ} 11$

\subsubsection{Planes de acción de producto}

\begin{tabular}{|c|c|c|c|c|c|c|}
\hline Decisión & Código & Acciones & Responsable & Plazo & $\begin{array}{l}\text { Costo en } \\
\$\end{array}$ & Kpi \\
\hline \multirow{4}{*}{$\begin{array}{c}\text { P1 } \\
\text { Introducir } \\
\text { una nueva } \\
\text { presentación } \\
\text { de la botella }\end{array}$} & P1.1 & $\begin{array}{l}\text { Evaluar a través de la } \\
\text { investigación } \\
\text { cualitativa la } \\
\text { aceptación de } \\
\text { presentaciones de } \\
\text { botellas de menor y } \\
\text { mayor volumen que la } \\
\text { presentación actual de } \\
750 \text { ml }\end{array}$ & \multirow{4}{*}{$\begin{array}{c}\text { Gerencia } \\
\text { comercial/Jefe } \\
\text { de producto }\end{array}$} & Agosto & 500 & \multirow{4}{*}{$\begin{array}{l}\text { Nivel de aceptación } \\
\text { de nueva } \\
\text { presentación. }\end{array}$} \\
\hline & P.1.2 & $\begin{array}{l}\text { Luego de la } \\
\text { investigación } \\
\text { cualitativa se realizará } \\
\text { y presentará un informe } \\
\text { de resultados de } \\
\text { evaluación, con } \\
\text { presentación final de } \\
\text { botella seleccionada. }\end{array}$ & & $\begin{array}{c}2^{\mathrm{a}} \text { semana } \\
\text { Octubre }\end{array}$ & & \\
\hline & P.1.3 & $\begin{array}{l}\text { Comunicar a todas las } \\
\text { áreas de nueva } \\
\text { presentación a lanzar, } \\
\text { mediante medios } \\
\text { informáticos. }\end{array}$ & & $\begin{array}{c}3^{\mathrm{a}} \text { semana } \\
\text { Octubre }\end{array}$ & & \\
\hline & P.1.4 & $\begin{array}{l}\text { Realizar la presentación } \\
\text { a los canales del nuevo } \\
\text { tamaño de la botella. }\end{array}$ & & Noviembre & 300 & \\
\hline
\end{tabular}




\begin{tabular}{|c|c|c|c|c|c|c|}
\hline Decisión & Código & Acciones & Responsable & Plazo & $\begin{array}{c}\text { Costo en } \\
\$\end{array}$ & Kpi \\
\hline \multirow{3}{*}{$\begin{array}{l}\text { P2 Evaluar } \\
\text { el diseño de } \\
\text { la botella del } \\
\text { producto }\end{array}$} & P.2.1 & $\begin{array}{l}\text { Realizar focus de } \\
\text { diseño actual de botella } \\
\text { y tapas, presentando } \\
\text { diseños alternativos. } \\
\text { Los diseños serán } \\
\text { provistos por los } \\
\text { proveedores de } \\
\text { botellas. }\end{array}$ & \multirow{3}{*}{$\begin{array}{c}\text { Gerencia } \\
\text { comercial/Jefe } \\
\text { de producto. }\end{array}$} & Marzo & 500 & \multirow{3}{*}{$\begin{array}{l}\text { Nivel de aceptación } \\
\text { de nuevo diseño. }\end{array}$} \\
\hline & $\mathrm{P} 2.2$ & $\begin{array}{l}\text { Luego de la } \\
\text { investigación } \\
\text { cualitativa se realizará } \\
\text { y presentará un informe } \\
\text { de resultados de } \\
\text { evaluación, con el } \\
\text { nuevo diseño de botella } \\
\text { seleccionado. }\end{array}$ & & $\begin{array}{l}2^{\mathrm{a}} \text { semana } \\
\text { Abril }\end{array}$ & & \\
\hline & $\mathrm{P} 2.3$ & $\begin{array}{l}\text { Comunicar a todas las } \\
\text { áreas el resultado de la } \\
\text { evaluación, mediante } \\
\text { medios informáticos. }\end{array}$ & & $\begin{array}{c}3^{\mathrm{a}} \text { semana } \\
\text { Abril. }\end{array}$ & & \\
\hline
\end{tabular}

\begin{tabular}{|c|c|c|c|c|c|c|}
\hline Decisión & Código & Acciones & Responsable & Plazo & $\begin{array}{c}\text { Costo en } \\
\$\end{array}$ & Kpi \\
\hline \multirow{4}{*}{$\begin{array}{c}\text { P3 Mejorar } \\
\text { el } \\
\text { etiquetado }\end{array}$} & P3.1 & $\begin{array}{l}\text { Rediseñar etiquetas de } \\
\text { producto con diseñador } \\
\text { freelance, teniendo en } \\
\text { consideración las } \\
\text { sugerencias de } \\
\text { investigación de } \\
\text { mercado realizada en la } \\
\text { evaluación del } \\
\text { producto. }\end{array}$ & \multirow[t]{4}{*}{$\begin{array}{c}\text { Gerencia } \\
\text { Comercial/Jefe } \\
\text { de Producto }\end{array}$} & Enero & 200 & \multirow[t]{4}{*}{$\begin{array}{l}\text { Nivel de aceptación } \\
\text { de nueva etiqueta. }\end{array}$} \\
\hline & P3.2 & $\begin{array}{l}\text { Realizar la evaluación } \\
\text { de aceptación de } \\
\text { nuevas etiquetas }\end{array}$ & & Febrero & 500 & \\
\hline & P3.3 & $\begin{array}{l}\text { Presentar informe de } \\
\text { resultados de } \\
\text { evaluación. }\end{array}$ & & $\begin{array}{c}3^{\mathrm{a}} \text { semana } \\
\text { Febrero }\end{array}$ & & \\
\hline & P3.4 & $\begin{array}{l}\text { Comunicar a todas las } \\
\text { áreas el nuevo diseño } \\
\text { de las etiquetas, } \\
\text { mediante medios } \\
\text { informáticos. }\end{array}$ & & Marzo & & \\
\hline
\end{tabular}




\begin{tabular}{|c|c|l|l|l|}
\hline P3.5 & $\begin{array}{l}\text { Agotar stock de } \\
\text { botellas con antiguas } \\
\text { etiquetas. }\end{array}$ & Abril & $\begin{array}{l}\text { Comunicar al mercado } \\
\text { el diseño de las nuevas } \\
\text { etiquetas, mediante } \\
\text { comunicación on line y } \\
\text { off line. }\end{array}$ & $\begin{array}{l}1^{\text {a }} \text { semana } \\
\text { Junio }\end{array}$ \\
\hline
\end{tabular}

\begin{tabular}{|c|c|c|c|c|c|c|}
\hline Decisión & Código & Acciones & Responsable & Plazo & $\begin{array}{c}\text { Costo en } \\
\$\end{array}$ & Kpi \\
\hline \multirow{2}{*}{$\begin{array}{l}\text { P4 Evaluar } \\
\text { el nombre } \\
\text { del } \\
\text { Producto }\end{array}$} & P4.1 & $\begin{array}{l}\text { Realizar estudio } \\
\text { cualitativo y } \\
\text { cuantitativo de nombre } \\
\text { del producto y } \\
\text { ocasiones de consumo. }\end{array}$ & \multirow[t]{2}{*}{$\begin{array}{c}\text { Gerencia } \\
\text { Comercial/Jefe } \\
\text { de Producto }\end{array}$} & $\begin{array}{l}\text { Octubre- } \\
2^{\mathrm{a}} \text { semana } \\
\text { Noviembre }\end{array}$ & 500 & \multirow[t]{2}{*}{ Informe final } \\
\hline & P4.2 & $\begin{array}{l}\text { Presentar informe con } \\
\text { los resultados obtenidos } \\
\text { de la evaluación. }\end{array}$ & & $\begin{array}{l}4^{\mathrm{a}} \text { semana } \\
\text { Noviembre }\end{array}$ & & \\
\hline
\end{tabular}

\subsubsection{Planes de acción de precio}

\begin{tabular}{|c|c|c|c|c|c|c|}
\hline Decisión & Código & Acciones & Responsable & Plazo & Costo, $\$$ & Kpi \\
\hline \multirow{4}{*}{$\begin{array}{l}\text { PX 1 Evaluar } \\
\text { periódicamente } \\
\text { los precios de } \\
\text { venta al } \\
\text { público de la } \\
\text { competencia }\end{array}$} & PX 1.1 & $\begin{array}{l}\text { Elegir a la } \\
\text { empresa que } \\
\text { realizara los } \\
\text { tracking de precios } \\
\text { trimestrales }\end{array}$ & \multirow{2}{*}{$\begin{array}{c}\text { Jefe } \\
\text { Comercial/Gerente } \\
\text { General }\end{array}$} & Enero & & $\begin{array}{l}\text { Contratación de } \\
\text { empresa de } \\
\text { investigación }\end{array}$ \\
\hline & PX 1.2 & $\begin{array}{l}\text { Determinar el } \\
\text { canal o canales en } \\
\text { los que se realizara } \\
\text { el tracking de } \\
\text { precios }\end{array}$ & & $\begin{array}{l}\text { 2da semana de } \\
\text { Enero } 2018\end{array}$ & & $\begin{array}{l}\text { Puntos para } \\
\text { determinar } \\
\text { canal elegido }\end{array}$ \\
\hline & PX 1.3 & $\begin{array}{l}\text { Realizar Tracking } \\
\text { de precios }\end{array}$ & $\begin{array}{c}\text { Jefe de } \\
\text { Producto/Empresa } \\
\text { Investigación de } \\
\text { mercados }\end{array}$ & Trimestralmente & 6,000 & $\begin{array}{l}\text { Cumplir con el } \\
\text { cronograma }\end{array}$ \\
\hline & PX 1.4 & $\begin{array}{l}\text { Revisión de } \\
\text { resultados de } \\
\text { tracking de precios }\end{array}$ & $\begin{array}{c}\text { Gerente } \\
\text { General/Jefe de } \\
\text { Administración y } \\
\text { Finanzas/Jefe } \\
\text { Comercial }\end{array}$ & $\begin{array}{l}1 \text { semana luego } \\
\text { de recibir } \\
\text { informe }\end{array}$ & & $\begin{array}{l}\text { Puntos claves a } \\
\text { medir en el } \\
\text { informe } \\
\text { recibido }\end{array}$ \\
\hline
\end{tabular}




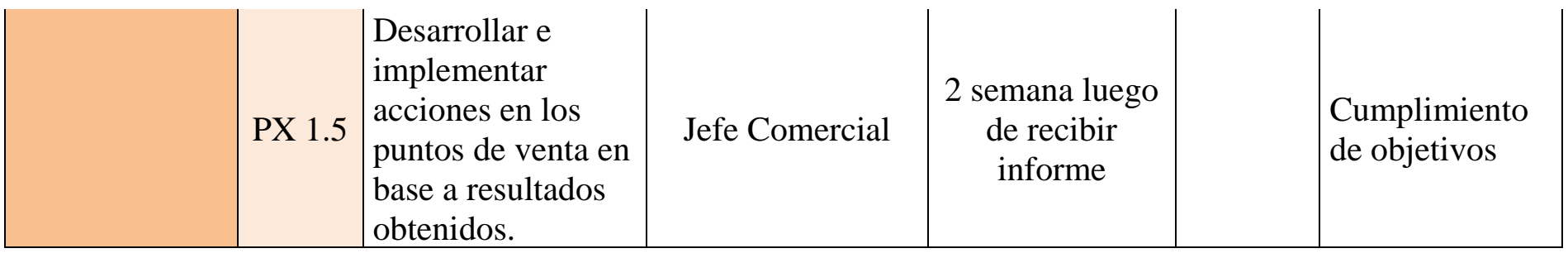

\begin{tabular}{|c|c|c|c|c|c|c|}
\hline Decisión & Código & Acciones & Responsable & Plazo & Costo, \$ & Kpi \\
\hline \multirow{3}{*}{$\begin{array}{c}\text { PX } 2 \\
\text { Implementar } \\
\text { política de } \\
\text { pagos clara } \\
\text { para cada } \\
\text { canal de } \\
\text { venta. }\end{array}$} & PX 2.1 & $\begin{array}{l}\text { Desarrollar la } \\
\text { política de pagos } \\
\text { para cada canal } \\
\text { de venta }\end{array}$ & \multirow{3}{*}{$\begin{array}{c}\text { Gerente } \\
\text { General/Jefe de } \\
\text { Administración y } \\
\text { Finanzas/Jefe } \\
\text { Comercial }\end{array}$} & Enero & & $\begin{array}{l}\text { Determinar puntos } \\
\text { clave a incluir en la } \\
\text { política }\end{array}$ \\
\hline & PX 2.2 & $\begin{array}{l}\text { Comunicar la } \\
\text { política } \\
\text { desarrollada a } \\
\text { toda la } \\
\text { organización con } \\
\text { énfasis en el } \\
\text { equipo } \\
\text { comercial }\end{array}$ & & $\begin{array}{c}2 \text { da } \\
\text { semana } \\
\text { de } \\
\text { febrero } \\
2018\end{array}$ & & \multirow[t]{2}{*}{$\begin{array}{l}\text { Recepción del } \\
\text { informe de nueva } \\
\text { política de pagos. }\end{array}$} \\
\hline & PX 2.3 & $\begin{array}{l}\text { Comunicar la } \\
\text { política } \\
\text { desarrollada a } \\
\text { todos los } \\
\text { clientes }\end{array}$ & & $\begin{array}{c}\text { 3ra } \\
\text { semana } \\
\text { de } \\
\text { febrero } \\
2018\end{array}$ & & \\
\hline
\end{tabular}

\begin{tabular}{|c|c|c|c|c|c|c|}
\hline Decisión & Código & Acciones & Responsable & Plazo & Costo en \$ & Kpi \\
\hline \multirow[b]{2}{*}{$\begin{array}{c}\text { PX } 3 \\
\text { Evaluación } \\
\text { de créditos } \\
\text { trimestrales } \\
\text { para } \\
\text { clientes }\end{array}$} & PX 3.1 & $\begin{array}{l}\text { Desarrollar la } \\
\text { política de } \\
\text { créditos de la } \\
\text { compañía. }\end{array}$ & $\begin{array}{c}\text { Gerente } \\
\text { General/Jefe de } \\
\text { Administración y } \\
\text { Finanzas }\end{array}$ & Enero & & \multirow[b]{2}{*}{$\begin{array}{l}\text { Recepción del } \\
\text { informe de } \\
\text { nueva política de } \\
\text { créditos. }\end{array}$} \\
\hline & PX 3.2 & $\begin{array}{l}\text { Comunicar la } \\
\text { política } \\
\text { desarrollada a } \\
\text { toda la } \\
\text { organización } \\
\text { con énfasis en } \\
\text { el equipo } \\
\text { comercial }\end{array}$ & Jefe de Producto & $\begin{array}{l}\text { 2da semana de } \\
\text { febrero } 2018\end{array}$ & & \\
\hline
\end{tabular}




\begin{tabular}{|c|l|l|l|l|} 
PX 3.3 & $\begin{array}{l}\text { Comunicar la } \\
\text { política } \\
\text { desarrollada a } \\
\text { todos los } \\
\text { clientes }\end{array}$ & Jefe de Producto & $\begin{array}{l}\text { 3ra semana de } \\
\text { febrero 2018 }\end{array}$ & \\
\hline PX 3.4 & $\begin{array}{l}\text { Realizar la } \\
\text { evaluación de } \\
\text { créditos para } \\
\text { cada cliente. }\end{array}$ & $\begin{array}{l}\text { Gerente de } \\
\text { Finanzas }\end{array}$ & Trimestralmente & \\
\hline
\end{tabular}

\begin{tabular}{|c|c|c|c|c|c|c|}
\hline Decisión & Código & Acciones & Responsable & Plazo & $\begin{array}{c}\text { Costo en } \\
\$\end{array}$ & Kpi \\
\hline \multirow{3}{*}{$\begin{array}{c}\text { PX } 4 \\
\text { Descuento } \\
\text { sobre precio } \\
\text { de lista para } \\
\text { nuevos } \\
\text { canales. }\end{array}$} & PX 4.1 & $\begin{array}{l}\text { Desarrollar Listas } \\
\text { de Precios para cada } \\
\text { canal de ventas }\end{array}$ & \multirow{3}{*}{$\begin{array}{c}\text { Gerente } \\
\text { General/Jefe de } \\
\text { Administración } \\
\text { y Finanzas/ Jefe } \\
\text { de Producto }\end{array}$} & Enero & & \multirow{3}{*}{$\begin{array}{l}\text { Lista de } \\
\text { precios para } \\
\text { cada canal. }\end{array}$} \\
\hline & PX 4.2 & $\begin{array}{l}\text { Determinar el } \\
\text { "Road to Market" } \\
\text { para cada canal de } \\
\text { ventas }\end{array}$ & & $\begin{array}{c}\text { 3ra semana de } \\
\text { enero } 2018\end{array}$ & & \\
\hline & PX 4.3 & $\begin{array}{l}\text { Comunicar a todo el } \\
\text { equipo comercial de } \\
\text { la organización }\end{array}$ & & $\begin{array}{c}\text { 4ta semana de } \\
\text { enero } 2018\end{array}$ & & \\
\hline
\end{tabular}

\begin{tabular}{|c|c|c|c|c|c|c|}
\hline Decisión & Código & Acciones & Responsable & Plazo & $\begin{array}{c}\text { Costo en } \\
\$\end{array}$ & Kpi \\
\hline \multirow{3}{*}{$\begin{array}{c}\text { PX 5 } \\
\text { Evaluar la } \\
\text { percepción } \\
\text { de valor de } \\
\text { la } \\
\text { competencia } \\
\text { y del } \\
\text { producto }\end{array}$} & PX 5.1 & $\begin{array}{l}\text { Determinar qué } \\
\text { empresa } \\
\text { realizara la } \\
\text { evaluación de la } \\
\text { percepción de } \\
\text { Jolly Roger y } \\
\text { Jagermeister }\end{array}$ & $\begin{array}{l}\text { Gerente General/ } \\
\text { Jefe de Producto }\end{array}$ & Enero & & $\begin{array}{l}\text { Contratación } \\
\text { de empresa de } \\
\text { investigación }\end{array}$ \\
\hline & PX 5.2 & $\begin{array}{l}\text { Desarrollo de las } \\
\text { encuestas para } \\
\text { medir la } \\
\text { percepción de } \\
\text { Jolly Roger y } \\
\text { Jagermeister }\end{array}$ & $\begin{array}{c}\text { Jefe de } \\
\text { Producto/Empresa } \\
\text { Investigación de } \\
\text { mercados }\end{array}$ & $\begin{array}{l}\text { 2da semana } \\
\text { febrero } 2018\end{array}$ & & \multirow{2}{*}{$\begin{array}{c}\text { Informe con } \\
\text { resultado final } \\
\text { de la } \\
\text { evaluación. }\end{array}$} \\
\hline & PX 5.3 & $\begin{array}{l}\text { Realizar la } \\
\text { evaluación de } \\
\text { percepción de } \\
\text { Jolly Roger y } \\
\text { Jagermeister y } \\
\text { medir el nivel de }\end{array}$ & $\begin{array}{c}\text { Empresa } \\
\text { Investigación de } \\
\text { mercados/ Jefe de } \\
\text { Producto }\end{array}$ & Trimestralmente & 6,000 & \\
\hline
\end{tabular}




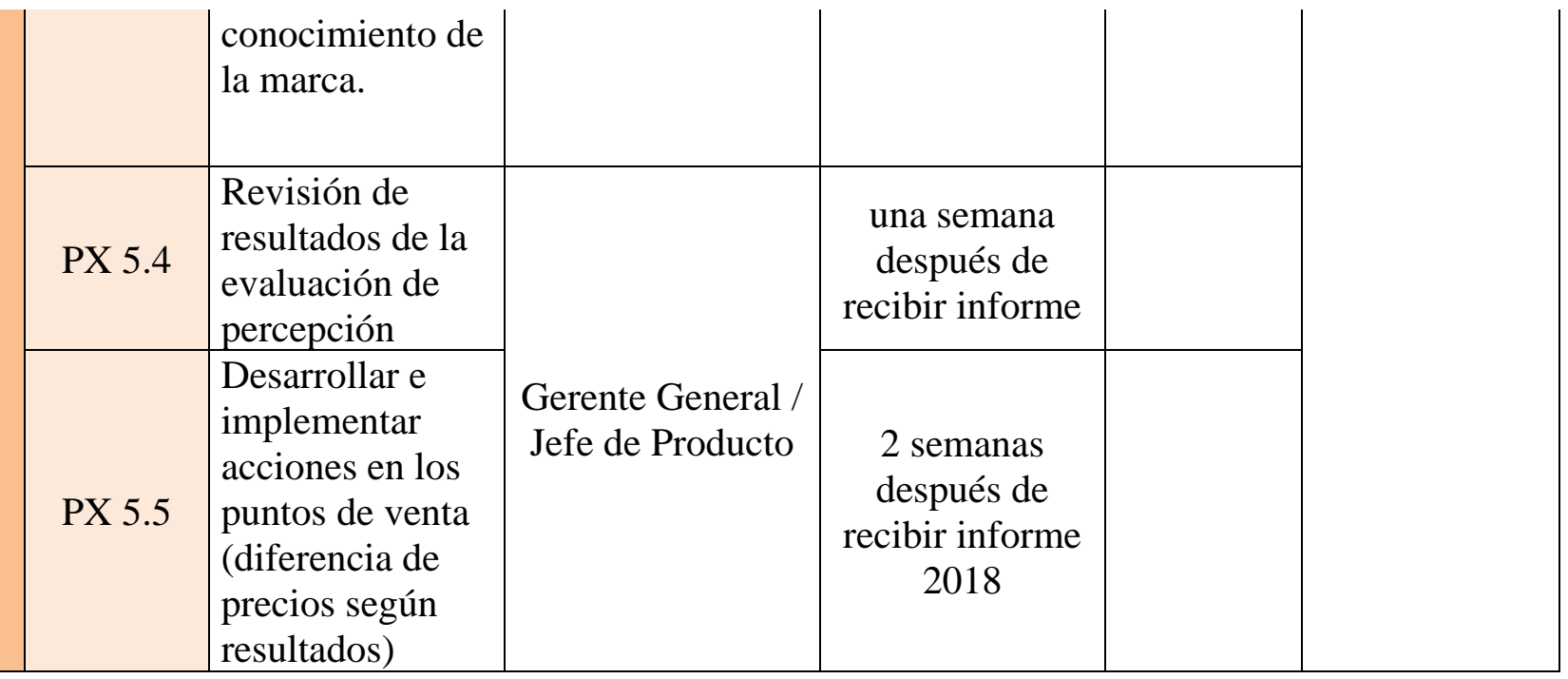

7.1.3. Planes de acción de distribución y ventas

\begin{tabular}{|c|c|c|c|c|c|c|}
\hline Decisión & Código & Acciones & Responsable & Plazo & $\begin{array}{c}\text { Costo en } \\
\$\end{array}$ & Kpi \\
\hline \multirow{4}{*}{$\begin{array}{l}\text { D1.- Reclutar y } \\
\text { Consolidar el } \\
\text { área comercial }\end{array}$} & D1.1 & $\begin{array}{l}\text { Contratar un Caza } \\
\text { Talentos para } \\
\text { encontrar un jefe de } \\
\text { producto }\end{array}$ & $\begin{array}{c}\text { Jefe } \\
\text { Administrativo }\end{array}$ & Enero & 1,000 & $\begin{array}{l}\text { Contratación del } \\
\text { jefe de Producto }\end{array}$ \\
\hline & D1.2 & $\begin{array}{l}\text { Fijar } \\
\text { Responsabilidades } \\
\text { Comerciales y de } \\
\text { Ventas }\end{array}$ & $\begin{array}{l}\text { Jefe } \\
\text { Administrativo }\end{array}$ & Enero & & $\begin{array}{l}\text { Comunicación de } \\
\text { Responsabilidades }\end{array}$ \\
\hline & D1.3 & $\begin{array}{l}\text { Definir zonas de } \\
\text { trabajo y visitas }\end{array}$ & \begin{tabular}{|l|} 
Jefe \\
Producto
\end{tabular} & Enero & & $\begin{array}{ll}\text { Ruteo } \\
\text { responsable }\end{array}$ \\
\hline & D1.4 & $\begin{array}{l}\text { Incorporación de } \\
\text { Fuerza de ventas }\end{array}$ & $\begin{array}{l}\text { Jefe } \\
\text { Administrativo }\end{array}$ & Febrero & & $\begin{array}{l}\text { Contratación de } 1 \\
\text { vendedor }\end{array}$ \\
\hline
\end{tabular}




\begin{tabular}{|c|c|c|c|c|c|c|}
\hline Decisión & Código & Acciones & Responsable & Plazo & Costo en \$ & Kpi \\
\hline \multirow{4}{*}{$\begin{array}{c}\text { D2.- Ingresar a } \\
\text { supermercados } \\
\text { (Wong y } \\
\text { Vivanda) }\end{array}$} & D2.1 & $\begin{array}{l}\text { Presentación } \\
\text { de propuesta } \\
\text { financiera y de } \\
\text { precios a Wong } \\
\text { y Vivanda }\end{array}$ & $\begin{array}{l}\text { Jefe de } \\
\text { Producto }\end{array}$ & Enero & & $\begin{array}{l}\text { Respuesta de } \\
\text { recepción y } \\
\text { aceptación de } \\
\text { propuesta }\end{array}$ \\
\hline & $\mathrm{D} 2.2$ & $\begin{array}{l}\text { Propuesta de } \\
\text { inversión en } \\
\text { Trade } \\
\text { Marketing para } \\
\text { Wong y } \\
\text { Vivanda }\end{array}$ & $\begin{array}{l}\text { Jefe de } \\
\text { Producto }\end{array}$ & $\begin{array}{l}\text { Febrero, } \\
\text { Mayo, } \\
\text { Julio, } \\
\text { Octubre y } \\
\text { Diciembre } \\
\text { del } 2018\end{array}$ & 6,000 & $\begin{array}{l}\text { Respuesta de } \\
\text { recepción de } \\
\text { propuesta de } 1 \text { local } \\
\text { por fecha por cada } \\
\text { autoservicio }\end{array}$ \\
\hline & D2.3 & $\begin{array}{l}\text { Diseño de Plan } \\
\text { de encartes } \\
\text { para Wong y } \\
\text { Vivanda }\end{array}$ & $\begin{array}{ll}\text { Jefe de } \\
\text { Producto }\end{array}$ & Octubre & 1,000 & $\begin{array}{l}\text { Presentación de arte } \\
\text { aprobado por } \\
\text { gerencia }\end{array}$ \\
\hline & D2.4 & $\begin{array}{l}\text { Comunicación } \\
\text { de rebate a } \\
\text { supermercados }\end{array}$ & $\begin{array}{l}\text { Jefe de } \\
\text { Producto }\end{array}$ & Marzo & & $\begin{array}{l}\text { Respuesta de } \\
\text { recepción de } \\
\text { propuesta }\end{array}$ \\
\hline
\end{tabular}

\begin{tabular}{|c|c|c|c|c|c|c|}
\hline Decisión & Código & \multicolumn{1}{|c|}{ Acciones } & Responsable & Plazo & Costo en \$ & \multicolumn{1}{|c|}{ Kpi } \\
\hline D3.1 & $\begin{array}{l}\text { Ruteo para llegar a las } \\
\text { 100 principales } \\
\text { HORECAS de Lima }\end{array}$ & $\begin{array}{c}\text { Jefe de } \\
\text { Producto }\end{array}$ & Febrero & $\begin{array}{l}\text { Ruta } \\
\text { comunicada } \\
\text { a la fuerza } \\
\text { de venta }\end{array}$ \\
\cline { 2 - 7 } D3.- \\
Ingreso a
\end{tabular}




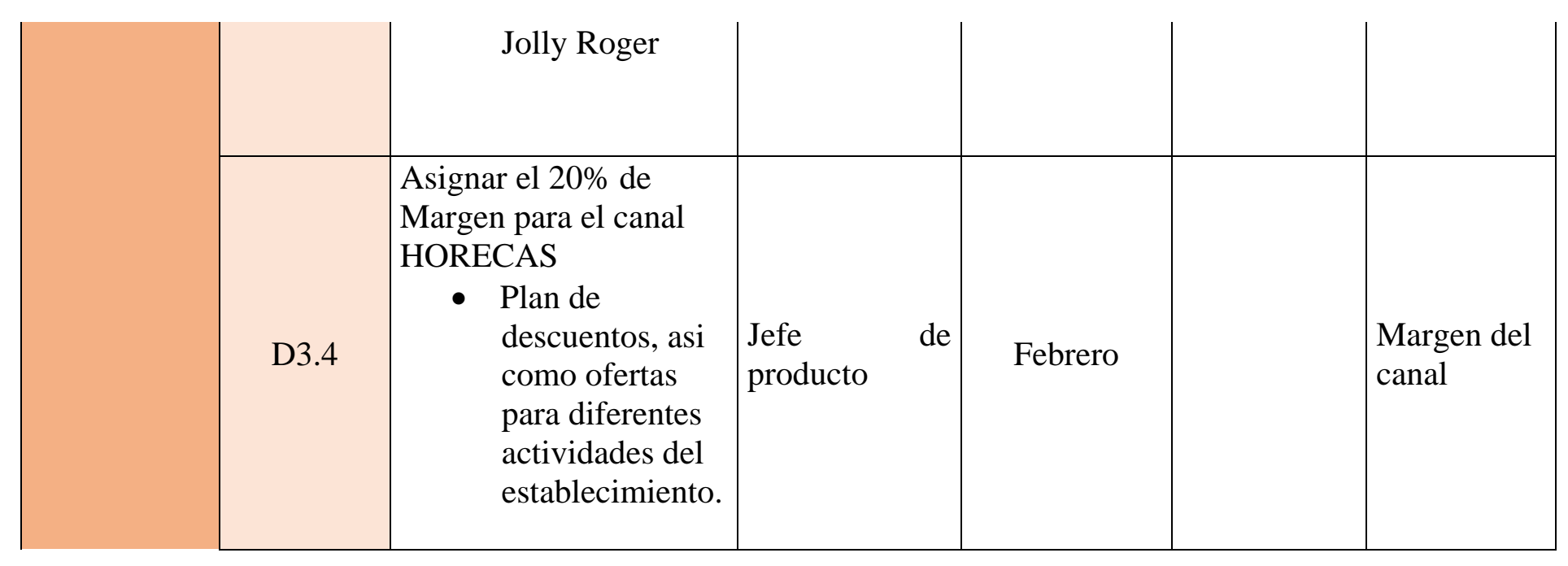

\begin{tabular}{|c|c|c|c|c|c|c|}
\hline Decisión & Código & Acciones & Responsable & Plazo & Costo en \$ & Kpi \\
\hline \multirow[t]{2}{*}{$\begin{array}{l}\text { D4.- Ingreso } \\
\text { a Licorerías }\end{array}$} & D4.1 & $\begin{array}{l}\text { Realizar ruteo de las } \\
20 \text { principales } \\
\text { licorerías de Lima y } \\
\text { Callao } \\
\text { - } \\
\text { Realizar plan } \\
\text { de } \\
\text { degustación y } \\
\text { muestreo del } \\
\text { producto } \\
\text { - Concurso para } \\
\text { los mejores } \\
\text { clientes. }\end{array}$ & Jefe de Producto & Marzo & & $\begin{array}{l}\text { Comunicación } \\
\text { de rutas a la } \\
\text { fuerza de } \\
\text { ventas }\end{array}$ \\
\hline & D4.2 & $\begin{array}{l}\text { Fijar un Margen } \\
\text { promedio de } 20 \% \\
\text { para licorerías }\end{array}$ & Jefe de Producto & Marzo & & $\begin{array}{l}\text { Margen del } \\
\text { canal }\end{array}$ \\
\hline
\end{tabular}

\begin{tabular}{|c|c|c|c|c|c|c|}
\hline Decisión & Código & \multicolumn{1}{|c|}{ Acciones } & Responsable & Plazo & Costo en \$ & \multicolumn{1}{|c|}{ Kpi } \\
\hline D5.1 & $\begin{array}{l}\text { Realizar ruteo de las } \\
5 \text { principales } \\
\text { mayoristas de Lima y } \\
\text { Callao }\end{array}$ & Jefe de producto & Abril & $\begin{array}{l}\text { Comunicación } \\
\text { de rutas al } \\
\text { área } \\
\text { comercial }\end{array}$ \\
\cline { 2 - 6 } D5.- Ingreso \\
a Mayoristas & $\begin{array}{l}\text { Asignar el 8\% de Mg } \\
\text { a los mayoristas } \\
\text { D5.2 } \\
\text { Plan de } \\
\text { capacitación } \\
\text { para los } \\
\text { clientes. } \\
\text { Entrega de } \\
\text { bonos por } \\
\text { monto de } \\
\text { compra. }\end{array}$ & Jefe de Producto & Enero & Margen del \\
canal
\end{tabular}




\begin{tabular}{|c|c|c|c|c|c|c|}
\hline Decisión & Código & Acciones & Responsable & Plazo & Costo en \$ & Kpi \\
\hline $\begin{array}{c}\text { D6.- Fijar } \\
\text { incentivos } \\
\text { para } \\
\text { vendedor y } \\
\begin{array}{c}\text { Jefe de } \\
\text { Producto }\end{array}\end{array}$ & D6.1 & $\begin{array}{l}\text { Comunicar incentivos } \\
\text { a los responsables de } \\
\text { Jolly Roger }\end{array}$ & Jefe de Producto & Diciembre & 2,780 & $\begin{array}{l}\text { Establecer } \\
\text { reglas de } \\
\text { comisiones y } \\
\text { fijar objetivos }\end{array}$ \\
\hline
\end{tabular}

\begin{tabular}{|c|c|l|c|c|c|c|}
\hline Decisión & Código & \multicolumn{1}{|c|}{ Acciones } & Responsable & Plazo & Costo en \$ & Kpi \\
\hline $\begin{array}{c}\text { D7.- } \\
\begin{array}{c}\text { Capacitación } \\
\text { a los canales } \\
\text { de venta }\end{array}\end{array}$ & D7.1 & $\begin{array}{l}\text { Establecer una } \\
\text { capacitación } \\
\text { bimestral a los } \\
\text { canales de venta } \\
\text { horecas, licorería y } \\
\text { mayoristas }\end{array}$ & Jefe de Producto & Bimestral & 2,000 & $\begin{array}{l}\text { Certificado de } \\
\text { asistencia a la } \\
\text { capacitación }\end{array}$ \\
\cline { 2 - 6 } & D7.2 & $\begin{array}{l}\text { Alianza con Escuela } \\
\text { de Bartenders para } \\
\text { capacitar canal } \\
\text { HORECAS }\end{array}$ & Jefe de Producto & Mayo & 45 & $\begin{array}{l}\text { Certificado de } \\
\text { escuela de } \\
\text { Barman }\end{array}$ \\
\hline
\end{tabular}

\subsubsection{Planes de acción de comunicación}

\begin{tabular}{|c|c|c|c|c|c|c|}
\hline \multicolumn{7}{|c|}{ Acciones Offline } \\
\hline Decisión & Código & Acciones & Responsable & Plazo & $\begin{array}{c}\text { Costo } \\
\text { en } \$\end{array}$ & Kpi \\
\hline \multirow{4}{*}{$\begin{array}{c}\text { C 1 } \\
\text { Implementar } \\
\text { Soporte de } \\
\text { material POP } \\
\text { en los puntos } \\
\text { de ventas }\end{array}$} & C1.1 & $\begin{array}{l}\text { Diseñar e imprimir } \\
5,720 \text { folletos y } 143 \\
\text { posters con el mensaje } \\
\text { de la marca y el } \\
\text { producto. }\end{array}$ & $\begin{array}{l}\text { Jefe de } \\
\text { Producto }\end{array}$ & Enero & $\$ 250$ & $\begin{array}{c}\text { Material físico } \\
\text { en stock }\end{array}$ \\
\hline & C 1.2 & $\begin{array}{l}\text { Distribuir los folletos, } \\
\text { poster y mostradores a } \\
143 \text { a los distintos } \\
\text { puntos de venta. }\end{array}$ & \multirow{3}{*}{$\begin{array}{l}\text { Jefe de } \\
\text { Producto }\end{array}$} & $\begin{array}{l}\text { Primera } \\
\text { semana } \\
\text { Febrero }\end{array}$ & $\$ 300$ & $\begin{array}{c}\text { Material físico } \\
\text { en tienda }\end{array}$ \\
\hline & C 1.3 & $\begin{array}{l}\text { Agendar reuniones con } \\
\text { los gerentes de los } \\
\text { canales de venta para la } \\
\text { exposición del plan a } \\
\text { realizar }\end{array}$ & & $\begin{array}{c}\text { Primera } \\
\text { semana } \\
\text { Enero }\end{array}$ & & $\begin{array}{l}\text { Reuniones } \\
\text { pactadas }\end{array}$ \\
\hline & C 1.4 & $\begin{array}{l}\text { Exponer el plan y } \\
\text { estrategia de } \\
\text { merchandising }\end{array}$ & & $\begin{array}{l}\text { Segunda, } \\
\text { tercera y } \\
\text { cuarta } \\
\text { semana de }\end{array}$ & & $\begin{array}{c}\text { Comunicación } \\
\text { de plan de } \\
\text { ventas al } \\
\text { canal. }\end{array}$ \\
\hline
\end{tabular}




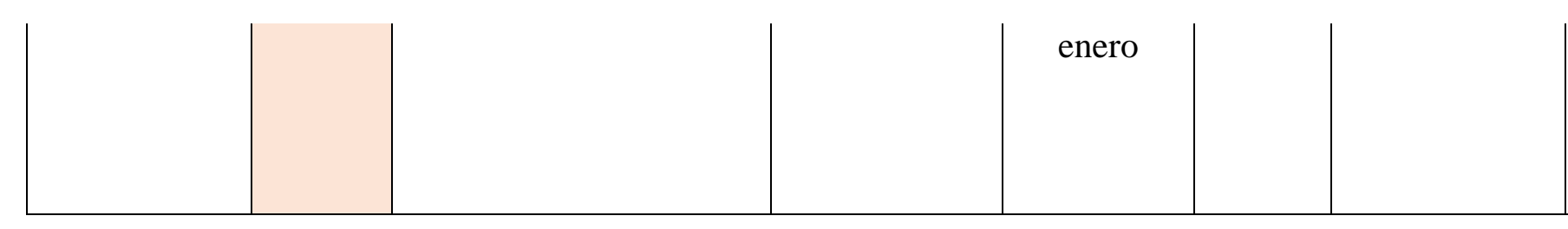

\begin{tabular}{|c|c|c|c|c|c|c|}
\hline \multicolumn{7}{|c|}{ Acciones Offline } \\
\hline Decisión & Código & Acciones & Responsable & Plazo & $\begin{array}{c}\text { Costo } \\
\text { en } \$\end{array}$ & Kpi \\
\hline \multirow{6}{*}{$\begin{array}{c}\text { C } 2 \\
\text { Implementar } \\
\text { Acciones } \\
\text { BTL para } \\
\text { generar un } \\
\text { mayor } \\
\text { impacto en el } \\
\text { punto de } \\
\text { venta }\end{array}$} & C 2.1 & $\begin{array}{l}\text { Realizar el plan de } \\
\text { acción BTL para cada } \\
\text { canal de venta. }\end{array}$ & \multirow{5}{*}{$\begin{array}{l}\text { Jefe de } \\
\text { Producto }\end{array}$} & $\begin{array}{l}\text { Tercera y } \\
\text { cuarta } \\
\text { semana de } \\
\text { enero }\end{array}$ & & \\
\hline & C 2.2 & $\begin{array}{l}\text { Contratar de } 1 \text { a } 2 \\
\text { anfitrionas para cada } \\
\text { acción BTL }\end{array}$ & & $\begin{array}{c}\text { Marzo, } \\
\text { Abril, } \\
\text { Julio, } \\
\text { Octubre y } \\
\text { Diciembre }\end{array}$ & $\$ 1200$ & $\begin{array}{l}\text { Contrato para } \\
\text { anfitrionas }\end{array}$ \\
\hline & C 2.3 & $\begin{array}{l}\text { Comprar material de } \\
\text { apoyo: } 200 \text { Gorras, } 200 \\
\text { Polos, } 300 \text { llaveros, } 500 \\
\text { vasos que será repartido } \\
\text { en las acciones BTL. }\end{array}$ & & $\begin{array}{c}\text { Cuarta } \\
\text { semana } \\
\text { Enero }\end{array}$ & $\$ 117$ & $\begin{array}{l}\text { Material físico } \\
\text { en tienda }\end{array}$ \\
\hline & C 2.4 & $\begin{array}{l}\text { Contratar movilidad } \\
\text { para el transporte de } \\
\text { todo el material de } \\
\text { apoyo }\end{array}$ & & Febrero & $\$ 220$ & $\begin{array}{l}\text { Número de } \\
\quad \text { viajes } \\
\text { contratado }\end{array}$ \\
\hline & C 2.5 & $\begin{array}{c}\text { Disponer de productos } \\
\text { para degustación para } \\
\text { cada acción BTL. }\end{array}$ & & $\begin{array}{c}\text { Marzo, } \\
\text { Abril, } \\
\text { Julio, } \\
\text { Octubre y } \\
\text { Diciembre }\end{array}$ & $\$ 1,350$ & $\begin{array}{l}\text { Productos en } \\
\text { el punto de } \\
\text { venta }\end{array}$ \\
\hline & C 2.6 & $\begin{array}{l}\text { Ejecutar los planes de } \\
\text { acción BTL }\end{array}$ & $\begin{array}{l}\text { Jefe de } \\
\text { Producto }\end{array}$ & $\begin{array}{c}\text { Marzo, } \\
\text { Abril, } \\
\text { Julio, } \\
\text { Octubre y } \\
\text { Diciembre }\end{array}$ & & \\
\hline
\end{tabular}




\begin{tabular}{|c|c|c|c|c|c|c|}
\hline \multicolumn{7}{|c|}{ Acciones Offline } \\
\hline Decisión & Código & Acciones & Responsable & Plazo & $\begin{array}{c}\text { Costo } \\
\text { en } \$\end{array}$ & Kpi \\
\hline \multirow{3}{*}{$\begin{array}{c}\text { C } 3 \\
\text { Implementar } \\
\text { un plan de } \\
\text { comunicación } \\
\text { con los } \\
\text { canales de } \\
\text { venta. }\end{array}$} & C 3.1 & $\begin{array}{l}\text { Generar una política de } \\
\text { comunicación para los } \\
\text { canales de venta }\end{array}$ & \multirow{3}{*}{$\begin{array}{c}\text { Jefe de } \\
\text { Comunicación }\end{array}$} & $\begin{array}{l}\text { Enero y } \\
\text { Febrero }\end{array}$ & & \\
\hline & C 3.2 & $\begin{array}{l}\text { Agendar una reunión } \\
\text { con los } 10 \text { gerentes de } \\
\text { los diferentes canales de } \\
\text { venta }\end{array}$ & & Febrero & & \\
\hline & C 3.3 & $\begin{array}{l}\text { Exponer el plan de } \\
\text { comunicación a los } 10 \\
\text { gerentes de los } \\
\text { diferentes canales } \\
\text { de venta }\end{array}$ & & $\begin{array}{l}\text { Tercera y } \\
\text { cuarta } \\
\text { semana de } \\
\text { febrero }\end{array}$ & & $\begin{array}{l}\text { Número de } \\
\text { presentaciones }\end{array}$ \\
\hline
\end{tabular}

\begin{tabular}{|c|c|c|c|c|c|c|}
\hline \multicolumn{7}{|c|}{ Acciones Online } \\
\hline Decisión & Código & Acciones & Responsable & Plazo & $\begin{array}{c}\text { Costo } \\
\text { en } \$\end{array}$ & Kpi \\
\hline \multirow{2}{*}{$\begin{array}{l}\text { C } 4 \text { Recopilar } \\
\text { información } \\
\text { para } \\
\text { mantenernos } \\
\text { informados } \\
\text { de todas las } \\
\text { tendencias y } \\
\text { gustos del } \\
\text { target }\end{array}$} & C 4.1 & $\begin{array}{l}\text { Realizar Benchmarks } \\
\text { diariamente el cual } \\
\text { analice la situación } \\
\text { actual de la competencia } \\
\text { y el mercado }\end{array}$ & \multirow{2}{*}{$\begin{array}{l}\text { Jefe de } \\
\text { Producto }\end{array}$} & $\begin{array}{l}\text { De Marzo } \\
\text { a diciembre }\end{array}$ & & $\begin{array}{l}\text { Número de } \\
\text { reportes }\end{array}$ \\
\hline & C 4.2 & $\begin{array}{l}\text { Comprar estudios de } \\
\text { mercado de IAB, IMS y } \\
\text { Quántico } \\
\text { bimestralmente para } \\
\text { mantenerse informado } \\
\text { sobre la industria. }\end{array}$ & & $\begin{array}{c}\text { Marzo, } \\
\text { Mayo, } \\
\text { Julio, } \\
\text { Setiembre, } \\
\text { Noviembre }\end{array}$ & 1,800 & \\
\hline
\end{tabular}




\begin{tabular}{|c|c|c|c|c|c|c|}
\hline \multicolumn{7}{|c|}{ Acciones Online } \\
\hline Decisión & Código & Acciones & Responsable & Plazo & $\begin{array}{c}\text { Costo } \\
\text { en } \$\end{array}$ & Kpi \\
\hline \multirow{6}{*}{$\begin{array}{l}\text { C } 5 \text { Utilizar } \\
\text { las redes } \\
\text { sociales para } \\
\text { comunicarnos } \\
\text { directamente } \\
\text { con nuestro } \\
\text { público, } \\
\text { generar } \\
\text { prospectos y } \\
\text { gestionar la } \\
\text { atención al } \\
\text { cliente. }\end{array}$} & C 5.1 & $\begin{array}{l}\text { Contratar agencia } \\
\text { publicitaria. Crear } \\
\text { página web y cuentas en } \\
\text { cada una las redes } \\
\text { sociales más usadas en } \\
\text { Lima y Callao: } \\
\text { Instagram y YouTube }\end{array}$ & \multirow{6}{*}{$\begin{array}{l}\text { Jefe de } \\
\text { Producto }\end{array}$} & $\begin{array}{l}\text { Primera } \\
\text { semana de } \\
\text { Enero }\end{array}$ & \multirow{5}{*}{10,000} & \\
\hline & C 5.2 & $\begin{array}{l}\text { Generar } 6 \text { contenidos } \\
\text { mensualmente para } \\
\text { Facebook e Instagram }\end{array}$ & & $\begin{array}{l}\text { De Enero a } \\
\text { Noviembre }\end{array}$ & & $\begin{array}{c}\text { Publicaciones } \\
\text { al mes. }\end{array}$ \\
\hline & C 5.3 & $\begin{array}{l}\text { Mantener un nivel de } \\
\text { respuesta rápida en las } \\
\text { redes sociales, en } \\
\text { promedio de } 1 \text { hora. }\end{array}$ & & $\begin{array}{l}\text { De Enero a } \\
\text { Diciembre }\end{array}$ & & \multirow{2}{*}{$\begin{array}{c}\% \text { de tiempo } \\
\text { respuesta }\end{array}$} \\
\hline & C 5.4 & $\begin{array}{l}\text { Atender consultas y } \\
\text { quejas, en promedio de } \\
1 \text { hora. }\end{array}$ & & $\begin{array}{l}\text { De Enero a } \\
\text { Diciembre }\end{array}$ & & \\
\hline & C 5.5 & $\begin{array}{l}\text { Comunicar las } \\
\text { promociones y } \\
\text { próximos eventos a } \\
\text { realizarse en las redes } \\
\text { sociales. }\end{array}$ & & $\begin{array}{c}\text { Marzo, } \\
\text { Mayo, } \\
\text { Julio, } \\
\text { Setiembre, } \\
\text { Noviembre }\end{array}$ & & \\
\hline & C 5.6 & $\begin{array}{l}\text { Invertir en publicidad } \\
\text { pagada en Facebook con } \\
\text { el objetivo de generar } \\
\text { un mayor alcance. }\end{array}$ & & $\begin{array}{l}\text { De febrero } \\
\text { a } \\
\text { Diciembre }\end{array}$ & 5,880 & $\begin{array}{l}\text { Número de } \\
\text { publicaciones } \\
\text { con pauta. }\end{array}$ \\
\hline
\end{tabular}

\begin{tabular}{|c|c|c|c|c|c|c|}
\hline \multicolumn{7}{|c|}{ Acciones Online } \\
\hline Decisión & Código & Acciones & Responsable & Plazo & $\begin{array}{c}\text { Costo } \\
\text { en } \$\end{array}$ & Kpi \\
\hline \multirow{3}{*}{$\begin{array}{l}\text { C } 6 \text { Crear una } \\
\text { página web }\end{array}$} & C 6.1 & $\begin{array}{l}\text { Programar la web de la } \\
\text { marca. }\end{array}$ & \multirow{3}{*}{$\begin{array}{l}\text { Jefe de } \\
\text { Producto }\end{array}$} & Enero & & $\begin{array}{l}\text { Página Web } \\
\text { creada. }\end{array}$ \\
\hline & C 6.2 & $\begin{array}{l}\text { Comprar el dominio y } \\
\text { servidor. }\end{array}$ & & $\begin{array}{c}\text { Segunda } \\
\text { semana de } \\
\text { Enero }\end{array}$ & 50 & $\begin{array}{l}\text { Número de } \\
\text { servidores }\end{array}$ \\
\hline & С 6.3 & $\begin{array}{l}\text { Implementar estrategia } \\
\text { de SEO }\end{array}$ & & Enero & & \\
\hline
\end{tabular}




\begin{tabular}{|c|c|c|c|c|c|c|}
\hline \multicolumn{7}{|c|}{ Acciones Online } \\
\hline Decisión & Código & Acciones & Responsable & Plazo & $\begin{array}{c}\text { Costo } \\
\text { en } \$\end{array}$ & Kpi \\
\hline \multirow{4}{*}{$\begin{array}{l}\text { C } 7 \text { Utilizar } \\
\text { KOL's para } \\
\text { reforzar el } \\
\text { concepto de } \\
\text { la marca. }\end{array}$} & C 7.1 & $\begin{array}{l}\text { Buscar y seleccionar } 2 \\
\text { influenciadores en las } \\
\text { redes sociales para que } \\
\text { transmitan el concepto } \\
\text { de comunicación }\end{array}$ & \multirow{4}{*}{$\begin{array}{l}\text { Jefe de } \\
\text { Producto }\end{array}$} & \multirow{4}{*}{ Febrero } & \multirow{3}{*}{1,200} & $\begin{array}{l}\text { Elección de } \\
\text { personaje }\end{array}$ \\
\hline & C 7.2 & $\begin{array}{l}\text { Agendar reuniones con } \\
\text { los influenciadores }\end{array}$ & & & & \\
\hline & C 7.3 & $\begin{array}{l}\text { Realizar un convenio y } \\
\text { alianza con los } \\
\text { influenciadores para que } \\
\text { publiquen y mencionen } \\
\text { contenido de la marca. }\end{array}$ & & & & $\begin{array}{l}\text { Contrato con } \\
\text { personajes } \\
\text { seleccionados. }\end{array}$ \\
\hline & C 7.4 & $\begin{array}{l}\text { Generar un cronograma } \\
\text { de publicaciones } \\
\text { semanales }\end{array}$ & & & & $\begin{array}{l}\text { Número de } \\
\text { publicaciones } \\
\text { semanales }\end{array}$ \\
\hline
\end{tabular}

\begin{tabular}{|c|c|c|c|c|c|c|}
\hline \multicolumn{7}{|c|}{ Acciones Online } \\
\hline Decisión & Código & Acciones & Responsable & Plazo & $\begin{array}{c}\text { Costo } \\
\text { en } \$\end{array}$ & Kpi \\
\hline \multirow{4}{*}{$\begin{array}{c}\text { C } 8 \\
\text { Implementar } \\
\text { un programa } \\
\text { de } \\
\text { fidelización } \\
\text { para generar } \\
\text { la recompra } \\
\text { del producto. }\end{array}$} & C 8.1 & $\begin{array}{l}\text { Crear y diseñar el } \\
\text { programa de } \\
\text { fidelización CRM } \\
\text { llamado: "Tripulación } \\
\text { Jolly Roger" }\end{array}$ & \multirow{4}{*}{$\begin{array}{l}\text { Jefe de } \\
\text { Producto }\end{array}$} & $\begin{array}{c}\text { Julio, } \\
\text { Agosto y } \\
\text { Setiembre }\end{array}$ & 3,000 & $\begin{array}{l}\text { Informe de } \\
\text { programa de } \\
\text { fidelización }\end{array}$ \\
\hline & C 8.2 & $\begin{array}{l}\text { Realizar alianzas con } 5 \\
\text { diferentes empresas para } \\
\text { que proporcionen los } \\
\text { premios. }\end{array}$ & & Julio & & $\begin{array}{l}\text { Contratos de } \\
\text { alianzas } \\
\text { realizadas. }\end{array}$ \\
\hline & C 8.3 & $\begin{array}{l}\text { Compra de premios de } \\
\text { las diferentes empresas } \\
\text { aliadas. }\end{array}$ & & Agosto & 2,000 & $\begin{array}{l}\text { Número de } \\
\text { códigos en } \\
\text { stock }\end{array}$ \\
\hline & C 8.4 & $\begin{array}{l}\text { Implementar el } \\
\text { programa por } 3 \text { meses }\end{array}$ & & $\begin{array}{l}\text { Primera } \\
\text { semana de } \\
\text { Octubre }\end{array}$ & & \\
\hline
\end{tabular}


7.2. Gantt de actividades por estrategia.

7.2.1. Gantt de actividades para producto

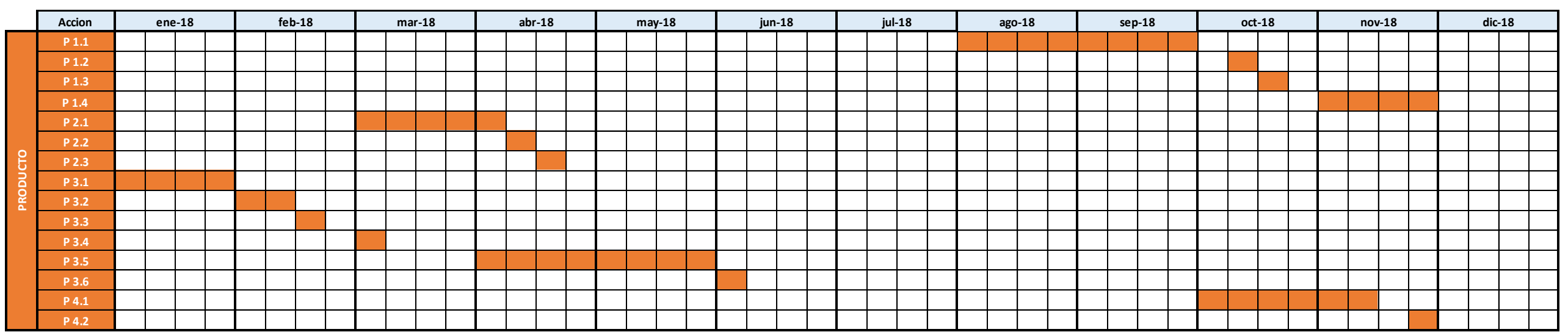

Fuente: Elaboración Propia 


\subsubsection{Gantt de actividades para precio}

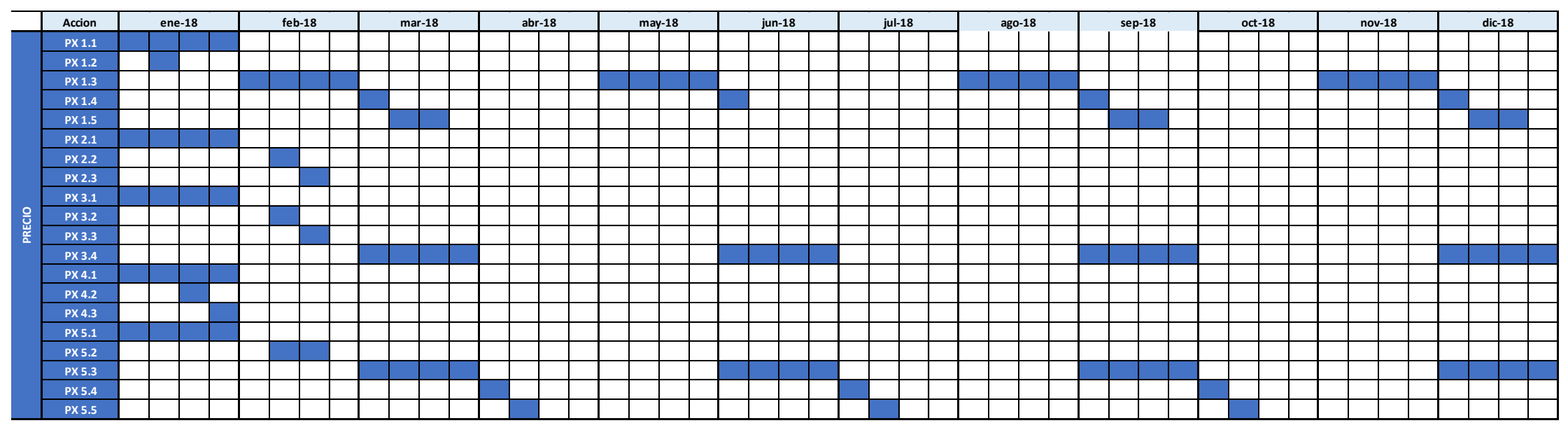

Fuente: Elaboración Propia 


\subsubsection{Gantt de actividades para distribución y ventas}

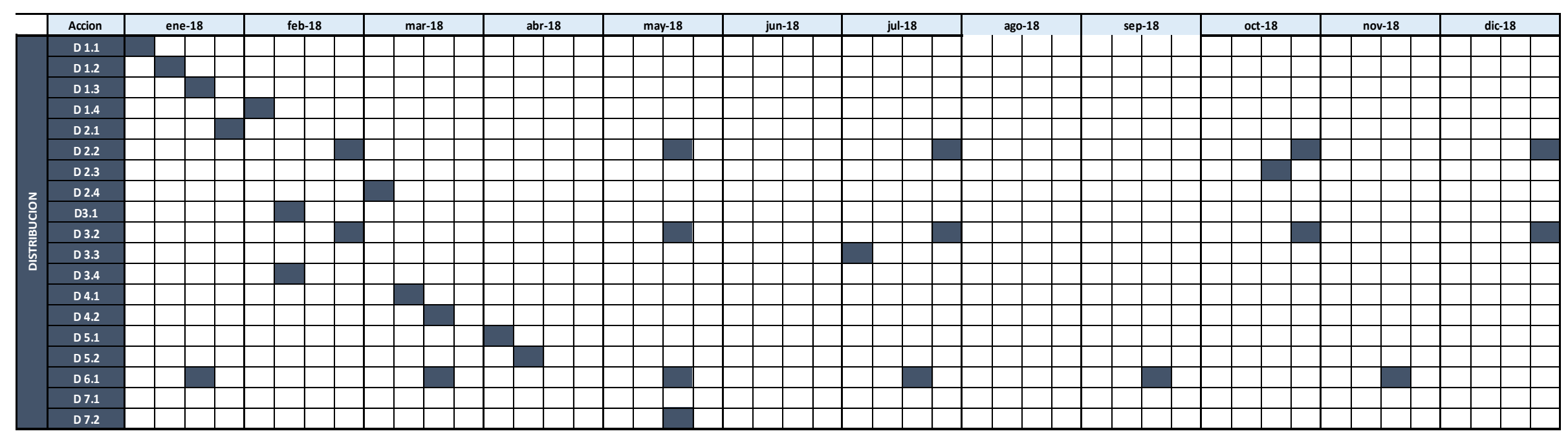

Fuente: Elaboración Propia 


\subsubsection{Gantt de actividades para comunicación}

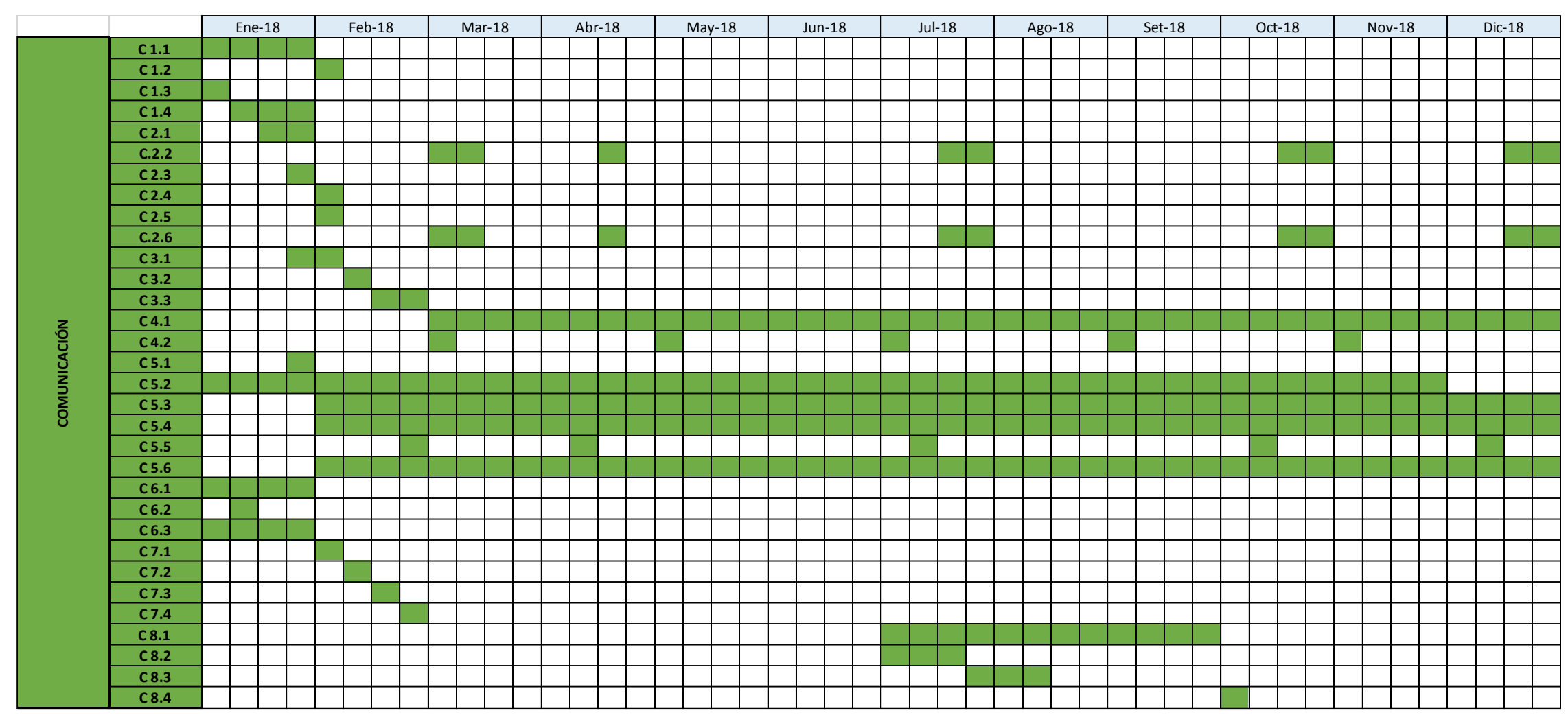

\section{Fuente: Elaboración Propia}




\subsection{Presupuesto de marketing}

En la siguiente tabla se presenta el presupuesto por cada mes para las diferentes acciones a realizar en el Plan de Marketing propuesto para el producto Jolly Roger de la Bodega Santa María.

Tabla 21: Presupuesto Plan de Marketing Jolly Roger(Dólares Americanos)

\begin{tabular}{lccccc}
\hline & $\begin{array}{c}\text { Distribución y } \\
\text { Ventas }\end{array}$ & Precio & Comunicación & Producto & Total \\
\hline Enero & $\$ 1,333.00$ & & $\$ 1,251.00$ & $\$ 200.00$ & $\$ 2,784.00$ \\
Febrero & $\$ 1,418.00$ & $\$ 1,500.00$ & $\$ 4,134.00$ & $\$ 500.00$ & $\$ 7,552.00$ \\
Marzo & $\$ 333.00$ & $\$ 1,500.00$ & $\$ 2,108.00$ & $\$ 500.00$ & $\$ 4,441.00$ \\
Abril & & & $\$ 2,108.00$ & & $\$ 7,108.00$ \\
Mayo & $\$ 1,796.00$ & $\$ 1,500.00$ & $\$ 1,194.00$ & & $\$ 4,490.00$ \\
Junio & & $\$ 1,500.00$ & $\$ 1,194.00$ & & $\$ 2,694.00$ \\
Julio & $\$ 2,551.00$ & & $\$ 5,348.00$ & & $\$ 4,899.00$ \\
Agosto & & $\$ 1,500.00$ & $\$ 3,194.00$ & $\$ 500.00$ & $\$ 3,194.00$ \\
Septiembre & $\$ 333.00$ & $\$ 1,500.00$ & $\$ 1,554.00$ & & $\$ 3,387.00$ \\
Octubre & $\$ 2,418.00$ & & $\$ 1,748.00$ & $\$ 500.00$ & $\$ 4,666.00$ \\
Noviembre & $\$ 333.00$ & $\$ 1,500.00$ & $\$ 1,554.00$ & $\$ 300.00$ & $\$ 3,687.00$ \\
Diciembre & $\$ 4,198.00$ & $\$ 1,500.00$ & $\$ 1,980.00$ & & $\$ 7,678.00$ \\
Total 2018 & $\$ 14,713.00$ & $\$ 12,000.00$ & $\$ 27,367.00$ & $\$ 2,500.00$ & $\$ 56,580.00$ \\
\hline
\end{tabular}

Fuente: Elaboración Propia 


\subsection{Proyección de estados de resultados}

En la siguiente tabla se presenta el estado de Resultados de la Bodega Santa María para el producto Jolly Roger, desde el año de su comercialización (2016), hasta el año proyectado en el presente Plan (2018)

Tabla 22: Estado de Resultados Jolly Roger (Dólares Americanos)

\begin{tabular}{|c|c|c|c|c|c|c|c|}
\hline \multicolumn{8}{|c|}{ BALANCE JOLLY ROGER } \\
\hline & & 2016 & & 2017 & & 2018 & \\
\hline & & USD & $\%$ & USD & $\%$ & USD & $\%$ \\
\hline & VENTAS & $25,200.00$ & & $88,452.00$ & & $173,189.00$ & \\
\hline$(-)$ & COSTO DE VENTAS & $10,560.00$ & $41.90 \%$ & $36,890.00$ & $41.71 \%$ & $76,146.00$ & $43.97 \%$ \\
\hline & UTILIDAD BRUTA & $14,640.00$ & $58.10 \%$ & $51,562.00$ & $58.29 \%$ & $97,043.00$ & $56.03 \%$ \\
\hline$(-)$ & $\begin{array}{l}\text { GASTOS DE } \\
\text { MARKETING }\end{array}$ & $3,800.00$ & & $14,800.00$ & & $56,580.00$ & \\
\hline & $\begin{array}{c}\text { UTILIDAD } \\
\text { OPERATIVA }\end{array}$ & $10,840.00$ & $43.02 \%$ & $36,762.00$ & $41.56 \%$ & $40,463.00$ & $23.36 \%$ \\
\hline
\end{tabular}

\section{Fuente: Elaboración Propia}

\subsection{PROYECCIÓN DE VENTAS JOLLY ROGER.}

En la siguiente tabla se muestra la proyección de ventas estimada para el año 2018 para el macerado en base a Pisco Jolly Roger (Ver detalle en Anexo 16). 
Tabla 23: Proyección de ventas Jolly Roger 2018

\begin{tabular}{|c|c|c|c|c|c|c|c|c|c|c|c|c|c|c|}
\hline Concepto & $\mathbf{0}$ & Enero & Febrero & Marzo & Abril & Mayo & Junio & Julio & Agosto & Septiembre & Octubre & Noviembre & Diciembre & $\begin{array}{c}\text { Total } \\
2018(\$)\end{array}$ \\
\hline \multicolumn{15}{|l|}{ Ingresos } \\
\hline Ventas & & $6,325.56$ & $12,742.20$ & $10,396.68$ & $10,022.52$ & $19,612.56$ & $20,447.16$ & $17,676.96$ & $11,018.76$ & $12,169.56$ & $13,187.28$ & $24,299.04$ & $15,291.00$ & \\
\hline $\begin{array}{l}\text { Total } \\
\text { Ingresos (\$) }\end{array}$ & & $6,325.56$ & $12,742.20$ & \begin{tabular}{|l|}
$10,396.68$ \\
\end{tabular} & $10,022.52$ & $19,612.56$ & \begin{tabular}{|l}
$20,447.16$ \\
\end{tabular} & $17,676.96$ & $11,018.76$ & $12,169.56$ & $13,187.28$ & $24,299.04$ & $15,291.00$ & $173,189.28$ \\
\hline \multicolumn{15}{|l|}{ Egresos } \\
\hline $\begin{array}{ll}\text { Costo } & \text { de } \\
\text { Ventas } & \\
\end{array}$ & & $1,458.00$ & $6,658.20$ & $4,787.10$ & $4,446.90$ & $8,480.70$ & $9,209.70$ & $7,630.20$ & $4,835.70$ & $5,321.70$ & $5,759.10$ & $10,716.30$ & $6,804.00$ & \\
\hline $\begin{array}{l}\text { Total } \\
\text { Egresos (\$) } \\
\end{array}$ & & $1,458.00$ & $6,658.20$ & $4,787.10$ & $4,446.90$ & $8,480.70$ & $9,209.70$ & $7,630.20$ & $4,835.70$ & $5,321.70$ & $5,759.10$ & $10,716.30$ & $6,804.00$ & $76,107.60$ \\
\hline $\begin{array}{l}\text { Presupuesto } \\
\text { Marketing }\end{array}$ & $56,580.00$ & & & & & & & & & & & & & - \\
\hline $\begin{array}{l}\text { Utilidad } \\
\text { Bruta (\$) }\end{array}$ & & $4,867.56$ & $6,084.00$ & $\mathbf{5 , 6 0 9 . 5 8}$ & $5,575.62$ & $11,131.86$ & $11,237.46$ & $10,046.76$ & 6,183.06 & 6,847.86 & 7,428.18 & 13,582.74 & $8,487.00$ & 97,043.00 \\
\hline $\begin{array}{l}\text { Gastos de } \\
\text { Marketing }\end{array}$ & & $2,784.00$ & $7,552.00$ & $4,441.00$ & $7,108.00$ & $4,490.00$ & $2,694.00$ & $4,899.00$ & $3,194.00$ & $3,387.00$ & $4,666.00$ & $3,687.00$ & $7,678.00$ & \\
\hline $\begin{array}{l}\text { Utilidad } \\
\text { Operativa }\end{array}$ & & $2,083.56$ & $\begin{array}{c}- \\
1,468.00 \\
\end{array}$ & $\mathbf{1 , 1 6 8 . 5 8}$ & $\begin{array}{c}- \\
1,532.38 \\
\end{array}$ & $6,641.86$ & $8,543.46$ & $5,147.76$ & 2,989.06 & $3,460.86$ & $2,762.18$ & $9,895.74$ & 809.00 & 40,463.00 \\
\hline
\end{tabular}

Fuente: Elaboración Propia 


\section{CAPITULO VIII: EVALUACIÓN DE LA ESTRATEGIA}

Cada Plan de Marketing debe de ser evaluado de manera constante, para saber en el camino los avances o si hay alguna medida correctiva que hacer. Según los avances hay que saber si el diagnóstico es el correcto, si los objetivos están bien planteados, si se puede cambiar de estrategias o si los planes de acción son los deseados.

\subsection{Sistema de información y control}

El sistema de control se debe de realizar periódicamente según los objetivos trazados, analizar las desviaciones y poder corregirlas a tiempo con nuevas acciones. Por tal motivo es importante establecer los indicadores de la gestión para el objetivo más importantes y las estrategias que más aportarán a cumplir el objetivo.

Tabla 24: Control de indicadores de gestión

\begin{tabular}{|c|c|c|c|}
\hline & & Indicador & $\begin{array}{l}\text { Unidad } \\
\text { de } \\
\text { Medida }\end{array}$ \\
\hline \multirow{3}{*}{ Objetivo } & \multirow{3}{*}{$\begin{array}{l}\text { Incrementar el Nivel de Conocimiento } \\
\text { de } 10.9 \% \text { a } 20 \% \text { en Lima Metropolitana } \\
\text { y Callao en el } 2018\end{array}$} & Market Share & Porcentaje \\
\hline & & Ventas Netas & Dólares \\
\hline & & $\begin{array}{c}\text { Numero seguidores en Redes } \\
\text { Sociales }\end{array}$ & Likes \\
\hline \multirow{3}{*}{ Estrategia } & $\begin{array}{l}\text { Ampliar presentaciones de Jolly Roger } \\
\text { Incursionar en nuevos Canales }\end{array}$ & Incremento Ventas & Dólares \\
\hline & Comisión por ventas & & \\
\hline & $\begin{array}{l}\text { Evaluación de Percepción } \\
\text { Comunicación Online }\end{array}$ & Nivel de Conocimiento & Porcentaje \\
\hline
\end{tabular}

Fuente: Elaboración Propia 


\subsection{Cuadro de mando trimestral}

Para realizar un seguimiento preciso, es necesario tener los objetivos de ventas por canal y de manera trimestral y así ver el avance y las diferencias que existen; este es el control que Bodega Santa María necesita hacer para poder cumplir con los objetivos de Jolly Roger. En las siguientes tablas se muestran los cuadros de control a utilizar:

Tabla 25: Cuadro de Mando 1er Trimestre

\begin{tabular}{cllll}
\hline & & & \multicolumn{2}{c}{ 1er Trimestre } \\
\hline & Canal & & Objetivo & Real Desviación \\
& & Tambo & $\mathbf{\$ 1 0 , 4 7 5 . 4 0}$ & \\
& Autoservicios & Wong & $\mathbf{\$ 4 , 2 7 1 . 5 2}$ & \\
Ventas por & & Vivanda & $\mathbf{\$ 3 , 2 0 3 . 6 4}$ & \\
Canal & & & \\
& HORECAS & & $\mathbf{\$ 3 , 1 6 0 . 0 8}$ \\
& Licorerías & & $\mathbf{\$ 6 , 6 5 2 . 8 0}$ \\
& Mayoristas & & $\mathbf{\$ 1 , 7 0 1 . 0 0}$ \\
\hline
\end{tabular}

Fuente: Elaboración Propia

Tabla 26: Cuadro de Mando 2do Trimestre

\begin{tabular}{cllcl}
\hline & & & \multicolumn{2}{c}{ 2do Trimestre } \\
\hline & Canal & & Objetivo & Real Desviación \\
& & Tambo & $\mathbf{\$ 1 8 , 4 8 6 . 0 0}$ & \\
& Autoservicios & Wong & $\mathbf{\$ 1 0 , 4 8 4 . 6 4}$ & \\
Ventas por & & Vivanda & $\mathbf{\$ 7 , 5 7 2 . 2 4}$ & \\
Canal & & & \\
& HORECAS & & $\mathbf{\$ 9 , 9 7 9 . 2 0}$ \\
& Licorerías & & $\mathbf{\$ 1 8 , 8 4 9 . 6 0}$ \\
& Mayoristas & $\mathbf{\$ 1 4 , 1 7 5 . 0 0}$ \\
\hline
\end{tabular}

Fuente: Elaboración Propia 
Tabla 27: Cuadro de Mando 3er Trimestre

\begin{tabular}{cllcr}
\hline & & & \multicolumn{2}{c}{ 3er Trimestre } \\
\hline & & & Objetivo & Real Desviación \\
& & Tambo & $\mathbf{\$ 2 8 , 3 4 5 . 2 0}$ & \\
Autoservicios & Wong & $\mathbf{\$ 1 3 , 9 7 9 . 5 2}$ & \\
Cantas por & & Vivanda & $\mathbf{\$ 1 0 , 1 9 3 . 4 0}$ & \\
& & & & \\
& HORECAS & & $\mathbf{\$ 1 7 , 5 1 9 . 0 4}$ \\
& Licorerías & & $\mathbf{\$ 2 8 , 8 2 8 . 8 0}$ \\
& Mayoristas & $\mathbf{\$ 2 1 , 5 4 6 . 0 0}$ & \\
\hline
\end{tabular}

Fuente: Elaboración Propia

Tabla 28: Cuadro de Mando 4to Trimestre

\begin{tabular}{cllrl}
\hline & & & \multicolumn{2}{c}{ 4to Trimestre } \\
\hline & Canal & & Objetivo & Real Desviación \\
& & Tambo & $\mathbf{\$ 3 6 , 9 7 2 . 0 0}$ & \\
& Autoservicios & Wong & $\mathbf{\$ 2 0 , 0 9 5 . 5 6}$ & \\
Ventas por & & Vivanda & $\mathbf{\$ 1 4 , 4 6 4 . 9 2}$ & \\
Canal & & & \\
& HORECAS & & $\mathbf{\$ 2 7 , 7 2 0 . 0 0}$ \\
& Licorerías & & $\mathbf{\$ 3 9 , 9 1 6 . 8 0}$ \\
& Mayoristas & & $\mathbf{\$ 3 4 , 0 2 0 . 0 0}$ \\
\hline
\end{tabular}

Fuente: Elaboración Propia

\subsection{Plan de contingencias}

Cada Plan de Marketing debe de tener un Plan de Contingencias para poder ejecutarlos en cuanto la desviación entre el objetivo y el avance real sea muy significativo y peligre no cumplir la meta trazada. Se muestra en la tabla 27 el detalle de los planes de contingencia 
Tabla 29: Plan de contingencia para Jolly Roger

\begin{tabular}{|c|c|c|c|c|}
\hline \multicolumn{2}{|c|}{ Objetivos 2018} & \multirow{3}{*}{\begin{tabular}{l}
\multicolumn{1}{c}{ Medidas de } \\
\multicolumn{1}{c}{ Contingencia } \\
Si en el mes de junio \\
no se llega al 40\% de \\
las ventas (\$ 69 276) se \\
realizará un concurso \\
de ventas donde \\
participarán todos los \\
vendedores del canal \\
de licorerías y \\
mayoristas. Además de \\
realizar un concurso \\
entre locales de los \\
Autoservicios Wong y \\
Vivanda. \\
Si al mes de octubre no \\
se llega a un Nivel de \\
Conocimiento de $18 \%$, \\
se realizará una \\
promoción cruzada con \\
diferentes productos \\
líderes en su categoría, \\
como Red Bull, \\
Evervest o Tampico. \\
Realizar descuentos \\
por la compra de los 2 \\
productos, \\
comunicando la \\
promoción en encartes \\
en los respectivos \\
Autoservicios.
\end{tabular}} & \multirow[t]{3}{*}{ Presupuesto } & Responsable \\
\hline $\begin{array}{l}\text { Ventas } \\
\text { Brutas }\end{array}$ & $\$ 173,189.00$ & & & $\begin{array}{l}\text { Jefe de } \\
\text { Producto }\end{array}$ \\
\hline $\begin{array}{c}\text { Nivel de } \\
\text { Conocimiento }\end{array}$ & $20.00 \%$ & & & $\begin{array}{l}\text { Jefe de } \\
\text { Producto }\end{array}$ \\
\hline
\end{tabular}

Fuente: Elaboración Propia 


\subsection{Evaluación financiera}

La evaluación financiera del Plan de Marketing Jolly Roger considera las ventas proyectadas al cierre del 2018. La tasa interna de retorno obtenida (TIR) es de $71.51 \%$ y el VAN obtenido fue $\$ 24178.45$ considerando un $15 \%$ como tasa referencial. Se obtuvo un ROI de 3.06.

Tabla 30: Tasa de descuentos

\begin{tabular}{|c|c|}
\hline TASA & VAN \\
\hline $95 \%$ & $-\$ 3,494.54$ \\
\hline $80 \%$ & $-\$ 1,481.79$ \\
\hline $\mathbf{7 1 . 5 1 \%}$ & $\mathbf{\$ 0 . 0 0}$ \\
\hline $50 \%$ & $\$ 5,410.22$ \\
\hline $30 \%$ & $\$ 13,898.82$ \\
\hline $20 \%$ & $\$ 20,240.97$ \\
\hline $\mathbf{1 5 \%}$ & $\mathbf{\$ 2 4 , 1 7 8 . 4 5}$ \\
\hline $10 \%$ & $\$ 28,764.46$ \\
\hline
\end{tabular}

Fuente: Elaboración Propia

Tabla 31: Indicadores Financieros

\begin{tabular}{cc}
\hline INDICADOR & VALOR \\
\hline TIR & $71.51 \%$ \\
ROI & 3.06 \\
\hline
\end{tabular}

Fuente: Elaboración Propia 


\section{CAPITULO IX: CONCLUSIONES Y RECOMENDACIONES}

\subsection{Conclusiones}

1. Bodega Santa María, cuenta con los recursos económicos para cubrir los costos de la implementación del presente plan de marketing para Jolly Roger, \$56580.00.

2. De los estudios Cuantitativos y Cualitativos se obtuvo información importante acerca del Nivel de Conocimiento de Jolly Roger (10.9), los motivos por qué no tienen conocimiento es la deficiencia en la distribución y la falta de comunicación del producto.

3. Los Objetivos planteados en el Plan de Marketing de Jolly Roger están enfocados a incrementar el nivel de conocimiento y de ventas de este producto nuevo.

4. Las estrategias están dirigidas para que Jolly Roger sea el producto estrella de la Bodega Santa María y así poder ayudar a las otras líneas de la empresa a ingresar al mercado peruano.

5. Los planes de acción de comunicación del Plan de marketing de Jolly Roger están basados en acciones off line y on line, teniendo el medio digital con las Redes Sociales una herramienta importante para la comunicación del producto.

6. La Evaluación Financiera nos refleja que el proyecto es viable; con un TIR de $71.51 \%$ y un ROI de 3.06.

7. Para determinar el nuevo mercado objetivo se realizarán después de la investigación cuantitativa donde se medirá en nivel de conocimiento del producto. 


\subsection{Recomendaciones.}

1. Se recomienda que para los años siguientes, el presupuesto del Plan de Marketing para Jolly Roger no debería disminuir para poder continuar su expansión a nivel nacional.

2. Realizar un Plan de Marketing para el ingreso de Jolly Roger a nivel nacional.

3. Evaluar el contar con distribuidores del producto a nivel nacional.

4. Desarrollar una línea de productos para JollyRoger.

5. Utilizar la base de datos recolectada con el programa de CRM de Jolly Roger, para generar tácticos enfocados a los usuarios en el 2019.

6. Contratar los servicios y herramientas de BigData de la empresa Advice para generar estrategias de ventas y promoción en el 2019.

\begin{tabular}{|c|c|c|c|c|c|}
\hline \multicolumn{6}{|c|}{ Estrategia de BigData 2019} \\
\hline Decisión & Acciones & Responsable & Plazo & Costo en $\$$ & Kpi \\
\hline \multirow{4}{*}{$\begin{array}{l}\text { Implementar } \\
\text { el uso de Big } \\
\text { Data para } \\
\text { generar } \\
\text { estrategias } \\
\text { de ventas y } \\
\text { promoción }\end{array}$} & $\begin{array}{l}\text { Contratar el servicio } \\
\text { mensual de la } \\
\text { empresa Advice, } \\
\text { experta en BigData }\end{array}$ & \multirow{4}{*}{ Jefe Comercial } & $\begin{array}{c}\text { Enero - } \\
\text { Diciembre }\end{array}$ & 36,000 & $\begin{array}{c}\text { Contrato del } \\
\text { servicio de uso } \\
\text { de herramienta }\end{array}$ \\
\hline & $\begin{array}{l}\text { Implementar la base } \\
\text { de datos recopilada } \\
\text { el } 2018 \text { a la } \\
\text { plataforma de } \\
\text { Advice } \\
\end{array}$ & & Enero & & \\
\hline & $\begin{array}{l}\text { Implementar la data } \\
\text { de ventas recopilada } \\
\text { el } 2018 \text { a la } \\
\text { plataforma de } \\
\text { Advice }\end{array}$ & & Enero & & \\
\hline & $\begin{array}{l}\text { Generar reportes y } \\
\text { analizar datos del } \\
\text { comportamiento del } \\
\text { consumidor de } \\
\text { bebidas alcohólicas } \\
\text { y de Jolly Roger }\end{array}$ & & $\begin{array}{c}\text { Enero - } \\
\text { Diciembre }\end{array}$ & & $\begin{array}{l}\text { Número de } \\
\text { reportes } \\
\text { generados }\end{array}$ \\
\hline
\end{tabular}




\section{BIBLIOGRAFÍA}

Carlos García, CCL. http://gestion.pe/economia/whisky-y-ron-son-licores-que-mas-importoperu-primer-trimestre-2130975 . Fecha de acceso 20 de Agosto del 2017

CCL, https://camaralima.org.pe/principal/noticias/noticia/whisky-continua-siendo-el-licorimportado-mas-consumido-de-peru/795. Fecha de acceso 20 de Agosto del 2017

Eslava, J. (2015), Pricing: Nuevas Estrategias De Precios (4ª Ed.), España: ESIC EDITORIAL.

Fred R., D., (2012), Conceptos de Administración Estratégica (14ª ED): ADDISONWESLEY.

Juan Carlos Mathews Salazar | Perfil profesional - LinkedIn." https://pe.linkedin.com/in/juancarlos-mathews-salazar-49712a37. Fecha de acceso 11 ago.. 2017.

Lawrence, J.G: Chad, J.Z. 2012. "Pincipios de Administración Financiera"

Malhotra, N., (2008), Investigación De Mercados, México: PRENTICE HALL MÉXICO.

Memoria de Gobierno 2016-2017. http://www.gob.pe/450-memoria-de-gobierno-2016-2017 . Fecha de acceso: 19 de Agosto 2017

Pedro Olaechea,http://gestion.pe/tendencias/congreso-eleva-rango-ley-declaracion-al-piscocomo-patrimonio-cultural-nacion-2197972 Fecha de acceso 20 de Agosto del 2017

Perú Retail. http://www.peru-retail.com/consumo-peru-caida-2017/ Fecha de acceso 21 de Agosto del 2017

Porter, M., (2010), Ventaja Competitiva: Creación Y Sostenimiento De Un Desarrollo Superior: PIRÁMIDE.

RPP. http://rpp.pe/economia/economia/ppk-subestime-el-esfuerzo-de-la-recuperacioneconomica-me-disculpo-noticia-1067074.Fecha de acceso 19 de Agosto del 2017

Sainz de Vicuña Ancín, J., (2015), El plan de Marketing en la Práctica (20ª ED.), Madrid, España: ESIC EDITORIAL.

Veritrade, Data Trade: importación Jagermeister, empresa Bebidas Premiun SAC, acceso 03 marzo 2017. 
ANEXOS 
PLAN DE MARKETING PARA LA BODEGA SANTA MARIA: JOLLY ROGER

ANEXO 1: Mapa Cañete y Lunahuana

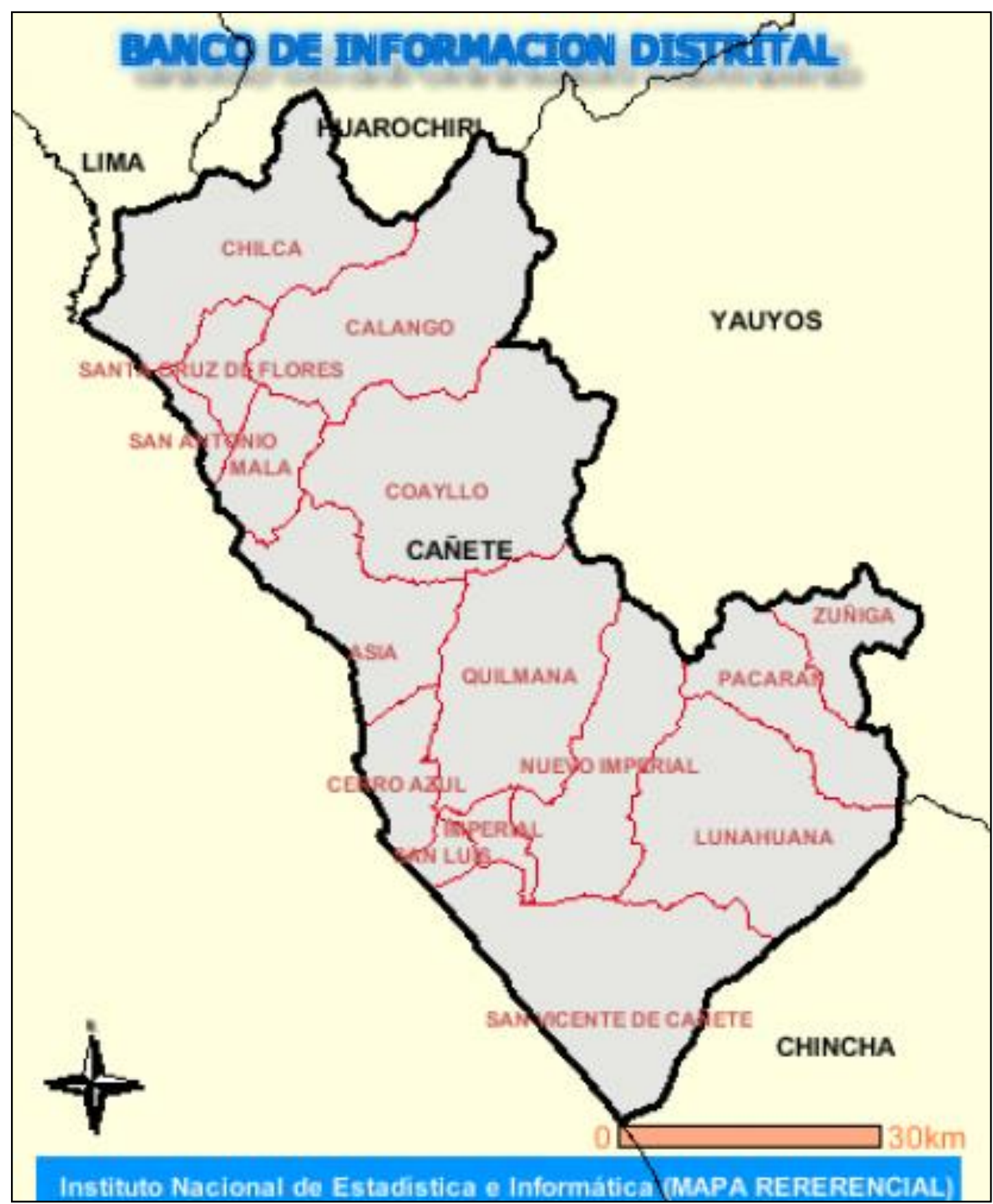


PLAN DE MARKETING PARA LA BODEGA SANTA MARIA: JOLLY ROGER

ANEXO 2: Mapa Cañete y Lunahuana

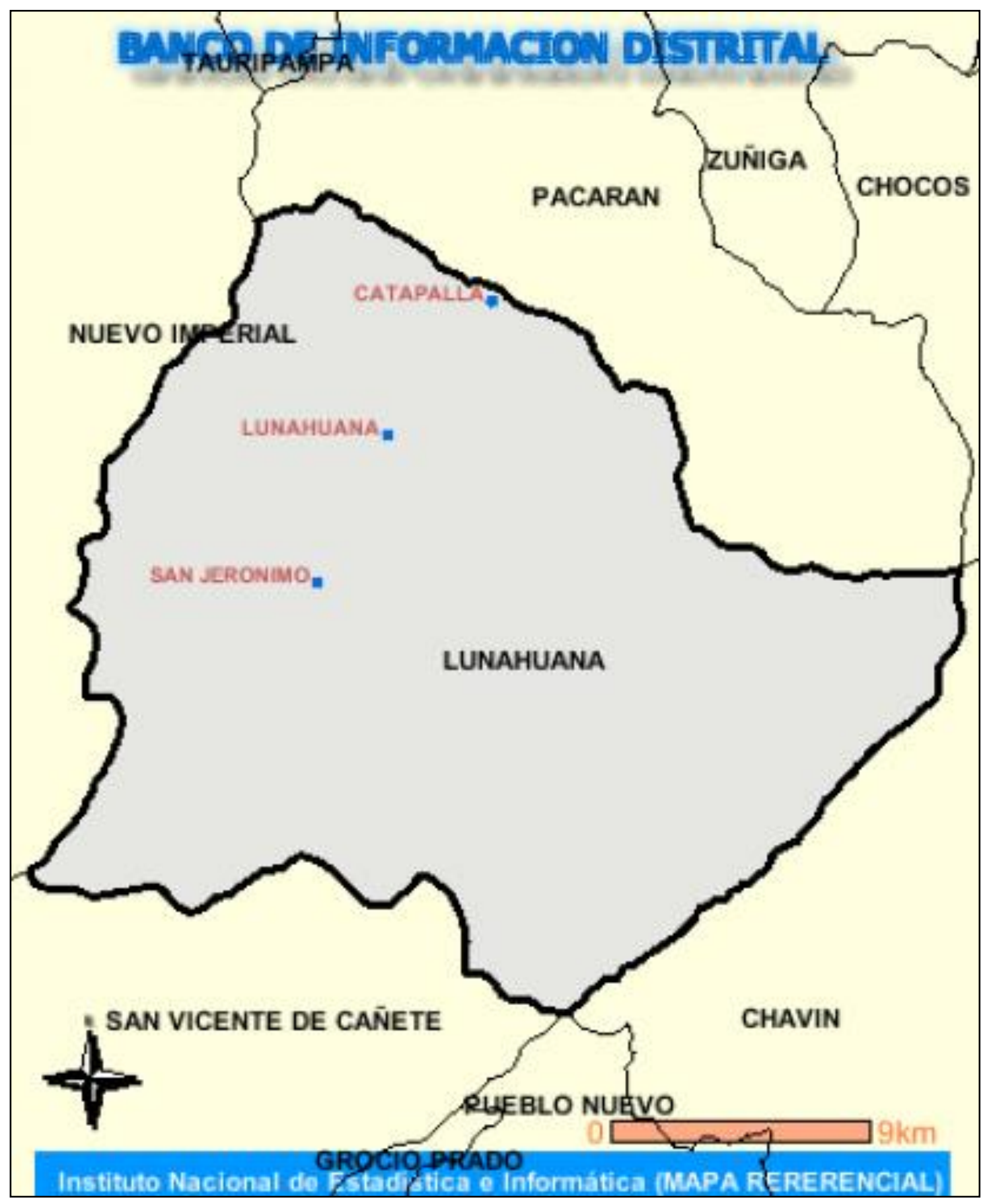




\section{ANEXO 3: LEY N 30460}

\section{LEY № 30460}

\section{EL PRESIDENTE DEL CONGRESO DE LA REPÚBLICA}

POR CUANTO:

EL CONGRESO DE LA REPÚBLICA;

Ha dado la Ley siguiente:

\section{LEY QUE DECLARA DE INTERÉS NACIONAL LA PROMOCIÓN Y DIFUSIÓN DEL VINO PERUANO Y DEL PISCO COMO BEBIDAS NACIONALES}

Artículo 1. Declaración de interés nacional

Declárase de interés nacional la promoción y difusión del vino peruano y del pisco como bebidas nacionales.

\section{Artículo 2. Alcances de la Ley}

Los alcances de la presente Ley son los siguientes:

a. Promover la imagen y la marca del vino peruano y del pisco en todo tipo de eventos oficiales en el pais y en el exterior.

b. Promover el desarrollo tecnológico y comercial de las economías regionales a partir de acciones relacionadas con actividades de servicios vinculadas al sector vitivinícola y pisquero del país.

c. Promover estudios, investigaciones y organizaciones tendientes a la definición de las distintas regiones vitivinícolas y pisqueras de cada provincia y departamento del país.

d. Difundir las características culturales que implican la producción, elaboración y consumo del vino peruano y del pisco, conjuntamente con sus tradiciones.

\section{Artículo 3. Autoridades competentes}

El Ministerio de Cultura, el Ministerio de Comercio Exterior y Turismo, el Ministerio de Relaciones Exteriores y el Ministerio de la Producción, de conformidad con sus competencias y funciones, dispondrán las normas y acciones pertinentes para la aplicación e implementación de la presente Ley.

\section{Artículo 4. Financiamiento}

La aplicación de lo establecido en la presente Ley se financia con cargo al presupuesto institucional de los pliegos respectivos, en el marco de las leyes anuales de presupuesto, conforme a sus competencias y sujetándose a la normatividad vigente.

\section{DISPOSICIÓN COMPLEMENTARIA FINAL}

ÚNICA. Declaratoria de patrimonio cultural

El Ministerio de Cultura realizará la evaluación de la procedencia de la declaratoria como capital cultural del vino peruano y del pisco a la provincia y departamento de Ica, y de la fiesta de la vendimia de Ica como fiesta nacional.

\section{POR TANTO:}

Habiendo sido reconsiderada la Ley por el Congreso de la República, aceptándose las observaciones formuladas por el señor Presidente de la República, de conformidad con lo dispuesto por el artículo 108 de la Constitución Política del Perú, ordeno que se publique y cumpla.

En Lima, a los veintiséis días del mes de mayo de dos mil dieciséis.

LUIS IBERICO NÚÑEZ

Presidente del Congreso de la República

NATALIE CONDORI JAHUIRA

Primera Vicepresidenta del Congreso de la República

$1392947-2$ 
ANEXO 4: Ley $\mathbf{N}^{\circ} 30639$

\section{LEY № 30639}

EL PRESIDENTE DE LA REPÚBLICA

POR CUANTO:

LA COMISIÓN PERMANENTE DEL CONGRESO DE LA REPÚBLICA;

Ha dado la Ley siguiente:

\section{LEY QUE ELEVA A RANGO DE LEY LA RESOLUCIÓN JEFATURAL QUE DECLARA \\ PATRIMONIO CULTURAL DE LA NACIÓN LA DENOMINACIÓN DE ORIGEN "PISCO"}

\section{Artículo 1. Objeto de la Ley}

Elévase a rango de ley la Resolución Jefatural 17988/INC-J, que declara Patrimonio Cultural de la Nación la denominación de origen "Pisco" que se produce en el Perú.

Artículo 2. Cumplimiento de la declaración de interés nacional

Encárgase al Ministerio de Cultura, al Ministerio de Comercio Exterior y Turismo, al Ministerio de Relaciones Exteriores y al Ministerio de la Producción, de conformidad con sus competencias y funciones, el seguimiento y cumplimiento de la presente ley.

Comuníquese al señor Presidente de la República para su promulgación.

En Lima, a los veintiséis días del mes de julio de dos mil diecisiete.

LUZ SALGADO RUBIANES

Presidenta del Congreso de la República

ROSA BARTRA BARRIGA

Primera Vicepresidenta del Congreso de la República

AL SEÑOR PRESIDENTE DE LA REPÚBLICA

POR TANTO:

Mando se publique y cumpla.

Dado en la Casa de Gobierno, en Lima, a los quince días del mes de agosto del año dos mil diecisiete.

PEDRO PABLO KUCZYNSKI GODARD

Presidente de la República

FERNANDO ZAVALA LOMBARDI

Presidente del Consejo de Ministros

$1554967-2$ 


\section{ANEXO 5: Ficha determinación NSE para}

\section{encuesta}

\section{DETERMINACIÓN DEL NSE}

Sr. / Sra. / Joven, Con la finalidad de agrupar sus respuestas con las de otras personas de similares características a las de usted, nos gustaría que responda a las siguientes preguntas.

1. ¿Quién es la persona que aporta MÁs al sostenimiento económico de su hogar? (E: 1 . Si identifica a dos personas o más, preguntar por la de mayor edad. 2. Si la persona que más aporta no vive en el hogar, preguntar por la que administra los ingresos que recibe de la persona ausente.)

2. Las siguientes preguntas se refieren a... que es la persona que aporta MÁs al sostenimiento de su hogar (E:según pregunta 1)

3. ¿Cuál es el grado de instrucción alcanzado por...? (E: mencione a la persona que aporta más al sostenimiento de su hogar según pregunta 1, circular el grado de instrucción y puntaje)

\begin{tabular}{|c|c|c|c|c|c|c|c|}
\hline Ninguno / Analfabeto & 1 & Ptos & Sequndaria mmoleta & 5 & P'tos & & \\
\hline Primaria incompleta & 2 & & Superior técnica inœmpleta & 6 & 2 & $\begin{array}{l}\text { Superior universitana } \\
\text { œmpleta }\end{array}$ & $\begin{array}{c}9 \\
10\end{array}$ \\
\hline Primaria completa & 3 & 1 & Superior técnica completa & 7 & & Post Grado (Maestrías, & 11 \\
\hline Secundaria incompleta & 4 & & Superior universitaria incompleta & 8 & 3 & Doctorados, equivalentes) & \\
\hline
\end{tabular}

4. Ante una consulta médica, ¿en qué tipo de establecimiento de salud se atiende la persona que aporta más al sostenimiento económico de su hogar?

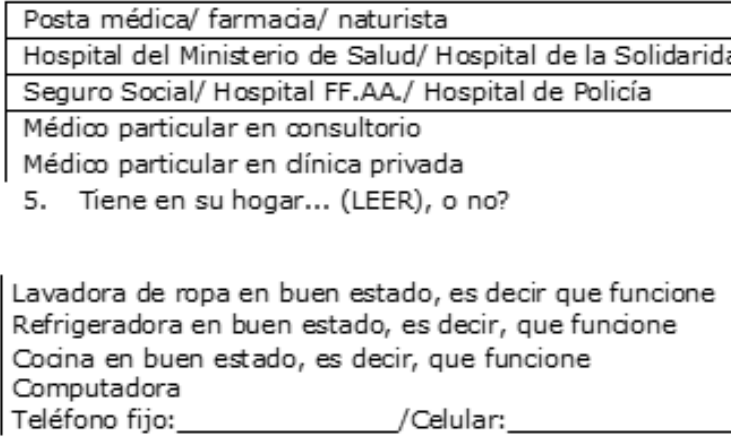

6. ¿Quántas personas, incluyéndose usted pero sin incluir al personal de servicio, viven en su hogar?

7. ¿Quántas habitaciones/ dormitorios exclusivos para dormir tiene dentro de su hogar o no tiene ninguno? (MARCAR "CERO" SI NO TIENE)

\section{(E: PARA ASIGN AR EL PUNTAJE DEBE DIVIDIR EL NUMERO DE HABITACIONES EXCLUSIVAS PARA DORMIR / EL NUMERO DE PERSONAS QUE VIVEN EN \\ EL HOGAR (NO SERVICIO DOMESTICO)}

8. De esta lista, ¿cuál es el material predominante en los pisos de su vivienda? (MOSTRAR TARJETA No. 2)

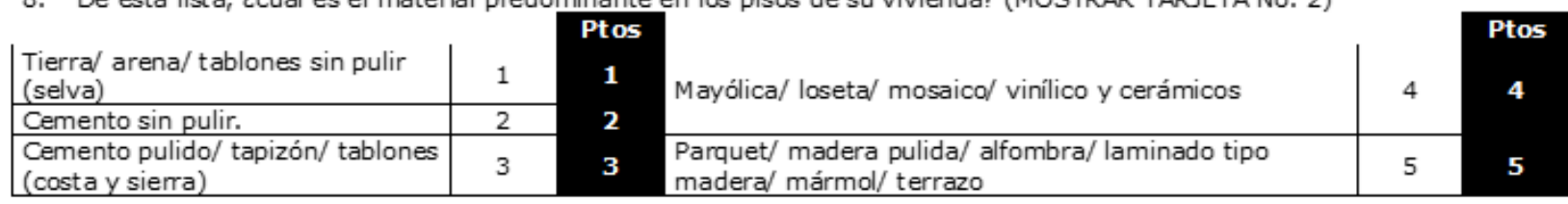

\begin{tabular}{|c|c|c|c|c|c|c|c|c|c|c|c|c|c|c|}
\hline Puntaje & & NSE & & Puntaje & & NSE & & Puntaje & & NSE & & Puntaje & NS & \\
\hline $25-24$ & $\mathrm{~A} 1$ & & & $20-19$ & B1 & & & $15-14$ & $\mathrm{Cl}$ & & & $10-6$ & & 04 \\
\hline $23-21$ & A2 & & & $18-16$ & B2 & & & $13-11$ & $C 2$ & & & Hasta 5 & E & 05 \\
\hline
\end{tabular}

Notas:

- Si el principal sostén económico no trabaja la variable COUPACIÓN deberá ser reemplazada por el puntaje correspondiente a la variable EDUCACÓN restándole 1 punto, no considerar puntaje negativo, el menor puntaje es cero (0).

- La ocupación corresponde a aquella que el entrevistado declara espontánememente y al mostrarle la tarjeta.

- Se considera tenencia de servicio doméstico, cuando por lo menos el personal trabaja 4 horas a la semana y 16 horas al mes, no interesa el número de días.

- El número de baños corresponde al total de baños dentro de la vivienda, incluidos los baños de servicio.

- Cuando la vivienda corresponde a un cuarto alquilado en una casa, donde se comparte el baño, la cantidad de baños es igual a 1 (puntaje = 2), - Cuando la vivienda está ubicada en un callejón o solar, con baño afuera, el número de baños es igual a 0 (puntaje = 1).

- Si la vivienda es multihogar, considerar para la evaluación de pisos TODA la vivienda así el hogar encuestado ocupe una parte. 


\section{ANEXO 6: Ficha filtro Focus Group}

1.- ¿Usted o algún miembro de su hogar trabajan o han trabajado en alguna de las siguientes empresas?

- $\quad$ Agencias de publicidad

- $\quad$ Empresas de Investigación de Mercados

- Empresas que fabrican o comercializan abarrotes, soya, leche, golosinas, bebidas, supermercados, bodegas

- $\quad$ Empresas que se dedican a relaciones públicas, TV, radio o prensa

2.- ¿Usted ha estudiado Ciencias Sociales, de la comunicación, Psicología, Marketing o Ventas?

3.- ¿Ud. Ha participado de alguna dinámica grupal / Focus Group en los últimos 6 meses, en una empresa de Investigación de Mercados / Publicidad?

\begin{tabular}{|c|c|c|c|}
\hline 4.- Grado de & Instrucción & Incompleto & Completo \\
\hline Primaria & & $($ ) & ( \\
\hline Secundaria & & ( ) & ( \\
\hline Técnico / Instituto & & ( ) & ( \\
\hline Superior / Universitario & & ( ) & ( \\
\hline Post Grado & & ( & ( \\
\hline Maestría / Doctorado & & ( ) & ( \\
\hline Profesión & & ( ) & ( \\
\hline
\end{tabular}

Ocupación Actual:

Lugar donde trabaja:

5.- ¿Pertenece a algún club?

6.- ¿En su familia tienen automóvil para uso personal?

Sí

No

No

Marca Año

7.- Posee tarjeta de Crédito Bancaria: $\quad$ Sí( ) No( )

8.- Su vivienda es: Propia( ) Alquilada( ) De mis Padres / Familiares( )

9.- Tipo de vivienda

- Solar ( )

- Quinta ( )

- $\quad$ Edificio ( )

- Casa Independiente ( )

- Condominio ( )

10.- Cuantos Baños tiene su casa: Ninguno( ) Uno Dos( ) Tres( ) Cuatro( ) o más( )

11.- Bienes que tiene en su hogar:

- Refrigeradora ( )

- TV a color ( )

- Lavadora ( )

- Secadora de ropa ( )

- Servicio doméstico ( )

- Aspiradora Horno ( )

- Microondas

- Computadora ( ) 
- $\quad$ Internet ( )

12.- Número de Familias que viven en su casa:

13.- Número de personas que viven en su hogar:

14.- Número de personas que trabajan:

15.- Periódicos que lee: El Comercio( ) La República( ）Ojo( ) Perú 21( ) El Popular( ) Expreso( ) Ajá( ) Otros( )

16.- ¿Donde suele Comprar Comestibles?
- $\quad \operatorname{Metro}($ )
- $\quad$ Plaza Vea ( )
- Wong ( )
- $\quad$ Tottus ( )
- $\operatorname{Ecco}($ )
- Minka ( )
- $\quad$ Mini Sol ( )
- $\quad \operatorname{Mercados}($ )
- $\quad$ Bodegas ( )
- Otros ( )

17.- ¿Compra productos envasados como menestras, azúcar, arroz, fideos, gelatina, sémola o galletas?

18.- El arroz que compra es: A granel( ） Embolsado( )

- ¿Qué marcas? Metro( ) Molino Rojo( ) Costeño( ) Paisana( ) Otros( )

- $\quad$ Frecuencia de compra: de 1 a 2 veces por mes( ) de 3 a 4 veces por mes( ) Más de 4 veces por mes( )

19.- El azúcar que compra es: A granel( ) Embolsado( )

\section{- ¿Qué marcas? Metro( ) Paisana( ) Otros( )}

- Frecuencia de compra: de 1 a 2 veces por mes( ) de 3 a 4 veces por mes( ) Más de 4 veces por mes( ) 


\section{ANEXO 7: Encuesta Jolly Roger}

Sírvase marcar con una $\mathrm{X}$ la respuesta a las siguientes preguntas:

1.- ¿Usted conoce el macerado de hierbas en base a Pisco Jolly Roger?

a.- No lo conozco. (Fin de la encuesta)

b.- Si lo conozco.

2.- ¿Cómo se enteró del producto?

(Puede marcar más de una opción)

a.- Por amigos

b.- Evento de la marca

c.- Facebook

d.- Otros:

3.- ¿Ha consumido Jolly Roger?

a.- Sí (Pasar a pregunta 5)

b.- No

4.- ¿Por qué no lo consumió? Puede responder más de 1 opción. (Fin de la encuesta)
a.- Precio
b.- Disponibilidad
c.- Falta de promoción
d.- Calidad percibida.

5.- ¿Dónde lo consumió?

(Puede marcar más de una opción)
a.- Discoteca
b.- Fiesta
c.- Casa
d.- Evento de la marca
e.- Otros:

6.- De 1 al 5 marca qué tan agradable o desagradable es el Jolly Roger en donde 1 es muy agradable y 5 muy Desagradable

\begin{tabular}{|l|l|l|l|l|l|}
\hline & $\mathbf{1}$ & $\mathbf{2}$ & $\mathbf{3}$ & $\mathbf{4}$ & $\mathbf{5}$ \\
\hline Sabor & & & & & \\
\hline Color & & & & & \\
\hline Presentación & & & & & \\
\hline Sabor Residual & & & & & \\
\hline $\begin{array}{l}\text { Grado de } \\
\text { alcohol }\end{array}$ & & & & \\
\hline
\end{tabular}

7.¿Cuál es la cantidad ideal de mililitros en una botella de Jolly Roger?

a.- Menos de 500 mililitros

b.- 500 mililitros

c.- 750 mililitros.

d.- 1 litro.

e.- Más de 1 litro.

8. ¿Cuál es el precio ideal que pagaría por una botella de Jolly Roger de 750 mililitros?

a.- Entre 20 y 30 soles

b.- Entre 31 y 40 soles

c.- Entre 41 y 50 soles

d.- Entre 51 y 60 soles

e.- Más de 60 soles

9.- ¿Cuál considera usted es el producto competencia de Jolly Roger? ¿Porque?

10.- En general cómo calificaría a Jolly Roger?

a.- Muy bueno 

b.- Bueno
c.- Regular
d.- Malo
e.- Muy malo

11.- De 1 al 5 marca qué características de Jolly Roger considera importante en donde 1 es más importante y 5 lo menos importante

\begin{tabular}{|l|l|l|l|l|l|}
\hline & $\mathbf{1}$ & $\mathbf{2}$ & $\mathbf{3}$ & $\mathbf{4}$ & $\mathbf{5}$ \\
\hline Etiqueta & & & & & \\
\hline Botella & & & & & \\
\hline Cantidad de ml & & & & & \\
\hline Tapa & & & & & \\
\hline Colores & & & & & \\
\hline
\end{tabular}

12.- Con qué frecuencia lo consume?

a.- 1 vez al mes

b.- 2 veces al mes

c.- 3 veces al mes

d.- Más de 4 veces al mes

13.- Cómo toma el Jolly Roger?

a.- Puro (pasar a la pregunta 15)

b.- Combinado

14.- Con que suele combina Jolly Roger?

a.- Gingerale

b.- Red Bull

c.- Jugo de naranja

d.- Agua

e.- Otros

15.- ¿Lo ha comprado?

a. $\mathrm{Si}$

b. No (Pasar a la pregunta 18)
16.- ¿Dónde lo compro? (Puede marcar más de una opción)
a.- Bodega Santa María
b.- Tambo
c.- Jet Market
d.- Discoteca

17.- Sírvase enumerar en orden de importancia los factores a la hora de hacer la compra de Jolly Roger, siendo 1 lo más importante y 5 lo menos importante

\begin{tabular}{|l|l|l|l|l|l|}
\hline & $\mathbf{1}$ & $\mathbf{2}$ & $\mathbf{3}$ & $\mathbf{4}$ & $\mathbf{5}$ \\
\hline $\begin{array}{l}\text { Calidad } \\
\text { percibida }\end{array}$ & & & & & \\
\hline Precio & & & & & \\
\hline $\begin{array}{l}\text { Cantidad en } \\
\text { mililitros }\end{array}$ & & & & & \\
\hline Marca & & & & & \\
\hline Disponibilidad & & & & & \\
\hline
\end{tabular}

18.- Recomendaría a Jolly Roger?

$$
\begin{aligned}
& \text { a.- } \mathrm{Si} \\
& \text { b.- No }
\end{aligned}
$$

19.- Compraría o volvería a comprar Jolly Roger?

1.- Definitivamente lo compraría

2.- Lo compraría

3.- Posiblemente lo compraría

4.- No lo compraría

5.- Definitivamente lo compraría

Datos de Control:

Nombre y Apellidos:

Edad:

Distrito en el que vive:

Número de DNI: 


\section{ANEXO 8: Guía de pautas Jolly Roger}

\section{I.SALUDO Y PRESENTACIÓN}

Buenos días/noches, gracias por participar en nuestro Focus Group. Mi nombre es... y soy el moderador de esta reunión. A continuación se les hará una serie de preguntas relacionadas a un tema en específico por lo que se les pide total sinceridad.

Sientanse en total libertad de decirnos su opinión, no existen respuestas buenas ni malas.

Para fines de investigación esta reunión será grabada.

\section{II.CALENTAMIENTO}

Para empezar haremos una breve presentación de cada uno, indicando como se llaman, cuántos años tienen, el distrito en donde residen y qué les gusta hacer en su tiempo libre.

\section{III.ESTUDIO EN PROFUNDIDAD}

\section{Hábitos de compra y consumo de bebidas alcohólicas}

Entiendo que en esta sala todos toman bebidas alcohólicas ocasionalmente, me gustaría conversar sobre este tema, por ejemplo:

-¿En qué lugares suelen consumir bebidas alcohólicas? ¿En qué ocasiones?

-¿Con qué frecuencia consumen bebidas alcohólicas?

-¿Cuál es el gasto promedio que realizan al comprar bebidas alcohólicas?

- ¿Cuáles son los motivos por el que consumen bebidas alcohólicas?

- ¿Cuáles son las bebidas alcohólicas que consumen?

- ¿Cuáles son los días y hora en que ustedes consumen bebidas alcohólicas?

- ¿Qué cantidad de bebidas alcohólicas consumen regularmente?

- ¿Con qué personas suelen tomar bebidas alcohólicas?

- ¿Suelen tomar las bebidas alcohólicas puras o en mezclas? ¿Con que lo mezclan?

- ¿Cuáles son las marcas que más consumen? ¿Cuáles son las marcas que menos consumen? ¿Por qué?

- ¿En qué presentaciones consumen bebidas alcohólicas? ¿Por qué?

Hábitos de consumo de Pisco y bebidas elaboradas en base a Pisco

- ¿En qué lugares suelen consumir Pisco? ¿En qué ocasiones?

- ¿Con qué frecuencia consumen Pisco?

- ¿Cuáles son los días y hora en que ustedes consumen Pisco?

- ¿Qué cantidad de Pisco consumen regularmente?

- ¿Cuáles son los motivos por los que consumen pisco? 
-¿Cuál es el gasto promedio que realizan al comprar Pisco?

- ¿Suelen tomar Pisco puro o mezclado con otros líquidos? ¿Con qué lo mezclan?

- ¿Qué tipo de pisco toman? ¿Por qué?

- ¿Cuáles son las marcas de Pisco que más consumen? ¿Cuáles son las marcas que menos consumen? ¿Por qué?

- ¿En qué presentaciones consumen Pisco? ¿Por qué?

(FOCUS JOLLY ROGER)Hábitos de consumo de Jolly Roger

- ¿En qué lugares suelen consumir Jolly Roger? ¿En qué ocasiones?

- ¿Con qué frecuencia lo consumes?

- ¿Qué cantidad de Jolly Roger consumen regularmente?

- ¿Cuáles son los motivos por los que consumen Jolly?

- ¿Suelen tomarlo puro o mezclado? ¿Con qué lo mezclan?

- ¿Cuáles otras marcas conoces que se parecen al Jolly Roger?

\section{(TODOS)}

\section{Concepto y evaluación del producto y la marca}

- ¿Les gusta el nombre Jolly Roger? ¿Porque?

- ¿Con qué asocias el nombre Jolly Roger?

- ¿Qué otros nombres le pondrías al macerado?

\section{Prueba de producto Jolly Roger Puro}

Bueno señores, en este momento haremos la prueba de producto

- ¿Qué les parece el sabor?

- ¿Qué sabores encuentran en este producto?

- ¿Qué sabor les deja en la boca?

- ¿En nivel de dulce es el adecuado?

- ¿Qué les parece el color?

- ¿Qué les pareció el aroma?

- ¿El aroma les recuerda a alguna situación o momento?

- ¿Qué recomendaciones le haría para mejorar el producto?

\section{Prueba de producto Jolly Roger combinado Evervest}

Bueno señores, en este momento haremos la prueba de producto

- ¿Qué les parece el sabor?

- ¿Que tal es la combinación?

- ¿Qué sabor les deja en la boca?

- ¿En nivel de dulce es el adecuado?

- ¿Qué les parece el color?

- ¿Qué les pareció el aroma?

- ¿El aroma les recuerda a alguna situación o momento?

- ¿Qué recomendaciones le haría para mejorar el producto? 


\section{Análisis del producto}

- ¿Les gusta el envase? ¿Cuál sería el ideal?

- ¿Cuantos mililitros debería tener el envase ideal de este producto?

- ¿Qué nivel de Pisco le gustaría tenga el producto? (nivel de alcohol)

- ¿Cómo debería ser la nueva etiqueta? ¿De qué color? ¿De qué forma? ¿De qué material? ¿Qué información le gustaría encontrar en la etiqueta del producto?

- ¿Cuál es el precio mínimo que pagarían por el producto?

- ¿Cuál es el precio máximo que pagarían por el producto?

- ¿Con qué frecuencia lo comprarían?

- ¿Cuántos comprarían?

- ¿En dónde quisieran encontrar este producto?

\section{Comunicación y Promoción}

- ¿En qué medios de comunicación debería aparecer el producto?

- ¿Cuál o cuáles serían los medios de comunicación ideales para comunicar este producto?

- ¿Qué tanto le gusta el mensaje o slogan "Eleva Tu Bandera? ¿Podría sugerir algún otro slogan?

- ¿Qué promociones le gustaría para este producto?

- ¿Qué información se debería comunicar en las promociones de este nuevo producto?

- ¿Qué personaje conocido sería ideal como imagen de la marca?

Agradecemos profundamente su participación en este Focus y apreciamos sus opiniones acerca de este producto. ¡Muchas gracias! 
ANEXO 9: Nuevo organigrama para el 2018

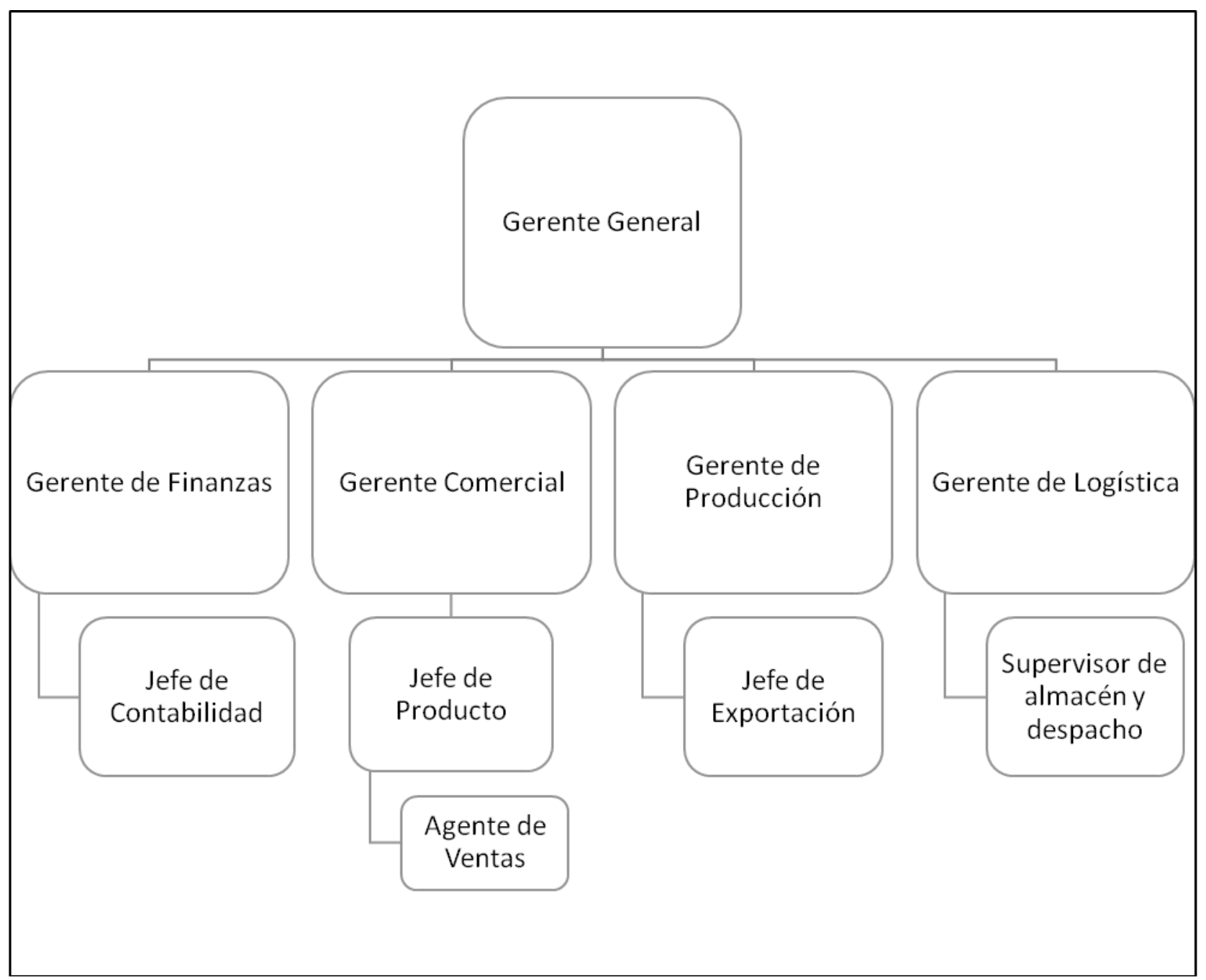


ANEXO 10: Acciones dirigidas a precio

\begin{tabular}{|c|c|c|}
\hline Estrategia & Acción & Tareas \\
\hline \multirow{8}{*}{$\begin{array}{c}\text { Evaluar } \\
\text { periódicamente los } \\
\text { precios de venta al } \\
\text { público de la } \\
\text { competencia } \\
\text { Jagermeister en los } \\
\text { diferentes canales en } \\
\text { los que tiene } \\
\text { presencia para } \\
\text { mantener una } \\
\text { diferencia }\end{array}$} & \multirow{2}{*}{$\begin{array}{l}\text { Elegir a la empresa que } \\
\text { realizara los tracking de precios } \\
\text { trimestrales }\end{array}$} & $\begin{array}{l}\text { Buscar información sobre las empresas que } \\
\text { realizan tracking de precios }\end{array}$ \\
\hline & & $\begin{array}{l}\text { Determinar y evaluar los puntos decisorios de } \\
\text { las empresas de investigación }\end{array}$ \\
\hline & $\begin{array}{l}\text { Determinar el canal o canales } \\
\text { en los que se realizara } \\
\text { el tracking de precios }\end{array}$ & $\begin{array}{l}\text { Evaluar con el equipo comercial el canal para } \\
\text { realizar el tracking de precios }\end{array}$ \\
\hline & Realizar Tracking de precios & $\begin{array}{l}\text { Reunión con la empresa seleccionada para } \\
\text { desarrollar el cronograma de trabajo }\end{array}$ \\
\hline & & $\begin{array}{l}\text { Seguimiento al desarrollo del tracking de } \\
\text { precios }\end{array}$ \\
\hline & $\begin{array}{l}\text { Revisión de resultados de } \\
\text { tracking de precios }\end{array}$ & $\begin{array}{l}\text { Programar la reunión de revisión de resultados } \\
\text { con el equipo comercial }\end{array}$ \\
\hline & & Realizar la reunión de revisión de resultados \\
\hline & $\begin{array}{l}\text { Desarrollar e implementar } \\
\text { acciones en los puntos de venta }\end{array}$ & $\begin{array}{l}\text { Desarrollar e implementar las acciones en el } \\
\text { canal de venta }\end{array}$ \\
\hline $\begin{array}{l}\text { Implementar política } \\
\text { de pagos clara para } \\
\text { cada canal de venta. }\end{array}$ & $\begin{array}{l}\text { Desarrollar la Política de pagos } \\
\text { para cada canal de venta }\end{array}$ & $\begin{array}{l}\text { El Gerente de Administración y Finanzas y el } \\
\text { Gerente General deberán desarrollar la Política } \\
\text { de pagos para cada canal de venta. }\end{array}$ \\
\hline & 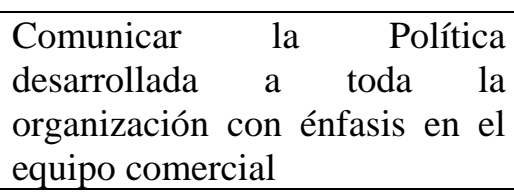 & $\begin{array}{l}\text { El Gerente General comunicara la Política de } \\
\text { pagos a toda la compañía con énfasis en su } \\
\text { equipo comercial }\end{array}$ \\
\hline & $\begin{array}{l}\text { Comunicar la Política } \\
\text { desarrollada a todos los nuevos } \\
\text { clientes }\end{array}$ & $\begin{array}{l}\text { El Gerente General comunicara la Política de } \\
\text { pagos a todos los clientes }\end{array}$ \\
\hline $\begin{array}{l}\text { Evaluación de } \\
\text { créditos trimestrales } \\
\text { para clientes }\end{array}$ & $\begin{array}{l}\text { Desarrollar la Política de } \\
\text { créditos de la compañía }\end{array}$ & $\begin{array}{l}\text { El Gerente de Administración y Finanzas y el } \\
\text { Gerente General deberán desarrollar la Política } \\
\text { de créditos para cada canal de venta. }\end{array}$ \\
\hline & 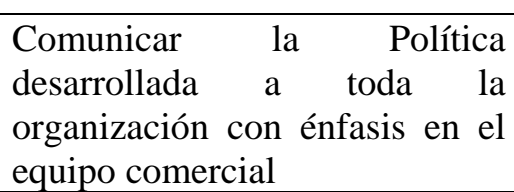 & $\begin{array}{l}\text { El Gerente General comunicara la Política de } \\
\text { pagos a toda la compañía con énfasis en su } \\
\text { equipo comercial. }\end{array}$ \\
\hline & $\begin{array}{l}\text { Comunicar la Política } \\
\text { desarrollada a todos los nuevos } \\
\text { clientes }\end{array}$ & $\begin{array}{l}\text { El Gerente General comunicara la Política de } \\
\text { pagos a todos los clientes }\end{array}$ \\
\hline
\end{tabular}




\begin{tabular}{|c|c|c|}
\hline & $\begin{array}{l}\text { Realizar la evaluación de } \\
\text { créditos para cada cliente }\end{array}$ & $\begin{array}{l}\text { El Gerente de Administración y Finanzas } \\
\text { evaluara la linea de crédito para cada cliente }\end{array}$ \\
\hline \multirow[t]{3}{*}{$\begin{array}{c}\text { Descuento sobre } \\
\text { precio de lista } \\
\text { para nuevos canales. }\end{array}$} & $\begin{array}{l}\text { Desarrollar Listas de Precios } \\
\text { para cada canal de ventas }\end{array}$ & $\begin{array}{l}\text { El Gerente de Administración y Finanzas y el } \\
\text { Gerente General deberán desarrollar la Política } \\
\text { de créditos para cada canal de venta. }\end{array}$ \\
\hline & $\begin{array}{l}\text { Determinar el road to market } \\
\text { para cada canal de ventas }\end{array}$ & $\begin{array}{l}\text { El Gerente Comercial desarrollara el road to } \\
\text { market para cada canal de venta. }\end{array}$ \\
\hline & $\begin{array}{l}\text { Comunicar a todo el equipo } \\
\text { comercial de la organización }\end{array}$ & $\begin{array}{l}\text { El Gerente General comunicara la Política de } \\
\text { pagos a toda la compañía con énfasis en su } \\
\text { equipo comercial. }\end{array}$ \\
\hline \multirow[t]{6}{*}{$\begin{array}{c}\text { Evaluar la } \\
\text { percepción de valor } \\
\text { de la competencia y } \\
\text { del producto }\end{array}$} & \multirow[t]{2}{*}{$\begin{array}{l}\text { Determinar que empresa } \\
\text { realizara la evaluación de la } \\
\text { percepción de Jolly Roger y } \\
\text { Jagermeister }\end{array}$} & $\begin{array}{l}\text { Buscar información sobre las empresas que } \\
\text { realizan evaluaciones de percepción de marcas. }\end{array}$ \\
\hline & & $\begin{array}{l}\text { Determinar y evaluar los puntos decisorios de } \\
\text { las empresas de investigación. }\end{array}$ \\
\hline & $\begin{array}{l}\text { Desarrollo de las encuestas para } \\
\text { medir la percepción de } \\
\text { Jolly Roger y Jagermeister. }\end{array}$ & $\begin{array}{l}\text { Reunión con la empresa seleccionada para } \\
\text { desarrollar el estudio a implementar. }\end{array}$ \\
\hline & $\begin{array}{l}\text { Realizar la evaluación de } \\
\text { percepción de Jolly Roger y } \\
\text { competencia }\end{array}$ & $\begin{array}{l}\text { Seguimiento a la empresa de investigación para } \\
\text { el cumplimiento del cronograma establecido. }\end{array}$ \\
\hline & $\begin{array}{l}\text { Revision de resultados de la } \\
\text { evaluación de percepción }\end{array}$ & $\begin{array}{l}\text { El Gerente Comercial agendará la reunión con } \\
\text { la empresa de investigación para revisar los } \\
\text { resultados de la evaluación de percepción. }\end{array}$ \\
\hline & $\begin{array}{l}\text { Desarrollar e implementar } \\
\text { acciones en los puntos de venta }\end{array}$ & $\begin{array}{l}\text { Se acordaran las acciones a realizar en cada } \\
\text { punto de venta según los resultados del estudio } \\
\text { de percepción. }\end{array}$ \\
\hline
\end{tabular}


ANEXO 11: Acciones dirigidas a producto

\begin{tabular}{|c|c|c|}
\hline Estrategia & Acción & Tareas \\
\hline \multirow[t]{4}{*}{$\begin{array}{l}\text { Introducir una } \\
\text { nueva } \\
\text { presentación de } \\
\text { botella. }\end{array}$} & $\begin{array}{l}\text { Evaluar la aceptación de } \\
\text { presentaciones de menor y mayor } \\
\text { volumen que la presentación actual } \\
\text { de } 750 \mathrm{ml}\end{array}$ & $\begin{array}{l}\text { - Coordinar con el abastecedor de botellas } \\
\text { el envío de los nuevos formatos de } \\
\text { botellas a evaluar. } \\
\text { - Presentar los formatos a jefaturas para } \\
\text { coordinar autorización de realización de } \\
\text { focus. } \\
\text { - Realizar las coordinaciones para } \\
\text { realización de focus group para } \\
\text { evaluación de formatos de nuevas } \\
\text { botellas. } \\
\text { - Realizar el análisis de los datos obtenidos } \\
\text { en el focus group }\end{array}$ \\
\hline & $\begin{array}{l}\text { Presentar informe de resultados de } \\
\text { evaluación, con presentación final } \\
\text { seleccionada. }\end{array}$ & $\begin{array}{l}\text { - Realizar el informe con los resultados } \\
\text { obtenidos en el focus realizado en la } \\
\text { evaluación. } \\
\text { - Presentar informe a la gerencia. }\end{array}$ \\
\hline & $\begin{array}{l}\text { Comunicar a todas las áreas de nueva } \\
\text { presentación a lanzar }\end{array}$ & $\begin{array}{l}\text { - Enviar comunicado a todas las areas de la } \\
\text { nueva presentación elegida. }\end{array}$ \\
\hline & $\begin{array}{l}\text { Preparar lanzamiento para el año } \\
2019\end{array}$ & $\begin{array}{l}\text { - Comunicar a los canales de la nueva } \\
\text { presentación a lanzar. } \\
\text { - Realizar sembrado de nueva presentación. } \\
\text { - Realizar coordinaciones con los canales } \\
\text { para el lanzamiento del nuevo formato. }\end{array}$ \\
\hline \multirow[t]{4}{*}{$\begin{array}{l}\text { Evaluar el diseño } \\
\text { de la botella del } \\
\text { producto }\end{array}$} & $\begin{array}{l}\text { Realizar focus de diseño actual de } \\
\text { botella y tapas, presentando diseños } \\
\text { alternativos. }\end{array}$ & $\begin{array}{l}\text { - Coordinar con abastecedores de botellas y } \\
\text { tapas muestras de nuevos diseños para } \\
\text { evaluación. } \\
\text { - Coordinar con jefaturas la programación } \\
\text { de los focus a realizar. } \\
\text { - Realizar focus group con los diseños } \\
\text { alternativos. } \\
\text { - Realizar el análisis de los datos obtenidos } \\
\text { en el focus group }\end{array}$ \\
\hline & $\begin{array}{l}\text { Presentar informe de resultados de } \\
\text { evaluación. }\end{array}$ & $\begin{array}{l}\text { - Realizar el informe con los resultados } \\
\text { obtenidos en el focus realizado en la } \\
\text { evaluación. } \\
\text { - Presentar informe a la gerencia. }\end{array}$ \\
\hline & $\begin{array}{l}\text { Comunicar a todas las áreas si se } \\
\text { mantiene el diseño o se cambia } \\
\text { diseño de botellas }\end{array}$ & $\begin{array}{l}\text { - Enviar comunicado a todas las áreas con } \\
\text { decisión de gerencia. }\end{array}$ \\
\hline & $\begin{array}{l}\text { Rediseñar etiquetas de producto con } \\
\text { diseñador freelance. }\end{array}$ & $\begin{array}{l}\text { - Evaluar los diseños presentados por } \\
\text { diseñador. }\end{array}$ \\
\hline
\end{tabular}


PLAN DE MARKETING PARA LA BODEGA SANTA MARIA: JOLLY ROGER

\begin{tabular}{|c|c|c|}
\hline \multirow[t]{6}{*}{$\begin{array}{l}\text { Mejorar el } \\
\text { etiquetado }\end{array}$} & & $\begin{array}{l}\text { - Presentar los diseños alternativos } \\
\text { seleccionados a gerencia para su } \\
\text { aprobación. }\end{array}$ \\
\hline & $\begin{array}{l}\text { Realizar la evaluación de aceptación } \\
\text { de nuevas etiquetas }\end{array}$ & $\begin{array}{l}\text { - Coordinar con jefaturas la programación } \\
\text { de los focus a realizar. } \\
\text { - Realizar focus group con los diseños } \\
\text { alternativos. } \\
\text { - Realizar el análisis de los datos obtenidos } \\
\text { en el focus group }\end{array}$ \\
\hline & $\begin{array}{l}\text { Presentar informe de resultados de } \\
\text { evaluación. }\end{array}$ & $\begin{array}{l}\text { - Realizar el informe con los resultados } \\
\text { obtenidos en el focus realizado en la } \\
\text { evaluación. } \\
\text { - Presentar informe a la gerencia. }\end{array}$ \\
\hline & $\begin{array}{l}\text { Comunicar a todas las áreas el nuevo } \\
\text { diseño de las etiquetas. }\end{array}$ & $\begin{array}{l}\text { - Enviar comunicado a todas las áreas de la } \\
\text { empresa de nuevo diseño de etiquetas. }\end{array}$ \\
\hline & $\begin{array}{l}\text { Agotar stock de botellas con antiguas } \\
\text { etiquetas. }\end{array}$ & $\begin{array}{l}\text { - Coordinar impresión de nuevas etiquetas. } \\
\text { - Realizar el etiquetado de las botellas con } \\
\text { nuevas etiquetas. } \\
\text { - Agotar stock de botellas con antiguo } \\
\text { etiquetado. }\end{array}$ \\
\hline & $\begin{array}{l}\text { Comunicar al mercado el diseño de } \\
\text { las nuevas etiquetas. }\end{array}$ & $\begin{array}{l}\text { - Informar a los canales de nuevo diseño de } \\
\text { etiqueta. } \\
\text { - Realizar campañas para comunicar el } \\
\text { nuevo diseño de las etiquetas. }\end{array}$ \\
\hline \multirow[t]{2}{*}{$\begin{array}{lr}\text { Evaluar } & \text { el } \\
\text { nombre } & \text { del } \\
\text { Producto } & \end{array}$} & $\begin{array}{l}\text { Iniciar evaluación con estudio } \\
\text { cualitativo y competitivo el nombre } \\
\text { del producto. }\end{array}$ & $\begin{array}{l}\text { - Realizar encuestas con posibles nombres } \\
\text { para el macerado. } \\
\text { - Realizar encuesta para conocer } \\
\text { posicionamiento del macerado en el } \\
\text { mercado. } \\
\text { - Realizar focus group con nombres } \\
\text { sugeridos para el macerado. }\end{array}$ \\
\hline & $\begin{array}{l}\text { Presentar informe de resultados de } \\
\text { evaluación. }\end{array}$ & $\begin{array}{l}\text { - Realizar el informe con los resultados } \\
\text { obtenidos en el focus realizado en la } \\
\text { evaluación. } \\
\text { - Presentar informe a la gerencia. }\end{array}$ \\
\hline
\end{tabular}


PLAN DE MARKETING PARA LA BODEGA SANTA MARIA: JOLLY ROGER

ANEXO 12: Acciones dirigidas a distribución y ventas

\begin{tabular}{|c|c|c|}
\hline Estrategia & Acción & Tareas \\
\hline \multirow{14}{*}{$\begin{array}{l}\text { Reclutar y } \\
\text { consolidar el Área } \\
\text { Comercial }\end{array}$} & \multirow{4}{*}{$\begin{array}{l}\text { Usar un Caza talentos para } \\
\text { encontrar un Jefe de } \\
\text { Producto }\end{array}$} & $\begin{array}{l}\text { Buscar proformas de } 3 \text { Caza talentos cuya base } \\
\text { de búsqueda sea tiempo y costo }\end{array}$ \\
\hline & & Realizar contrato con caza talentos elegido \\
\hline & & Entrevista con postulantes al cargo \\
\hline & & Elección del mejor candidato \\
\hline & \multirow{4}{*}{$\begin{array}{l}\text { Fijar Responsabilidades } \\
\text { Comerciales y de Ventas }\end{array}$} & Fijar Objetivos Comerciales y de Ventas \\
\hline & & $\begin{array}{l}\text { Determinar Las estrategias, planes de acción y } \\
\text { tareas a desempeñar }\end{array}$ \\
\hline & & $\begin{array}{l}\text { Designar responsables de cada tarea, acción, } \\
\text { estrategia y objetivo }\end{array}$ \\
\hline & & $\begin{array}{l}\text { Comunicar a cada responsable sobre sus } \\
\text { responsabilidades comerciales y de ventas }\end{array}$ \\
\hline & \multirow{3}{*}{$\begin{array}{c}\text { Definir Zonas de Trabajo y } \\
\text { Visitas }\end{array}$} & $\begin{array}{l}\text { Realizar zondeo de posibles clientes, zonas de } \\
\text { trabajo y alternativas de rutas }\end{array}$ \\
\hline & & Definir clientes, zonas y rutas \\
\hline & & $\begin{array}{l}\text { Definir responsables de cada ruta y de cada } \\
\text { cliente }\end{array}$ \\
\hline & \multirow{3}{*}{$\begin{array}{l}\text { Incorporación de } \\
\text { Vendedor }\end{array}$} & $\begin{array}{l}\text { Requerimiento de personal indicado para el } \\
\text { puesto }\end{array}$ \\
\hline & & Entrevista de terna de 4 personas \\
\hline & & Elección y contratación del vendedor \\
\hline \multirow{9}{*}{$\begin{array}{c}\text { Ingresar a } \\
\text { Supermercados } \\
\text { WONG y VIVANA }\end{array}$} & \multirow{4}{*}{$\begin{array}{l}\text { Presentación de propuesta } \\
\text { financiera y de precios a } \\
\text { WONG y VIVANDA }\end{array}$} & $\begin{array}{l}\text { Realizar alternativas de propuesta financiera y de } \\
\text { precios para cada Autoservicio y seleccionar la } \\
\text { más indicada }\end{array}$ \\
\hline & & \begin{tabular}{|lll}
$\begin{array}{l}\text { Presentar la propuesta seleccionada a cada } \\
\text { Supermercado }\end{array}$ & \\
\end{tabular} \\
\hline & & $\begin{array}{l}\text { Realizar una propuesta mejorada según } \\
\text { requerimientos del supermercado }\end{array}$ \\
\hline & & $\begin{array}{l}\text { Aceptación y confirmación de propuesta del } \\
\text { supermercado }\end{array}$ \\
\hline & \multirow{3}{*}{$\begin{array}{c}\text { Presentación de propuesta } \\
\text { de inversión en Trade } \\
\text { Marketing a } \\
\text { Supermercados }\end{array}$} & $\begin{array}{l}\text { Realizar alternativas de propuesta de inversión } \\
\text { en Trade para cada Autoservicio y seleccionar la } \\
\text { más indicada, teniendo como fechas Febrero, } \\
\text { Junio, Julio, Octubre y Diciembre. }\end{array}$ \\
\hline & & $\begin{array}{l}\text { Presentar la propuesta seleccionada a cada } \\
\text { Supermercado }\end{array}$ \\
\hline & & $\begin{array}{l}\text { Aceptación y confirmación de propuesta del } \\
\text { supermercado }\end{array}$ \\
\hline & \multirow{2}{*}{$\begin{array}{l}\text { Diseño de Plan de } \\
\text { Encartes para los } 2 \\
\text { Supermercados }\end{array}$} & $\begin{array}{l}\text { Realizar propuesta de Encarte para el Mes de } \\
\text { Octubre }\end{array}$ \\
\hline & & $\begin{array}{l}\text { Aceptación y confirmación de propuesta del } \\
\text { supermercado }\end{array}$ \\
\hline
\end{tabular}




\begin{tabular}{|c|c|c|}
\hline & \multirow{2}{*}{$\begin{array}{l}\text { Comunicación de los } \\
\text { rebates a los } \\
\text { supermercados }\end{array}$} & $\begin{array}{l}\text { Realizar estudio financiero para determinar } \\
\text { descuentos por monto de compra }\end{array}$ \\
\hline & & $\begin{array}{l}\text { Comunicar los rebates a cada supermercado y las } \\
\text { condiciones para obtener ese beneficio }\end{array}$ \\
\hline \multirow{10}{*}{$\begin{array}{l}\text { Ingreso a nuevo } \\
\text { canal HORECAS }\end{array}$} & \multirow{2}{*}{$\begin{array}{c}\text { Ruteo para llegar a las } 100 \\
\text { principales Horecas de } \\
\text { Lima }\end{array}$} & $\begin{array}{l}\text { Definir las principales HORECAS por cada } \\
\text { distrito y definir las } 100 \text { principales }\end{array}$ \\
\hline & & Definir las rutas y establecer responsables \\
\hline & \multirow[t]{2}{*}{$\begin{array}{c}\text { Implementar } 5 \text { actividades } \\
\text { de Trade Marketing para } \\
\text { las } 5 \text { principales } \\
\text { Discotecas de Lima }\end{array}$} & Definir las 5 principales discotecas de Lima \\
\hline & & $\begin{array}{l}\text { Establecer un Plan de Trade para los meses de } \\
\text { Febrero, Junio, Julio, Octubre y Diciembre }\end{array}$ \\
\hline & \multirow{3}{*}{$\begin{array}{l}\text { Realizar una publicación } \\
\text { en la revista con mayor } \\
\text { tiraje de HORECAS }\end{array}$} & Definir la Revista y la fecha en que se publicará \\
\hline & & Realizar el diseño del arte a publicar \\
\hline & & Realizar la publicación. \\
\hline & \multirow{3}{*}{$\begin{array}{c}\text { Asignar el } 20 \% \text { de margen } \\
\text { para el Canal HORECAS }\end{array}$} & Realizar estudio económico y de precios \\
\hline & & Definir precio de venta al canal \\
\hline & & $\begin{array}{l}\text { Realizar descuentos por montos de compra o por } \\
\text { diferentes negociaciones. }\end{array}$ \\
\hline \multirow{5}{*}{$\begin{array}{l}\text { Ingreso al Canal } \\
\text { Licorerías }\end{array}$} & \multirow{2}{*}{$\begin{array}{c}\text { Realizar ruteo de las } 20 \\
\text { principales licorerías de } \\
\text { Lima y Callao }\end{array}$} & $\begin{array}{l}\text { Definir las } 20 \text { principales licorerías de Lima y } \\
\text { Callao }\end{array}$ \\
\hline & & $\begin{array}{l}\text { Realizar rutas y responsable de las visitas y de } \\
\text { las ventas }\end{array}$ \\
\hline & \multirow{3}{*}{$\begin{array}{l}\text { Asignar Margen de } 20 \% \\
\text { para Canal Licorerías }\end{array}$} & Realizar estudio económico y de precios \\
\hline & & Definir precio de venta al canal \\
\hline & & $\begin{array}{l}\text { Realizar descuentos or montos de compra o por } \\
\text { diferentes negociaciones }\end{array}$ \\
\hline \multirow{2}{*}{$\begin{array}{l}\text { Ingreso a canal } \\
\text { Mayorista }\end{array}$} & \multirow{2}{*}{$\begin{array}{c}\text { Realizar ruteo de las } 5 \\
\text { principales mayoristas de } \\
\text { Lima y Callao }\end{array}$} & $\begin{array}{l}\text { Definir las } 5 \text { principales licorerías de Lima y } \\
\text { Callao }\end{array}$ \\
\hline & & $\begin{array}{l}\text { Realizar rutas y responsable de las visitas y de } \\
\text { las ventas }\end{array}$ \\
\hline
\end{tabular}


PLAN DE MARKETING PARA LA BODEGA SANTA MARIA: JOLLY ROGER

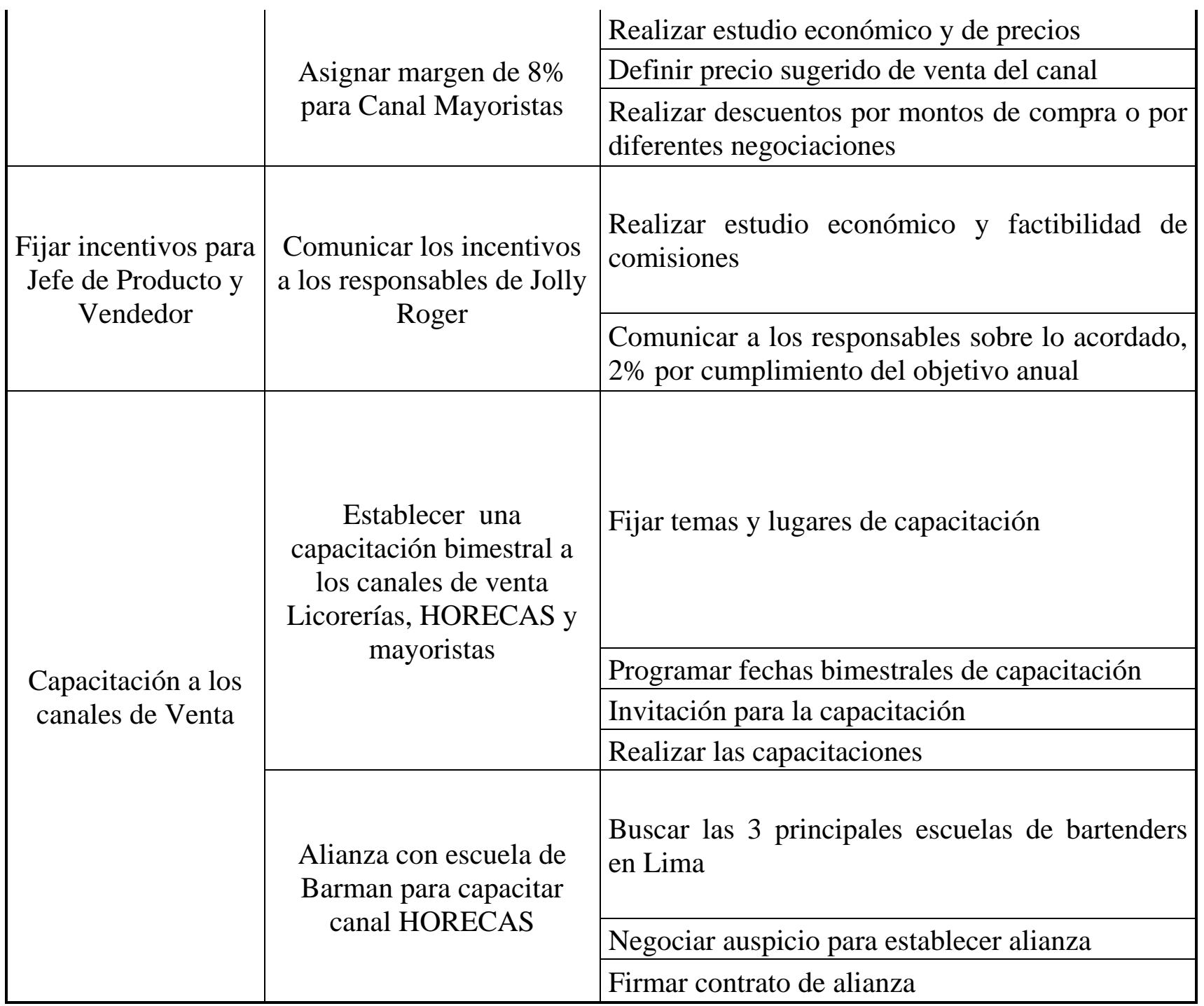




\section{ANEXO 13: Acciones dirigidas a Comunicación Offline}

\begin{tabular}{|c|l|l|}
\hline Estrategia & \multicolumn{1}{|c|}{ Acción } & \multicolumn{1}{c|}{ Tareas } \\
\hline $\begin{array}{c}\text { Implementar soporte de } \\
\text { material POP en los } \\
\text { puntos de ventas }\end{array}$ & $\begin{array}{l}\text { Diseñar e imprimir } \\
\text { folletos y posters }\end{array}$ & $\begin{array}{l}\text { Presentación del brief a la } \\
\text { agencia de publicidad }\end{array}$ \\
& $-\begin{array}{l}\text { Realización del mensaje y } \\
\text { diseño creativo Agencia) y } \\
\text { aprobación por parte de la }\end{array}$ \\
Bodega Santa María
\end{tabular}




\section{ANEXO 14: Acciones dirigidas a Comunicación Online}

\begin{tabular}{|c|c|c|}
\hline Estrategia & Acción & Tareas \\
\hline \multirow{2}{*}{$\begin{array}{l}\text { Recopilar información para } \\
\text { mantenernos informados de } \\
\text { todas las tendencias y gustos } \\
\text { del target }\end{array}$} & $\begin{array}{l}\text { Realizar } \\
\text { diariamente }\end{array}$ & $\begin{array}{l}\text { - Investigar y realizar un reporte de } \\
\text { las acciones de comunicación que } \\
\text { la competencia directa e indirecta } \\
\text { está realizando } \\
\text { - } \text { Presentar el informe al jefe de } \\
\text { medios y social media. }\end{array}$ \\
\hline & $\begin{array}{l}\text { Comprar estudios de } \\
\text { mercado de IAB, IMS y } \\
\text { Quántico bimestralmente }\end{array}$ & $\begin{array}{l}\text { - Contactarse con los encargados de } \\
\text { ventas de las diferentes empresas de } \\
\text { estudios en inversión en digital } \\
\text { - Establecer un convenio a } 1 \text { año para } \\
\text { la compra de los estudios de } \\
\text { mercado. }\end{array}$ \\
\hline \multirow{3}{*}{$\begin{array}{l}\text { Utilizar las redes sociales } \\
\text { para comunicarnos } \\
\text { directamente con nuestro } \\
\text { público, generar prospectos } \\
\text { y gestionar la atención al } \\
\text { cliente. }\end{array}$} & $\begin{array}{l}\text { Generar } 6 \text { contenidos } \\
\text { mensualmente para } \\
\text { Facebook e Instagram }\end{array}$ & $\begin{array}{l}\text { - } \text { Realización de contenido para redes } \\
\text { sociales: Fotos y videos (Agencia) } \\
\text { - } \text { Presentación de piezas publicitarias } \\
\text { (Agencia) y aprobación por parte de } \\
\text { la Bodega Santa María }\end{array}$ \\
\hline & $\begin{array}{l}\text { Atender consultas y } \\
\text { quejas, en promedio de } 1 \\
\text { hora. }\end{array}$ & $\begin{array}{l}\text { - Elaborar una base de datos de todas } \\
\text { las personas que se comunican con } \\
\text { la empresa. } \\
\text { - Plantear soluciones rápidas para } \\
\text { cada queja o consulta }\end{array}$ \\
\hline & $\begin{array}{l}\text { Invertir en publicidad } \\
\text { pagada en redes sociales }\end{array}$ & $\begin{array}{l}\text { - } \text { Realizar un plan de medios } \\
\text { (Agencia) y aprobación de por parte } \\
\text { de la Bodega Santa María } \\
\text { - } \text { Monitorear el desempeño } \\
\text { diariamente para optimizar la } \\
\text { inversión }\end{array}$ \\
\hline
\end{tabular}


PLAN DE MARKETING PARA LA BODEGA SANTA MARIA: JOLLY ROGER

\begin{tabular}{|c|c|c|}
\hline \multirow{2}{*}{ Crear una página web } & $\begin{array}{l}\text { Programar la web de la } \\
\text { marca. }\end{array}$ & $\begin{array}{l}\text { - Realizar la propuesta gráfica y la } \\
\text { línea gráfica a utilizar } \\
\text { - Generar contenido sobre el } \\
\text { producto e información importante } \\
\text { en la web } \\
\text { - Presentación de la propuesta de } \\
\text { web a la bodega }\end{array}$ \\
\hline & $\begin{array}{l}\text { Implementar estrategia } \\
\text { SEO }\end{array}$ & $\begin{array}{l}\text { - Buscar optimizar la web en el } \\
\text { buscador google. } \\
\text { - Utilizar palabras clave como Pisco, } \\
\text { Macerado, diversión, Perú para que } \\
\text { el público encuentre la web } \\
\text { - Mantener actualizada la web con } \\
\text { información sobre los eventos }\end{array}$ \\
\hline $\begin{array}{l}\text { Implementar un programa de } \\
\text { fidelización para generar la } \\
\text { recompra del producto. }\end{array}$ & $\begin{array}{l}\text { Crear y diseñar el } \\
\text { programa de fidelización } \\
\text { "Tripulación Jolly Roger" }\end{array}$ & $\begin{array}{l}\text { - Realizar una maqueta y el journey } \\
\text { de cómo funcionaría la nueva web } \\
\text { con el programa. } \\
\text { - Implementar y programar el } \\
\text { sistema de acumulación de puntos. } \\
\text { - Presentación del diseño web } \\
\text { (Agencia) y aprobación por parte de } \\
\text { la Bodega Santa María }\end{array}$ \\
\hline
\end{tabular}




\section{ANEXO 15: Programa de fidelización "Jolly Roger"}

Son personas que llevan un rito de vida acelerada y son pocos fieles a las marcas, se podrían decir que en su mayoría son Milenialls.

Ellos son nativos digitales por lo cual basaremos una estrategia usando principalmente los medios de comunicación digital como las redes sociales para apalancar la estrategia de marketing relacional.

\section{Programa:}

Se creará un programa Co-branding por el cual nuestros consumidores podrán disfrutar de los beneficios adicionales al comprar el producto. Se creará una página web en donde nuestros fans puedan registrarse para poder canjear premios y beneficios.

\section{Mecánica:}

Cada botella de Jolly Roger contará con un código en el reverso de la etiqueta el cual deberá ser ingresado a la web por los consumidores. Cada código ingresado valdrá puntos con los cuales podrán canjear premios en la web. Cada código ingresado valdrá 100 puntos. 
Cuadro de canjes:

\begin{tabular}{|l|c|l|}
\hline \multicolumn{1}{|c|}{ Premio } & Puntos & \multicolumn{1}{c|}{ Valor } \\
\hline Uber Ride & 150 & S/ 20 en viajes \\
\hline Entradas a conciertos (Joinnus) & 200 & $30 \%$ de descuento \\
\hline Cigarros electrónicos / Vaporizadores & 100 & $20 \%$ de descuento \\
\hline Music Market & 200 & $10 \%$ de descuento \\
\hline Sorteo Viaje al Caribe para 2 & 100 & 1 oportunidad de ganar \\
\hline
\end{tabular}

Con este programa no solo lograremos una fidelización por parte de los consumidores, sino también sus hábitos de comprar y de consumo. Además, dispondremos de una gran base de datos la cual podremos utilizar para poder tener una comunicación más directa con el consumidor. 
PLAN DE MARKETING PARA LA BODEGA SANTA MARIA: JOLLY ROGER

ANEXO 16: Proyección de ventas por canal

Autoservicios

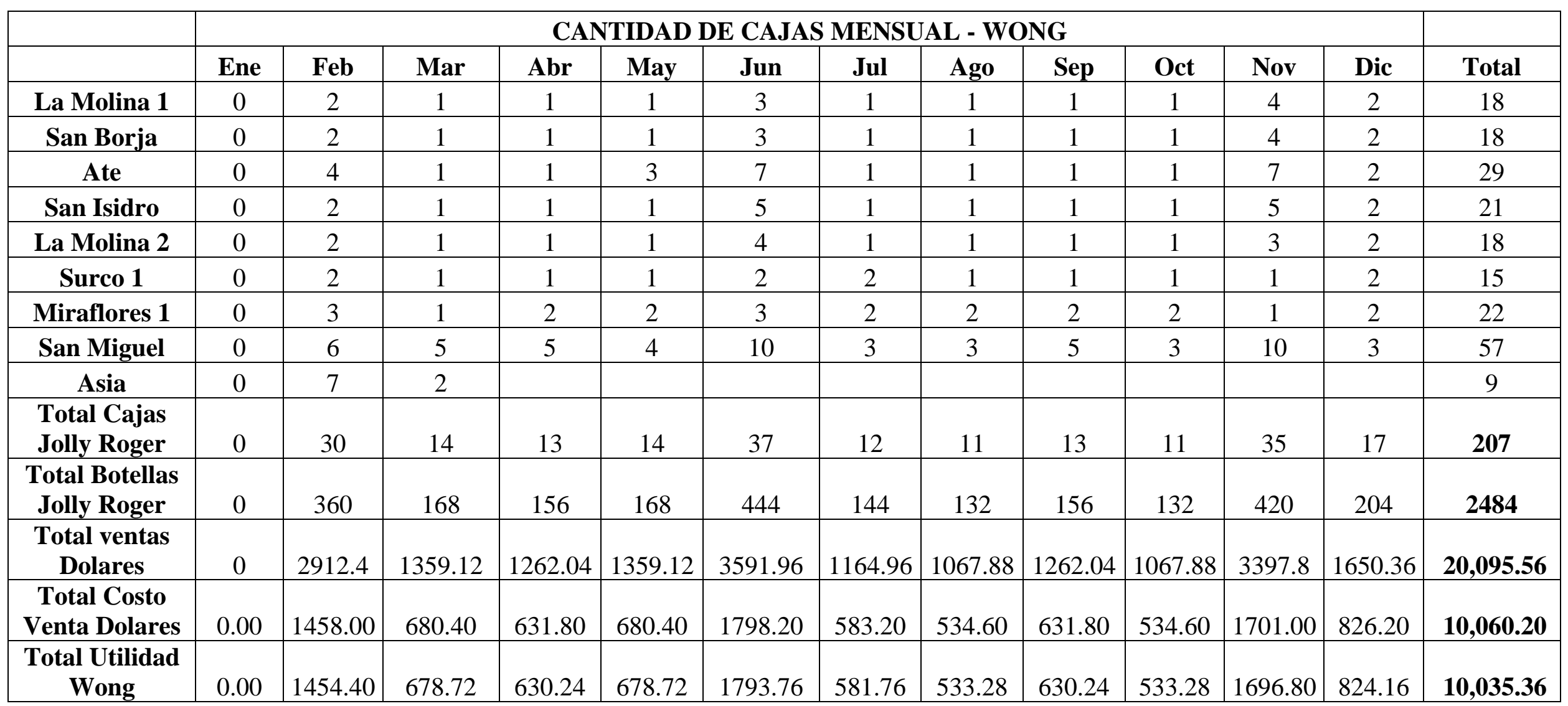


PLAN DE MARKETING PARA LA BODEGA SANTA MARIA: JOLLY ROGER

\begin{tabular}{|c|c|c|c|c|c|c|c|c|c|c|c|c|c|}
\hline & \multicolumn{12}{|c|}{ CANTIDAD DE CAJAS - VIVANDA } & \multirow[b]{2}{*}{ Total } \\
\hline & Ene & Feb & Mar & Abr & May & Jun & Jul & Ago & Sep & Oct & Nov & Dic & \\
\hline Asia & 0 & 6 & 1 & & & & & & & & & & 7 \\
\hline La Molina & 0 & 4 & 1 & 1 & 1 & 1 & 1 & 1 & 1 & 1 & 1 & 2 & 15 \\
\hline Jv Prado & 0 & 2 & 1 & 2 & 1 & 3 & 1 & 1 & 1 & 1 & 3 & 2 & 18 \\
\hline Pardo & 0 & 2 & 1 & 1 & 1 & 3 & 1 & 1 & 1 & 1 & 3 & 2 & 17 \\
\hline Monterrico & 0 & 2 & 1 & 1 & 2 & 1 & 1 & 1 & 1 & 1 & 1 & 2 & 14 \\
\hline Benavides & 0 & 2 & 1 & 5 & 2 & 5 & 1 & 1 & 4 & 1 & 5 & 2 & 29 \\
\hline Dos de Mayo & 0 & 2 & 1 & 1 & 1 & 3 & 1 & 1 & 1 & 1 & 3 & 2 & 17 \\
\hline Pezet & 0 & 2 & 1 & 1 & 1 & 3 & 1 & 1 & 1 & 1 & 3 & 2 & 17 \\
\hline Libertadores & 0 & 2 & 1 & 1 & 1 & 3 & 1 & 1 & 1 & 1 & 1 & 2 & 15 \\
\hline $\begin{array}{l}\text { Total Cajas } \\
\text { Jolly Roger }\end{array}$ & 0 & 24 & 9 & 13 & 10 & 22 & 8 & 8 & 11 & 8 & 20 & 16 & 149 \\
\hline $\begin{array}{c}\text { Total } \\
\text { Botellas } \\
\text { Jolly Roger }\end{array}$ & 0 & 288 & 108 & 156 & 120 & 264 & 96 & 96 & 132 & 96 & 240 & 192 & 1788 \\
\hline $\begin{array}{l}\text { Total ventas } \\
\text { Dolares }\end{array}$ & 0 & 2329.92 & 873.72 & 1262.04 & 970.8 & 2135.76 & 776.64 & 776.64 & 1067.88 & 776.64 & 1941.6 & 1553.28 & $14,464.92$ \\
\hline $\begin{array}{c}\text { Total Costo } \\
\text { Venta } \\
\text { Dolares } \\
\end{array}$ & 0.00 & 1166.40 & 437.40 & 631.80 & 486.00 & 1069.20 & 388.80 & 388.80 & 534.60 & 388.80 & 972.00 & 777.60 & $7,241.40$ \\
\hline $\begin{array}{c}\text { Total } \\
\text { Utilidad } \\
\text { Vivanda } \\
\end{array}$ & 0.00 & 1163.52 & 436.32 & 630.24 & 484.80 & 1066.56 & 387.84 & 387.84 & 533.28 & 387.84 & 969.60 & 775.68 & $7,223.52$ \\
\hline
\end{tabular}


PLAN DE MARKETING PARA LA BODEGA SANTA MARIA: JOLLY ROGER

\begin{tabular}{|c|c|c|c|c|c|c|c|c|c|c|c|c|c|}
\hline & \multicolumn{13}{|c|}{ CANTIDAD DE CAJAS - TAMBO } \\
\hline & Ene & $\mathrm{Feb}$ & Mar & Abr & May & Jun & Jul & Ago & Sep & Oct & Nov & Dic & \\
\hline $\begin{array}{l}\text { Total Cajas } \\
\text { Jolly Roger }\end{array}$ & 25 & 35 & 25 & 15 & 40 & 10 & 40 & 15 & 25 & 20 & 35 & 15 & \\
\hline $\begin{array}{l}\text { Total Botellas } \\
\text { Jolly Roger }\end{array}$ & 300 & 420 & 300 & 180 & 480 & 120 & 480 & 180 & 300 & 240 & 420 & 180 & 3600 \\
\hline $\begin{array}{c}\text { Total ventas } \\
\text { Dolares }\end{array}$ & 3081 & 4313.4 & 3081 & 1848.6 & 4929.6 & 1232.4 & 4929.6 & 1848.6 & 3081 & 2464.8 & 4313.4 & 1848.6 & $36,972.00$ \\
\hline $\begin{array}{c}\text { Total Costo } \\
\text { Venta Dolares }\end{array}$ & 1215 & 1701 & 1215 & 729 & 1944 & 486 & 1944 & 729 & 1215 & 972 & 1701 & 729 & $14,580.00$ \\
\hline $\begin{array}{l}\text { Total Utilidad } \\
\text { Tambo }\end{array}$ & 1866 & 2612.4 & 1866 & 1119.6 & 2985.6 & 746.4 & 2985.6 & 1119.6 & 1866 & 1492.8 & 2612.4 & 1119.6 & $22,392.00$ \\
\hline
\end{tabular}


PLAN DE MARKETING PARA LA BODEGA SANTA MARIA: JOLLY ROGER

\section{Licorerías}

\begin{tabular}{|c|c|c|c|c|c|c|c|c|c|c|c|c|c|}
\hline & \multicolumn{12}{|c|}{ CANTIDAD DE CAJAS - LICORERIAS } & \multirow[b]{2}{*}{ Total } \\
\hline & Ene & Feb & Mar & Abr & May & Jun & Jul & Ago & Sep & Oct & Nov & Dic & \\
\hline $\begin{array}{l}\text { Total Cajas } \\
\text { Jolly Roger }\end{array}$ & 5 & 40 & 15 & 10 & 50 & 50 & 50 & 20 & 20 & 20 & 40 & 40 & 360 \\
\hline $\begin{array}{c}\text { Total ventas } \\
\text { Dolares }\end{array}$ & 554.4 & 4435.2 & 1663.2 & 1108.8 & 5544 & 5544 & 5544 & 2217.6 & 2217.6 & 2217.6 & 4435.2 & 4435.2 & $39,916.80$ \\
\hline $\begin{array}{c}\text { Total } \\
\text { Utilidad } \\
\text { Licorerías } \\
\end{array}$ & 311.4 & 2491.2 & 934.2 & 622.8 & 3114 & 3114 & 3114 & 1245.6 & 1245.6 & 1245.6 & 2491.2 & 2491.2 & $22,420.80$ \\
\hline
\end{tabular}


PLAN DE MARKETING PARA LA BODEGA SANTA MARIA: JOLLY ROGER

\section{Horecas}

\begin{tabular}{|c|c|c|c|c|c|c|c|c|c|c|c|c|c|}
\hline & \multicolumn{12}{|c|}{ CANTIDAD DE CAJAS - HORECAS } & \multirow[b]{2}{*}{ Total } \\
\hline & Ene & Feb & Mar & Abr & May & Jun & Jul & Ago & Sep & Oct & Nov & Dic & \\
\hline Restaurantes & & & 2.5 & 2.5 & 2.5 & 2.5 & 5 & 2.5 & 2.5 & 2.5 & 2.5 & 5 & 30 \\
\hline Casinos & & & 1 & 1 & 1 & 1 & 1 & 1 & 1 & 1 & 1 & 1 & 10 \\
\hline $\begin{array}{c}\text { Discotecas y } \\
\text { Bares }\end{array}$ & & 8 & 16 & 16 & 16 & 16 & 20 & 16 & 16 & 30 & 16 & 30 & 200 \\
\hline Hoteles & & & 1 & 1 & 1 & 1 & 1 & 1 & 1 & 1 & 1 & 1 & 10 \\
\hline $\begin{array}{l}\text { Total Cajas } \\
\text { Jolly Roger }\end{array}$ & & 8 & 20.5 & 20.5 & 20.5 & 20.5 & 27 & 20.5 & 20.5 & 34.5 & 20.5 & 37 & 250 \\
\hline $\begin{array}{l}\text { Total Botellas } \\
\text { Jolly Roger }\end{array}$ & & 96 & 246 & 246 & 246 & 246 & 324 & 246 & 246 & 414 & 246 & 444 & 3000 \\
\hline $\begin{array}{l}\text { Total ventas } \\
\text { Dolares }\end{array}$ & & 887.04 & 2273.04 & 2273.04 & 2273.04 & 2273.04 & 2993.76 & 2273.04 & 2273.04 & 3825.36 & 2273.04 & 4102.56 & $27,720.00$ \\
\hline $\begin{array}{c}\text { Total Costo } \\
\text { Venta Dolares }\end{array}$ & & 388.8 & 996.3 & 996.3 & 996.3 & 996.3 & 1312.2 & 996.3 & 996.3 & 1676.7 & 996.3 & 1798.2 & $12,150.00$ \\
\hline $\begin{array}{c}\text { Total Utilidad } \\
\text { Horecas }\end{array}$ & & 498.24 & 1276.74 & 1276.74 & 1276.74 & 1276.74 & 1681.56 & 1276.74 & 1276.74 & 2148.66 & 1276.74 & 2304.36 & $15,570.00$ \\
\hline
\end{tabular}


PLAN DE MARKETING PARA LA BODEGA SANTA MARIA: JOLLY ROGER

\section{Mayoristas}

\begin{tabular}{|c|c|c|c|c|c|c|c|c|c|c|c|c|c|}
\hline & \multicolumn{12}{|c|}{ CANTIDAD DE CAJAS - MAYORISTAS } & \multirow[b]{2}{*}{ Total } \\
\hline & Ene & Feb & Mar & Abr & May & Jun & Jul & Ago & Sep & Oct & Nov & Dic & \\
\hline $\begin{array}{l}\text { Total Cajas } \\
\text { Jolly Roger }\end{array}$ & & & 15 & 20 & 40 & 50 & 20 & 25 & 20 & 25 & 70 & 15 & 300 \\
\hline $\begin{array}{l}\text { Total Botellas } \\
\text { Jolly Roger }\end{array}$ & & & 180 & 240 & 480 & 600 & 240 & 300 & 240 & 300 & 840 & 180 & 3600 \\
\hline $\begin{array}{c}\text { Total ventas } \\
\text { Dolares }\end{array}$ & & & 1701 & 2268 & 4536 & 5670 & 2268 & 2835 & 2268 & 2835 & 7938 & 1701 & $34,020.00$ \\
\hline $\begin{array}{c}\text { Total Costo } \\
\text { Venta Dolares }\end{array}$ & & & 729 & 972 & 1944 & 2430 & 972 & 1215 & 972 & 1215 & 3402 & 729 & $14,580.00$ \\
\hline $\begin{array}{c}\text { Total Utilidad } \\
\text { Horecas }\end{array}$ & & & 972 & 1296 & 2592 & 3240 & 1296 & 1620 & 1296 & 1620 & 4536 & 972 & $19,440.00$ \\
\hline
\end{tabular}

